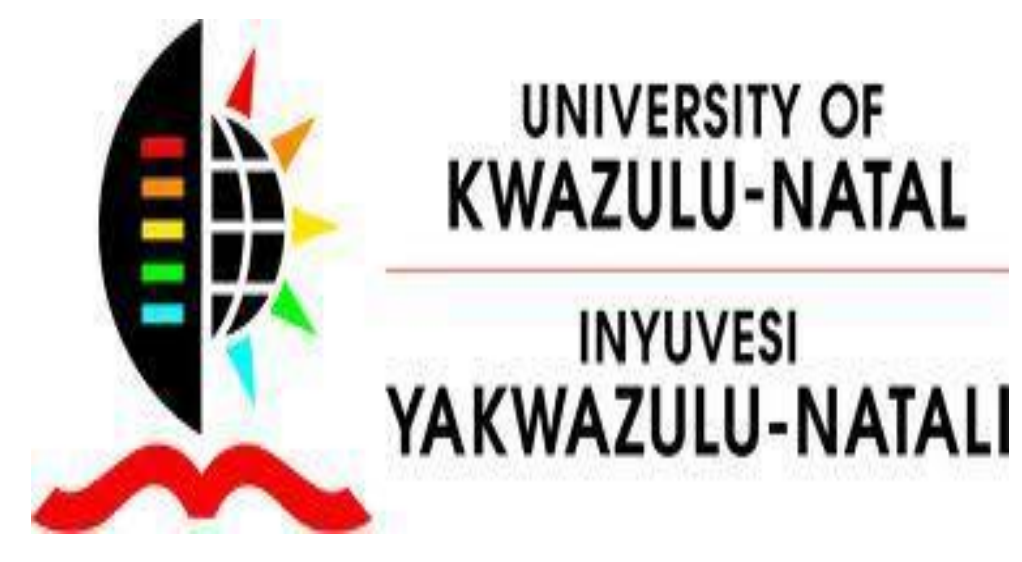

\title{
Records Management Readiness for Open Government in the Kenyan Judiciary
}

\section{Elsebah Jepkemboi Maseh (BSc, MPhil)}

Submitted in fulfilment of the requirements for the degree of Doctor of Philosophy (Information Studies) in the School of Social Sciences, College of Humanities, University of KwaZulu-Natal, Pietermaritzburg, South Africa.

Supervisor:

Prof. Stephen Mutula

April, 2015 


\begin{abstract}
Records are valuable assets that need to be managed by any organization or nation. They are vital to virtually every aspect of the governance process and fulfill important functions in society by providing evidence of and information about the transactions of individuals and organizations. Records are fundamental to the efficient and effective operation of the legal system of any country and are more critical to the administration of law than to any other function of the public sector.
\end{abstract}

This study sought to investigate records management practices in the Kenyan judiciary with a view to promoting transformation and facilitation of open government for effective and efficient justice delivery. It sought to address the following research questions: How are records created, accessed and used, stored and maintained, appraised and disposed of, and preserved?; What records management policies, plans, and guidelines are available?; What skills and competencies do the records management staff have?; What is the level of awareness and attitude of staff towards sound records management practices? and What strategies is the Kenyan judiciary using to achieve openness?

The study was underpinned by the Records Continuum Model, the IRMT e-records Readiness Tool and the Open Government Implementation Model. Literature was reviewed based on themes gleaned from the research questions, the underpinning models and broader areas of the study. The study adopted a pragmatic paradigm associated with the mixed methods approach (MMR) where the qualitative aspects were dominant and quantitative less dominant. The study adopted an embedded case study design and data was collected through the use of interviews, questionnaires, observation and document review methods. The population of the study comprised court registrars, deputy registrars, records officers, registry assistants, judges and magistrates in the high court and magistrates' courts in Nairobi and Uasin Gishu counties. Since the population was considered small, a complete enumeration of the population (census sampling) was included in the study. Reliability and validity of the instruments was ascertained through the use of peer debriefing, triangulation, member checking and Cronbach's alpha. The data collected were presented and analyzed both qualitatively and quantitatively where the qualitative data were analyzed thematically and presented in narrative description 
while the quantitative data were coded and analyzed using computer software (SPSS) and then presented in tables, graphs and charts where applicable.

The findings of the study revealed that although records management had been improved in the Kenyan judiciary it was still weak. Records were not managed well in a continuum of care from creation to disposition. Further, there were no records management policies and trained records officers were inadequate. Furthermore, though records were recognized as pivotal in the administration of justice, records management had not been fully supported by the top management. There was no independent budgetary allocation for records management for instance and records management had not been accorded the status of a directorate like other administrative functions such as human resources. Moreover although the Kenyan judiciary was only in its initial phase of implementing its openness, there were notable benefits that had already accrued to the judiciary. However, there were challenges facing the judiciary that needed to be addressed if justice was to be delivered effectively and efficiently.

The study therefore concluded that the current state of records management was most likely going to impede successful implementation of judiciary transformation and openness and the delivery of justice thereof. The study therefore recommended that among other things, records management in the judiciary needed to be improved by: formulation of records management policies; building records management capacity by either hiring qualified persons or retraining the available staff; soliciting top management support; and using the Open Government Implementation Model (Lee and Kwak, 2011) as a bench mark for the implementation of open government in the judiciary. 


\section{DECLARATION}

I, Elsebah Jepkemboi Maseh, declare that

1. The research reported in this thesis, except where otherwise indicated, is my original research.

2. This thesis has not been submitted for any degree or examination at any other university.

3. This thesis does not contain other persons' data, pictures, graphs or other information, unless specifically acknowledged as being sourced from other persons.

4. This thesis does not contain other persons' writing, unless specifically acknowledged as being sourced from other researchers. Where other written sources have been quoted, then:

a. Their words have been re-written but the general information attributed to them has been referenced

b. Where their exact words have been used, then their writing has been placed in italics and inside quotation marks, and referenced.

5. This thesis does not contain text, graphics or tables copied and pasted from the Internet, unless specifically acknowledged, and the source being detailed in the thesis and in the References sections.

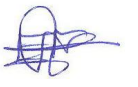

Date: 20/02/2015

Elsebah Jepkemboi Maseh

Supervisor:

-Date

Prof. Stephen Mutula 


\section{ACKNOWLEDGEMENT}

First and foremost, I wish to thank the almighty God for his divine care, health and presence throughout my entire life and more so during the period of my $\mathrm{PhD}$ studies. Secondly I'm forever grateful to my supervisor Prof. Stephen Mutula for his guidance, constructive criticism and encouragement from the very beginning of the research proposal to the ultimate submission of the thesis. Without his input the thesis would not have seen the light of the day. I also acknowledge professional editorial work of Dr. Rosemary Kuhn which further shaped the thesis.

I would also like to express my appreciation to Prof. Justus Wamukoya for his input in proposing the research problem and his continued support throughout my studies. My thanks go to my employer Moi University for granting me time to be away from work to attend to the thesis writing on two occasions. I thank my head of department Dr. Damaris Odero specifically for her support and understanding and my all other colleagues for their support as well.

Many thanks go to the Kenyan judiciary staff for their time in providing the valuable data that made this research a success. I'm specifically thankful to Benjamin Kinuthia for introducing me to the registrars and other staff in the judiciary and for organizing most of my interviews.

My very special appreciation goes to my entire family for their support and prayers throughout my study period. I specifically thank my husband Kiptum Yego and my children Ivan, Ian and Faith for their understanding and love that made life bearable throughout the entire study period. I also thank my parents Mr. and Mrs. Paul Mandago for their concern, inspiration and fervent prayers that kept me going. I'm indebted to my sister in-law Sophy for taking care of my children for the entire period, my sister Rael for hosting me throughout the data collection period and my sister Ann for always being there when I needed her. I also appreciate all my brothers for their moral support and their presence in times of need, God bless you all.

Last but not least, I thank all my friends and relatives who took time to pray for me and encouraged me when the going became tough. My special thanks to my friend Irene Moseti Morara, indeed we journeyed together in the otherwise lonely path, and many more thanks to Dr. Rebecca Majinge for her encouragement and motherly advice. I also wish to sincerely thank Mr. Wilson Muna and Ms. Stella Sabi for being my help in times of need. My thanks also go to all the staff in the School of Social Sciences for making life worth living in one way or another. Lastly, I thank all the PhD students in the 2013 class Irene, Juliana, Lucas, John and Faraja for the team work especially at proposal writing stage. 
Indeed, many more people contributed in one way or another to the completion of this thesis. Time and space limitations cannot allow me to mention every person by name. I wish to stress, however, that I am utterly grateful to all these unmentioned names. Thank you very much! 


\section{DEDICATION}

This work is dedicated to the glory of God; to my parents Mr. and Mrs. Paul Mandago for their prayers and inspiration; to my husband Kiptum Yego; sons Ivan and Ian and to my daughter Faith for their love, understanding and sacrifice during the entire period of my studies. 


\section{TABLE OF CONTENTS}

ABSTRACT

i

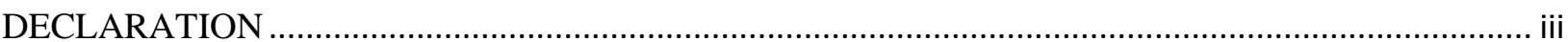

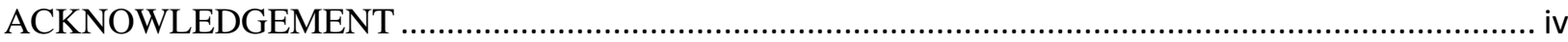

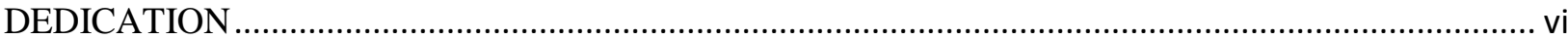

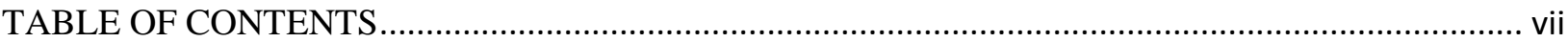

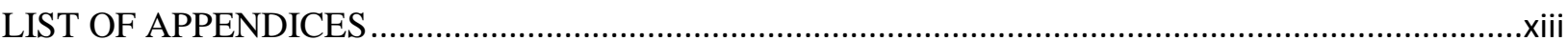

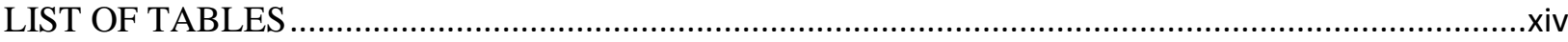

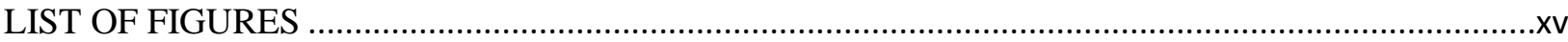

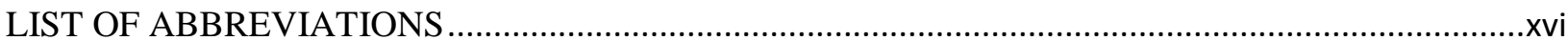

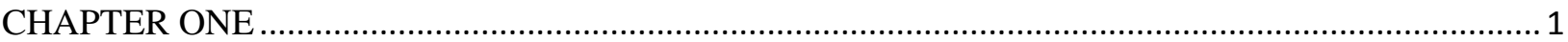

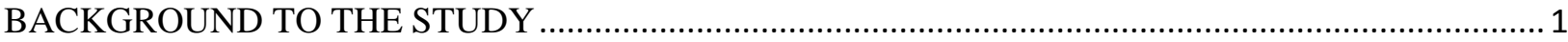

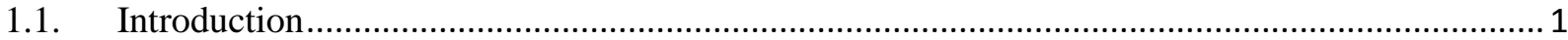

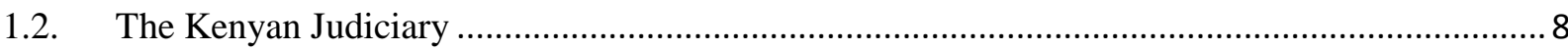

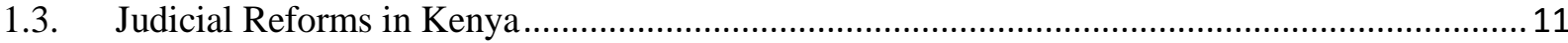

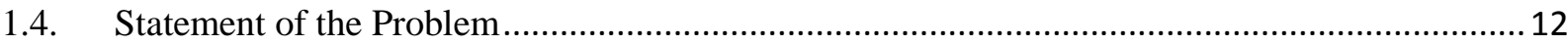

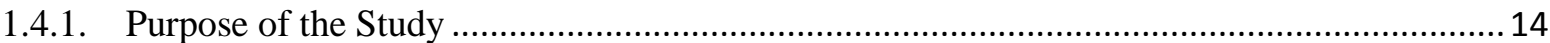

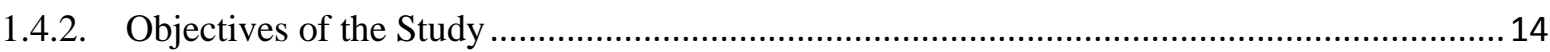

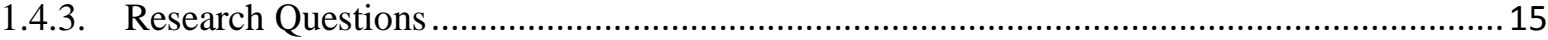

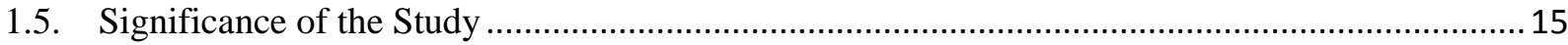

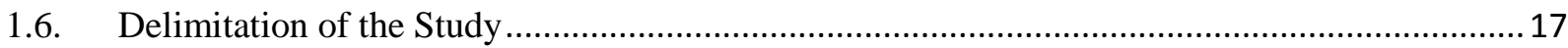

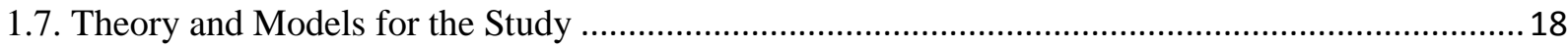

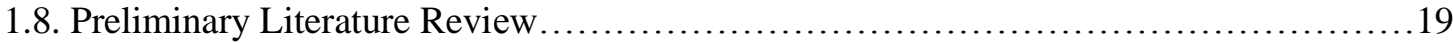

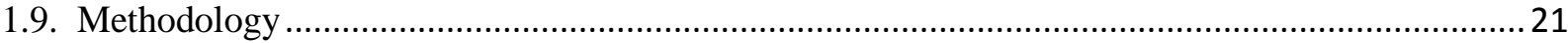

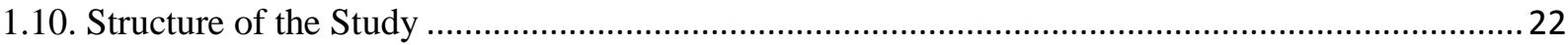

1.11. Summary ............................................................ 21

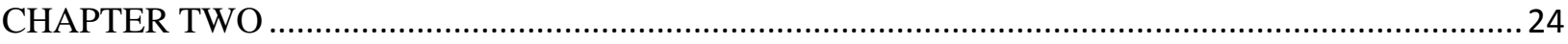

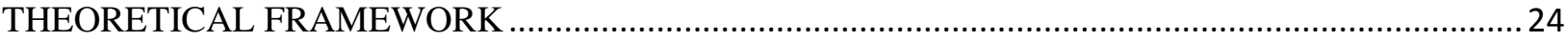

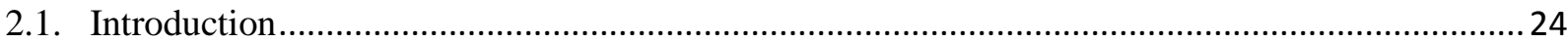


2.2. The Use of Theory in Quantitative, Qualitative and Mixed Methods Researches 25

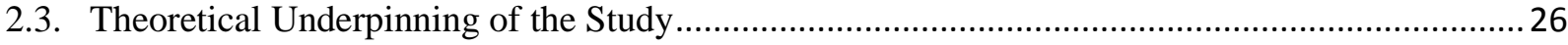

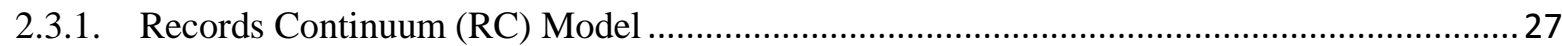

2.3.1.1. Relevance of the RC Model to the Study................................................................32

2.3.1.2 Gaps in the Use of the RC Model in the Study............................. 34

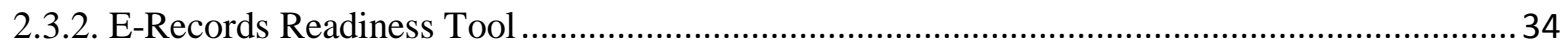

2.3.2.1 Relevance of the E-Records Readiness Tool..............................36

2.3.2.2 Gaps in the Use of the Tool........................................ 37

2.3.3. Open Government Implementation Model (OGIM) ...................................................... 38

2.3.3.1 Relevance of the Model in the Study ...................................41

2.3.3.2 Gaps in the Use of the Model......................................42

2.3.4. Complementary Theoretical Models for this Study ….................................................... 42

2.3.4.1 Records Entity Life History..........................................43

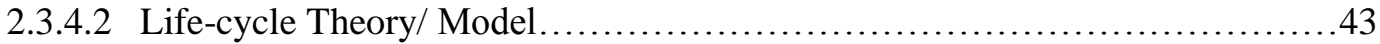

2.3.4.3 Integrated Approach.................................................45

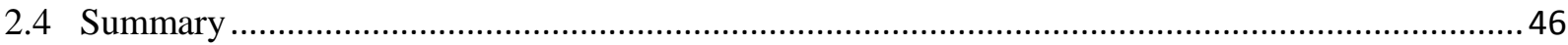

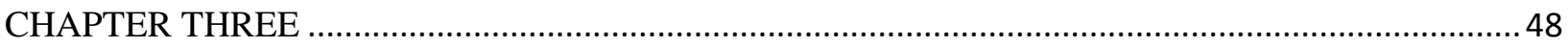

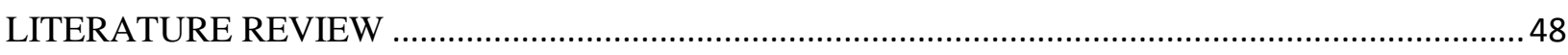

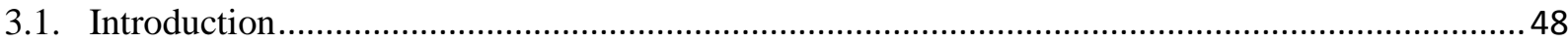

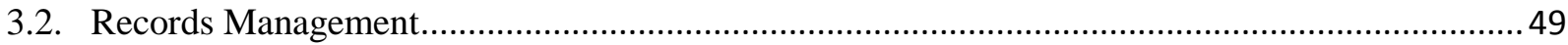

3.2.1. Objectives of a Records Management Programme .......................................................... 52

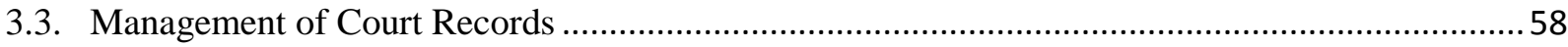

3.4. Policies and Guidelines for Records Management ..................................................................60

3.5. Skills and Resources Required for Records Management ....................................................61

3.6. Awareness about Records and Attitudes of Staff towards Sound Records ..................................63

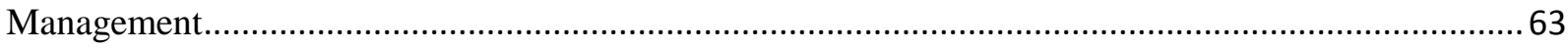

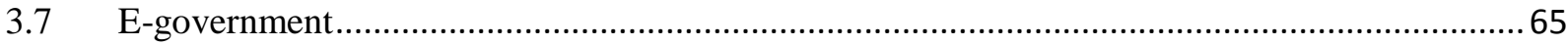

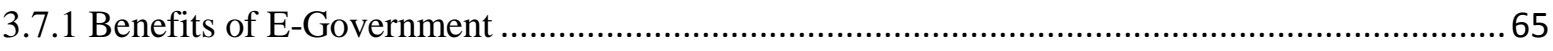

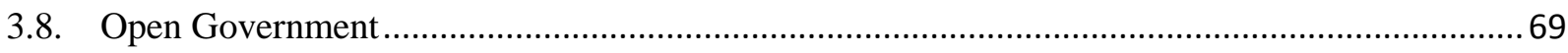

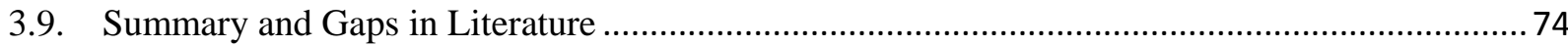




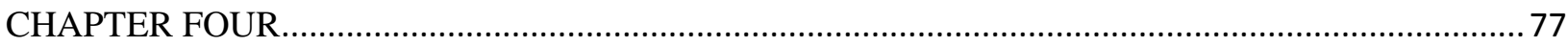

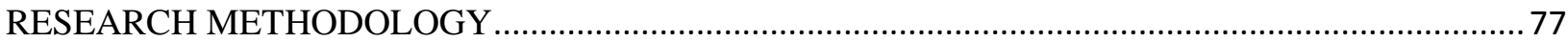

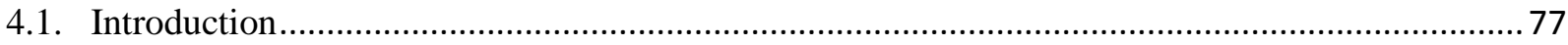

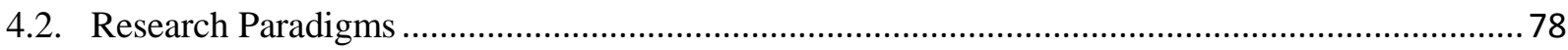

4.2.1. Pragmatic Paradigm .................................................................................................... 79

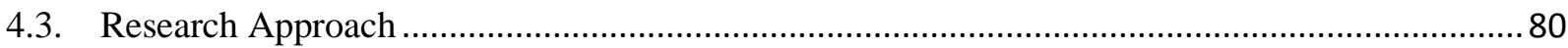

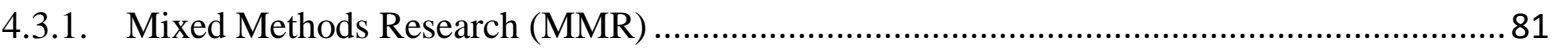

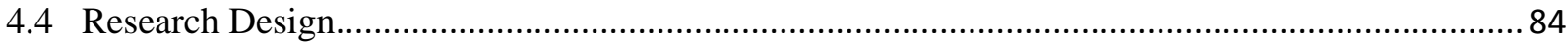

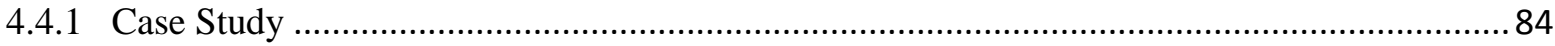

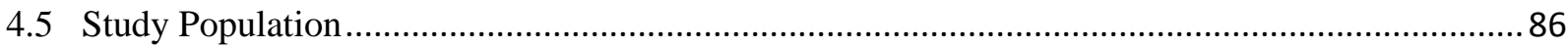

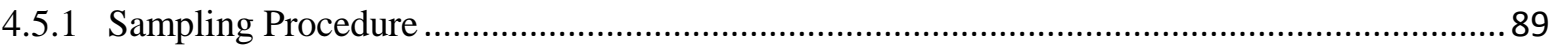

4.6 Data Collection Techniques ................................................................................................ 90

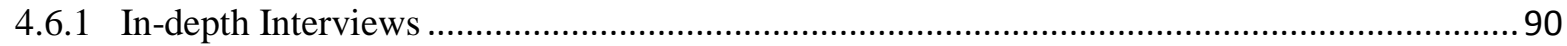

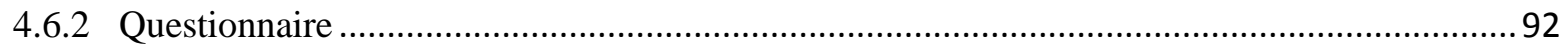

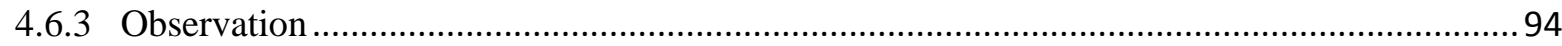

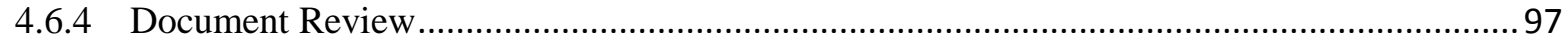

4.7 Data Collection Procedures........................................................................................................ 98

4.8 Reliability and Validity of the Instruments ................................................................................99

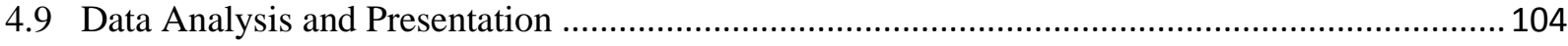

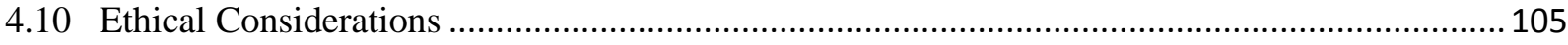

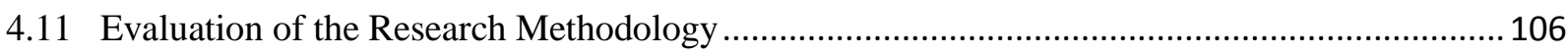

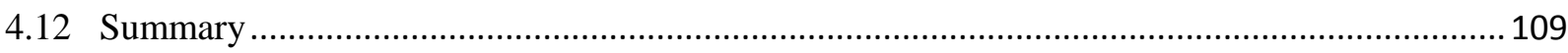

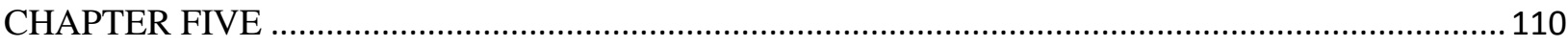

DATA ANALYSIS AND PRESENTATION OF FINDINGS ......................................................... 110

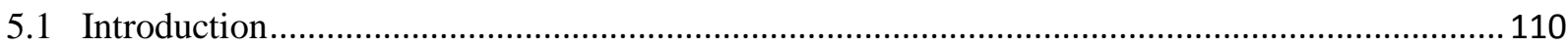

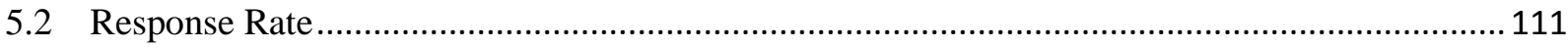

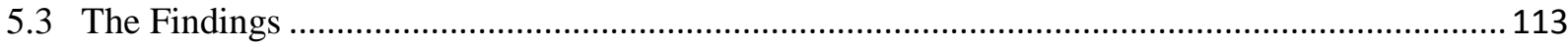

5.3.1 Records Management from Creation to Disposition........................................................... 113

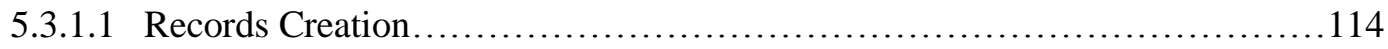

5.3.1.2 Records Access and Use................................................117 
5.3.1.3 Records Storage and Maintenance.....................................119

5.3.1.3.1 Storage Facilities and Equipment................................122

5.3.1.3.2 Security of Records at Storage...................................... 123

5.3.1.4 Records Appraisal and Disposition..................................... 128

5.3.1.4.1 Criteria for Records Disposal.......................................129

5.3.1.4.2 Procedure for Disposal......................................... 131

5.3.1.5 Records Preservation................................................... 133

5.3.1.5.1 Preservation Policy...............................................134

5.3.1.5.2 Disaster Planning and Preparedness...............................134

5.3.1.6 E-records Management in the Kenyan Judiciary............................135

5.3.1.7 Overall State of Records Management in the Kenyan Judiciary...............137

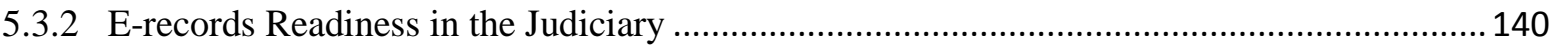

5.3.2.1 Existing Records Management Policies, Plans and Guidelines................141

5.3.2.1.1 Judiciary Strategic Management Plan................................. 142

5.3.2.2 Skills and Competencies............................................ 143

5.3.2.3 Level of Awareness about Records and Attitude of Staff towards Sound Records Management......................................................... 146

5.3.3 Status of E-Government in the Kenyan Judiciary.....................................149

5.3.4 Records Related Strategies Used to Achieve Openness................................................... 151

5.3.4.1 Level of Openness.............................................. 154

5.3.4.2 Challenges Faced by the Judiciary as it Transforms Itself and Move Towards Openness....................................................156

5.3.4.3 Possible Solutions to Records and Archives Management Related Challenges Facing the

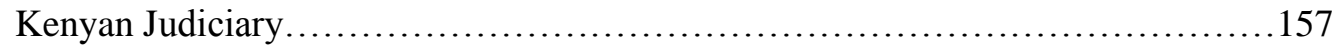

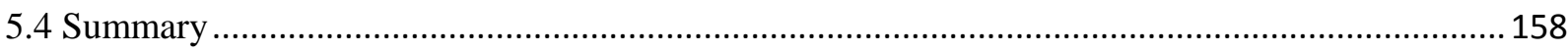

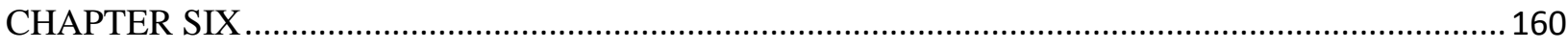

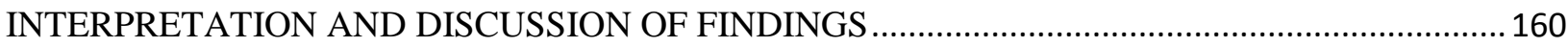

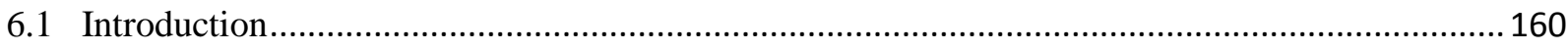

6.2 Records Management from Creation to Disposition................................................................ 161 


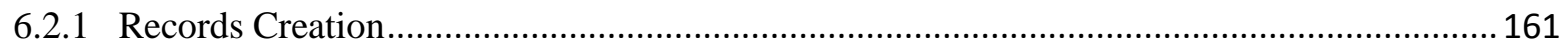

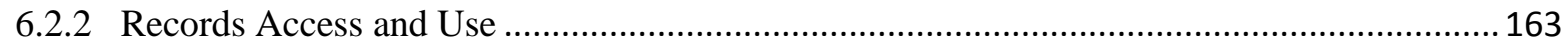

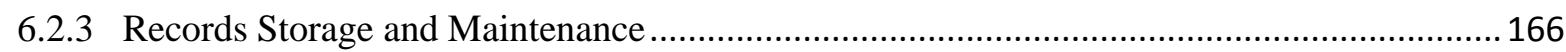

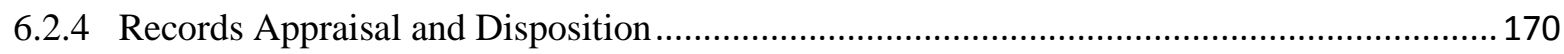

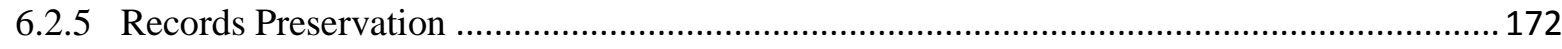

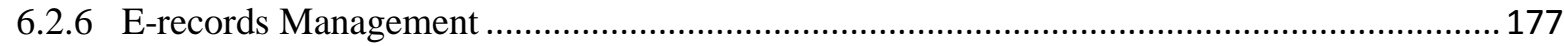

6.2.7 Overall State of Records Management in the Kenyan Judiciary ....................................... 180

6.3 E-records Readiness in the Kenyan Judiciary ..................................................................... 181

6.3.1 Existing Records Management Policies, Plans and Guidelines .......................................... 182

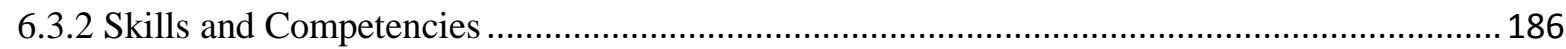

6.3.3 Level of Awareness about Records and Attitude of Staff towards Sound Records .............. 190

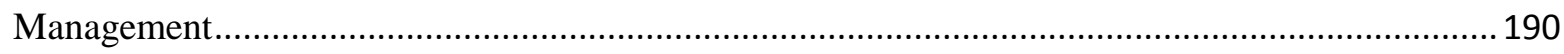

6.4 State of E-government in the Judiciary …................................................................................... 192

6.5 Records Related Strategies Used to Achieve Openness ........................................................ 195

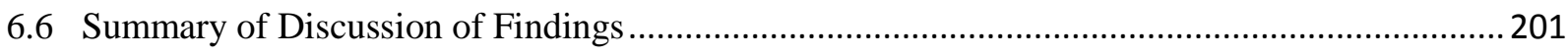

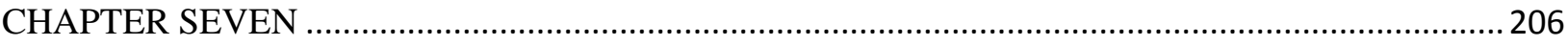

SUMMARY OF FINDINGS, CONCLUSIONS AND RECOMMENDATIONS ................................2206

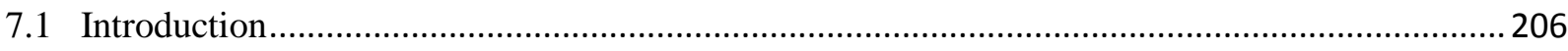

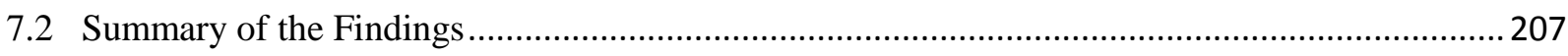

7.2.1 Records Management from Creation to Disposition........................................................ 207

7.2.1.1 Records Creation...................................................208

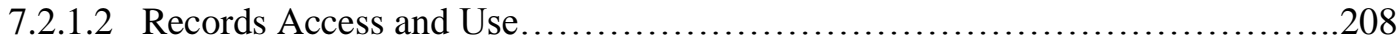

7.2.1.3 Records Storage and Maintenance...................................209

7.2.1.4 Security of Records................................................209

7.2.1.5 Records Appraisal and Disposition...................................210

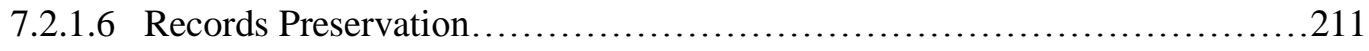

7.2.1.6.1 Disaster Planning and Preparedness................................ 212

7.2.1.7 E-Records Management........................................212

7.2.1.8 Overall State of Records Management in the Kenyan Judiciary.............212

7.2.2 E-records Readiness in the Kenyan Judiciary ............................................................. 213 
7.2.2.2 Skills and Competencies.........................................214

7.2.2.3 Level of Awareness about Records and Attitude of Staff Towards Sound Records Management.......................................................214

7.2.3 Status of E-government in the Kenyan Judiciary ........................................................... 215

7.2.4 Records Related Strategies Used to Achieve Openness ...................................................... 215

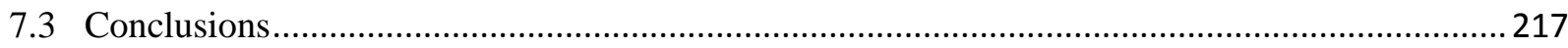

7.3.1 Conclusion on Records Management from Creation to Disposition .................................. 217

7.3.2 Conclusions on Policies, Plans, and Guidelines Available in the Kenyan Judiciary ............. 217

7.3.3 Conclusions on Skills and Competencies among Records Management Staff in the ............218

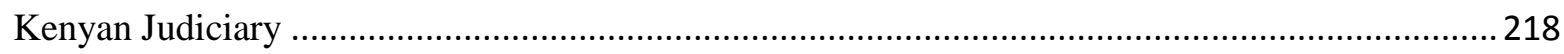

7.3.4 Conclusions on the Level of Awareness about Records and Attitude of Staff towards......... 218

Sound Records Management in the Kenyan Judiciary .............................................................. 218

7.3.5 Conclusions on Records Management Strategies Used to Achieve Openness in the ............219

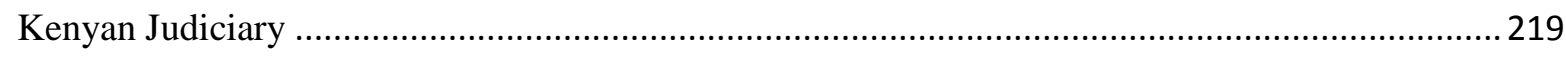

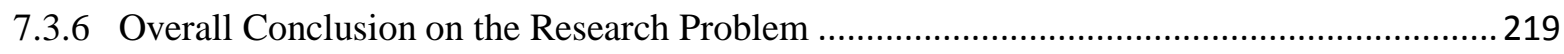

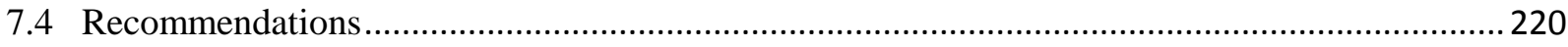

7.4.1 Recommendation: Records Management from Creation to Disposition .............................. 221

7.4.2 Recommendation: Records Management Policy Formulation........................................... 222

7.4.3 Recommendation: Skills and Competencies Requirement .............................................. 223

7.4.4 Recommendation: Top Management Support …................................................................ 225

7.4.5 Recommendation: Open Government Implementation in the Kenyan Judiciary .................. 225

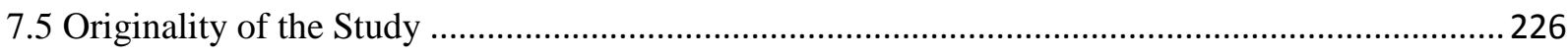

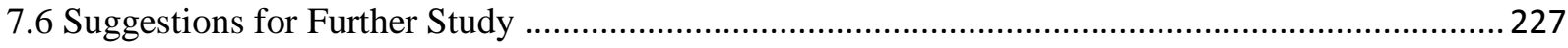

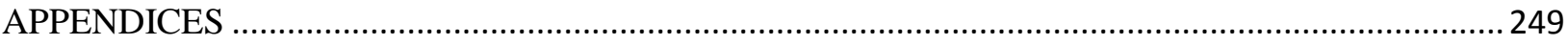




\section{LIST OF APPENDICES}

Appendix 1: Interview Schedule for Records Officers and Registry Assistants----------249

Appendix 2: Interview Schedule for Registrars and Chief Executive Officers-----------255

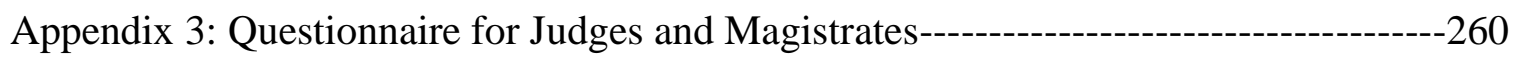

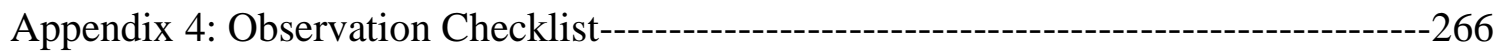

Appendix 5: Research Permit from National Commission for Science, Technology and

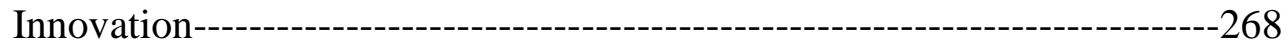

Appendix 6: Clearance Letter from the National Commission for Science, Technology and Innovation----------------------------------------------269

Appendix 7: Authorization Letter from Judiciary Training Institute---------------------270

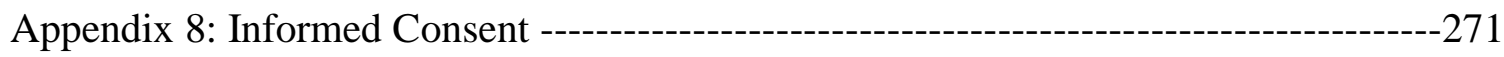

Appendix 9: Introduction Letter by the Supervisor----------------------------------273

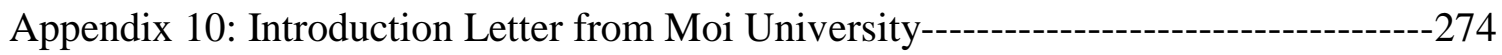

Appendix 11: Request for Permission to Undertake Research---------------------------275 


\section{LIST OF TABLES}

Table 1: Summary of Mapping of Research Questions to Variables of the Theoretical

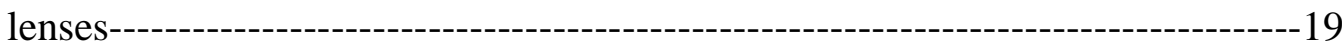

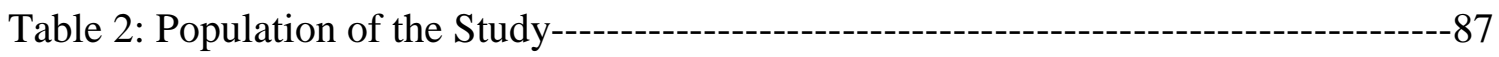

Table 3: Cronbach's Alpha Values---------------------------------------------------------------103

Table 4: Interview Response Rate---------------------------------------------------------------112

Table 5: Responsibilities of Records Officers and Registry Staff--------------------------114

Table 6: Summary of Responses on Records Storage----------------------------------------119

Table 7: Programme for Records Appraisal------------------------------------------------------128

Table 8: Criteria for Records Disposal----------------------------------------------------------130

Table 9: Reasons for Case Backlogs in the Kenyan Judiciary------------------------------139

Table 10: Responses on Facilitation to Attend Records Management Conferences and

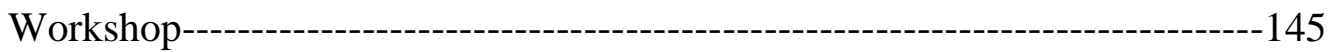

Table 11: Questionnaire Response on the Judiciary E-Government Readiness-----------151

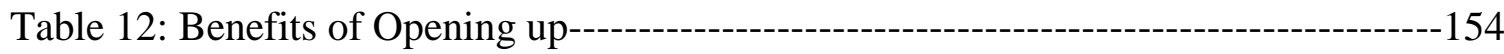

Table 13: Summary of Findings Mapped to the Theoretical Models and the Research

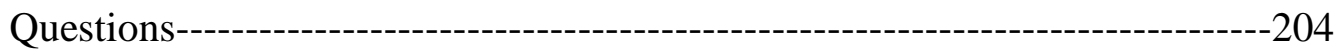




\section{LIST OF FIGURES}

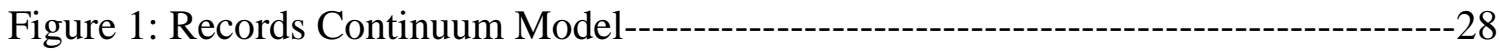

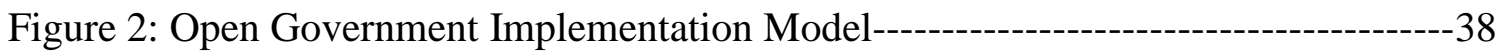

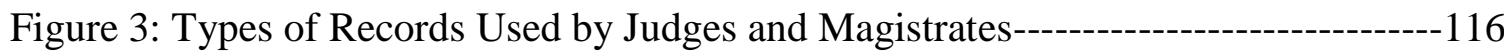

Figure 4: Records are Vital for the Administration of Justice----------------------------116

Figure 5: Files on the Floor in One of the Courts---_-

Figure 6(a): Records Competing for Space with Broken Chairs---------------------------121

Figure 6(b): Deplorable State of Records Storage in One of the Courts-----------------121

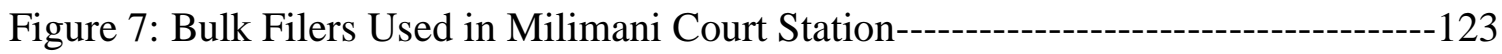

Figure 8: Experiences of Missing Files---------------------------------------------126

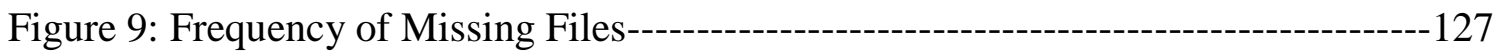

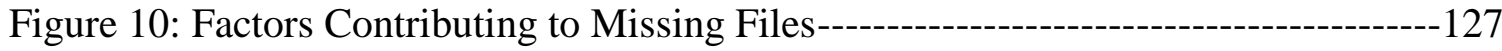

Figure 11: Records Management Rating by the Judges and Magistrates------------------138

Figure 12: Reasons for the State of Records Management-----------------------------138

Figure 13: Value of Records Management in the Administration of Justice-------------148

Figure 14: Strategies Used to Open up to the Public-------------------------------------153

Figure 15: Benefits of Opening up the Judiciary------------------------------------155

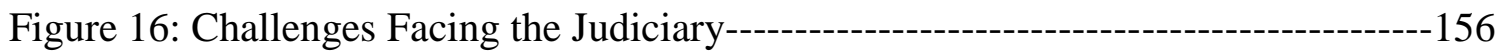

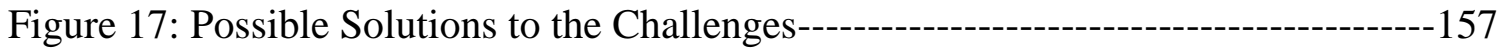




\section{LIST OF ABBREVIATIONS}

\begin{tabular}{|c|c|}
\hline APC & : Associations for Progressive Communications \\
\hline ARMA & : American Records Management Association \\
\hline BNARS & : Botswana National Archives and Records Service \\
\hline CCTV & : Closed Circuit Television \\
\hline CIPESA & : Collaboration of International ICT Policy for East and Southern Africa \\
\hline CJ & : Chief Justice \\
\hline CPI & : Corruption Perception Index \\
\hline DCA & : Department for Constitutional Affairs \\
\hline DIRKS & : designing and implementing recordkeeping systems \\
\hline EPA & : Environment Protection Agency \\
\hline \multirow[t]{2}{*}{ ESARBICA } & : East and Southern Africa Regional Branch of International Council on \\
\hline & Archives \\
\hline FOI & : Freedom of Information \\
\hline $\mathrm{HCC}$ & : High Court Civil \\
\hline ICTs & : Information and Communication Technologies \\
\hline IDRC & : International Development Research Centre \\
\hline IRMT & : International Records Management Trust \\
\hline ISO & : International Organization of Standards \\
\hline IT & : Information Technology \\
\hline JTF & : Judiciary Transformation Framework \\
\hline KODI & : Kenya Open Data Initiative \\
\hline KRA & : Key Result Area \\
\hline LAN & : Local Area Network \\
\hline
\end{tabular}




$\begin{array}{ll}\text { MMR } & : \text { Mixed Methods Research } \\ \text { NARA } & : \text { National Archives and Records Administration } \\ \text { NACOSTI } & : \text { National Commission for Science, Technology and Innovation } \\ \text { NASCIO } & : \text { National Association of State Chief Information Officers } \\ \text { NEMA } & : \text { National Environment Management Authority } \\ \text { NGO } & : \text { None Governmental Organizations } \\ \text { OECD } & : \text { Organization for Economic Co-operation Development } \\ \text { OGD } & : \text { Open Government Data } \\ \text { OGIM } & : \text { Open Government Implementation Model } \\ \text { RC } & : \text { Records Continuum } \\ \text { SMS } & : \text { Short Message Service } \\ \text { SPSS } & : \text { Statistical Package for Social Scientists } \\ \text { UK } & : \text { United Kingdom } \\ \text { UNESCO } & : \text { United Nations Organization for Education, Science and Culture } \\ \text { US } & : \text { United States } \\ \text { USAID } & : \text { United States Agency for International Development }\end{array}$




\section{CHAPTER ONE \\ BACKGROUND TO THE STUDY}

\subsection{Introduction}

The purpose of this study is to investigate records management in the Kenyan judiciary with a view to promoting transformation and open government for effective and efficient justice delivery. "Records are valuable assets that need to be managed by any organization or nation" IRMT 2000:1). "They are vital to virtually every aspect of the governance process because they fulfill important functions in society by providing evidence of and information about the transactions of individuals and organizations" (Sichalwe, 2010:1). Government records not only document past decisions but also establish and protect current rights and responsibilities of both the government and the governed (Mnjama and Wamukoya, 2007). Records therefore, provide a source of public accountability of how governments and government agencies carry out their public duties and the mandates of the citizenry. IRMT (1999:7) contends that "records are particularly fundamental to the efficient and effective operation of the legal system of any country and are more critical to the administration of law than to any other function of the public sector". Without records there can be no rule of law and no accountability. Records are therefore indispensable to the delivery of services by any government to its citizens.

The term record has been defined by different scholars in different ways. Shepherd and Yeo (2003:20) defined it as "any recorded evidence of an activity not defined by its physical format or storage medium, its age or the fact that it has been set aside for preservation". Meanwhile, ISO (2001:3) defined records as “information created, received and maintained as evidence and information by an organization or person in pursuance of legal obligations or in transaction of business". From these two definitions it is clear that a record serves an important purpose of providing evidence among other uses of records. This is particularly important in instances where transparency is required like in an open government environment. 
Records management on the other hand has also been defined in various ways by different scholars. Wamukoya (1996:7) opined that "records management incorporates the policies, systems and professional and management techniques systematically applied to the control of recorded information to enhance an organization's efficiency and effectiveness while at the same time consolidating its evidential base". ISO (2001:3) defined records management as "a field of management responsible for the efficient and systematic control of the creation, receipt, maintenance, use and disposition of records including processes for capturing and maintaining evidence of and information about business activities and transactions in the form of records". From these two definitions, records management is a means of ensuring that records serve their purpose of promoting transparency and accountability in an effective and efficient manner.

Moloi and Mutula (2007) point out that sound management of records in whatever format has increasingly become a topical issue. The World Bank (2000) observes that records are essential for the effective and efficient service delivery in both private and public sector organizations. This is largely attributed to the fact that records document decisions and activities of government and organizations thus providing a benchmark upon which future activities and decisions are based. For these reasons, records are increasingly viewed as "organizational strategic resources that need to be managed within a sound records management system" (IRMT, 2000:4).

Records management in developed countries such as Australia, Canada, United States and United Kingdom has made great advancements (Moloi and Mutula, 2007). Shepherd (2006:8) for instance pointed out that "in 2004 - 2005, most public sector organizations, in preparation to comply with the requirements of the Freedom of Information Act among other things, reviewed the records management function and endeavored to support it with adequate resources". Shepherd (2006) observed that these organizations formulated records management policies, established effective records management systems, including a records retention and disposal policy, trained staff on records management and audited performance to show best value and accountability. According to Shepherd (2006:8) "enhancement of records management was taken so seriously that it was 
codified in the Lord Chancellor's Code of Practice on the management of records under section 46 of the Freedom of Information Act".

Great advancements have also been witnessed in Australia over the years. Swan, Cinningham and Robertson (2002:80) argued that "historically the Australian Commonwealth Government has had good records management". The authors pointed out that "before its demise in 1987, the Public Service Board set the standard for what records should be created, who was responsible for ensuring that these records were created and how management of the records was undertaken". Swan et al. (2002) posits that the general quality of records dating from the first seventy (70) or so years of the $20^{\text {th }}$ Century in the collection of the National Archives of Australia are evidence of the success of this approach to promoting good records management as a key enabler of good commonwealth governance. In the late 1990s the National Archives of Australia took up the role of steering records management in the Commonwealth government (National Archives of Australia, 2006). Under its auspices, several standards have been developed to streamline records management which include: the "Australian Standard for Records Management AS4390" (Standards Australia, 1996) and "ISO 15489" (ISO, 2001); "DIRKS" (National Archives of Australia, 2001); and "Recordkeeping Metadata Standard for Commonwealth agencies" (National Archives of Australia, 2000) among others. With these standards and others, Australia has emerged a world-class records management champion. Many of these standards have been recognized internationally as best practice standards for records management.

In Canada, the government has perfected the use of records to document the decisions of government, the statutes of the nation, and correspondence with citizens since the 1860s (McDonald, 2000). Like other developed countries, Canada has sound records management legislation which has made public records once protected by government accessible to the citizens under privacy laws which have encouraged the sharing of these records. The Canadian government has also formulated a national standard for e-records (Electronic Record as Documentary Evidence) which establishes requirements for organizations to follow when creating digital records in text, database, image and audio 
formats (American Records Management Association, 2005). Accordingly, agencies are able to demonstrate the authenticity of e-records and the integrity of the system that recorded and stored the electronic record.

The United States of America also has a strong history of records management excellence. Moloi and Mutula (2007:292) quoting David (1994) identify several records management milestones that have been witnessed in the United States to include: the "first General Records Disposal Act passed in the United States of America Congress in 1889"; "promotion of the use of modern office equipment in 1912"; and "the formation of the first Association of Records Managers (ARMA) in 1956". Moloi and Mutula (2007) maintain that records management in the United States of America has experienced strong growth since the 1980s in terms of integrating modern Information and Communication Technologies (ICTs) and electronic records management spearheaded by National Archives and Records Administration (NARA). Consequently, records management is an important aspect of governance in the United States of America government and government agencies.

Studies show that most countries in Africa however, compared to their counterparts elsewhere especially in Europe and Americas are lagging behind in records management (Moloi and Mutula (2007). Thurston (2005:1) contends that "many developing countries (including all African countries) lack a systematic approach to managing records". Mnjama and Wamukoya (2004) identified the following challenges as affecting most countries in the East and Southern region of Africa where Kenya belongs: absence of organizational plans for managing records; low awareness of the role of records management in support of organizational efficiency and accountability; lack of stewardship and coordination in handling records; absence of legislation, policies and procedures to guide the management of records; and absence of core competencies in records management.

The last twenty years have witnessed significant reforms in the public sector world over during which the global community has focused on improving service delivery to the 
citizens of the world and forging better interaction between governments and citizens (Wamukoya, 2013). Wamukoya explained that these reforms began with calls for organizations and governments to infuse "good governance", "transparency", "accountability", "and more recently "open government" in their operations.

Good governance could mean different things to different people. Kargbo (2009:3) defines it as "the process by which power, authority and influence are wielded to define and achieve desired public policy objectives in economic, social and other spheres". Kargbo (2009) identifies the following features of good governance: transparency; accountability; participatory; sustainability; transparency; promotion of equity and equality; and operation of the rule of law among other things.

Transparency and accountability are critical to good governance. Lipchak (2002) observes that good governance based on transparency, accountability and trust has become a shared goal among governments around the world. IRMT (2000:4) observes that "the foundation for accountability and transparency is well-managed records". IRMT contends that "when managed in a way that ensures integrity and authenticity through time, records allow employees to account to their managers and the managers are permitted to account to the head of government institutions". McDonald (2002) posits that the effective management of records from creation through to disposition is an integral component of governments' ability to uphold the values associated with good governance. Mutula and Wamukoya (2009:335) maintain that "sound records management systems are critical to the ability of the public sector to be accountable and transparent and to improve services to citizens especially in poor countries". The authors observe that good records management is the basis for accountability, transparency, democratic governance, poverty eradication and efficient use of public resources. Borrowing from studies on records management in African countries alluded to earlier (Moloi and Mutula, 2007; Thurston, 2005; and Mnjama and Wamukoya, 2004), these countries may not be ready for transparency and accountability due to their dismal performance in records management. Wamukoya (2013) in support of this view opines that transparency and accountability can only be made possible if government / public 
records are managed within a sound records management regime that lacks in most African countries.

Open government is defined as a "commitment to ensure that all aspects of the way that government and public services are administered and operated are open to effective public scrutiny and oversight" (Centre for Technology Policy Research, 2010:2). Open government is part of public sector reforms that begun with a call for new public management in the mid-80s to the arrival of computers, software programs and digital information management (Heusser, n.d). Alongside these transformations, transparency became a key word in the process leading to an increased enactment of Freedom of Information (FOI) legislations which gives citizens the right to request information from governments and requiring governments to publish and provide information to its citizens. Wamukoya (2013) points out that open government has its origin in the proclamation of the Freedom of Information legislations which were the first to recognize the citizen's right to access information held by a public agency.

Yu and Robinson (2012) observed that the world's first FOI legislation was enacted in Sweden in 1766, followed by similar Laws in Finland (1951) and the United States of America (1966). Currently about 100 countries have enacted these Laws including a few African countries such as South Africa, Liberia, Niger, Nigeria, Zimbabwe, Angola, Guinea Conakry, Ethiopia, Uganda and Tanzania (UNESCO, 2012). Wamukoya (2013) pointed out that the operationalization of the FOI Laws varies from country to country but most countries operate under either of two principles namely reactive and proactive transparency. Heusser (n.d) noted that "under the principle of reactive transparency, the Law requires public agency to answer public information requests addressed by citizens, normally within five to 30 working days. The principle of proactive transparency on the other hand, requires public bodies to proactively disclose and publish public information without mediating any particular information request".

Yu and Robinson (2012) observed that following the promulgation of FOI Laws, the term open government was used primarily as a synonym for public access to previously 
undisclosed government information. When Congress in the United States of America amended the FOI legislation in 1974, it noted that open government had been recognized as the best insurance that government is being conducted in the public interest. Consequently, as FOI and related statutes developed through 1970s and 80s, federal court decisions began to use the term open government as well referring to governmental transparency.

Open government is hinged on three essential pillars namely: transparency, participation and collaboration (Obama, 2009).To operationalize these pillars, governments and agencies are expected to avail quality information to its citizens and stakeholders which is reliable, accurate, trustworthy, authentic and timely. This information can only be obtained in an environment where a sound records management regime is practiced. Records and the evidence they contain therefore are the instruments by which governments and agencies with statutory responsibility for law and justice can promote a climate of trust and demonstrate an overall commitment to openness (World Bank, 2000). Open government is thus predicated on sound records management as the benchmark for making decisions and services of governments more efficient and transparent. Millar (2003) points out that the ultimate success of open government rests firmly on the ability of governments to create and maintain reliable, trustworthy and accurate government records. Open government anticipates that all public data should be openly published and made available not only for scrutiny and review but potential re-use (Centre for Technology Policy Research, 2010). Stott (2012) points out that the purpose of open government is to get users' voices to be heard so that they can play an active part in the release and use of Government data. Gaveline, Burall and Wilson (2009) contend that the open government agenda has gained momentum over the past decade because of the recognition that openness benefits not only the citizens but the government as well. Governments are therefore coming under increasing pressure to become more accessible to the citizens and also open up their operations to public scrutiny (OECD, 2005).

Open Government Data (OGD) is the pillar of an open government strategy that obliges ministries and state agencies to put their raw data on the Web in readable formats. The 
public can then review and download the data and even create new applications around it (World Wide Web Foundation, 2011). Janssen, Charalabidis \& Zuierwijk (2012) observes that by publicizing data, a new situation is created in which the public can use and create information through collaborative networking. This is made possible through processing of data by the public by enriching the data, combining with other sources or even collecting new data to generate information that is used in socio, economic and political development in a country. It follows therefore that data after processing generates information that is useful to the public for various reasons. RightNow (2010) asserts that the impact of the Internet, social networks and discussion forums has undoubtedly led to transparency and openness in governance. However, OGD cannot be complete without the auxiliary process of records maintenance since much of the information generated and maintained by any government or government agency exists in the form of records. As stated earlier open government is predicated on sound records management and its success relies on the ability of governments to create and maintain reliable, trustworthy and accurate government records.

\subsection{The Kenyan Judiciary}

The judiciary is an important institution for promoting the rule of law in any country. Its centrality in any jurisdiction cannot be underestimated as its absence or dysfunctionality could lead to insecurity and recourse to private justice (Ojielo, 2010). The judiciary promotes the rule of law and thus creates a conducive environment for economic, political and social transformation.

"The judiciary in Kenya as in other jurisdictions ensures that the government governs within the rule of law so that both foreign and domestic investment can thrive to spur socio-economic development" (Kioko, 2000:1-2). The judiciary also provides a forum for the just resolution of disputes in order to preserve the rule of law, maintain law and order, and protect the rights and liberties guaranteed by the Constitution of Kenya (Judiciary Transformation Framework, 2012). 
In Kenya, the judiciary is one of the three arms of government established under Chapter 10 of the Constitution of Kenya (National Council for Law Reporting, 2010). The other two arms are the Executive and the Legislature whose role is to exercise executive authority of the republic and to make and amend laws respectively. The judiciary like the other two arms of government is independent with the mandate of administration of justice and judicial matters (Presidential Circular No. 1 /2008). The Kenyan judiciary is divided into two units: the technical unit comprising of the courts and the administrative unit consisting of departments such as administration, personnel and library service to name but a few. The courts consist of: the Supreme Court; Court of Appeal; High Court; magistrates courts; kadhis' courts and specialized and tribunal courts (IRMT, 2011). The courts are broadly categorized into two branches: superior courts; and subordinate courts (Lubale, 2012).

The Constitution of Kenya 2010 provides the hierarchy of the superior courts as the Supreme Court, the Court of Appeal, and the High Court respectively (National Council for Law Reporting, 2010: Article 162). The Supreme Court is placed at the apex of the judicial hierarchy system. The court is comprised of the Chief Justice who is the President of the court, Deputy Chief Justice, who deputizes the Chief Justice and is the deputy vice president of the Court and five other judges appointed by the President on the advice of the Judicial Service Commission [National Council for Law Reporting, 2010: Article 163 (1)].

The Supreme Court has original, appellate and advisory jurisdiction as indicated below [National Council for Law Reporting, 2010: Article 163 (3a, 3b and 6)]:

- Exclusive original jurisdiction to hear and determine disputes relating to the elections to the office of the president;

- Appellate jurisdiction to hear and determine appeals from the Court of Appeal and any other court or tribunal as prescribed by national legislation; 
- Advisory jurisdiction to give an opinion at the request of the national government, any state organ or any County government with respect to any matter concerning County government.

The Court of Appeal consists of not less than twelve judges who elect a President of the Court of Appeal from among themselves. This court has jurisdiction to hear appeals from the High Court and from any other court or tribunal as prescribed by an Act of Parliament (National Council for Law Reporting, 2010: Article 164). In contrast, The High Court is established vide Article 165 and comprises of a number of judges prescribed by an Act of Parliament and is organized and administered in the manner prescribed by an Act of Parliament. It has jurisdiction for the following [National Council for Law Reporting, 2010: Article 165 (3)]:

- Unlimited original jurisdiction in criminal and civil matters;

- Determining the question of whether a right or fundamental freedom in the Bill of Rights has been denied, violated, infringed or threatened;

- Hearing an appeal from a decision of a tribunal appointed under the Constitution to consider the removal of a person from office, other than a tribunal appointed under Article 144 which makes provision for the procedure for removal of the President for reasons of incapacity;

- Hearing any question regarding the interpretation of the Constitution; and

- Any other jurisdiction, original or appellate, conferred on it by legislation.

The Kenya High Court in Nairobi undertakes the bulk of litigation. For administrative reasons therefore, it is organized into seven divisions each headed by a judge. These are: the Criminal; Civil; Commercial and Admiralty; Judicial Review; Land; Constitution and Human Rights; and Family division (Republic of Kenya, the Judiciary, 2013).

Finally, the Subordinate Courts comprise of the Magistrates Courts, Kadhis' Courts, Court Martials and any other court or local tribunal as may be established by an Act of 
Parliament (National Council for Law Reporting, 2010: Article 169). Magistrates Courts were created under the Magistrates Act Chapter 10 of the laws of Kenya (amended in 2012) and reconstituted under Article 169 of the Constitution of Kenya 2010. They handle civil and criminal matters depending on the rank of the magistrate.

\subsubsection{Judicial Reforms in Kenya}

Kenya has gone through a series of constitutional reforms since its independence from British colonial rule in 1963. A recent reform was the promulgation of a new Constitution in 2010. This Constitution contains a progressive bill of rights that is expected to address issues that have been of great public debate in Kenya such as governance, equity and equality, security, and justice (Maingi, 2010; and Cowell, 2010). The Constitution 2010 is expected to address injustices such as "human rights violations, including land clashes, massacres, arbitrary arrests, extrajudicial execution, and detention without trial, torture, electoral violence, grand corruption and economic crimes that the country has experienced since independence" (Mue, 2010:4). It establishes the framework for the restoration of constitutional democracy in Kenya and heralds a new beginning for most institutions (Human Rights World Report, 2012) judiciary included.

The quest for judicial reforms in Kenya has been a subject of continuing concern for many stakeholders in the country and even the international community. The Chief Justice and President of the Supreme Court in Kenya in 2011 lamented that "we found an institution so frail in its structures, so thin in resources, so low in its confidence, so deficient in integrity, so weak in public support that to expect it to deliver justice is wildly optimistic, we found a judiciary destined to fail" (Mutunga, 2011:6). Ndungu (2012) in the same breath noted that the desire by the Kenyan public for a new constitution has been spurred by decades of dissatisfaction with the judiciary's performance and susceptibility to impunity. A report from the Security Sector Reforms (2000), notes that the judiciary was widely perceived as the weakest branch of government in Kenya while the Constitution of Kenya Review Commission (2012), found the Kenyan Judiciary to be among the most incompetent and insufficient in Africa. 
Similarly, a report from Human Rights Watch (2012) contended that judges in Kenya commonly accepted bribes and many were subject to political influence. The report also observed that the courts were understaffed and underfinanced, and Kenyans awaiting trial faced long delays that violated the right to due process. The Constitution 2010 paved the way for Kenyans to institute the much needed judicial reforms in this arm of government.

One key pillar upon which the new Constitution is constructed is continuous engagement with citizens in the development of bills, the public vetting of state officers and oversight role on public affairs. President Mwai Kibaki of Kenya launched the Kenya Open Data Initiative (KODI) in July 2011 (Majeed, 2012) that is aimed at opening up government to the public by providing citizens with granular data relating to Kenya's development so that every citizen could be empowered to participate in development (Excell and Sendugwa, 2012). One of the key aspects of KODI is the open government data portal initiative which is widely acclaimed globally as one of the most significant steps Kenya has made to improve governance and access to information (Kenya ICT Board, 2012).

The Kenyan judiciary launched its Transformation Framework in May 2012 with the three main pillars being: access to and expeditious delivery of justice; public participation and engagement and stakeholder engagement (Judiciary Transformation Framework, 2012). With these pillars in place, the judiciary hopes to inculcate a culture of openness in line with the spirit of the new constitution in order to inspire faith and confidence in the people of Kenya. The effective implementation of an open and transparent judiciary will largely be determined by the records management regime that is put in place.

\subsection{Statement of the Problem}

"Records are indispensable for the efficient, transparent, and accountable management of organizations but are often under-valued, ignored or misunderstood" (Williams 2006:1). Initiatives aimed at enhancing economic performance, increasing government accountability and strengthening civil society such as administration of justice, administration and civil service reforms, e-government and open government all rely on 
access to accurate evidence (Thurston, 2005). However, ineffective management of records in many countries especially developing countries is common. Thurston (2005:1) argued that "mountains of paper fill offices and corridors while record storage areas have become the 'Siberia' to which difficult staff are sent".

A study conducted by IRMT on "Establishing E-records as a Component of Electronic Government in African Countries" (IRMT 2003) revealed various challenges facing the African countries in as far as managing records was concerned such as: absence of legislation, absence of organizational policies and procedures to guide the management of records; absence of core competencies in records and archives management; absence of dedicated budgets for records management; and low awareness of the role of records management in supporting organizational efficiency and accountability to name but a few.

During the launch of the Judiciary Transformation Framework in Kenya, the Chief Justice Willy Mutunga (Mutunga, 2012:3-4) observed that an "oft-repeated criticism of the Kenyan judiciary had been over how it had accumulated impossible case backlogs". $\mathrm{He}$ pointed out that "case delays had become the badge of inefficiency and ineffectiveness the judiciary wore as its mark of distinction and an important source of public frustration". Moreover, Mutunga (2012:4) noted that "where records storage, management and retrieval system is weak or non-existent, the sagacity of judges and /or magistrates alone would not be adequate in preventing a miscarriage of justice". Thurston (2005) pointed out that well managed records are essential to efficient and effective legal systems and accurate and readily accessible records of judicial rulings reduce the potential for injustices that may result from delays, corruption and inaccuracies. Michira (2013) in an article in the Standard Newspaper noted a very slow justice system in the Kenyan judiciary. He estimated that an appellant would be heard within five years at best and gave an example of a convict whose appeal had been pending conclusion for 19 years. He attributed these delays to limited capacity in the number of judicial staff, few or lack of courtrooms and poor records management. Michira (2013:3) observed that "files containing years of criminal proceedings were strewn on broken chairs and many 
more spilled onto the earthen floor". According to Michira (2013:4) the "records were at times infested by termites and in a particular law court in Machakos, snakes and hedgehogs were found crawling under files in the dilapidated registry".

Sound records management in the Kenyan judiciary is also hampered by limited skills. IRMT (2011) revealed that there is limited capacity especially at senior records management level in the Kenyan judiciary to facilitate the design of systems that leverage ICT that are crucial for enhancing sound records management. Meaningful transformation of the Kenyan judiciary cannot ignore a sound records management regime that is capable of availing to citizens' information and data that is accurate, complete, reliable, authentic and trustworthy. This study therefore sought to investigate records management in the Kenyan judiciary with a view to promoting transformation and open government for effective and efficient justice delivery.

\subsection{Purpose of the Study}

The study sought to investigate records management in the Kenyan judiciary with a view to promoting transformation and open government so that justice can be achieved effectively and efficiently.

\subsubsection{Objectives of the Study}

This study sought to address the following objectives:

- To determine the status of records management in the Kenyan judiciary;

- To establish the link between records management and open government;

- To assess e-records readiness in the Kenyan judiciary. 


\subsubsection{Research Questions}

The major research question this study sought to address was: What is the current status of records management in the Kenyan judiciary in facilitating openness?

In order to address this question, the study sought to answer the following subsidiary research questions:

- How are records created, accessed and used, stored and maintained, appraised and disposed of and preserved?

- What records management policies, plans, and guidelines are available?

- What skills and competencies do the records management staff have?

- What is the level of awareness and attitude of staff towards sound records management practices?

- What records management strategies is the Kenyan judiciary using to achieve openness?

\subsection{Significance of the Study}

According to Creswell (2003), significance of any study is determined by: how the study adds to scholarly research and literature in the field; how it improves practice in the area of interest; and how it improves policy. The current study was necessitated by the fact that the Kenyan judiciary in its transformation framework commits to among other things engaging the public and encouraging citizen participation in judicial matters following many years of judicial malpractice. For these efforts to bear fruits it requires citizens to be provided with accurate, complete, reliable and trustworthy information which is a product of a sound records management regime.

The study therefore investigated among other issues how records were being managed in the Kenyan judiciary from creation to its ultimate disposition using the Records Continuum Model, IRMT E-Records Readiness Tool and Open Government Implementation Model as the theoretical lenses. This study therefore contributes to the 
existing body of knowledge by integrating records management and open government. Furthermore extant literature revealed that open government is a relatively new area of study (Yu and Robinson, 2012). Besides, most open government models have been generated in the developed countries notably the United States of America and United Kingdom. Consequently, few empirical studies on open government have been done in Africa and particularly in Kenya. This study is therefore significant in contributing to the scholarly research and literature in the field where empirical studies are few.

The study findings indicated that although records management in the judiciary had improved following the promulgation of the Kenya Constitution 2010 and the JTF, it was still weak compared to available standards. The study therefore provided empirical evidence on the importance of managing records in a continuum of care from creation to disposition as a means to attaining the transformation and open government agenda. Consequently, the study suggested strategies that could be used to improve records management practice so that the transformation and open government agendas would succeed and justice would be delivered effectively and efficiently. Moreover, although the idea of open government is not yet well understood and practiced in Africa (CIPESA, 2011), Excell and Sendugwa (2012) identify countries such as South Africa, Kenya, Tanzania, Liberia and Ghana that are starting to implement open government. This study could provide a bench mark on the implementation of open government in these African countries.

Lastly, this study is expected to improve policy by creating awareness among policy makers about the need to align records management policies with open government. This alignment is particularly important since records management provides the means through which the creation, capture, availability and usability of accurate reliable and trustworthy records takes place. 


\subsection{Delimitation of the Study}

The study was carried out at the high court and magistrate courts in Nairobi and Uasin Gishu counties. Nairobi County was selected because it is the capital of Kenya where the law courts are concentrated with a large number of civil and criminal cases being handled. On the other hand, Uasin Gishu County was selected since it is quasi-urban and hence removed from the capital and represents the status of records management and openness in the judicial system outside Nairobi. The choice of Uasin Gishu is also informed by its accessibility to the researcher since the researcher resides in this county.

The study focused on the High Court and the magistrate courts because anecdotal evidence shows that majority of the problems identified above emanate from these two courts. The magistrate courts in particular comprise the most extensive service network of the judiciary in Kenya and perform the bulk of service delivery because they are the first line of redress for many litigants. In addition, the Supreme Court came into being after the promulgation of the new constitution in 2010 and therefore has not experienced most of the challenges identified. The Court of Appeal on the other hand has jurisdiction and powers to hear and determine appeals from the High Court of Kenya and any other court or tribunal. The Kadhis and specialized courts handle very specific issues like marriage and divorce among parties professing the Muslim religion. This means the number and complexity of such cases is relatively low. The High Court and the magistrate courts therefore are left with so many cases to handle. As mentioned earlier, the High Court in Nairobi is organized into seven divisions for administrative reasons; therefore, this study looked at all the seven divisions of the court.

Although the judiciary creates and maintains different types of records, including administrative files, staff records and case files, the study focused on case files referred herein as court records. The case files are a working tool of the judicial officers where all decisions made pertaining to a case are recorded and filed in. It therefore plays a critical role in administering justice thus the focus of the study. 
The study had limitations that the researcher had to contend with. Firstly, given that open government is a relatively new area of study (Yu and Robinson, 2012), obtaining adequate literature was a challenge. The researcher had to depend on journal articles given that no single book was available to the researcher, and had to rely extensively on studies in related fields such as e-government.

Secondly, tight schedules among some of the would-be participants of the study (judges and magistrates) were also a limiting factor. Some of them could not afford time to fill in the questionnaires and the study had to rely on the response of only $52 \%$ of them. To ensure that the data was adequate, interview sessions with deputy registrars were intensified to allow collection of in-depth data given that they are also magistrates though acting on the capacity of court administration.

Lastly, the study was also limited by financial constraints which restricted the researcher to covering only two counties. However, the researcher felt that the two counties selected provided good case studies given that one was in Kenya's capital while the second one was in a quasi-urban area and removed from the capital. In spite of the limitations identified, the validity and reliability of the study findings was ensured through the use of such measures as peer debriefing, member checks and triangulation of data sources and methods of data collection alluded to earlier.

\subsection{Theory and Models for the Study}

The substantive coverage of the theory/models underpinning this study is presented in Chapter two (Theoretical Framework). This section however, is intended to provide an introduction to the theoretical models that are covered in the next chapter. This study was underpinned by Records Continuum Model (RC), IRMT E-Records Readiness Tool and Open Government Implementation Model. The RC model presents a consistent and coherent regime of management processes from the time of the creation of records to their ultimate disposition (Standards Australia, 1996). 
The RC model could however, not provide the basis of more specific issues of records management readiness for open government such as policy, skills, and awareness and attitude of staff towards records management. For these issues to be well addressed, the study applied IRMT E-Records Readiness Tool. The tool was useful in addressing the second research question (What records management policies, plans, and guidelines are available?), the third research question (What skills and competencies do the records management staff have?), and the fourth (What is the level of awareness and attitude of staff towards sound records management practices?). The fifth research question on implementation of Open government was addressed using Open Government Implementation Model (OGIM) (Lee and Kwak,2011) Table 1, provides a summary of the mapping of research questions to variables of theoretical lenses of the theories used.

Table 1: Summary of mapping of research questions to variables of the theoretical lenses

\begin{tabular}{|l|l|l|}
\hline Research Question (s) & $\begin{array}{l}\text { Theoretical } \\
\text { Model(s) }\end{array}$ & Key Variables Addressed \\
\hline $\begin{array}{l}\text { How are records created, } \\
\text { accessed and used, } \\
\text { stored and maintained, } \\
\text { appraised and disposed } \\
\text { of, and preserved in the } \\
\text { judiciary? }\end{array}$ & $\begin{array}{l}\text { Records } \\
\text { Continuum Model }\end{array}$ & $\begin{array}{l}\text { Records creation, records use, records } \\
\text { distribution, records storage, records } \\
\text { maintenance, records appraisal, records } \\
\text { disposition and records preservation. }\end{array}$ \\
\hline $\begin{array}{l}\text { What records } \\
\text { management policies, } \\
\text { plans and guidelines are } \\
\text { available? }\end{array}$ & $\begin{array}{l}\text { E-Records } \\
\text { Readiness Tool }\end{array}$ & $\begin{array}{l}\text { Records management policies, records } \\
\text { management responsibilities }\end{array}$ \\
\hline $\begin{array}{l}\text { What skills and } \\
\text { competencies do the } \\
\text { records management } \\
\text { staff have? }\end{array}$ & $\begin{array}{l}\text { E-Records } \\
\text { Readiness Tool }\end{array}$ & $\begin{array}{l}\text { Records management skills, records } \\
\text { management competencies, records resources } \\
\text { and training. }\end{array}$ \\
\hline
\end{tabular}




\begin{tabular}{|l|l|l|}
\hline $\begin{array}{l}\text { What is the level of } \\
\text { awareness and attitude of } \\
\text { staff towards sound } \\
\text { records management } \\
\text { practices? }\end{array}$ & $\begin{array}{l}\text { E- Records } \\
\text { Readiness Tool }\end{array}$ & $\begin{array}{l}\text { Records management awareness and attitude } \\
\text { towards records management }\end{array}$ \\
\hline $\begin{array}{l}\text { What records } \\
\text { management related } \\
\text { strategies is the Kenyan } \\
\text { judiciary using to } \\
\text { achieve openness? }\end{array}$ & $\begin{array}{l}\text { Open Government } \\
\text { Implementation } \\
\text { Model }\end{array}$ & $\begin{array}{l}\text { Data transparency, open participation, open } \\
\text { collaboration and ubiquitous engagement }\end{array}$ \\
\hline
\end{tabular}

Source: Field Data (2014)

\subsection{Preliminary Literature Review}

The literature is substantively reviewed in chapter three (Literature review) and covers empirical and theoretical sources. This section only serves to introduce key aspects of literature that are discussed in chapter three. The literature reveals in general that studies on records management and open government are modest, in part due to the fact that open government and records management respectively do not have a long tradition of existence. Records management emerged in the 1940s (Cox, 2000) while open government emerged more recently during the 1990s (Yu and Robinson, 2012). The literature further reveals that court records management, e-readiness and e-government, and open government are major issues of concern in many countries such as the United States of America, Singapore, South Africa, Botswana, Uganda, Rwanda, Tanzania and Kenya among others (Thurston 2005:2; IRMT, 2002; Motsaathebe and Mnjama, 2007; Wamukoya and Mutula, 2005; Moloi and Mutula, 2007 and Mnjama and Wamukoya, 2007; IRMT,2011) because of the growing emphasis on transparency, and accountability in the administration of justice and the need to reduce large backlogs of court cases. The substantive literature presented in chapter three therefore covers issues related to among others case management reforms; electronic filing; management of case files and other court records; e-government; e-records management; challenges of records management; and open government (Alonso, Boyera, Bratt, Grawal and Iglesias, 2011; Nam, 2011; 
NASCIO, 2009; Davies 2010; Centre for Technology Policy Research, 2010; Stott, 2012; and Africa Centre for Open Government, 2011) among others. The literature in chapter three reveals inadequate alignment of e- government and open government (Wamukoya, 2012) and reliance on open government models developed in the developed countries notably the United States of America and United Kingdom. Some of these gaps are addressed in this study.

\subsection{Methodology}

The substantive issues on methods and research design are covered in chapter four (Methodology \& Research Design). Aspects of methodological issues covered here introduce key issues that are discussed in detail in chapter four.

This study adopted the pragmatic paradigm with the mixed methods in which the qualitative approach was the dominant while the quantitative method was less dominant. Moreover, case study design was used. Questionnaires, in-depth interviews, observation and document review techniques were used to collect data.

The study population comprised of court registrars, deputy registrars, judges and magistrates of the high court and magistrates courts respectively, executive officers, records officers (archivists) and registry assistants (executive assistants and clerical officers) in both the high court and the magistrates' courts in Nairobi and Uasin Gishu counties. A complete enumeration of the study population (census) was undertaken involving all members of the population. Validity of the research tools was ensured by pre-testing through peer debriefing and triangulating of data collection methods. Reliability of the questionnaire was tested using Cronbach Alpha and was found to be reliable at 0.7 .

The study complied with the University of KwaZulu-Natal code of research ethics. In addition, a research permit was sought from the relevant government ministry in Kenya (appendix 5) and further permission to conduct the research obtained from the respective 
courts. The detailed discussion of methodological and design issues is covered in the chapter on methodology.

\subsection{Structure of the Study}

The study is divided into seven chapters as shown below:

\section{Chapter One: Introduction and Background Information}

The chapter covers: introduction and background to the research problem; statement of the problem; the purpose of the study; research objectives; research questions; significance and contribution of the study; delimitation of the study; brief introduction to theoretical framework covered in chapter two; and introduction to methodology covered in chapter four.

\section{Chapter Two: Theoretical Framework}

The chapter presents detailed overview of theoretical framework that was introduced in chapter one.

\section{Chapter Three: Literature Review}

This chapter provides a detailed review of both theoretical and empirical literature that was briefly introduced in chapter one.

\section{Chapter Four: Research Methodology}

The chapter builds on the aspects of methodology introduced in chapter one and presents in detail the research paradigm, research approach, and research design; study population; sampling methods and techniques; sample sizes; data collection procedures; reliability and validity of the instruments; ethical consideration and presentation and analysis of data.

\section{Chapter Five: Data Analysis and Presentation of Findings}

The chapter analyzed data and presented findings based on the research questions. 


\section{Chapter Six: Interpretation and Discussion of Findings}

The chapter interpreted and discussed the findings and examined their implications based on the research questions.

\section{Chapter Seven: Summary, Conclusions and Recommendations}

The chapter provides a summary of findings, conclusions and recommendations of the study based on the data presented and interpreted.

\subsection{Summary}

Chapter one laid down the foundation for the other chapters. It presents the introduction and background information to the research problem, statement of the problem, purpose and objectives of the study, and the research questions. Further, the chapter provides the significance and delimitations of the study, and covers the ethical issues. Furthermore,

the chapter introduces the theoretical framework, literature reviewed and the methodology adopted. 


\section{CHAPTER TWO \\ THEORETICAL FRAMEWORK}

\subsection{Introduction}

A theoretical framework is a conceptual model of how one theorizes or makes logical sense of the relationships among several factors that have been identified as important to a problem (Sekeran, 2003). As such, theories are found early in the research plan of the research and basically act as an orienting lens shaping the questions to be asked, who participates in the study, how data is collected and the overall plan of the dissertation (Creswell, 2003).

Generally, theory discusses the interrelationships among the variables that are deemed to be integral to the dynamics of the situation being investigated (Sichalwe, 2010). According to Polit and Beck (2004) the purpose of a theoretical framework is to make research findings meaningful and generalizable thus stimulating research and the extension of knowledge by providing both direction and impetus. The frameworks are therefore orientations or ways of looking at the social world, at a level less abstract than the meta-science positions. They provide collections of assumptions, concepts and forms of explanations (Mikkelsen, 2005).

Theory has many meanings but from the social scientist's point of view, theory can be defined as "a system of interconnected abstractions or ideas that condenses and organizes knowledge about the social world" (Mikkelsen, 2005:157). To Mikkelsen, theory gives us concepts, provides basic assumptions, directs us to the important questions and suggests ways for us to make sense of data, therefore making the researchers to think through the research. Creswell (2003) on the other hand, defined a theory as an interrelated set of constructs or variables formed into propositions, or hypotheses, which specify the relationship among variables.

An author may present a theory as a visual model, the term 'model' is sometimes used interchangeably with the term theory. However, as noted by Cohen, Manion and 
Marrison (2007), though models are often characterized by the use of analogies to give a more graphic or visual representation of a particular phenomenon, like theories they may be seen as an explanatory device or scheme having a broad conceptual framework. Case (2007) defined a model as a simplified representation of a real situation including the main features of that situation. Like theories, models can be of great help in achieving clarity and focusing on key issues in the nature of phenomena or problem area (Cohen, Manion and Marrison, 2007).

In this study, models were used to form the theoretical perspective of the study and to explain theories that were deemed to be relevant but did not directly inform the study.

\subsection{The Use of Theory in Quantitative, Qualitative and Mixed Methods Researches}

This study is underpinned by mixed methods involving both qualitative and quantitative approaches. In quantitative studies, theories are used deductively and placed at the beginning of the plan for a study (Creswell, 2003). In this case, the researcher uses the theory with an objective of testing or verifying the theory rather than developing it (Sichalwe, 2010). The researcher therefore advances a theory, collects data to test it and reflects on the confirmation or disconfirmation of the theory by the results (Creswell, 2003). The theory thus becomes a framework for the entire study, an organizing model for the research questions or hypotheses and the data collection procedure.

On the other hand, theories are used in qualitative studies either to provide an explanation for behavior and attitude, and it may be complete with variables, constructs and hypotheses. Alternatively, qualitative researchers may use theories as lenses or perspectives to guide their study (Creswell, 2003). In this case, the researcher is guided as to what issues are important to examine, the people that need to be studied, how the researcher should position himself or herself in the qualitative study and how the final written account should be like. 
In mixed methods research, the use of theories may be directed by the emphasis on either quantitative or qualitative approaches (Creswell, 2003). As already pointed out this study adopted the mixed methods approach in which the qualitative aspect was dominant and quantitative less dominant. In this regard several theoretical models were used as an orienting lens to the study.

\subsection{Theoretical Underpinning of the Study}

The purpose of this study was to investigate records management in the Kenyan judiciary with a view to promoting transformation and open government for effective and efficient administration of justice. The following research questions were addressed: How are records created, accessed and used, stored and maintained, appraised and disposed of, and preserved?; What records management policies, plans, and guidelines are available?; What skills and competencies do the records management staff have?; What is the level of awareness and attitude of staff towards sound records management practices?; and What records management related strategies is the Kenyan judiciary using to achieve openness?

The study was primarily underpinned by the Records Continuum Model, E-records Readiness Tool and the Open Government Implementation Model (OGIM). These three primary theoretical models were complemented by the records entity life history; records life-cycle and integrated approach to records management models.

The three primary models addressed records management and open government which are central themes of this study. No one single theoretical model was found adequate since the areas of records management and open government are relatively new and do not have firm theory to underpin their study. 


\subsubsection{Records Continuum (RC) Model}

The RC Model originated in Canada, though it was developed and adopted in Australia in 1980s (Bantin, 2002). Shepherd and Yeo (2003) assert that the RC Model was developed in response to criticism of the life-cycle models. Artherton (1985) on the other hand, pointed out the logical weakness of the life-cycle concept and wondered whether the management of current records was the first stage in the administration of archives on one hand, and the continuing preservation of valuable records the last step in records management. The life-cycle model as a string of related but separate functions and responsibilities is found misleading because it ignores the working relationships that exist between the archivists and records managers.

Artherton (1985) observes that the separation of records management and archives administration under the life-cycle model is unsatisfactory and suggest its replacement by the RC Model with four stages namely: creation or receipt; classification; establishment of retention/ disposal; and maintenance and use. The four stages are interrelated forming a continuum in which both records officers and archivists are involved to varying degrees in the on-going management of recorded information. The underlying unifying factor in this continuum is the function of service to the records creator and all their users.

Kemoni (2008) opined that the RC Model has gained international acceptance as a basis for the management of records both in paper and electronic formats. In this regard, the model is succinctly defined in the Australian Standard for records management as:

... a consistent and coherent regime of management processes from the time of the creation of records (and even before creation in the design of recordkeeping systems) through to the preservation and use of records as archives (Standards Australia, 1996).

The RC Model as presented by Artherton was revised and a more elaborate presentation

provided by archival theorists in the 1990s chief among them being Frank Upward 
(Flynn, 2001). Upward (2000) outlined four principles of the RC Model through a diagrammatic representation of the model as reflected in Figure 1. These principles are:

- A concept of records which is inclusive of records of continuing value (archives) which stresses their uses for transactional, evidentiary and memory purposes and which unifies approaches to archiving/recordkeeping;

- A focus on records as logical rather than physical entities, regardless of whether they are in paper or electronic form;

- Institutionalization of the recordkeeping professional's role with a particular emphasis on the need to integrate recordkeeping into business and societal processes.

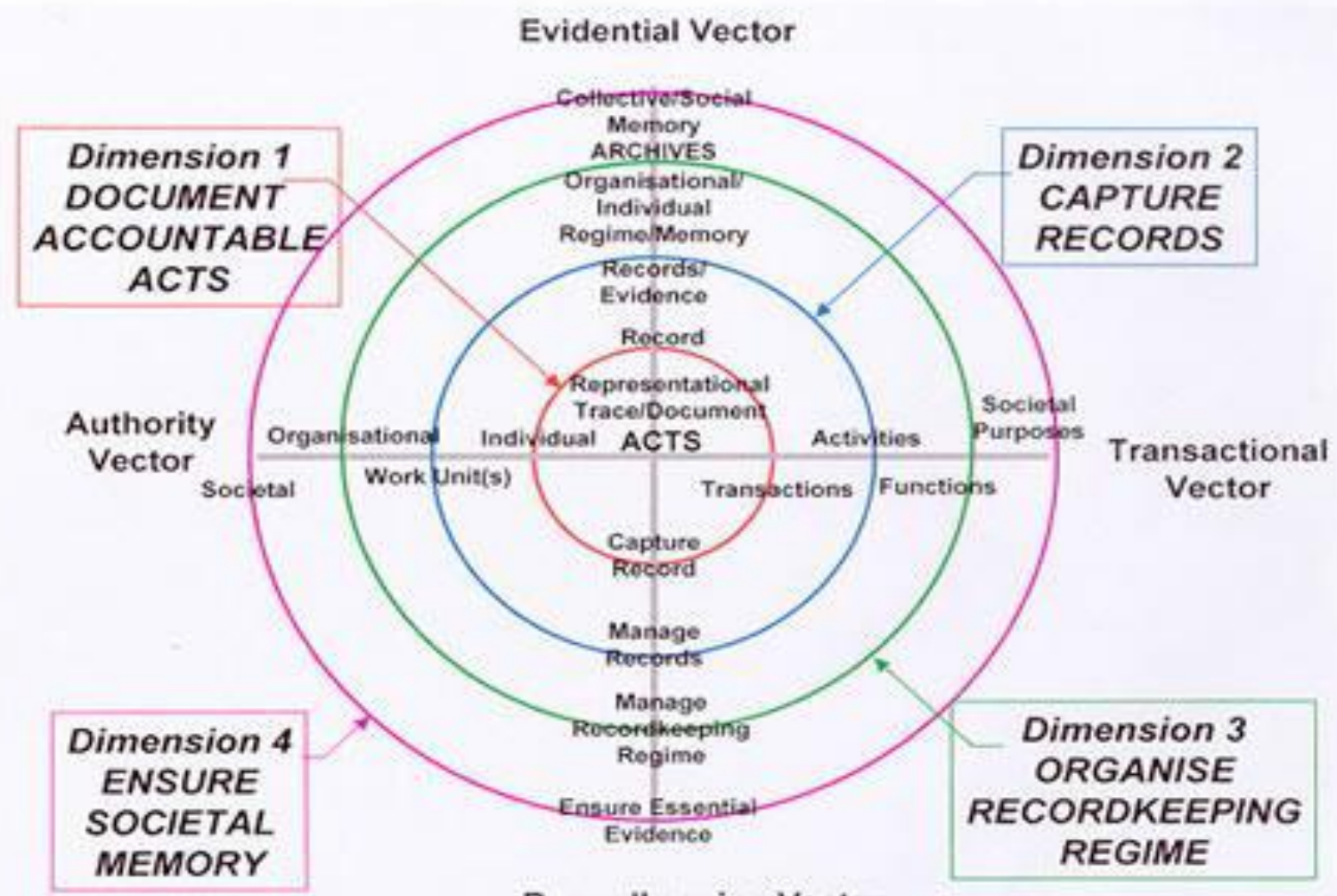

Recordkeeping Vector

Figure 1: Records Continuum Model (Source: Upward, 2000:123)

Four major themes in archival service are evidenced in Figure 1 above namelyauthority/identity, transactionality, evidentiality and record keeping containers/vector. 
Flynn (2001) observed that the themes are linked by concentric circles representing the dimensions of the continuum joining the individual record to its contexts. Flynn explained that the themes serve as coordinates giving the diagram a structure. The circular layout - unlike the linear, diachronic depiction of the life-cycle model demonstrates the synchronic nature of the RC Model. Upward (2000) commented that the dimensions are not boundaries, the coordinates are not invariably present and things may happen simultaneously across dimensions. Shepherd and Yeo (2003) concurring with Upward observed that the dimensions in the continuum (creation, capture, organize, and pluralize) are not time-based, but represent different perspectives on the management of records. The description of each of the dimensions follows:

\section{a) Records Creation}

At the very center, the whole process of records management is offset by work activity involving a flow of individual actions, decisions and transactions over time. Some but certainly not all of these activities are important enough to be worthy of documentation capturing a reliable record of it using a record keeping system. According to Upward (2000), the document thus passes from dimension one- that of general activity - into dimension two. As depicted in the Figure 1, Dimension One (Creation) involves a creator or creators; the transaction in which he she or they take part of which a document is a result; the document itself (with or without archival characteristics); and the trace (or representation) of that transaction embodied in a document.

\section{b) Records Capture}

Dimension Two (capture) involves the work unit with which the actor is associated; the activity in the context of which transactions take place; the created document together with information about its context as a record (provenance or relationships to other documents; and the evidence which results. Upward (2000) asserts that in the perspective

of records management, the record keeping system of the particular work unit transforms 
the document into a record, fixing its content, structure and context in an immutable relationship.

Upward (2000) differentiates the isolated document of the first dimension from the captured record of the second dimension. This conforms to the definition provided by Jenkinson (1937) of a record as one which was drawn up or used in the course of an administrative or executive transaction of which it formed a part. At this point, record keeping professionals establish a master plan to manage each record effectively until its ultimate disposal. The instructions designate how a record is to be organized, identified, accessed and preserved for as long as it is required and ultimately set out terms for its final disposition. An (2001) explains that these instructions are attached to the record as metadata in the case of electronic records which interact automatically with the record keeping system to achieve effective management of electronic records.

\section{c) Records Organization}

The Dimension Three (Organize) is linked to its functions and the activities which constitute those of functions to archives and to its own corporate memory. Some accountable acts are considered important enough to warrant retaining evidence of them beyond their immediate business and regulatory use in dimension one and two. These records therefore inevitably become part of the cumulative corporate memory represented by dimension three (An, 2001). Here records are organized as evidence by placing them in the context of the corporate or individual archive and managing them in frameworks that enable the records to function as individual, group or corporate memory. In this case, the frameworks provided by national and institutional standards, policies and guidelines come into play and are concerned with establishing accountable, corporate recordkeeping and archiving regimes (Upward, 2000). These frameworks therefore establish systems and processes for the creation and capture of records in the first and second dimensions which support their evidential quality as well as their capacity to function as individual, corporate and collective memory. 


\section{d) Records Pluralization}

Finally Dimension Four (Pluralize) represents the placement of records and archives in society. The archives (records of several organizations) are set in a context of collective or societal memory; the term institution is meant to reflect the broader social recognition of organizations, while purpose equates to functions viewed from a broader societal perspective (Upward, 2000). This perspective of records management is therefore concerned with the constitution and protection of society's collective memory in a way that crosses organizational and jurisdictional boundaries. Ultimately, a small portion of corporate records have long term significance as documentation of the larger society (An, 2001). Such records though owned and maintained by the corporation are the concern of public archival authorities and as such must have their existence registered and their integrity protected as public archives of dimension four. This registration should take place at the moment of creation so that the integrity of society's valuable records can be protected from the very beginning.

Explaining the model, Shepherd and Yeo (2003) observed that the circles move out from creation of records of business activities to ensuring that records are captured as evidence and to their inclusion in formal systems for records management within the organization, while the fourth dimension looks out towards the needs of society for collective memory. McKemmish (2001) asserts that the model was built as a unifying concept for records inclusive of archives, which are defined as records of continuing value. The RC model also drew on ideas about the 'fixed' and 'mutable' nature of records, the notion that records are always in a process of becoming articulations of the role of recordkeeping and archiving in society in relation to governance, accountability, identity, memory and information provision. The model therefore aims at developing records management systems that capture, manage and maintain records with sound evidential characteristics for as long as the records are of value to the organization, any successor or society (Flynn, 2001). 


\subsubsection{Relevance of the RC Model to the Study}

The first principle of the RC Model relates to the concept of records which is inclusive of the records of continuing value (archives). This implies that the usefulness of records both for current business and historical (research use) can never really be separated; in fact research use is a subset of business use and the RC Model enables both uses to be clearly seen as two sides of the same coin (Upward, 2000). This view is particularly important for records created and managed in the Kenyan judiciary since all such records are important and useful as a basis for passing legal judgment, showing evidence of cases arbitrated upon or as memory of the judicial system. This is even more important given that an archival document can be retrieved and returned to current state when for instance an old case is revived just as a newly created record can be archived immediately after its use. Jenkinson (1937) shared the view that records could lie dormant for a while and then be activated for business purposes. It is therefore important to manage court records holistically from creation to final disposition as postulated by the RC Model.

Flynn (2001) noted that the model provides for a unified and homogeneous system for the management of records (including archives) in any format throughout their life time, however long or short that life time is. Concurring with this, the State Records New South Wales Recordkeeping Manual (2004), observed that the RC Model offers an integrated approach to managing records. The model, according to the manual, recognizes that records pass through identifiable stages but the stages act as a point of reference rather than as functions of records management. The model thus allows records managers and archivists to operate at appropriate stages of the records continuum to meet their different but harmonious objectives. This is useful in the management of records at the judiciary since all records created (whether active or archived) are important and useful as described above.

Moreover, Flynn (2001) points out that democratic government or government bodies (agencies) make their records (including archives) available whether for right to know or research purposes as obligated by legislation. The Kenya government promulgated a new 
constitution in 2010 (Cowell, 2010). Under this new constitution, citizens have a right to free access of information (National Council for Law Reporting, 2010: Article 35). Additionally, the Kenya government committed to an open government Initiative (Majeed, 2012) whose ideals are provision of public information to the citizens so that they can take part in socio-economic development of their country. In order to comply with the ideals of the new constitution and the open government initiative, the Kenyan judiciary launched its transformation framework whose pillars among others are to engage with the public and stakeholders (Judiciary Transformation Framework, 2012). This can only be achieved if the judiciary adopts a holistic management of records as provided for by the model.

Additionally, Flynn (2001) identified two, among other characteristics, of the RC Model as follows: its emphasis on the concept of service to the users of records whether internal or external to the creating organization throughout the lifetime of those records; and its provision of a sense of the provenancial, organizational and social context in which records are created and maintained. In agreement with this, the model according to Curtin University of Technology (2005), presents an overview of a seamless and dynamic recordkeeping regime that transcends time and space to capture and manage records for as long as they are required to satisfy business, regulatory, social and cultural requirements.

Lastly, the RC Model focuses on records as logical rather than physical entities. This is particularly significant for electronic records given that the essential qualities of a record (content, structure and context) are not necessarily all physically present in an electronic record but may be available to the user logically or virtually (IRMT, 2009). The model recognizes electronic records and provides for all records irrespective of their formats to be properly managed. The Kenyan judiciary recently embarked on an exercise to digitize its records meaning that records in both formats need to be well managed making the model relevant for the study. 
The relevance of the model to the study can also be seen in that other similar studies have adopted its use as theoretical perspectives. Examples of these studies are Garaba (2010) who used this model to investigate the management of the records and archives for former liberation movements in East and Southern Africa held by national and private archival institutions and Ambira (2010) who used it to investigate records management and risk management in Kenya Commercial Bank Nairobi.

\subsubsection{Gaps in the Use of the RC Model}

Although the RC Model provided a general framework for the management of records in the Kenyan judiciary, it could not specifically address the necessary records management readiness for an open government in the judiciary. The model for instance does not indicate records management requirements for an open government and therefore cannot be used as a stand-alone theoretical framework for the study. This is because it addresses the first research question which sought to find out how records are generally managed in the judiciary from the time they are created to their final disposition. To address the specific requirements thus answering the more specific research questions, the study adopted the e-records readiness tool as a second model underpinning the study.

\subsubsection{E-Records Readiness Tool}

This tool is aimed at providing a bench mark for organizations to assess themselves and determine where they stand in respect to the management of electronic records (IRMT, 2004). The tool is expected to enable governments to conduct high-level assessment of key areas of e-records readiness in relation to e-government and to determine whether the records and information management infrastructure is capable of supporting egovernment initiatives (Mnjama and Wamukoya, 2007). It is also intended to provide information to assist organizations to develop plans and strategies aimed at improving their paper based and electronic records environments. The tool was designed by the International Records Management Trust, a charitable organization in the United Kingdom. It is in form of a brief questionnaire that provides a risk assessment of e- 
records readiness both at the government-wide, national level and at the agency specific level. The questionnaire consists of twelve components of e-records readiness. The first six components address national, government-wide e-records readiness while the last six components address agency specific e-records readiness. The current study is concerned with agency specific e-records readiness and the following issues pertinent to this study are discussed: policies and responsibilities for records and information management; resources and training for records management personnel; and internal and public awareness and attitude towards records management.

\section{a) Policies and Responsibilities for Records and Information Management}

The e-records readiness tool requires each government agency implementing egovernment services to establish internal policies and responsibilities for records and information management in a form appropriate to its internal organizational structure, culture and resources (IRMT, 2004). Mnjama and Wamukoya (2007) observed that the level of commitment to managing e-records can be gauged by the existence or nonexistence of records management policies and procedures. In assessing the e-records readiness therefore one has to determine the availability of records management policies in the agency as stipulated by the tool (IRMT, 2004).

\section{b) Resources and Training for Records Management Personnel}

The e-records readiness tool asserts that although the agency may have established records management policies, tools and procedures, they will be ineffective unless they are supported by qualified records management staff with adequate and regular financial support to implement and maintain them (IRMT, 2004). According to Wamukoya and Mutula (2005) records and archives management staff should be equipped with new skills and competencies through training or retraining to be able to effectively operate and undertake projects in an e-environment. Similarly, Mnjama and Wamukoya (2007) observed that with few or non-existent trained and qualified staff in records management, 
coupled with the low status accorded to records work, the principles and standards that should guide records work are never included as part of an institution's strategic plans. They further pointed out that the availability of trained personnel and resources therefore become an assessable area in determining a country's or agency's e-readiness.

c) Internal and Public Awareness and Attitude towards Records Management

This last aspect assesses the extent to which senior management and all other staff in the agency are aware of principles of e-records management, understand and demonstrate commitment to a clear vision and set of objectives for the management of both paper and e-records (Mnjama and Wamukoya, 2007). A government agency may have put in place relevant records management policies, plans, procedures, tools and resources but these will be ineffective unless there is a commitment to implementing them. Managers and staff therefore need to be aware of the importance of trustworthy and effectively managed records for effective service delivery for transparency, accountability and integrity purposes (IRMT, 2004).

\subsubsection{Relevance of the E- Records Readiness Tool to the Study}

As mentioned earlier, over the past few years a paradigm shift has been emerging around how governments work and use ICT to deliver better services to their citizens; an approach that has come to be known as open government (Centre for Technology Policy Research, 2010). Mnjama and Wamukoya (2007) observed that an increasing number of governments all over the world are adopting modern information and communication technologies as tools for providing effective and efficient services to their citizens.

An open government is characterized by three principles: transparency; participation; and collaboration (Obama, 2009). Governments commit to disclose government operations to the public by making relevant information available to the citizens (Wamukoya, 2013). To achieve the three principles, ICT acts as an enabler towards achieving this goal. It is 
therefore necessary that an agency assesses its readiness in terms of policies, infrastructure and resources before embarking on implementation of the ICTs.

The Kenyan judiciary through its transformation framework is committed to engaging the public and stakeholders in matters of governance (Judiciary Transformation Framework, 2012). The engagement is predicated on the ability of the judiciary to harness the power of ICTs in order to providel quality information to the public (Kenya ICT Board, 2012). It is therefore necessary to assess the readiness of the judiciary is in terms of its ability to manage its records in an ICT enabled environment so as to facilitate its commitment to uphold open governance.

In a nutshell, the degree of e-readiness in an institution can be used as an indication of the institution's readiness to embrace an open government. The tool therefore appropriately guides the study by providing a relevant mechanism for assessing the e-readiness in the judiciary relating to policies, plans and guidelines; skills and competencies among records management staff; and the level of awareness and attitude of staff towards sound records management practices. Moreover the e-records readiness tool was designed by the International Records Management Trust, a charitable organization in the United Kingdom specifically to be used in developing countries to assess their e-records readiness. It therefore suits the current study very well since it is applied in an environment that the tool was designed to be used in.

\subsubsection{Gaps in the Use of the Tool as a Model}

The E- Records Readiness Tool guided the study by providing the mechanism of assessing records management readiness for open government in the Kenyan judiciary. However, the tool does not indicate how the open government initiative can be achieved in the judiciary. It therefore cannot be relied upon to take the study to its conclusive stage. As a result there was need to adopt a third model (Open government Implementation Model), to address the last aspect of the research problem which is the strategies that the judiciary is using to achieve the open government initiative. 


\subsubsection{Open Government Implementation Model (OGIM)}

This model was developed by Lee and Kwak (2011) as a road map that government agencies in the US can follow in moving towards the accomplishment of a more open government in response to a directive from the White House in December 2009 ( Obama, 2009). This directive required all executive departments and agencies to take the following steps towards the goal of creating a more open government:

- Publish government information online;

- Improve the quality of government information;

- Create and institutionalize a culture of open government and

- Create an enabling policy framework for open government.

The OGIM defines four implementation stages and recommends that government agencies should advance their open government initiatives incrementally, focusing on one implementation stage at a time. Lee and Kwak (2011) argued that by following the sequence, agencies can minimize risk and effectively harness the power of social media in order to engage the public. The OGIM model is depicted in Figure 2:

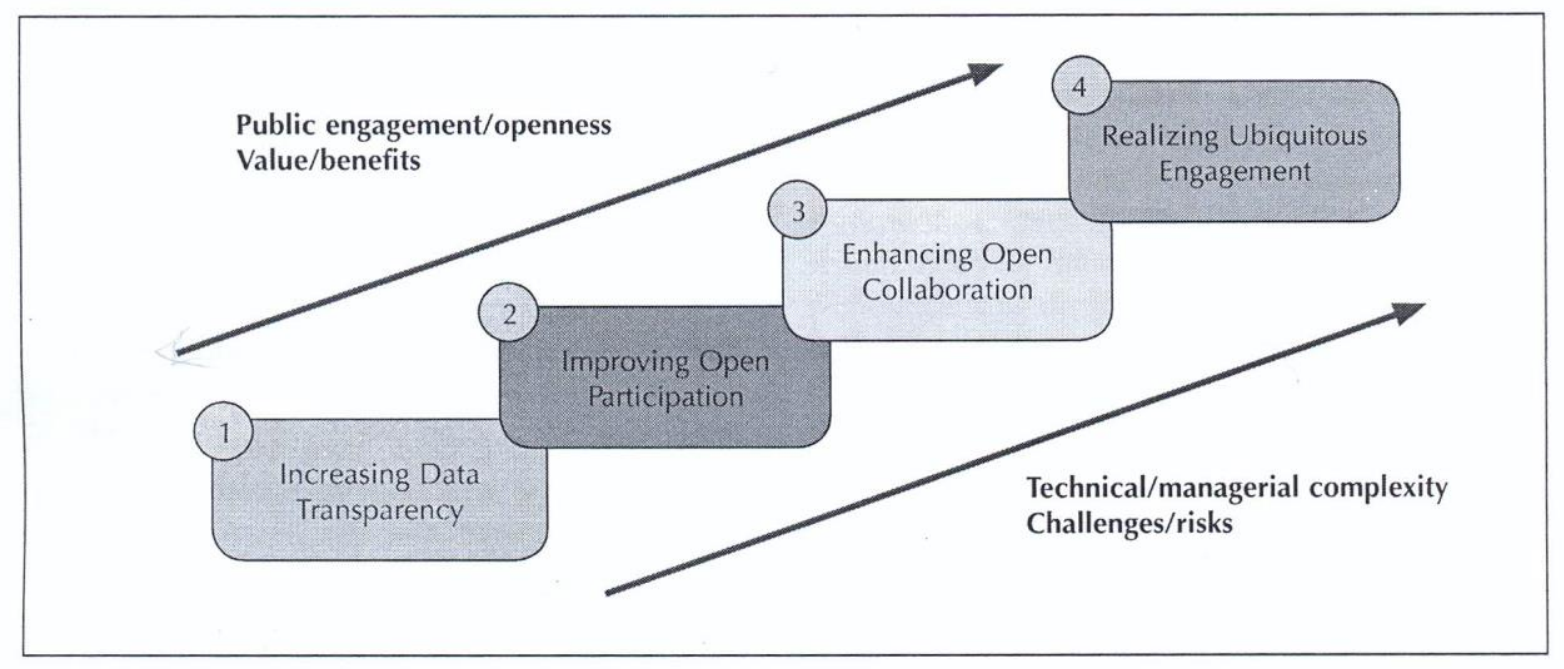

Figure 2: Open Government Implementation Model, OGIM

(Source Lee and Kwak, 2011:10) 
From figure 2, with each successive implementation stage, public engagement and openness of government work increases thus producing greater value and benefits for both government and the public. However, the technical and managerial complexity of the open government initiatives also increases at each stage. As a result agencies should expect to face greater challenges and risks in later implementation stages. These stages as depicted in Figure 2 above include: stage one - Increasing data transparency; stage two Improving open participation; stage three - Enhancing open collaboration; and stage four

- Realizing ubiquitous engagement.

\section{a) Stage One: Increasing Data Transparency}

This is the first step towards open government. At this stage, agencies focus on providing more data and information about government operations to the citizens. The goal here is to increase government or agency transparency and increase the ability of the citizens to scrutinize government and/or agency operations and play a more active role in socio economic development in the country. Data transparency is fundamental to the implementation of open government since the other stages are dependent on available data in formats that enable the realization of subsequent stages (CIPESA, 2012).

Lee and Kwak (2011) identified the following as two most important tasks at this stage:

- Identifying high - value, high impact data for the public;

- Improving and assuring data quality in terms of accuracy, consistency, and timeliness.

Agencies should therefore put in place an effective governance structure and processes to formally identify relevant data, assure its quality and publish it in a timely manner. Data quality is critical as low quality data may misinform and mislead the public about government work and performance. The quality of the data can only be assured in instances where government or agency records are managed within a sound records management regime (Thurston, 2012). Proper records management is therefore an integral part of open government implementation. 


\section{b) Stage Two: Improving Open Participation}

When quality data is provided to the citizens, they stand a better chance of participating meaningfully in the on-going developments within the government and / or the agencies. Stage two of the implementation model focuses on improving open participation of the public in government work and decision making through various methods and tools. Open participation enhances policy decisions and government services by welcoming and utilizing the input of the public. While stage one opens up government data to the public, stage two opens up the government itself to the public's ideas and knowledge. At this stage, agencies turn to social media and web 2.0 tools including web dialogues, blogs, micro blogging, social networking among others thought to be expressive social media. These allow the public to engage in informal, spontaneous, conversational interactions with governments. These interactions help government agencies to make informed, reliable decisions in real time (BonaBeau, 2009).

\section{c) Stage Three: Enhancing Open Collaboration}

The open participation of stage two if managed well will create an environment with meaningful collaboration between the government / agency with members of the public for better development. Open collaboration refers to the public engagement in complex tasks or projects that aim to produce specific outputs. Such tasks include group writing and editing of documents, wiki applications development and open source software development among others. This stage relies on collaborative social media such as wikis, google docs and JIVE SBS (Lee and Kwak, 2011). Agencies at stage three collaborate with other agencies, the public and the private sectors by utilizing government data and public input and feedback and co-create value added government services for the public response to national emergencies/ natural disasters and innovation of products and services. This stage requires increased use of modern ICT equipment and very good internet connectivity. 


\section{d) Stage four: Realizing Ubiquitous Engagement}

Ubiquitous engagement is at the apex of the open government implementation. At this stage agencies take transparency, participation and collaboration to the next level of public engagement. The agencies improve and fine tune existing open government initiatives to maximize their benefits.

According to Lee and Kwak (2011), agencies at this stage strive to achieve two important goals:

- Public engagement becomes easier and more accessible through mobile and ubiquitous computing devices and applications. Here, the public accesses government data, and participates and collaborates using smartphones, tablets, laptops, desktop computers among others;

- Seamless integration of various public engagement methods, tools and services within and across government agencies so that the public can easily navigate and engage in various activities without having to jump around different applications or keep logging in and out.

Agencies at stage four put an effective governance structure and process in place to enable continuous improvement and innovation of public programs. Furthermore, the agencies, the public, the private sector and other stakeholders form and nurture a sustainable ecosystem and a virtuous cycle for effective public engagement.

\subsubsection{Relevance of the Model to the Study}

The model provides agencies with a logical, sequential and systematic approach that seeks to minimize risks while maximizing benefits. Its step by step implementation process enables agencies to effectively build infrastructure and capabilities for open government without overburdening government employees, overstretching budgets and overwhelming the public. 
As mentioned elsewhere, the Kenyan judiciary launched its Transformation Framework in 2012 (Judiciary Transformation Framework, 2012) which among other things seeks to engage with members of the public and other stakeholders. This in effect seeks to inculcate a culture of openness and transparency in the judiciary's governance process. To succeed, this needs to be done in a logical, sequential and systematic manner as is provided for by the model. The model is therefore appropriate as a framework for the study since looking at the four implementation stages, it is possible to ascertain the level of openness in the Kenyan judiciary and establish the specific strategies being used by the judiciary to achieve its open government initiative.

\subsubsection{Gaps in the Use of the Model}

The model was formulated in a developed country (United States of America) where the technology adaptation is massive among the governments, government agencies and the public. The model thus assumes an elaborate use of technology and communication tools notably the social media to propel the openness, a scenario which may not be possible in a developing country like Kenya. However, the model was found to be useful to this study as a benchmark of how other countries are implementing their open government initiatives. The idea of open government is relatively new on the African continent (Excell and Sendugwa, 2012). For this reason, studies such as this one may have to rely on models from other parts of the world for the foreseeable future. To overcome this, more research should be undertaken especially in developing countries so that a more appropriate and practical model can be formulated.

\subsubsection{Complementary Theoretical Models for this Study}

The complementary theoretical models used for this study included records entity life history, life-cycle theory / model and integrated approach. These models were found to address the broader aspect of the study which is generally records management. 


\subsubsection{Records Entity Life History}

According to Shepherd and Yeo (2003) this model was developed by Jackson in 1983. The model advances the view that records have a life history which is built on a sequence (birth, life and death), on iteration (recordings), selections (choice of what is and what is not recorded and kept), of objects and actions (Garaba, 2010). Shepherd and Yeo (2003) observed that it is a method employed by systems analysts to represent different events that affect materials or other entities used in the conduct of business.

Following this model, Shepherd and Yeo (2003:8) explained that a record is created or received, is captured into a records management system and is then subject to actions that is, the maintenance and use where this will be repeated as necessary until the records are destroyed. However, for records of continuing value, destruction need never occur, but when it does occur it is the final event in the life of the record (Shepherd and Yeo, 2003). Shepherd and Yeo opined that this model is valid for all records whether in paper or electronic formats. The model however is not popularly used as a best practice model hence was not selected to inform the current study.

\subsubsection{Life-cycle Theory / Model}

This theory / model is recognized by a majority of records and archives management scholars as a theory / model in common use (Shepherd and Yeo, 2003:5). It can be traced back to the United States of America and particularly to Theodore Schellenberg who wrote about the lifespan of records in 1956. The National archives of the United States of America adopted this theory in response to the ever increasing volume of records produced by organizations. The theory stated that records have a clearly defined life from 'birth' to 'death' and was regarded as relevant in providing a framework for identifying the specific elements or functions of records management (Penn, Pennix and Coulson, 1994). 
Shepherd and Yeo (2003) recorded that since the 1950s, many variants on records lifecycle theory have been modeled. Most models aim to show a progression of actions taken at different times in the life of a record typically, its creation, capture, storage, use and disposal. Shepherd and Yeo observed that some writers show this as a linear progression while others describe a loop or circle.

According to Millar (1997) the records life cycle concept was an analogy of the life of a biological organism which was born, lived and died. In the same vein, a record was created, used as long as it had continuing value and was subsequently transferred to national archives or destroyed. Accordingly, Millar pointed out that the records lifecycle has three stages which he termed current, semi-current and non-current. In stage one; the record is created ostensibly for legitimate reasons. In the second stage, the record goes through an active phase when it has maximum primary value and is used or referred to frequently by the creating office and others involved in decision making. During this time, the record is stored on-site in the active or current files of the creating office. When the record ceases to be active, it is either destroyed (if it is found to have no further value) or relegated to semi-active status (if it still has value but not referred to frequently). At this point the record is stored in an off-site record center. At the end of this stage, a decision is made to either destroy the record (if without further value) or send to the next stage, which is reserved for inactive records with indefinite archival value (Bantin, 1994). Such records are sent to an archival repository for long term preservation.

Though the records life-cycle concept has influenced the development of records and archives management in many parts of the world, it has been found to have two pronounced weaknesses. Firstly, the view of records in a linear progression and its clear distinction of the role played by records managers and archivists are misleading. Artherton (1985) argued that although the life cycle has been useful in promoting a sense of order in the overall management of records, strict adherence to its principles undermined any trends towards greater cooperation and coordination among archivists and records managers and hence ignored the many ways in which records and archives operations are interrelated. 
Secondly, perhaps the most glaring weakness is seen in its application in managing electronic records (Yusof and Chell, 2000). The authors pointed out that the records lifecycle concept would not be used in managing electronic records and needed to be replaced by a model which appropriately reflected the special characteristics of these records. Similarly Barry (1994) observed that documents in a distributed electronic environment are dynamic and recursive in nature and may exist in more than one stage of the life-cycle simultaneously. To him, electronic records may not follow a serial path from creation to disposal but may be reappraised at the disposition time and reappear in a later stage. For this reason therefore, the records lifecycle concept may not be useful in the management of electronic records.

It is in consideration of the above discussion that the theory / model though relevant to the current study could not be used as an underpinning theory.

\subsubsection{Integrated Approach}

IRMT (1999) proposed an integrated approach to records management as a way to ensure that records are useful from the creation to their ultimate disposal. This is achieved by ensuring that these records are managed so that they are available and useful from their creation to their disposition.

An integrated records management programme recognizes that records follow a life-cycle and need to be taken care of in a continuum of care (Roper and Millar, 1999). The primary purpose of an integrated records management service as observed by Roper and Millar are two-fold:

- To preserve records and archives in an accessible, intelligible and useable form for as long as they have continuing value;

- To make information from records and archives available in the right format, to the right people at the right time. 
The integrated approach is a blending of the lifecycle and the continuum models in an integrated records and archives management system. The model was however, not used as an underpinning theory/model to the study since its explanation in literature is modest and not as elaborate as each of the individual models. Furthermore its application to the management of electronic records is not clearly elaborated.

\subsection{Summary}

The nature of the current study is interdisciplinary in that it looks at records management and relates it to open government. Literature reviewed did not reveal any theory that addresses these two areas of study. This made it necessary for the researcher to use the three models as an attempt to address the interdisciplinary nature of the study. Furthermore, open government is a relatively new field of study (Yu and Robinson, 2012) and therefore its theories are very modest. Moreover, there are very few studies that have been undertaken in Africa and Kenya in particular on open government. This study is therefore an attempt by the researcher to fill these gaps.

Three theories / models were discussed in reference to the management of records: the records entity life history which views records as having a life history built on sequence; the life-cycle concept which postulates that a record goes through stages in its life; and the integrated approach which proposes a blending of the life-cycle concept and the continuum concept. These theories / models though relevant to the study were not chosen to underpin the study.

The RC Model, E-records Readiness Tool and Open government Implementation Model formed the theoretical foundations of the study. The RC Model offers a holistic approach to records management since managing records is seen as a continuous process where one element of the continuum passes seamlessly into the other (Garaba, 2010:84). Furthermore, the RC Model presents an overview of a seamless and dynamic recordkeeping regime that transcends time and space to capture and manage records for as long as they are required to satisfy business, regulatory, social and cultural requirements. Moreover, the RC Model focuses on records as logical rather than physical 
entities, regardless of whether they are in paper or electronic formats. These reasons made the model relevant to the study. The E-records Readiness Tool on the other hand provided a mechanism to assess the ability of the Kenyan judiciary to support the open government initiative through the presence or otherwise absence of the relevant policies and infrastructure for managing e-records. The Open government Implementation Model was used to provide a benchmark on how the open government initiative would be implemented following success stories in other parts of the world.

This chapter therefore presented theories/models underpinning the study. From the theoretical framework, the following variables that are central to this study as also reflected in the research problem have been isolated and will form the thrust of the literature review in the next chapter:

- Records management (from creation to disposition);

- Policies and responsibilities for records and information management;

- Resources and training for records management personnel;

- Internal and public awareness and attitude towards records management;

- Open government;

- Open government and records management.

Literature will also be reviewed on related areas to the research problem as well as on research questions. 


\section{CHAPTER THREE LITERATURE REVIEW}

\subsection{Introduction}

Literature review refers to "a systematic, explicit and reproducible method for identifying, evaluating and interpreting an existing body of completed and recorded work produced by researchers, scholars and practitioners" (Fink, 2010:3). It is based on the assumption that knowledge accumulates and that people learn from and build on what others have done (Neuman, 2006). A review of literature is thus important because it enables the researcher to acquire an understanding of the topic; identify related research and place the work in the context of what has already been done. Lyons (2005) suggests the following purposes for conducting literature reviews:

- It helps place each work in the intellectual context of its contribution to the understanding of the subject under review hence position the study relative to the others;

- Identify new ways to interpret and shed light on any gaps in previous research studies. This helps in reviewing the field which allows the researcher to build on the platform of existing knowledge and ideas;

- Identify conflicts amongst seemingly contradictory previous studies;

- Place one's original work in the context of existing literature; and

- Identify research methods that could be relevant to the research.

The purpose of this study was to investigate records management in the Kenyan judiciary with a view to promoting transformation and open government for effective and efficient administration of justice. It addressed the following research questions: How are records created, accessed and used, stored and maintained, appraised and disposed of, and

preserved?; What records management policies, plans, and guidelines are available?; What skills and competencies do the records management staff have?; What is the level of awareness and attitude of staff towards sound records management practices?; and 
What records management related strategies is the Kenyan judiciary using to achieve openness?

The chapter is organized around themes gleaned from the underpinning theoretical models (see section 2.3.1 - 2.3.3 and table 1 in chapter 1), research questions and broader issues of the research problem (see section 1.4 in chapter 1). The review of literature is therefore organized around the following themes: records management; managing court records; policies and guidelines for records management; skills and resources requirements for records management; staff awareness and attitude towards records management; e-government and open government.

\subsection{Records Management}

Records management has been defined in various ways by different scholars. Iwhiwhu (2005) defines records management as a discipline of applying well-established techniques and procedures to the control of those sources of information, which arises internally within an organization as a result of its own activities. Meanwhile, ISO (2001:3) perceives records management as "a field of management responsible for the efficient and systematic control of the creation, receipt, maintenance, use and disposition of records including processes for capturing and maintaining evidence of and information about business activities and transactions in the form of records". The latter definition was adopted for the current study as it encompasses an emphasis on the management of records from creation to disposition thus covering the entire lifecycle of the records. Wamukoya (2000) observed that if records are to meet the requirements for accountability and good governance, their management must cover the whole extent of their existence from creation to disposition.

At creation, Upward (2000) observes that a master plan should be developed to manage each record effectively until its final disposition. The instructions designate how a record is to be organized, identified, accessed and preserved for as long as it is required and ultimately set out terms for its final disposition. With electronic records these instructions 
should be attached to the record as metadata that will interact automatically with the record keeping system to achieve affective management. For proper utilization of the records created their access and use should be managed as well. Motsaathebe and Mnjama (2009) note that access to records contributes greatly to the attainment of accountability and good governance required in any judicial system. To facilitate access to the records, retrieval systems must be put in place. These may include: a file classification system; file tracking mechanism; and shelf labelling.

ISO (2001) contends that classification of business activities acts as a powerful tool to assist the conduct of business and in many of the processes involved in the management of records including: providing linkages between individual records which accumulate to provide a continuous record of activity; ensuring records are named in a consistent manner over time; assist in retrieval of all records; determining security protection and access appropriate for sets of records; and allocating user permissions for access to, or action on a particular groups of records among others. Supporting this, Chinyemba and Ngulube (2005) posit that classification systems ensure there is consistency in classifying records which consequently makes retrieval easier. On the other hand, tracking has been defined by Ngoepe (2008) as documenting the movement and use of records within a records system. The author identified the following as being important to tracking records in any system: identifying outstanding action required; enabling retrieval of records; preventing loss of records; monitoring usage for systems maintenance and security and maintaining an auditable trail of records transaction; and maintaining capacity to identify the operational origins of individual records where systems have been amalgamated or migrated. ISO (2001) identifies two types of tracking: action tracking and location tracking.

According to ISO, action tracking may be implemented in a records system for processes where time limits for actions are imposed by or on the organization. Action tracking: allocates steps to be taken in response to decisions or transactions documented in a record; assigns responsibility for action to a designated person; and records dates by which the predefined action is to be taken and dates when those actions occur. On the 
other hand ISO (2001) provides that in location tracking the tracking mechanism may record the item identifier, the title, the person or unit having possession of the item and the time /date of movement. The system should: track the issue; transfer between persons; return of records to the storage areas as well their disposition or transfer to any other authorized external organization including an archives authority.

Storage of records should also be well managed to ensure continuous accessibility of the records. Iwhiwhu (2005) opined that proper storage is a vital aspect of every records management programme. ISO (2001) recommends that suitable records storage conditions should be provided so as to protect the records from unauthorized access, loss or destruction especially in the event of a disaster. ISO provides that priority is given to records with continuing value which require higher quality of storage and handling to preserve them as long as their value exists. To achieve this, designated storage areas for current, semi current and non-current records should be provided. This is in keeping with Wema's (2003) assertion that keeping current and non-current records together makes records storage difficult and may render the records irretrievable. Furthermore security of records at storage is another important aspect of records management. Millar (2003) observed that where security of records is not guaranteed, corruption is rife and cases of missing / lost records become common. Proper storage with security in mind should therefore be a goal of any records system.

Records appraisal and disposition are other aspects of records management that are fundamental to effective and efficient records management. Iwhiwhu (2005) identifies the need for records appraisal and disposition as this: helps in controlling the growth of record; helps in demonstrating compliance to disposition laws; and helps in reducing financial losses that may arise from missing files. According to ISO (2001) appraisal refers to taking decisions about how long records should be maintained within a records system. These decisions are then documented in the form of retention / disposal schedules. Disposition in contrast refers to implementing the decisions taken in disposal of records. ISO (2001) identifies the following disposition options available for an organization: immediate physical destruction which involves such measures as 
incineration, overwriting and deletion of records due for destruction; transfer to an appropriate storage area or medium under organizational control where the organization physically moves the records to a secondary storage area or a storage medium such as an external drive or Compact Disk Read Only Memory (CD ROM); transfer to an organizational archive which involves moving all inactive records to an archival repository run by the organization; and transfer to an external archives authority where records with permanent value are moved to a recognized archival repository in any given country such as national archival institutions

Records preservation is yet another crucial element in the whole operation of a records management programme. The aim of preservation is to prolong the usable life of information materials including records in two ways: preventive preservation which seeks to reduce risks of damage and slow down the rate of deterioration of the materials; and prescriptive preservation which seeks to identify and treat already damaged information materials to enhance their useful access (IRMT 1999). Preservation of records is therefore a key factor in determining long term and continued access to such records. Ngulube and Tafor (2006) assert that preservation is an activity that runs through the total life of records and must form an integral part of records management. On the other hand, Akussah (2012) argues that preservation must be seen as golden thread which must run through the total life of records and must be proactively pursued.

\subsubsection{Objectives of a Records Management Programme}

According to ISO (2001), the objectives of records management programmes are to: set policies and procedures; assign responsibilities for RM at various levels within the organization; set best practice standards; process and maintain records in safe and secure storage; implement access policies; implement retention and disposal policies; integrate

records management into business systems and processes; assign, implement and administer specialized systems for managing records; and provide a range of services relating to the management and use of records. 
Shepherd (2006) provided a three-fold argument on the importance of records and records management in an organization. Firstly, organizations use records in the conduct of current business, to enable decisions to be made and actions taken. She argued that records provide access to precedents and policies, and evidence of what was done or decided in the past. They therefore enable organizations to guard against fraud and to protect their rights and assets. Concurring with this, Wamukoya (2000) maintained that records management is fundamental and core activity of public sector management. To him, records represent a major source of information and are almost the only reliable and legally verifiable data source that can serve as evidence of decisions, actions and transactions in the public service.

Second, organizations use records to support accountability, when they need to prove that they have met their obligations or complied with best practice or established policies. Organizations are accountable in many ways, to meet legal, regulatory and fiscal requirements, undergo audits and inspections, or provide explanations for what was done. Internally, records are used to prove or assess performance. External accountability is especially important to public sector bodies which are responsible for their actions to government and the wider public. Thurston (2000) opined that if governments are to be held accountable for their actions and if the public is to have legally enforceable rights of access to government information, then it is essential to ensure that evidence is accurately and securely preserved. Without reliable, authentic documentary evidence, government cannot demonstrate to society that it has used state resources responsibly and that it has fulfilled its mandate to the people.

Third, records may also be used for cultural purposes, for research, to promote awareness and an understanding of corporate history. The wider community also has expectations of transparency in public service, the protection of rights and the maintenance of sources for collective memory. Wamukoya (2000) presented this purpose for records as the cultural domain of records management and noted that since records document organizational history over time, they provide the basis for writing cultural and national history. This by 
extension enables social cohesion since it accords members of a given community a sense of belonging and togetherness as a result of shared history and cultural beliefs.

In summary, the usefulness of records and records management cannot be overemphasized. Piggot (2002) contended that without access to good records, officials are forced to take decisions on an ad hoc basis without the benefit of institutional memory. Fraud cannot be proven, meaningful audits cannot be carried out and government actions are not open to review. Shepherd (2006) argue that effective records management helps an organization to conduct business in an efficient, accountable manner, deliver services consistently, support managerial decision making and transparent policy formation and ensure continuity in policy execution, management and administration. Swan et al. (2002) identify the following as benefits of an effective records management: increased efficiency and effectiveness of business activity since relevant and timely information is available; improved compliance with legal and regulatory requirements and community expectation; improved knowledge sharing and retention of and access to corporate memory; improved capacity to explain and provide evidence of an organization's actions and decisions; and appropriate management of records consistent with their retention requirements.

In the United States of America for instance, federal agencies keep records to facilitate conduct of business. They keep records because they need to be accountable to themselves and to external entities like the Congress, other agencies and the public for how they have spent public funds in discharging their mandates. "The business imperative to keep records is so strong that it is codified in the statute of the Federal Records Act" (Sprehe, 2000:15). Records management in the USA took center stage in the running of federal agencies and organizations from the late 1980s and has undergone radical changes. For example, by the 1990s information technology managers had adopted electronic records management as a mandatory undertaking (Sprehe, 2000).

An empirical study undertaken in the United Kingdom by Shepherd and Ennion (2007) on "the effects of the implementation of the Freedom of Information Act (FOI) of 2000, 
on archives and records services" revealed that with the enactment of the FOI, records management improved a great deal. The study revealed that following the FOI Act, the Department for Constitutional Affairs (DCA) issued a code (section 46) which sets out good practice in records management. This was because of the realization that records management service had a key role to play in effective FOI compliance. Additionally, the DCA recommended the appointment of a records officer in all organizations covered by FOI citing the fact that records management services are a cornerstone of FOI and that the Act can only be upheld through effective management of current and the long term preservation of records. This decision further improved records management practices in the United Kingdom.

Records management in China unlike in the United Kingdom is understood more narrowly as emphasis is given to non- current records only (An and Jiao, 2004).The features of records management in China according to An and Jiao include:

- There is neither an independent administrative agency to control and supervise records management in all organizations nor is there a national professional associations for records management;

- Records management is controlled by different agencies or organizations and there are difficulties with collaboration amongst these agencies or organizations for consistent and coherent records management;

- National archival records management policies and standards lack flexibility for different uses and contexts;

- Records management lacks purposely designed records systems to control records management throughout the entire life of the records or throughout the records continuum.

In Africa the records management scenario is no different from that of China. Kargbo (2009) in a study on the link between record keeping and good governance in Sierra Leone revealed the poor state of records management characterized by untrained, poorly paid records management staff generally lacking motivation; lack of appreciation of the 
role played by records in ensuring good governance and poor attitude towards records management.

Nengomasha (2009) in a study on the management of public sector records in Namibia also revealed the poor status of records management. The study established that Namibia's public service record keeping systems had collapsed and the National Archives of Namibia had not been able to undertake any meaningful records management activities due to staff constraints. The study further revealed that the poor culture of managing paper records had been transferred to the management of electronic records. The study therefore recommended an integrated records management programme which would provide a holistic approach covering both paper and electronic records.

Back in 2004, a study on the management of electronic records in the public sector in Lesotho showed that the public sector was not managing its electronic records satisfactorily (Sejane, 2004). The findings revealed the non-existence of legislation and policy governing the management of electronic records. Guidelines and procedure manuals were non-existent and there was a lack of qualified personnel with expertise and skills required in the management of electronic records.

Ngoepe and Van der Walt (2009) in another study on records management trends in the South African public sector found that there was a general lack of proper records management in the South African public sector. They identified factors contributing to this state of affairs: paucity of records management policies in government departments; lack of top management support; lack of awareness of the importance of records management and lack of the relevant skills amongst records management practitioners.

Ngulube and Tafor (2006) undertook a cross-sectional study between 2004 and 2005 on the management of public records and archives in the member countries of East and Southern Africa Regional Branch of the International Council on Archives (ESARBICA) and concluded that records and information management systems were weak. They noted that the surveyed institutions had taken a piecemeal approach to the management of 
records and archives. The study revealed that standards development and implementation was an exception rather than a norm in the ESARBICA region. Furthermore the framework for determining the proper disposal of records was non- existent in half of the surveyed institutions. Moreover, although electronic records were proliferating throughout governments, many institutions had not yet addressed the implications of the management of such records.

Similarly, Wamukoya and Mutula (2005) pointed out that the ESARBICA region faces major challenges with regard to the management of records and archives due to historical, political, cultural, managerial and technological factors. In the same vein, IRMT (2003) identified the following challenges facing the ESARBICA region with regard to records management: absence of organizational plans for managing records; low awareness of the role of records management in support of organizational efficiency and accountability; lack of stewardship and coordination in handling records; absence of legislation, policies and procedures to guide the management of records; absence of core competencies in records and archives management; absence of budgets dedicated to records management; poor security and confidentiality controls; lack of records retention and disposal policies; and absence of migration strategies for records.

Kenya being a member of the ESARBICA is not an exception to the above challenges. Mnjama (2003) noted that the state of records management in Kenya was poor for the following reasons: failure by senior management to establish acceptable records management goals and practices; failure to hire competent and qualified staff in the area of archives and records management; failure to provide adequate storage facilities, thus causing registry staff to lose morale and motivation; failure to encourage training in the area of archives and records management; failure to provide financial and administrative support to those involved in registry work; and failure to implement various recommendations on the management of records. 
Kemoni (2007) conducted a study on records management practices in government ministries in Kenya and established that the existing policies and practices for managing records throughout their continuum were not effective. Most registries according to the study lacked mission statements and records management manuals. In addition, records management personnel lacked the necessary skills and competences.

A recent empirical study by the IRMT (IRMT, 2011) on managing records as reliable evidence for ICT/ e-government and freedom of information concluded like Mnjama (2003) above that Kenya is still grappling with many challenges with regard to records management. Some of the challenges identified in the study included: absence of policies and guidelines relating to the management of electronic records; lack of records management trained personnel; limited financial resources; and lack of good will from the senior management staff to name but a few.

From the foregoing discussion, although records management is considered crucial to the governance process it is not fully embraced by the public sector in developing countries in Africa including Kenya. Therefore more research is needed to provide policy and practical interventions to improve records management not only in Kenya but the rest of sub-Saharan Africa.

\subsection{Management of Court Records}

According to Motsaathebe and Mnjama (2007) the importance of records in dispute settlement and adjudication is crucial for several reasons. Firstly, in order for a case to proceed, the initial documents (the summons) should be available. Failure to provide or locate these documents means that the case cannot proceed thus, occasioning delays in determining the case. Lack of evidence in the form of records can lead to failure of the judicial system to bring justice to the citizens. This may lead to loss of faith in the administration of justice. Motsaathebe and Mnjama (2007), also asserted, when an accused person appeals against conviction, the decision of the judge is made after assessing the record of proceedings from the lower court. This is achieved by having a 
complete and accurate record from the lower court. If the record of proceedings cannot be located for whatever reasons including poor record keeping practices, the accused person might be denied justice.

Furthermore, Motsaathebe and Mnjama (2009) noted that there is a tendency for some civil litigation to continue for many years or be revived after a long period of time. Accordingly, good record keeping enables the concerned parties to enquire about the status of their cases. The overall effect is that the court staff will be able to update the concerned parties, due to good record keeping. In a nutshell, the daily operations of the court depends on the availability of accurate, authentic and reliable information, presented in a timely manner, hence the need to maintain an effective and efficient records management system for the judicial system (Motsaathebe and Mnjama, 2007). If a case file relating to a trial cannot be located it becomes impossible for a judge or magistrate to pass judgment, thus justice being denied or delayed to the plaintiff.

Thurston (2005:2) observed that the growing emphasis on transparency and the need to reduce large backlogs of court cases have led to case management reforms and greatly increased use of technology and electronic filing highlighting the need for effective management of case files and other court records. Federal courts in the United States of America for instance have embraced electronic access to court records because they realize this practice allows courts to run more efficiently (Caughey, 2004:407). In 1990, Singapore embarked on reforms that transformed its legal system by adopting an electronic filing system which made case information and court records more readily available and policies and procedures were established for creating, maintaining and disposing of electronic records (Thurston, 2005). South Africa on the other hand embarked on an e-justice programme designed to support and strengthen the Department of Justice and Constitutional Development within an Integrated Justice System (IRMT, 2002). Lastly, in the study on the management of high court records in Botswana Motsaathebe and Mnjama (2007) revealed that in the past the management of legal records at the high court received little attention but they had embarked on measures including the introduction of an automated court record system to manage its records. 
A recent empirical study done by the IRMT (IRMT, 2011) on the management of records as evidence for ICT and freedom of information revealed some improvement in the management of court records in Kenya. Digitization of court records for instance was on and by 2010; five million of the 30 million targeted pages had been digitized. However, the study also revealed some glaring challenges such as; the digitization process being implemented without specifications to manage digital surrogates over time. Policies for managing the digital records were also lacking and trained staff was inadequate.

\subsection{Policies and Guidelines for Records Management}

ISO 15489-1 provides that an organization seeking to put in place a sound records management strategy should first and foremost establish, document, maintain and promulgate policies procedures and practices for records management to ensure that its business need for evidence, accountability and information about its activities is met (ISO, 2001). The organization should thus define and document a policy for records management whose objective is the creation and management of authentic, reliable and usable records capable of supporting business functions and activities for as long as they are required. The organization should ensure that the policy is communicated and implemented at all levels in the organization. It should also be adopted and endorsed at the highest decision-making level and promulgated throughout the organization. Finally, the policy should be regularly reviewed to ensure that it reflects current business needs. Mnjama and Wamukoya (2007) observed that the level of commitment to managing records can be gauged by the existence or non-existence of records management policies, plans and guidelines. In the same vein Griffin (2003) has observed that in many governments, policies and guidelines for managing the records are often non-existent and the legislative and regulatory framework is largely weak or outdated. In some countries the responsibility for managing the information on which government and citizens depend is often not properly assigned or is unclear. It is also important to note that the existence of a records management policy that does not embrace all forms of records and particularly electronic and digital records remains inadequate. 
A study undertaken by Chinyemba and Ngulube (2005) on managing records at the University of KwaZulu-Natal established that policies for managing records in the institution were inadequate. Likewise, a recent study on the alignment of records management with ICT in East Africa showed that some governments in the region including Kenya had policies in place for managing current records, but in practice they did not address the management of digital records, and there was no evidence that records management practices had been applied to digital records. It was also significant that policies addressing the management of ICT or e-government initiatives had yet to incorporate provisions for managing e-records (IRMT, 2011).

It is clear that governments and institutions in sub-Saharan African countries (Kenya included) do not have adequate policies governing the management of electronic records. For this reason, the second research question (see section 1.4.2) is an attempt to establish what policies, plans and guidelines that have been put in place by the Kenyan judiciary to enhance sound records management.

\subsection{Skills and Resources Required for Records Management}

Although an agency may have records and information management policies, tools and procedures in place, they will be ineffective unless they are supported by qualified records management staff and adequate and regular financial support to implement and support them (IRMT, 2004). As governments adopt the use of ICT in the provision of services to the citizens, the intended benefits will be compromised unless the issue of capacity building is addressed. The failure to address capacity building needs could lead to reduced government effectiveness; increased operating costs; gaps in recorded memory; reduced public access to entitlements; erosion of rights and weakened capacity for decision making (IRMT, 2004). The issue of records management capacity building is imperative given that governments are increasingly under public pressure to demonstrate that they are accountable, transparent and committed to efforts to root out corruption or malpractice (Wamukoya and Mutula, 2005). 
Wamukoya and Mutula (2005) identified various competencies and skills required by records management staff in the ESARBICA region. Such skills and competencies are diverse but can be categorized at various levels into: records and information management skills; technological skills; managerial skills and project management skills. Others include but are not limited to: skills to create, capture, classify, index, store, retrieve, track, appraise, preserve, archive and dispose of records in both the manual and electronic environment. These skills need to be complemented by knowledge of records management practices and trends, knowledge of the types of records including emails and web pages and knowledge of ICT application to records and archives management (IRMT, 2004).

The need for capacity building in records management is premised on the belief that accurate and reliable records form the documentary evidence needed to provide a foundation for all development strategies, and the loss of control of records and information systems particularly in electronic environments, is a highly significant global problem (Wamukoya and Mutula, 2005). Sound records management systems are critical to the ability of the public sector to be accountable and transparent and to improve services to citizens especially in developing countries.

Chinyemba and Ngulube (2005) concluded that the University of KwaZulu-Natal lacked personnel with formal qualification in records management and did not seem to provide consistent continual training for its staff. In a similar study by Iwhiwhu (2005), it was concluded that Nigerian universities lacked qualified records personnel and their records were managed by staff that are often ill-equipped as they have little or no knowledge of records management practices.

The study by IRMT (2011) on the East African situation found that out of an establishment of 66 records officers in the Kenyan judiciary, only 40 had been employed and posted in the over 120 court stations in Kenya. These officers had trained in archives and records management on their own personal initiative rather than that of the courts. Of the 40, the study established that three had trained at degree level; 25 at diploma level; 
and 12 at certificate level. This depicted the judiciary as having limited capacity especially at management level to facilitate effective and efficient records management. This conforms to the observation by Wamukoya and Mutula (2005) that within the East and Southern Africa Region of which Kenya forms part, staff competencies, skills and tools needed to effectively and efficiently manage records have not been adequately developed in many public sector organizations resulting to inadequate capacity and skills gaps.

Beside records management competencies, Mnjama and Wamukoya (2007) pointed out that key resources such as equipment, basic supplies and finances, were often not made available in a majority of governments and agencies with statutory responsibility for records in developing countries including Kenya. They observed that with a few or nonexistent trained and qualified staff in records management, and the low status accorded to records work, the principles and standards that should guide records and information work were never included as part of organization's strategic plans.

To bridge this gap in literature, the third research question (see section 1.4.2) in this study sought to establish the skills and competencies amongst the records management staff within the judiciary.

\subsection{Awareness about Records and Attitudes of Staff towards Sound Records Management}

As discussed earlier, records play a pivotal role in the governance process in any given institution. In this regard IRMT (2004) pointed out that managers and staff need to be aware of the importance of trustworthy and well-managed records for delivering effective government services and for protecting institutional accountability and integrity. According to Mnjama and Wamukoya (2007), the level of awareness and commitment of staff can be used to gauge where an organization is placed in terms of records management readiness on a scale of 1-5: 
- Level 1 - senior management has no understanding of and commitment to the management of the organization's records;

- Level 2 - senior management has a broad understanding of and recognize the need to embrace and support records management in the organization;

- Level 3 - senior management is highly committed to and are supportive of records management programmes in the organization;

- Level 4 - senior management has created an environment whereby records management is highly valued as part of the organization's overall information management strategy;

- Level 5 - The organization is recognized for its stewardship and leadership role in implementing records management programmes.

A study by Yusof and Chell as far back as 1998 showed that in developed countries particularly the United Kingdom and United States of America the usefulness and benefits of systematic records management in business had promoted advanced training in records and archives management (Yusof and Chell, 1998). Consequently, records are managed by staff with the required skills and competence. Members of staff in most of these organizations are therefore aware of the role played by records and records management and are likely to have a good attitude towards sound records management.

The situation in Africa in general and Kenya in particular is quite different, as studies have shown that records management is given the least priority in terms of staff and resource allocation (Sichalwe, 2010; Wamukoya and Mutula, 2005; Ngoepe, 2008; Ngulube and Tafor, 2006; Iwhihu, 2005 and Wamukoya, 2000). This may in part be attributed to a general lack of awareness and a poor attitude towards records management. The fourth research question of this study therefore sought to find out the level of awareness and attitude of staff towards records management practices in the judiciary (section 1.4.2) 


\subsection{E-government}

Increasingly, governments all over the world are adopting e-government by deploying information and communication technologies (ICTs) to carry out their activities and operations (Mnjama and Wamukoya, 2007). E-government has been defined in extant literature in different ways. Broadly, it can be defined as the use of ICTs in the public sector to improve operations and delivery of services (Kumar and Best, 2006). According to the World Bank website (2005), e-government is seen as the use of ICTs that have the ability to transform relations with citizens, businesses and other arms of government by government agencies for better service delivery.

Basu (2004) observed that a common theme behind e-government involves the automation or computerization of existing paper-based procedures that will prompt new styles of leadership, new ways of listening to citizens and communities and new ways of organizing and delivering information. In summary, the crucial element of all egovernment definitions is the use of ICT tools to reinvent the public sector by transforming its internal and external way of doing things and its interrelationships with customers and the business community (Ndou, 2004). However, Dada (2006) observed that e-government is not merely the computerization of a government system but a belief in the ability of technology to achieve high levels of improvement in various areas of government, thus transforming the nature of politics and the relations between governments and citizens. Basing on this definition, e-government is thus a predecessor of open government since ICT has largely been seen as an enabler of open government initiatives.

\subsubsection{Benefits of E-Government}

Affisco and Soliman (2006) contend that the most frequently cited motive behind initiating e-government projects is the need for more efficiency in public sectors. In fact, according to the authors, federal, state and local governments worldwide are under pressure to deliver services more efficiently at lower costs and are recognizing e- 
government as an attractive option both commercially and politically (Affisco and Soliman, 2006).

Wescott (2001) identified the following as benefits of e-government: lowering administrative costs; providing faster and more accurate response to requests and queries; directing access to transaction or customer accounts held in different parts of government; providing ability to harvest more data from operational systems which in turn increases the quality of feedback to managers and policy makers. E-government is therefore increasingly being seen as the answer to a plethora of challenges faced by governments in their service delivery to the citizens (Kumar and Best, 2006). The authors opined that this is especially true in developing countries where resource constraints are a major challenge. E-government is therefore touted as a means to save costs while at the same time improving quality, response times and access to services.

Concurring with the above view, Schuppan (2009) posits that e-government is especially relevant for developing countries where public administration is characterized by inefficiency, limited capacity and poorly trained personnel. The author however cautions that since e-government and its related organizational concepts were developed in industrialized countries, it should not be assumed that it is automatically appropriate for developing countries (Schuppan, 2009). Accordingly, the author pointed out that when introducing e-government in developing countries, it is expected that different and more far-reaching efforts will be necessary than in developed countries.

In a nutshell, e-government aims to enhance access to and delivery of government services to benefit citizens and more importantly to help strengthen government's drive towards effective governance and increased transparency to better manage a country's social, political and economic resources for development (Basu, 2004).

According to Chadwick and May (2003), the concept and practices of e-government first emerged in the most technologically advanced western countries (United States of America, United Kingdom, Canada and Australia) which were pioneers in the adoption of 
the Internet. Although the United States of America had earlier been rated the world leader in e-government, the Republic of Korea was at the top of the e-government index as per the UN e-government survey of 2012 (UN E-Government Survey, 2012). Other world leaders included the Netherlands, United Kingdom and Denmark.

Chen, Chen, Huang and Ching (2006) identified three phases of e-government implementation practiced by most of the countries identified as leaders in e-government development. These phases are: the Initial Phase; the Infusion Phase and the Customization Phase. According to the authors, the initial phase focuses on providing citizens with a single point of access to government information and the Web, thus allowing them a minimum level of political involvement by providing them with information on the general political scene. On the other hand, the Infusion Phase involves adoption of the principles of e-government, with online reviews and payment applications being widely installed. At this stage therefore, citizens can make most of the payments online and electronic bill presentations become the norm. Lastly, the Customization Phase aims at establishing a one-to-one relationship between citizens and government in order to improve citizen's efficiency by enabling them to create a personal profile with government.

At the United States of America federal level of government, evolving frameworks of laws and policies have been influencing the speed, scope and direction of e-government initiatives (Lee, Tan and Trimi, 2005). The authors identified influential statutes which in their opinion have helped propel the e-government initiative to include: Government Performance Results Act of 1998; Clinger-Cohen Act of 1996; Government Paperwork Elimination Act of 1998 and E-Government Act of 2002. Chen et al. (2006) observed that the United States of America as the largest economic powerhouse on earth has one of the most advanced national e-government infrastructures in the world. The authors opined that the United States of America's rich history and culture of democracy and its capitalist economic system could have boosted the e-government initiatives. Mutula (2013) noted the three-fold strategic principles that the implementation of e-government in the United States of America is hinged on as being: citizen-centered rather than 
bureaucracy-centered; results oriented; and market based. These principles over the years propelled the United States of America government to greater heights with regard to egovernment implementation.

An empirical study undertaken by Reddick (2004) to investigate the development of egovernment in American cities revealed great advancement in e-government implementation especially with regard to the Government to Business (G2B) relationship in which e-procurement of equipment and office supplies was done by around half the surveyed cities.

Another empirical study by Choudrie, Weerakkody and Jones (2005) on the realization of e-government in the United Kingdom revealed that e-government had taken root in the United Kingdom. However, the study established a challenge of digital divide between the urban and rural areas of the United Kingdom. The study concluded that this together with other challenges identified needed to be surmounted by the Government if the benefits of e-government were to be realized.

Although the UN E-Government Survey (2012) ranked southern Asia fourth in the regional comparison of e-government implementation after North America, Europe, and East Asia, a study by Wescott (2001) pointed out that most Asia-Pacific governments were only in the initial phases of adopting e-government. The author identified the following as possible reasons for slower adoption of e-government: higher costs of ICT introduction due to scale of public organizations; the inertia of existing options and habits; paper trail required for approval processing; security concerns; confidentiality of information; obsolete regulations and laws among others.

The UN E-Government Survey (2012) showed that sub-Saharan African countries were ranked much below the developed regions of North America, Europe and eastern Asia with regard to e-government implementation. Bannister (2007) posited that the sub Saharan region was still in its infant stages with limited public services being processed online. Agreeing with this view, Schuppan (2009), pointed out that from a global 
perspective the countries of sub-Saharan Africa (Kenya included) were particularly underdeveloped in the implementation of e-government since Internet access is scarce and e-government services are rare. Arther, Onishi and Kidokoro (2007), noted that subSaharan Africa was still lagging behind with the implementation of e-government since required data such as land registers, residential or geographic data is often non-existent or outdated. The authors further pointed out that processing of permits (building, property acquisition registration etc.) frequently takes several years to finalize and many citizens especially those living in slum areas often have never been issued with birth certificates.

This notwithstanding Schuppan (2009) observed that the region has development potential for the growth of e-government. This concurs with Mutula's conclusion (Mutula, 2013) that there has been improvement in the region since the year 2008, particularly in northern Africa where Tunisia and Egypt were highly ranked in Africa alongside Mauritius, South Africa and the Seychelles. Mutula (2013) observed that the completion of the undersea fiber connectivity on the east coast of Africa has provided high speed internet links to the rest of the world and is likely to improve e-government services in the region even further. Further, the author noted that the mobile phone revolution has brought communications to hundreds of millions of people across Africa and e-government projects should leverage these new technologies to provide citizens the opportunity to obtain services and /or information on time. With the improvement of egovernment in the region then open government can be made a reality.

\subsection{Open Government}

Open government is concerned with moving from government deciding which data to release to a much more user driven approach. The concept of open government anticipates that all public data should be openly published and made available not only for scrutiny and review but potential re-use (Centre for Technology Policy Research, 2010). Stott (2012) points out that the purpose of open government is to get users' voices to be heard so that they can play an active part in the release and use of Government data. Gaveline, Burall and Wilson (2009) contend that open government agenda has gained momentum over the past decade because of the recognition that openness benefits not 
only the citizens but the government as well. According to OECD (2005) governments therefore are coming under increasing pressure to become more accessible to the citizens and also open up their operations to public scrutiny.

The concept of open government has emerged to describe a rethinking of governance and how administration should adapt their procedures to meet the demands and necessities of their citizens (Alonso, Boyera, Bratt, Grawal, \& Iglesias, 2011). The Centre for Technology Policy Research (2010) defined open government as a commitment to ensure that all aspects of the way that government and public services are administered and operated are open to effective public scrutiny and oversight. Open Government Data (OGD) is the pillar of open government strategy where ministries and state agencies put their raw data on the Web in readable formats. The public can then review and download the data and even create new applications around it (World Wide Web Foundation, 2011). RightNow (2010) asserts that the impact of the internet, social networks and discussion forums has undoubtedly led to a society of transparency and openness. Wamukoya (2013) quoting Fernando (2012) identified the following as the importance of building OGD initiatives:

- Greater transparency and accountability of governments;

- Greater participation of the civil society;

- Innovation in the creation and improvement of public services;

- Efficiency and efficacy of public service delivery;

- Better governance in fragile states (post-conflict countries);

- Improved quality of record keeping and data;

- Socio-economic and political growth/development; and

- Environmental sustainability.

Similarly, Janssen et al. (2012) identified many potential benefits for open government categorized as follows: political and social befits which include transparency, democratic accountability, and creation of trust in government to name but a few; economic benefits including stimulation of innovation, development of new products and services and availability of information for investors and companies; and operational and technical 
benefits which include creation of new data based on combining data, validation of data, and sustainability of data. Janssen et al. (2012) concluded that the ready availability of information about what governments are doing and why is increasingly recognized as an important precondition to meaningful exercise of democratic accountability, transparency and building of trust in government. The researcher however, opines that this openness could lead to exposure of incompetency of some government officials therefore reducing the much needed trust. That notwithstanding openness is not an option in democratic states and upcoming democracies since the benefits far outweighs the harm it could cause.

Curtin and Meijers (n.d) asserts that by definition, democratic governments function through widespread public deliberations on important issues. They pointed out that democratic power remains in citizens and for a democratic society to succeed, its citizens must be informed in order to be able to criticize their government and government officials. On their part, Harrison, Guerrero, Burke, Cook, Cresswell, Helbig, Hrdinova and Pardo (2012) contend that the earliest form of democratic governance is participatory democracy in which through discussions and deliberations, citizens engage directly in decision making about their civic affairs. Harrison et al. (2012) continue to point out that participatory democracy requires individuals to become more knowledgeable about the perspectives of others and the interests that underlie those perspectives so they may deliberate more effectively. This calls for execution of open government as a tool for the democratic participation.

The governments of the United States of America and United Kingdom are the most prominent practitioners of the open government offering data that is usable and freely exploitable by non-governmental organizations, activists, real estate developers, IT companies, people and organizations (Alonso et al., 2011). As earlier reported in chapter one, President Barack Obama of the US signed a memorandum on transparency and open government in January 2009 thus, affirming his administration's commitment towards creating an unprecedented level of openness in government (Obama, 2009). Nam (2011) pointed out that through greater openness and new technologies, the Obama 
administration hopes to empower the public to influence the decisions that affect their lives. To this end, NASCIO (2009) states that local governments in the US are increasingly opening up their data by creating data.gov sites. NASCIO points to the need for collaboration of various stakeholders with responsibility for records - records centres/archives, records managers, librarians, archivists, portal developers, data architects to name but a few, for successful planning and execution of open government initiatives.

In the United Kingdom, the last 10 years have seen significant progress towards open government with the establishment of the Data.gov.uk portal being the most significant development to allow open access to government datasets (Davies, 2010). Agreeing with this, Thurston (2013) observed that the United Kingdom government is increasing transparency for instance by opening up data on public spending and crime and has shown commitment to spreading the practice of openness globally. Thurston noted that "since 2012, the United Kingdom has played a leading role in international efforts to share this open approach so that people across the world can hold their governments accountable" (Thurston, 2012:18).

Other countries that that have demonstrated success in open government initiatives include Brazil and Singapore. According to Open Government Partnership Report (2013), Brazil is one of the eight founding countries of open government partnership whose formal participation started in September 2011. The open government partnership report showed that Brazil started off with 32 commitments and by the early 2013 all the commitments had been implemented. In their action plan, Brazil focused on using technology to improve on access to information, better service delivery, public integrity and better management of public resources.

Similarly, as part of its strategy to drive social innovation and deepen co-creation efforts with the citizens, the Singapore government launched a one-stop data portal data.gov.sg in 2011 (Infocomm Development Authority, 2013). Accordingly, the public could access over 8800 datasets from more than 60 public agencies for apps development or research. 
The success of the open data like in other jurisdiction depends on successful deployment of ICT. Kelly (2014) observes that ICT plays an important role in shaping the future of Singapore. Kelly observed that the Singapore government is seeking to provide consistent high quality and seamless broadband experience for residents by improving pervasiveness and connectivity as a means towards the success of open data.

In contrast, in Africa, the idea of open government is not yet well understood and practiced. CIPESA (2011) observes that African countries have generally been slow to embrace the open government initiative largely due to the dismal performance of many African governments on governance, anti-corruption and transparency indicators. The Guardian (2010) revealed that most African countries were ranked very poorly in the Corruption Perception Index (CPI) of 2010 which examined the extent of corruption in the public sector among 178 countries worldwide. The CPI measures the extent of bribery among public officials, kickbacks in public procurement, embezzlement of public funds and the effectiveness of anti-corruption efforts. Kenya was ranked number $154^{\text {th }}$, Burundi $170^{\text {th }}$, Uganda $127^{\text {th }}$, Tanzania $116^{\text {th }}$ and South Africa $54^{\text {th }}$ in the CPI survey (The Guardian, 2010). The poor performance of Africa in the CPI may perhaps explain why many governments on the continent are averse to passing freedom of information laws with only less than 10 countries having the legislation in place. These countries as mentioned earlier include Angola; Niger; Uganda; Ethiopia; Nigeria; Zimbabwe; Liberia; South Africa and Guinea Conakry (UNESCO, 2012). CIPESA (2011) noted that corruption, poor service delivery and undemocratic governance survive on systems that keep information hidden from the public and bureaucracies which place near unfettered power into the hands of the few public officials that control this information.

Despite the fact that African countries are lagging behind in implementing open government some countries are taking some leadership roles. CIPESA identifies South Africa as leading the pack in embracing open government in Africa followed by Kenya, Tanzania, Liberia and Ghana (Excell and Sendugwa, 2012). One key aspect in Kenya's open government initiative is the citizens' right to access information and the state's duty to provide the information without any discrimination as spelt out in the Bill of Rights 
(Chapter 4 Article 35) of the Constitution of Kenya (National Council for Law Reporting, 2010).

An empirical study conducted by IRMT (2012) on public records as evidence for openness, confirmed that across the East Africa region including Kenya, governments were aggressively pursuing ICT and e-government projects in their bid to open up their government operations for citizen participation. The study however, noted that the projects were at the risk of failing because of glaring gaps in regulatory frameworks for the management of records in such areas as policy, legislation, human capacity and infrastructure. Thurston (2012) observed that to be trusted government data needs to be drawn from reliable sources in most cases official records which requires sound records management programme.

Wamukoya (2013) however, observed that in most of sub-Saharan Africa, official records are not managed to meet international best practices. This will most likely impede the move towards openness in the region since where records are poorly managed, the evidence base required to formulate policy, manage state functions, build reliable systems and monitor official transaction is undermined (IRMT, 2012). Thurston (2012) concluded that since official records are often poorly kept in developing countries (Kenya included), there is a high risk that open data will not meet international expectations if inaccurate data is used for development planning or holding governments accountable. The study therefore aimed at investigating how records are managed in the judiciary in order to determine whether this facilitates or undermines openness in the judiciary. Research question five particularly sought to investigate the strategies that the judiciary was using to make records available to the public (see section 1.4.2).

\subsection{Summary and Gaps in Literature}

This chapter provided a review of the empirical and descriptive literature from different parts of the world on the subject under study. The literature review was organized thematically using themes gleaned from the theories underpinning the study, the research 
questions and the broader aspects of the study. The following issues were therefore discussed: records management; managing court records; policies and guidelines for records management; skills and resources requirements for records management; staff awareness and attitude towards records management; e-government and open government. Previous studies under each theme were highlighted where possible.

The literature reviewed revealed that the role played by records and records management has been recognized worldwide albeit to different extents. Additionally, the literature reviewed established that globally, governments are under pressure to adopt ICTs in their governance and delivery of services to the citizens. This has come to be referred to as open government whose predecessor is e-government. The success of open government relies on the availability of accurate, reliable and trustworthy information which is to be found in government records. However, much of the theoretical and empirical studies reviewed on open government focused on releasing datasets. These, according to Wamukoya (2013), provide valuable information about government activities and transactions although even when well-described and classified, they tend to provide limited meaningful information. Wamukoya therefore believes that there is an opportunity to make a more substantial contribution to transparency, accountability, anticorruption and citizens' rights by linking open government to the availability of accurate, reliable and trustworthy records as evidence of government activities and transactions.

Moreover, the literature reviewed revealed that most governments in sub-Saharan Africa (Kenya included) were aggressively pursuing ICT and e-government projects without paying attention to policies addressing the management of electronic records. As a result these projects are bound to fail. This study therefore seeks to demonstrate the necessity of aligning records management with the implementation of ICT projects by formulating the necessary policy and the infrastructure required. This study therefore fills the gaps in literature by providing a link between records management and open government. Additionally, the study provides the framework for putting in place the requisite policies governing the management of electronic records to precede open government and egovernment projects. 
Literature review therefore, contributed enormously to the success of this study. To begin with, it accorded the researcher a thorough understanding of records management issues as it relates to open government. This in part enabled the researcher to refine the research problem and to develop the research topic. Upon completion of the study, the literature review enabled the researcher to place the current study in its intellectual context thus contributing to the body of knowledge in the field. Secondly, literature review revealed gaps that exist in literature as described in the preceding paragraph which allowed the researcher to build on the platform of existing knowledge and ideas and helped in placing the original work in the context of existing literature. Thirdly, the review identified research methods that had been used by similar studies and that could be relevant to the current study. Lastly, the literature reviewed partially addressed research questions as follows: research questions two (what records management policies, plans and guidelines are available?); research question three (what skills and competencies do the records management staff have?); and research question four (what is the level of awareness and attitude of staff towards sound records management practices) of the study. These research questions are further subject to empirical treatment in chapter four. 


\section{CHAPTER FOUR RESEARCH METHODOLOGY}

\subsection{Introduction}

Pickard (2007) defines research methodology as the theoretical perspective of the research, that is, the overall nature of the research activity. Shensul (2012) looks at methodology as the strategies that researchers use to ensure that their work can be critiqued, repeated, and adapted. These strategies guide the choices researchers make with respect to sampling, data collection and analysis. There must therefore be a close association and integration among research questions, research methodology and methods of data collection.

The purpose of this study was to investigate records management readiness for open government in the Kenyan judiciary. The study was aimed at making a contribution towards promoting transformation and facilitation of open government for effective and efficient administration of justice. It addressed the following research questions: How are records created, accessed and used, stored and maintained, appraised and disposed of, and preserved?; What records management policies, plans, and guidelines are available?; What skills and competencies do the records management staff have?; What is the level of awareness and attitude of staff towards sound records management practices?; and What records management related strategies is the Kenyan judiciary using to achieve openness?

This chapter is organized into the following thematic areas: research paradigms; research approach; research design; study population; sampling procedures; data collection techniques; reliability and validity; data presentation and analysis; ethical considerations; and evaluation of the research methodology. 


\subsection{Research Paradigms}

A paradigm can be defined as a discipline's specific method of structuring reality. Lauden (1995) described a paradigm as a set of assumptions about the basic kinds of entities in the world, about how these entities interact, and about the proper methods to use for constructing and testing theories of these entities. Polit and Beck (2008) stated that paradigms for human inquiry are often characterized in terms of the ways in which they respond to basic philosophical questions: ontological; epistemological and methodological. Lincoln and Guba (1985) explained these three questions as being: the chronological question referring to the nature of reality; the philosophy of how we come to know that reality; and the practice of how we come to know that reality. Looking at these questions a paradigm can conclusively be referred to as a way of looking at natural phenomena that encompasses a set of philosophical assumptions that guide one's approach to inquiry (Polit \& Beck, 2008). Simply put therefore, it is an overarching philosophical framework of the way in which scientific knowledge is produced.

Creswell (2003:12) in this regard identified the following paradigms:

- Positivist also referred to as the scientific method. It reflects a deterministic philosophy in which causes probably determine effects or outcomes and is reductionist in nature. The knowledge that develops through it is based on careful observation and measurement of the objective reality that exists out there;

- Socially constructed paradigms are also referred to as interpretivism. This relies as much as possible on the participants' views of the situation being studied;

- Advocacy / participatory paradigm. This is the belief that the research should contain an action agenda for reform that may change the lives of the participants;

- Pragmatic paradigms posit that knowledge claims arise out of actions, situation and consequences rather than antecedent conditions. Studies using pragmatism are concerned with "what works" and solutions to problems rather than the methods used. In this case researchers use all approaches to understand the problem. This paradigm is therefore suited for mixed methods approaches and was used to underpin this study. 


\subsubsection{Pragmatic Paradigm}

This paradigm recognizes that there are many different ways of interpreting the world and that in undertaking research there is no single point of view that can give an entire picture of a phenomenon since there may be multiple realities (Saunders, Lewis \& Thornhill 2012). Creswell (2003) identified the following two characteristics of the pragmatic paradigm:

- It is not committed to any one system of philosophy and reality making inquirers adopting it to liberally draw from both quantitative and qualitative assumptions when they engage in their research. In this case, researchers are free to choose the methods, techniques and procedures of research that best meet their needs and purposes;

- It does not see the world as an absolute unity and truth but what works at the time. It is not based in a strict dualism between the mind and a reality completely independent of the mind.

This study adopted the pragmatic approach since it allows for the use of both qualitative and quantitative approaches which makes it possible to look at the "what" and "how" of the study thus providing full coverage of the research questions identified. This study sought to investigate records management in the Kenyan judiciary with a view to promoting transformation and open government for effective and efficient justice delivery. For the research problem to be fully addressed, both qualitative and quantitative data were required, thus the choice of the paradigm. Moreover, since the pragmatic paradigm is concerned with what works and the fact that solutions to problems are more important than the methods used, it was found to be suitable in the setting of the current study. The study envisaged collecting data from both the technical and administrative teams in the Kenyan judiciary as explained elsewhere and the researcher was not quite sure which method was going to work especially for the technical team whose work schedules were very tight. Although questionnaires had been prepared for this group of 
respondents at one point the researcher had to interview one particular judge who said he would not have time to attend to the questionnaire. The paradigm adopted was therefore very useful in such a scenario.

A similar study by Garaba (2010) on "An investigation into the management of the records and archives of former liberation movement in East and Southern Africa held by national and private archival institutions" also adopted the pragmatic paradigm. The study was aimed at among other things examining issues comprising policies, procedure and resources for the management of the said records. In another recent study in the field of Information Studies, the pragmatic paradigm was selected to inform the study (Majinge, 2014). The study investigated library services' provision for people with visual impairment and in wheelchairs in academic libraries in Tanzania.

\subsection{Research Approach}

There are three different approaches to research identified by research scholars (Creswell, 2003; Edmonds \& Kennedy, 2013; Henning, 2004; Lapan, Quartaroli \& Riemer, 2012). These approaches are the quantitative approach; qualitative approach and mixed methods approach (MMR).

The quantitative approach invokes a positivist perspective and includes true experiments, quasi-experiments, correlation and survey studies (Creswell, 2003). The qualitative approaches on the other hand involve studies that place more emphasis on the study of phenomena from the perspective of insiders. Such studies use interpretive frameworks but also reveal ways that power is embedded in social contexts. Included here are ethnographies, grounded theory, case studies, phenomenological and narrative research. Lastly, the mixed methods approach lends itself to triangulating data sources by seeking convergence across qualitative and quantitative methods.

The present study adopted the mixed methods approach (see justification in the section that follows) where the qualitative aspect was dominant and the quantitative aspect 
embedded within it. The qualitative data comprised of the opinions and /or the attitudes and the general perspectives of the respondents on records management in the judiciary (see Appendix 1 questions 1 - 12, Appendix 2 questions 2- 6, and Appendix 4 questions 2-19) while the quantitative data comprised of quantifiable data that helped in generating statistics which was useful in drawing conclusions (see Appendix 3 questions 2 ii -xii).

\subsubsection{Mixed Methods Research (MMR)}

The Mixed Methods Research (MMR) approach to research has been defined in various ways by different research scholars. According to Denscombe (2007), MMR applies to research that combines alternative approaches within a single research project. Denscombe explains further that it is a research strategy that crosses the boundaries of conventional paradigms of research deliberately combining methods drawn from different traditions with different underlying assumptions. Tashakkori and Creswell (2007:4) define it as an inquiry in which the investigator collects and analyses data, integrates the findings, and draws inferences using both qualitative and quantitative approaches in a single study or program of inquiry. Meanwhile, Bazeley (2008) observed that the term "mixed methods" has developed currency as an umbrella term applying to almost any situation where more than one methodological approach is used in combination with another, usually, but not essentially, involving a combination of at least some elements drawn from each of the qualitative and quantitative approaches. The common denominator of the definitions therefore is that MMR mixes qualitative and quantitative approaches to conduct an inquiry. This study adapted a definition given by Leech \& Onwuegbuzie (2009:273) who defined MMR as

...those designs that integrate quantitative and qualitative approaches in a single study or a multi-phased study, comprising the following five specific designs: sequential studies, parallel/ simultaneous studies, equivalent status designs, dominant-less dominant designs, and designs with multilevel use of approaches wherein researchers utilize different techniques at different levels of data aggregation. 
On his part, Creswell (2003) identified six major strategies used in MMR studies: sequential explanatory strategy; sequential transformative strategy; concurrent triangulation strategy; concurrent nested strategy and concurrent transformative strategy. This study adopted the concurrent nested strategy where quantitative and qualitative data are collected simultaneously though the quantitative method is embedded within the qualitative method. Edmonds \& Kennedy (2013), referred to this approach simply as the embedded approach. To them, the approach is used when different questions require different types of data; when one type of data clearly plays a secondary role and would not be meaningful if not embedded within the primary data set and when the researcher logistically cannot place equal priority on both types of data.

Different purposes for using MMR abound in the literature. Ngulube, Mokwatlo and Ndwandwe (2009) enumerated five purposes of MMR as being: triangulation; complementarity; development; initiation; and expansion. Triangulation seeks convergence and corroboration of findings through the use of more than one method of gathering and analyzing data about the same phenomena in order to eliminate the inherent biases associated with using only one method. Polit and Beck (2004) argues that complementarity aims at amplification and enhancement of the results from one research approach with the results from another methodology using different phenomena. According to Ngulube at al. (2009), development means using results from one stage of research in a sequential design to inform the development of the methods for the subsequent stage. While initiation seeks contradictions and new perspectives in order to find out why such inconsistencies and paradoxes exist, expansion aims at extending the breath and scope of investigation employing different methods for various components of the research.

In the current study, the researcher employed MMR for the following reasons: Firstly, in order to seek convergence and corroboration of findings through the use of more than one method of gathering and analyzing data about records management practices in the judiciary and its impact on open government therefore eliminating the inherent biases associated with using only one method (Denscombe, 2007). Second, MMR allowed the 
researcher to gain broader perspective as a result of using the different methods as opposed to using the predominant method alone; third, so that results from one methodology would be enhanced by the results from the other methodology (Polit and Beck, 2004). In this case qualitative data from the registrars and records officers were in some cases enhanced by quantitative data from the judges and magistrates. Lastly, MMR allowed the researcher to study different groups or levels. The qualitative methods were used to collect data that pertained to records management practices from records management staff and court registrars and also through observations made by the researcher (see Appendices 1, 2 and 4), while the quantitative methods were used to collect statistical data from judges and magistrates (see Appendix 3). The strength of this approach is seen in its ability to enable the researcher to collect two types of data simultaneously therefore providing the advantages of both the qualitative and quantitative data. The researcher therefore gained different perspectives from the different types of data and from the different levels within the study.

This approach has been used in other similar studies: Sichalwe (2010) in a study on "The significance of records management to fostering accountability in the public service reform programme of Tanzania" adopted a dominant - less dominant MMR design. The study sought to examine current records management practices in government ministries in Tanzania in order to establish the extent to which they foster accountability in the public service reform programme. In another similar study, Kumar and Best (2007) in their research on "The impact and sustainability of e-government services in developing countries: Lessons learned from Tamil Nadu, India" also adopted the MMR. The study aimed at investigating the systemic and institutional factors responsible for the initial success and subsequent sustainability failures of E-government service with a view to enhancing the efficiency and effectiveness of e-government services and realizing the long term sustainability of these programs. 


\subsection{Research Design}

This section discusses the research strategy / design that was adopted by the current study. A research strategy is defined as a plan of how a researcher will go about answering his /her research questions (Saunders et al. 2012). According to Denzin and Lincoln (2005) it is a methodological link between the philosophy adopted for the study and the subsequent choice of methods to collect and analyze data. Creswell (2003) identified several research designs that are associated with the different research approaches and paradigms. Strategies associated with quantitative research as mentioned earlier are "those that invoke the post-positivist perspectives and include true experiments, quasi experiments, correlation and survey studies designs" (Creswell, 2003:13-16). Those research designs that are associated with qualitative approaches and invoke interpretivist perspective and include case studies, ethnographies, grounded theory, phenomenological and narrative research, archival research, action research etc. While those that are associated with MMR include sequential, concurrent and transformative procedures. The study adopted a concurrent / embedded case study design as discussed in the section that follows.

\subsubsection{Case Study}

This refers to exploring a research topic or phenomenon within its context or within a number of real-life contexts. Yin (2009:18) defined a case study as "an empirical inquiry that investigates a phenomenon in depth and within its real-world context, when the boundaries between the phenomena and context are not clearly evident". Meanwhile, Moore, Lapan and Quartaroli, (2012) look at the case study as an investigative approach used to thoroughly describe complex phenomena such as recent events, important issues or programmes in ways to unearth new and deeper understanding of these phenomena. Moore, Lapan and Quartaroli opine that case study results offer those directly affected by the case (stakeholders) and others interested in the event or programme (audiences) extended awareness by providing rich details about highlighted aspects of the case. 
Scriven (1991) explains the difference between a case study and survey research. He says survey studies seek to gather broad surface - level data about a topic covering a state, regional or national issues. Conversely, case studies set out to examine the particular, portraying local topics or single instances. Denscombe (2007) observed that the focus on one or a few instances allows the researcher to deal with the subtleties and intricacies of complex social situations. In particular it enables the researcher to grapple with relationships and social processes in a way that is denied to other survey approaches (Denscombe, 2007). Lapan and Armfield (2009) explain the special nature of case study efforts as a microscopic approach where intensive examination of the particular is emphasized; a situation referred to as "peeling the onion" to carefully view each layer of identified case related programme activity.

Moore, Lapan and Quartaroli (2012) identify bounding the case as a major characteristic of case studies. Henning (2004) denotes that in a case study, the main assumption is that a phenomenon is investigated as a bounded system where the system may be a group of people, a set of documents or even a programme. To her any social entity that can be bounded by parameters and which shows a specific dynamic and relevance, revealing information that can be captured within these boundaries may be a case study.

Saunders et al. (2012) advised that the case study would be relevant if the researcher wishes to gain a rich understanding of the context of the research and the processes being enacted. Some case studies may employ quantitative approaches to collect, present and analyze data while others may employ qualitative approaches. Further still, other case studies may combine quantitative and qualitative approaches (Henning, 2004). To substantiate this point, she says that when you read a case study, you expect to find therein detailed data about the phenomenon that has been studied no matter what methods have been used and what theoretical position of the researcher may be.

Yin (2009) identified four major forms of case study strategies as: single case studies; multiple case studies; holistic case studies and embedded case studies. The current study utilized the embedded case study which involves examining a number of logical sub-units 
within a larger whole. In the case of this study, the researcher examined the high courts and the magistrates' courts in the two counties selected (Nairobi and Uasin Gishu) which forms part of the larger judiciary of Kenya.

The choice of a case study was largely informed by the need to develop a rich narrative and reveal records management practices in the Kenyan judiciary based on an in-depth, real time and retrospective analysis which is made possible by a case study. The case study design has been adopted and used widely by similar studies. Choudrie, Weerakkody and Jones (2005) in their study on "Realizing e-government in the United Kingdom: rural and urban challenges" adopted the case study design in order to obtain rich data that would provide a deep and meaningful understanding of the phenomenon. In another study, Shepherd and Ennion (2007) adopted the case study to investigate the impact of the Freedom of Information Act (FOI) on records management. In yet another study, IRMT (2011) undertook a case study on managing records as reliable evidence for ICT / e-government in the Kenyan judiciary which decried the inadequacy of records management staff. Similarly Komen (2012) in her study on the management of personnel records in support of good governance at the ministry of local government headquarters in Nairobi, Kenya adopted a case study design.

\subsection{Study Population}

A study population refers to a set of entities in which all the measurements of interest to the researcher are represented. The entities may be people or things such as all records maintained in an institution. A sample comprising of elements of the population considered for actual inclusion in the study can be drawn from the population (De Vos, Strydom and Delport, 2005). It is generally stated that the larger the population, the smaller the percentage of that population the sample needs to be, and vice versa. If the population itself is relatively small, the sample should comprise a reasonably large percentage of the population. 
The population in this study comprised staff from both the technical and administrative units of the judiciary. The technical unit comprised of judicial staff (judges and magistrates), court registrars, and deputy registrars. On the other hand, the administrative unit comprised the executive officers, records officers (this cadre are however designated as archivists in the Kenyan judiciary), and registry assistants (this group is designated either as executive assistants or clerical officers) in both the high court and the magistrates' courts. The relative sizes of the population that were involved in the study are reflected in Table 2:

\section{Table 2: Population of the Study}

\begin{tabular}{|l|l|l|}
\hline Category of Staff & Population(Nairobi & Population (Uasin \\
& County) & Gishu County) \\
\hline Court Registrars & 4 & $*$ \\
\hline Deputy Registrars & 7 & 1 \\
\hline Judicial Staff (Judges and Magistrates) & 71 & 11 \\
\hline Executive Officers & 11 & 1 \\
\hline Records Officers (Archivists) & 12 & 1 \\
\hline Registry Staff & & 4 \\
\hline
\end{tabular}

(Source: Kenya Law Reports Website, 2013) * All court registrars are based in Nairobi

From the Table 2 above, most of the subjects of the study were located in the Nairobi County; along with all the four court registrars, seven deputy registrars, 71 judicial staff (judges and magistrates), 11 executive officers, 12 records officers (archivists) and 20 
registry officers. Uasin Gishu County on the other hand had one deputy registrar, 11 judicial staff, one executive officer, one records officer and four registry staff.

\section{The Court Registrars.}

The court registrars are responsible for the general administration of the entire judiciary. They were selected for inclusion into the study because they were believed to be information rich especially in as far as the running of the judiciary and policy issues was concerned.

\section{Judicial Staff (Judges and Magistrates)}

The judges and magistrates preside over the courts and are charged with the responsibility of delivering justice through hearing and passing judgment on cases brought before the courts. They were chosen because they are the primary creators and users of the court records as they deliver justice and therefore believed to be able to give a true reflection of the status of records management in the judiciary

\section{Deputy Registrars}

These are heads of all the administrative services in the registry and are responsible for registry services, case management and execution of court decisions as well as overseeing allocation and performance of duties by all staff. As such this is where the "buck stops" in matters of registry management and by extension, the management of records at each court in the judiciary. They however still hear cases in their respective stations as they are also magistrates.

\section{Executive Officers}

This cadre of staff offer support services for the administration and supervision of the registry processes and procedures. They therefore ensure the smooth flow of work in the registries and report directly to the deputy registrars. They were included in the study to offer insights into how the records were being managed at the courts they served. 


\section{Records Management Officers (Archivists)}

This cadre of staff as explained elsewhere had been designated "archivists" in the Kenyan judiciary and referred to those staff that had records management training either at Certificate, Diploma or Degree level. They were responsible for the effective and appropriate management of court records from creation to disposition while ensuring that legal obligations are complied with in the process. Being at the center of records management they were considered crucial for the success of the study.

\section{Court Registry Assistants (Executive Assistants and Clerical Officers)}

They are responsible for the registration of cases, filing of documents, assessment of court fees, retrieval of files, preparation of statistical returns, preparation of cause lists, entry of court results in case registers and customer service. They were deemed relevant for the study since they are directly involved with records creation and maintenance.

\subsubsection{Sampling Procedure}

Sampling refers to the process of drawing a sample from a larger population. Krishnaswami and Ranganathan (2010) point out that a researcher must decide whether he/she should cover all the units or a sample of units. According to Aina and Ajiferuke (2002), four variables determine the sample size of a study: the size of the population; the variables in the characteristics being measured; the number of ways in which data is to be stratified in the analysis and the precision required of the data. In the same breath, Krishnaswami and Ranganathan (2010:119) provide that when the population to be studied is relatively small, the investigator may decide to study the entire population. The total population for this study is considered small (see Table 2); therefore, the researcher took a complete enumeration of the study population (census) whereby all members of the population were included in the study. 


\subsection{Data Collection Techniques}

This section discusses the instruments used in collecting data to answer the research questions. This study employed the following tools: in-depth interviews; questionnaire and observation.

\subsubsection{In-depth Interviews}

Saunders et al. (2012:372) define a research interview "as a purposeful conversation between two or more people requiring the interviewer to establish rapport, to ask concise and unambiguous questions to which the interviewee is willing to respond and to listen attentively". According to Pickard (2007), interviews are usually used when one is seeking qualitative, descriptive, in-depth data that is specific to the individual and when the nature of the data is too complicated to be asked and answered easily. Saunders et al. (2012) identified three categories of interviews as: structured; semi-structured and unstructured or in-depth interviews. According to Pickard (2007) the structured interview refers to a situation in which an interviewer asks each respondent a series of preestablished questions with a limited set of response categories which is often referred to as a researcher administered questionnaire. Further, Saunders et al. (2012) explained that in a semi-structured interview the researcher prepares a list of themes and possibly some key questions to be covered, although their use may vary from interview to interview. Lastly the unstructured or in-depth interview, involves the use of open-ended questions that allow the interviewee to tell their own story in their own words.

This research made use of in-depth interviews to collect data from court registrars and executive officers who were considered informants of the study and from the records officers and registry assistants who were considered to have hands on experience in the management of records and thus information - rich. The data collected was highly qualitative and focused on records management practices in the judiciary. This involved developing interview schedules to guide the researcher during the interviews (see Appendices 1 and 2). Pickard (2007) explains that in-depth interviews are used to gain a holistic understanding of the thoughts and feelings of the interviewee to enable the 
interviewer to learn about their point of view. Denscombe (2007) observes that in-depth interviews lend themselves to the collection of data based on opinions, feelings, emotions and experiences all of which due to their nature require that they are explored in depth and in detail rather than simply reported in a word or two.

The use of in-depth interviews in this study was informed by the following:

- Its ability to collect a rich and detailed set of data made possible by the fact that the researcher had the opportunity to probe answers when the interviewees were to explain or build on their responses. This is particularly important when it is necessary to understand decisions taken, attitudes and opinions of the participants as was required in this study;

- It was also deemed necessary to establish personal contact with the participants in order to increase the response rate. According to Saunders et al. (2012), it has been proven that personal interviews may achieve higher response rates because it provides the interviewees an opportunity to reflect on events without needing to write down. This situation also provides the opportunity for interviewees to receive feedback and personal assurance about the way in which information will be used. The net effect is an increased response rate. The current study for instance recorded a $75 \%$ response rate on interviews compared to $52 \%$ on the questionnaires;

- In order to address the research problem, the researcher relied on the opinions, feelings, and experiences of the participants. As observed by Denscombe (2007), in-depth interviews played a key role;

- Lastly, the in-depth interview accorded the researcher contact with key players in the judiciary including the registrars, deputy registrars and the records staff who gave privileged information that was very pertinent to successful completion of the research (Denscombe, 2007).

Related studies that have used this method to collect data include research undertaken by the Association for Progressive Communications (APC) (2012) on "Uganda open government data readiness study". The study aimed at assessing the government open 
data readiness in Uganda and to recommend actions needed for the country to implement an open government data. Another study that used the interview method was that of Motsaathebe and Mnjama (2007) on the management of high court records in Botswana. The interviews were conducted with the deputy registrar and the persons in charge of the administration of the legal system in Botswana in a way similar to how the current study interviewed the deputy registrar and the records officers. In yet another study on student assessment of the Master of Philosophy in Information Sciences (Records and Archives Management) Degree program at Moi University Kenya, Kemoni, Maseh and Mzerah (2011) used in-depth interviews to collect data. In that study, 21 students who had been admitted into the MPhil and MSc Records and Archives Management program from the academic year 2007/2008 to 2009/2010 were interviewed. Similarly, Kemoni and Ngulube (2007) in their study on national archives and the effective management of public sector records in Kenya interviewed senior ministerial officers and archives personnel in order to obtain in-depth data to address the research problem.

\subsubsection{Questionnaire}

A questionnaire is a document containing questions designed to solicit information appropriate for analysis and usually expected to be completed personally by the respondent (Babbie, 2004). Pickard (2007:183) observed that "questionnaires are without doubt the single most popular data collection tools in any research involving human subjects". They are therefore widely used and useful instruments for collecting survey information, providing structured, often numerical data to be administered without the presence of the researcher and often being comparatively straightforward to analyze (Blaxter, Hughes and Tight, 2006). While constructing the questionnaire, Denscombe (2007) identified two types of questions: open-ended questions that leave the respondent to decide the wording of the answer, the length of the answer and the kind of matters to be raised in the answer; and closed ended questions which structures the answers by allowing only answers which fit into categories that have been established in advance by the researcher. Denscombe (2007) opined that the data gathered by the open-ended 
questions are more likely to reflect the full richness and complexity of the views held by the respondents.

The current study collected data from judges and magistrates of the high court and magistrates' court respectfully in the selected counties using questionnaires. The data collected required very specific responses and therefore many of the questions were closed-ended. This included questions that required a yes or no response while others were subjected to a Likert scale or some form of quantitative measure (see Appendix 3 questions 2 ii-xii). However some of the questions sought to investigate the opinion and attitude of the respondents towards records management and therefore were qualitative in nature and as such structured as open-ended type of questions (see question 4 vii and viii in Appendix 3).

Pickard (2007) identified the following reasons for using questionnaires: the researcher can reach a large and geographically dispersed community at relatively low cost; data can be harvested from a larger sample than would be possible using any other technique; anonymity can be offered as well as confidentiality and that data analysis can be determined from the outset, even as far as coding before the questionnaires have been distributed. According to Saunders et al. (2012) questionnaires work best with standardized questions that one can be confident will be interpreted the same way by all respondents. They therefore tend to be used for descriptive or explanatory research. The choice of a questionnaire as one of the data collection instruments for this study was informed by the fact that the targeted group of respondents (judges and magistrates) had very tight schedules in their places of work and the questionnaire therefore afforded them flexibility to complete them at their own convenient time. The anonymity of the questionnaires played a role in making some of the judges and magistrates agree to take part in the study since they provided their responses without fear of being quoted. The questionnaires also provided data that was relatively easy to analyze using Statistical Package for the Social Sciences (SPSS) program and yielded results that were easy to interpret. 
Saunders et al. (2012) identified two broad categories of questionnaires: self-completed and interviewer completed. Self-completed questionnaires are usually completed by the respondents and depending on how they are sent could be further categorized into the following: Internet-mediated or Web-based questionnaires; intranet mediated questionnaires; postal or mail questionnaires and delivery and collection questionnaires. Interviewer -completed questionnaires are recorded by the interviewer on the basis of each respondent's answers. This can be further categorized into telephonic questionnaires or structured interviews depending on the mode of contact between the researcher and the respondent. The current study made use of delivery and collection questionnaires where the questionnaires were hand-delivered by the researcher to each respondent and collected later. This approach was adopted in order to allow the respondents time to fillin the questionnaires.

The survey questionnaire has been used by other studies which include a study by the World Wide Web Foundation (2011) on the "Open government data feasibility study in Ghana". The target group comprised people and organizations that may be key to any future success of implementation of the OGD initiative in Ghana. In the same vein, Uwaifo (2004) carried out a study on the "Management use of records in Delta State University, Abraka, Nigeria" and used the questionnaire in conjunction with the interview method. Similarly, Kemoni and Ngulube (2007) administered questionnaires on registry personnel and 157 of the 210 registry personnel in the ministries studied completed and returned the questionnaires. Lastly, Chinyemba and Ngulube (2005) in a study on managing records at the University of KwaZulu-Natal used the questionnaire as the principal instrument of data collection.

\subsubsection{Observation}

Observation means watching attentively in a scientific or systematic manner (Powell and Connaway, 2004). Observations are carried out in order to provide evidence of the "here and now' to discover how people behave and interact in particular situations (Pickard, 2007:201). According to Pickard almost all research involves observation of some sort 
from the most formulaic laboratory experiment to the most natural ethnographic observation. A distinctive feature of observation is that it offers an investigator the opportunity to gather live data from naturally occurring social situations (Cohen, Manion and Morrison, 2007). They enable researchers to see things which might otherwise be unconsciously missed and to discover things which participants might not freely talk about in interview situations (Cohen, Manion and Morrison, 2000). Observation offers the social researcher a distinct way of collecting data. It does not rely on what people say they do, or what they say they think. However, it draws on the direct evidence of the eye to witness events first hand and is based on the premise that, for certain purposes, it is best to observe what actually happens. Observation can therefore be used "in both basic and applied research and in quantitative and qualitative studies" (Powell and Connaway, 2004:157).

Powell and Connaway (2004) identified two types of observation: structured and unstructured. The structured observation is a more formal technique used in order to provide systematic descriptions made possible by having a predetermined set of categories of activities to be observed commonly referred to as an observation schedule or checklist. On the other hand, the unstructured observation refers to a situation in which activities to be observed are not specified. The whole purpose of the schedule is to minimize, and possibly eliminate, the variations that will arise from data based on individual perceptions of events and situations (Denscombe, 2007). Its aim is to provide a framework for observation which all observers will use, and which will enable them to:

- Be alert to the same activities and be looking out for the same things;

- Record data systematically and thoroughly; and

- Be able produce data which are consistent between observers, with two or more researchers who witness the same event recording the same data.

To achieve these three aims, observation schedules contain a list of items that operate something like a checklist. The researcher who uses an observation schedule will monitor the items contained in the checklist and make a record of them as they occur. 
This study made use of structured observation which involved developing an observation check list (see Appendix 4) which guided the researcher. Basically this method was used to collect qualitative data pertaining to observable aspects of records management like arrangement and storage of records; preservation of records and disaster management. This was useful in corroborating and complementing data collected from both the interviews and the questionnaires. The choice of observation was a result of the fact that it allowed the researcher to collect and record aspects of records management such as the adequacy of storage space and facilities; physical condition of the records and security mechanisms put in place among other things as they were and thus allowed the comparison of what people said and what actually was seen on the ground that is, direct data collection was made possible. Furthermore, observation allowed otherwise unnoticed or ignored aspects of the study to be seen such as the arrangement of the records and layout of the records centres / registries. Lastly it provided a means for collecting substantial amounts of data in a relatively short time span.

Observation has been used in collecting qualitative data in other studies such as Sichalwe (2010) on the significance of records management to fostering accountability in the public service reform programme of Tanzania. Among issues observed by the study included procedures/systems used for managing records, tools for accessing and tracking records use, filing systems used, storage equipment for paper records and storage space; records preservation measures, records security measures and the existence of computers in the registry. On the other hand Garaba (2010) in a study investigating the management of records and archives of former liberation movements in East and Southern Africa held by national and private archival institutions used observation to supplement data captured by questionnaires and interviews. Issues observed in the study pertained to: records groups; filing; storage; and access and use among others. Lastly, Uwaifo (2004) in a study on the use of records in Delta State University, Abraka, Nigeria used observation to corroborate data obtained from questionnaires. 


\subsubsection{Document Review}

Documentary data are often used in research projects that also collect primary data although they can also be used on their own (Saunders at.al, 2012). Saunders et.al identify the following as possible documentary data sources: text materials such as notices, correspondence (including emails), minutes of meetings, reports to shareholders, diaries, transcripts of speeches and conversations, administrative and public records, books, journal and magazine articles and newspapers. Denscombe (2007) cautions that materials to be used need to be evaluated in relation to four basic criteria:

- Authenticity - referring to whether it is real and genuine;

- Credibility - addressing the accuracy and freedom from bias and errors;

- Representativeness - referring to whether the document is typical of its type; and

- Meaning - addressing whether the meaning of words are clear and unambiguous and whether there are hidden meanings of words. This also looks at the possibility of the document containing argot and subtle codes and whether there are meanings which involve 'what's left unsaid' or 'reading between the lines'

Documents that were reviewed by the current study included: judiciary annual report covering the period July 2012 to June 2013, the Judiciary Transformation Framework document, proposed registry manual, Records Disposal Act Cap 14, and Standard newspapers dated $14^{\text {th }}$ October 2013 and $26^{\text {th }}$ July 2014. The judiciary report and JTF document were found to be authoritative since information in them had been produced by the judiciary management employing resources and expert professionals thus thought to be credible. Moreover, since the data were produced by officials they might be regarded as impartial. The newspapers on the other hand, provide a potentially valuable source of information for research purposes since they can supply good up to date information.

Documentary review was used in the current study to corroborate and complement data obtained from other sources of data such as interviews, questionnaires and observations. 
Similar studies have also used documentary review to solicit for data. For instance, Kalcul (2009) on a study on the evolution of e-records management from the perspective of Turkey used document review to collect data. Among documents reviewed were policy documents and legislative documents such as the Trukish Civil Procedure Code, the Electronic Signature Act among others. Similarly, Katuu (2012) in a study on enterprise content management implementation in South Africa reviewed both published and unpublished articles in his data collection.

\subsection{Data Collection Procedures}

This section gives an account of how the researcher prepared for and undertook the data collection. Prior to the commencement of data collection, the researcher prepared the instruments to be used in the data collection including the questionnaire for judges and magistrates, interview schedules for the registrars, records staff and registry assistants, and an observation schedule. These instruments were later subjected to a peer debriefing team to improve the validity of the instruments (Polit and Beck, 2004).

Meanwhile the researcher after obtaining a research permit (see Appendix 5) from the relevant ministry in Kenya wrote to the judiciary to obtain access to the staff and relevant documents (see Appendix 11). Upon receipt of the judiciary's authorization letter via the Judiciary Training Institute (see Appendices 6 and 7), preparation for the data collection exercise began.

Two weeks before the start day the researcher visited the judiciary for an introduction session and to book appointments with the court registrars. The respective court registrars gave the date they would be available for interviews and introduced the researcher to deputy registrars of the high courts and executive officers in the magistrate courts through emails instructing them to accord the researcher the necessary assistance. All the deputy registrars and executive officers were also visited to book appointments for interview sessions. They also indicated the dates that they would be available and asked the records officers (archivists) and the registry clerks to offer assistance to the 
researcher. The judges and magistrates were also approached by the researcher through the deputy registrar in each of the high court or the executive officers in the magistrates' courts requesting them to fill in the questionnaires. Some of them consented and asked the researcher to pick up the questionnaires on particular days. Some of them however declined outright to taking part in the study explaining that their schedules were too tight and could not afford time to attend to the questionnaires. In some instances even those who had consented did not fill in the questionnaires by the dates they had indicated to the researcher. Some of them, after many reminders, honored their word but a few of them did not respond even after repeated reminders. One particular judge asked to be interviewed instead since he felt he would not have the time to attend to the questionnaire. The researcher then quickly thought through the questions in the questionnaire and converted this to an interview session which had to be done in 15 minutes.

During the interviews, many of the discussions were audio recorded and the researcher also made hand written notes as a back up to the audio recording. Denscombe (2007) recommended audio recording interviews since it offers a permanent record and one that is fairly complete in terms of the speech that occurred. He also opines that audio recording lends itself to being checked by other researchers. In a few instances however,

the interviewees declined to be recorded and the researcher relied on the field notes to make a record of the discussion. Two to three interviews would be done in a day depending on the availability of the interviewees until all the interviews had been completed. In some cases interview dates had to be rescheduled many times owing to the busy nature of the staff involved. The interviews for each day were usually transcribed the same day, mostly in the evenings, though in isolated cases, this would be done a day or two later.

\subsection{Reliability and Validity of the Instruments}

Reliability refers to the ability of a particular technique, applied repeatedly to the same object to yield the same result each time (Babbie and Mouton, 2001). Similarly, 
Saunders et al. (2012) look at reliability as the ability of the data collection techniques and analytic procedures to produce consistent findings if they were repeated on another occasion or if they were replicated by a different researcher. Gorman and Clayton (2005) identified three types of reliability as: quixotic reliability which refers to the circumstances in which a single method yields an unvarying measurement; diachronic reliability which refers to the stability of an observation through time, demonstrated by similarity of measurements, or findings, taken at different times; and synchronic reliability which refers to the similarity of observations within the same period of time.

Research methods scholars have identified the following methods that can be used to measure the reliability of research instruments: test-retest method; parallel forms techniques and split-half method (Krishnaswami and Ranganathan, 2010; Babbie and Mouton, 2001; Pickard, 2007; Saunders et al., 2012). Saunders et al. observed that testretest estimates are obtained by correlating data collected with those from the same questionnaire collected under as near equivalent conditions as possible. The parallel forms on the other hand refer to estimating the reliability within the questionnaire through comparing responses to alternative forms of the same question or groups of questions. In a split-half method, the questions are randomly split in two sets and responses from each set correlated with the other set and the two should measure the variable in question in the same way.

Babbie and Mouton (2001) define validity as the extent to which an empirical measure adequately reflects the real meaning of the concept under consideration. Basically validity refers to the effectiveness (or success) of an instrument in measuring the specific property which it intends to measure. Krishnaswami and Ranganathan (2010) identify the following types of validity: content validity (face validity and sampling validity); predictive validity (criterion related) and construct validity. Saunders et al. (2012) defines content validity as the extent the measurement device (questions in the questionnaire), provides adequate coverage of the investigative questions. Predictive validity on the other hand is concerned with the ability of the measures to make accurate predictions while the construct validity refers to the extent to which the measurement questions 
actually measure the presence of the constructs that the researcher intended them to measure. The following methods can be used to measure the validity of research instruments: the known group method; the multitrait-multimethod matrix and factor analysis.

Both reliability and validity are measures of research quality and are taken seriously by all researchers who wish others to accept their research as credible. Saunders et al. (2012) however, think that these scientific canons of inquiry may be seen as placing interpretive, pragmatist, realist and qualitative researchers in some sought of dilemma. Gorman and Clayton (2005) attesting to this argue that the quality of research instruments in qualitative studies cannot be judged using the statistical measures of validity and reliability. In a rejoinder Pickard (2007) suggested the following as measures of quality in qualitative studies: credibility; transferability; dependability; and confirm ability. On the other hand, Moore, Lapan and Quartaroli (2012) opine that improving validity and trustworthiness of findings in a qualitative study involves the following: triangulation of data collection methods and data sources; using pre-tested tools; member checking; and if necessary undertaking an external review and interpretation. In the current study, validity and reliability were assured through the following methods:

- The reliability (trustworthiness) of the tools was improved by peer debriefing. Peer debriefing according to Polit and Beck (2004), involves sessions with peers to review and explore various aspects of the inquiry. Polit and Beck assert that it exposes components of research such as research instruments to a critical review by other researchers who could be experienced in either the methods of naturalistic inquiry, the phenomenon being studied, or both. In this case selected lecturers in the School of Information Sciences at Moi University, Kenya, among them a Professor in records management, were invited to critique the data collection tools and their input helped improve the tools;

- Triangulating of data sources by collecting data from judges, magistrates, court registrars, records officers and registry assistants. In some instances all the groups were asked similar questions for instance questions on records management 
policies (see Appendices 1, 2 and 3). Responses from all these groups were compared and the response with the highest frequency from all the groups was taken to be the true reflection of the matter at hand. Methods of data collection were also triangulated by using interviews, questionnaires, observation and document review to collect data that addressed similar aspects of the research problem. Polit and Beck (2004) noted that the purpose of using triangulation is to provide a basis for convergence on the truth. By using multiple methods and perspectives, researchers strive to sort out "true" information from "error" information, thereby enhancing the credibility of the findings. Denscombe (2007) supports this view by indicating that researchers can improve their confidence in the accuracy of findings through the use of different methods to investigate the same phenomenon;

- Member checking which involved preparing a summary of preliminary findings and allowing the participants to react to the findings as the process of data collection went on. However, it should be noted that not all the participants had the time or the willingness to look through the findings as they unfolded. Nevertheless, the few participants who were willing had the chance to clarify the issues they felt were misinterpreted by the researcher. Lincoln and Guba (1985) consider member checking the most important technique for establishing the credibility of qualitative data. Polit and Beck (2004) contend that in a member check, researchers provide feedback to study participants regarding the emerging data and interpretations, and obtain participants' reactions. They explain that if researchers purport that their interpretations are good representations of participants' realities, then participants should be given an opportunity to react to them. Polit and Beck (2004) advise that member checking with participants can be carried out both informally in an ongoing way as data are being collected, and more formally after data have been fully analyzed. The current study adopted the former strategy to undertake a member check on the findings; 
- Reliability of the questionnaire was determined by calculating "Cronbach alpha" values of the questions. Table 3 shows the Cronbach's alpha values for the item total correlation coefficients. From the table, all the dimensions had alpha values of at least 0.7. Going by Nyagowa's (2012) assertion, the questionnaire used to solicit data from judges and magistrates in the current study had high internal consistency since its correlation coefficients alpha values are over 0.7. Polit and Beck (2004) point out that the most widely used method for evaluating internal consistency is coefficient alpha (or Cronbach's alpha) whose normal range of values is between .00 and +1.00 , and higher values reflect a higher internal consistency.

Table 3: Cronbach's Alpha Values

\begin{tabular}{|l|c|}
\hline \multicolumn{1}{|c|}{ Dimension } & Cronbach's Alpha \\
\hline Value of records management & .660 \\
\hline Strategies used to open up the judiciary & .679 \\
\hline Factors contributing to the state of records management & .670 \\
\hline Reasons for missing files & .655 \\
\hline Reasons for case backlogs & .697 \\
\hline Benefits for opening up & .670 \\
\hline
\end{tabular}

Source: Field Data 2014

A similar study by Sichalwe (2010) achieved reliability and validity by the use of pretesting and triangulation. Another study by Komen (2012) on the "Management of personnel records in support of good governance at the Ministry of Local Government Headquarters Nairobi, Kenya" achieved reliability and validity by the use of pre-testing and member checking while a study by Nyagowa (2012) demonstrated its internal 
consistency by calculating the Cronbach's alpha values on the evaluation of NEPAD's pilot E-schools in Kenya.

\subsection{Data Analysis and Presentation}

The process of analysis involves the search for things that lie behind the surface content of the data in order to get the deeper meaning that can help in arriving at some general principles that can be applied elsewhere to other situations (Denscombe, 2007). According to Polit and Beck (2004:586), "the purpose of both qualitative and quantitative data analysis is to organize, provide structure to and elicit meaning from research data". Ngulube (2005b) argued that a researcher may fail to interpret research data or to draw conclusions and make recommendations if he/she does not understand how to analyze data. In the current study data were collected using qualitative and quantitative approaches as explained elsewhere. Qualitative data (data collected using the interviews and observation) were analyzed thematically. This involved coding the data where labels were attached to the raw data, categorizing the codes which involved identifying ways in which the codes could be grouped into categories, identifying themes and relationships among the codes and categories where patterns within the data begun to unfold, and developing concepts and arriving at some generalized statements which meant drawing conclusions based on the relationships, patterns and themes that emerged from the data. During presentation, if data was presented verbatim, codes were used to disguise the identity of the respondents for example using such codes as "R1" in reference to a particular respondent.

On the other hand, quantitative data was edited, coded and subjected to the computer software package (SPSS version 16) for analysis. Editing data is a process of examining the raw data to detect errors and omissions and to correct where possible. "Editing is done to ensure that data collected are accurate, consistent with other facts gathered, uniformly entered, as complete as possible and arranged to facilitate coding and tabulation" (Kothari, 2004:122). Coding on the other hand involves recording data in numerical codes. Coding enables the researcher to enter the data quickly using the 
numeric keypad on the keyboard and with fewer errors (Saunders et al., 2012). Once the data had been coded it was entered onto the computer taking considerable care that the data were entered correctly. Saunders et al. (2012) suggests methods for checking data for errors as follows: looking for illogical codes; looking for illogical relationships; and checking that rules in filter questions are followed. The software was then used to generate descriptive and inferential statistics in tables, graphs and pie-charts. The analysis of these data was done with help from a statistician since the researcher was not very conversant with the use of SPSS.

\subsection{Ethical Considerations}

Ethics generally refer to the norms or standards of behavior that guide moral choices about behavior and our relationships with others (Johnson and Christensen, 2008). Saunders et al. (2009) defined research ethics as the appropriateness of researcher's behavior in relation to the rights of those who become the subjects of the study or are

affected by it. Research ethics therefore relates to questions about how we formulate and clarify our research topic, design our research and gain access, collect data, process and store data, analyze data and write up research findings in a moral and responsible way. Saunders et al. (2009) identify the following key ethical issues that arise across the stages and duration of a research project:

- Privacy of possible and actual participants;

- Voluntary nature of participation and the right to withdraw partially or completely from the process;

- Consent and possible deception of participants;

- Maintenance of the confidentiality of data provided by individuals or identifiable participants and their anonymity;

- Reactions of participants to the way in which one seek to collect data, including embarrassment, stress, discomfort, pain and harm;

- Effects on participants of the way in which the data is used, analysed and reported and

- Behavior and objectivity of the researcher. 
To address ethical issues, the current study first and foremost complied with the University of KwaZulu-Natal code of research ethics which is guided by the following principles: honesty and integrity; safe and responsible methods and fairness and equity for the participants. Secondly, a research permit was sought from the National Council of Science and Technology which is a body that regulates all researches in Kenya (see Appendices 5 and 6). Thereafter, permission was sought from the chief registrar of Kenyan judiciary (see Appendices 9, 10 and 11) who through the Judiciary Training Institute gave authorization for the research to be undertaken in the judiciary (see Appendix 7). The respondents were then assured that their privacy, confidentiality and anonymity would be observed throughout the research process. They were asked to sign the informed consent (see Appendix 8) which among other things explains that there was no monetary gain for those who chose to participate in the study and that they could voluntarily withdraw from the study at any time without any victimization. During data analysis and presentation, respondents were referred to by use of codes earlier prescribed to each respondent.

\subsection{Evaluation of the Research Methodology}

This section attempts to undertake an assessment of the methods used in carrying out the current study. Ngulube (2005b:48) pointed out that "all research designs are imperfect and it is mandatory for researchers to evaluate their investigation procedures". He adds that there is no one type of research design that is universally better or worse than any other since all research designs are different and used for different purposes. Ngulube (2005a:139) observes that research methods should be evaluated in order to bring to the fore what data was required, how it was collected and how it was analyzed. Specifically, unexpected changes to the research design, limitations of the research design, acknowledgement of shortcomings of the execution of the study and ethical issues are dealt with when evaluating research procedures (Ngulube, 2005a:139). 
The current study adopted a pragmatic paradigm based on a mixed methods research approach where the qualitative aspects were dominant while the quantitative less dominant. Consequently, in-depth interviews, observations and document review were used to collect qualitative data from court registrars, executive officers, records officers (herein referred to as archivists), and registry assistance (executive assistance or registry clerks). On the other hand questionnaires were used to collect both qualitative and quantitative data from judicial officers who are the judges and magistrates of the high court and magistrates courts respectively. The qualitative data was addressed by open ended questions while the quantitative data was obtained from closed ended questions in the questionnaire. It is however worth mentioning that some of the respondents left the open ended questions unanswered though some took time and provided very valuable information.

The triangulation of data sources and methods of data collection played a very important role in improving the trustworthiness and dependability of the data collected (reliability and validity) (Denscombe, 2007; Polit and Beck, 2004; Saunders et al., 2012). At the proposal stage, the researcher had hoped to interview the registrars and records officers. However, the initial visit to the judiciary revealed two other cadres of staff that played a key role in the management of records. These were the executive officers who were actually in charge of the registry operations and the registry assistants who were either designated as executive assistants or registry clerks. It emerged that the latter were the ones running the registries although they did not have any records management training and the researcher had to change the research plan to include them in the study. Further although the study had planned to administer questionnaires to all the judges and magistrates, one of the judges had to be interviewed since she felt that she did not have time to attend to the questionnaire later.

Once data had been collected, the qualitative data were analyzed thematically and presented in narrative discussions while the quantitative data were analyzed using SPSS and presented in tables, pie-charts, bar charts, frequencies and percentages. The qualitative data were analyzed by the researcher while the quantitative data were 
analyzed with the assistance of a statistician since the researcher did not have good knowledge of SPSS.

The process of data collection was marred with many challenges. To begin with, the study was done at a time when the Kenyan judiciary was undergoing some structural changes. As a result, when the researcher wrote to the Chief Registrar to ask for permission to undertake the research, the response took about two months and it was not clear initially who was to handle such requests. Eventually, the request was forwarded to the Judiciary Training Institute and the director of the institute later responded that the researcher had been permitted to do the research though the process ended up delaying the commencement of the data collection.

Another challenge arose when the judicial officers seemed not to have the time to fill in the questionnaires. This forced the researcher to make many trips to Nairobi where the majority of the respondents were based. Even with the many visits and reminders only 43 $(52 \%)$ of the questionnaires were filled. Fortunately, all the deputy registrars granted interview time and since they are also magistrates, the depth of information they gave made up for the seemingly lower response rate from the judges and magistrates. Further, some of the respondents did not consent to being recorded and so irrespective of the role that audio recording plays in collecting qualitative data, the researcher had to rely on written notes during the transcription stage. Lastly, since the researcher was not on any scholarship, finances were another challenge. The many trips that had to be made to the research site financially drained the researcher but every effort was made to ensure successful completion of data collection.

Irrespective of all the challenges mentioned, the researcher crossed these hurdles to ensure that credible data were collected and she is confident that the study findings adequately address the research problem. 


\subsection{Summary}

The chapter described the research methodology used in the study. It discussed the overall research approach for the study and presents the research design that was deemed appropriate to address the research questions for the study. The topics covered in this chapter include: research methodology; research approach; research design; case study designs; study population; data collection instruments; reliability and validity; data presentation and analysis; and ethical considerations. The next chapter presents the results of the empirical study. 


\section{CHAPTER FIVE \\ DATA ANALYSIS AND PRESENTATION OF FINDINGS}

\subsection{Introduction}

The process of data analysis involves the search for meanings that lie behind the surface content of the data (Denscombe, 2007). The process of data analysis involves clustering together related types of narrative information into a coherent scheme (Polit and Beck, 2004). Ngulube (2005a) argues that data analysis may help a researcher to arrive at a better understanding of the operation of social process. During data analysis, the researcher's task is to probe the data in a way that helps to identify the crucial components that can be used to explain the nature of the phenomenon being studied, with the aim of arriving at some general principles that can be applied elsewhere to other situations. The purpose of data analysis and presentation of findings in research is therefore to showcase the empirical findings in an attempt to answer the research questions addressed by the study (Garaba, 2010). This study sought to address the following research questions: How are records created, used, distributed, maintained, stored, disposed of and preserved?; What records management policies, plans, and guidelines are available?; What skills and competencies do the records management staff have?; What is the level of awareness and attitude of staff towards sound records management practices?; and What records management related strategies is the Kenyan judiciary using to achieve openness?

This chapter therefore presents and analyzes data obtained from the population of the study. The data were gathered through in-depth interviews with court registrars, deputy registrars, executive officers, records officers, and registry assistants. Questionnaires were also administered to judicial staff (judges and magistrates). In addition, observation of records management operations was done and documents including a High Court Operations Manual, judiciary Transformation Framework and judiciary report were reviewed. The data gathered through the interviews, observation and document review were analyzed thematically and presented in narrative discussions while data from the 
questionnaires were analyzed using SPSS to generate descriptive statistics that were presented in tables, charts and percentages.

\subsection{Response Rate}

Response rate refers to the number of successful interviews and questionnaires completed and returned. This is expressed as a percentage of total target interviews and questionnaires issued. Different scholars have given their opinion on the acceptable response rate levels. Babbie and Mouton (2001:261) opined that "a response rate of 50 per cent is adequate for analysis and reporting, while a response rate of 60 per cent is good and a response rate of 70 per cent is very good". On the other hand, Polit and Beck (2004:366) asserted that a response rate greater than $65 \%$ is probably sufficient for most purposes, but lower response rates are common. Meanwhile, Neuman (2000) argued that anything below $50 \%$ is considered to be poor and over $90 \%$ as excellent.

A study by Sichalwe (2010) investigated the significance of records management for fostering accountability in the public service reform programme in Tanzania where, 180 registry personnel were issued with questionnaires and 120 of them completed and returned thus obtaining a $67 \%$ response rate. In the same study 40 senior ministry officials were targeted for interview and only 26 interviews was done giving a response rate of $65 \%$. In another study by Kemoni and Ngulube (2008) on the relationship between records management, public service delivery and the attainment of the United Nations Millennium Development Goals in Kenya, 210 registry personnel were targeted and a response rate of $75 \%$ was obtained. The same study obtained an interview response rate of $53 \%$ among senior ministerial officers.

In yet another a study by Komen (2012) on the management of personnel records in support of good governance at the ministry of local government headquarters Nairobi, Kenya, 75 registry personnel were targeted and 68 of them were interviewed giving a response rate of 91\%. Lastly, in a study by Ngoepe and Van Der Walt (2009) on records management trends in the South African Public sector, 37 questionnaires were administered and only 27 were returned giving a response rate of $72.9 \%$. 
From the foregoing it is clear that different studies will obtain different response rate depending on the prevailing conditions. The current study obtained an overall interview response rate of $75 \%$ as indicated in the Table 4. According to Babbie and Mouton's (2001) this rate of response is deemed very good.

Table 4: Interview Response Rate

\begin{tabular}{|l|l|l|l|}
\hline Target Group & Target & Interviewed & Percentage \\
\hline Court Registrars & 4 & 2 & \\
\hline Deputy Registrars & 8 & 8 & $50 \%$ \\
\hline Executive Officers & 12 & 11 & $100 \%$ \\
\hline Records Officers & 13 & 9 & $99 \%$ \\
\hline Registry Assistants & 24 & 16 & $67 \%$ \\
\hline Average response rate & $\mathbf{6 1}$ & $\mathbf{4 6}$ & $\mathbf{7 5 \%}$ \\
\hline
\end{tabular}

Source: Field Data (2014)

A total of 82 questionnaires were also administered to judicial officers comprising judges and magistrates and only 43 were completed and returned representing a $52 \%$ response rate. This level of response rate was attributed to the fact that the respondents reported that they had extremely busy schedules and could not make time to respond to the questionnaires. Some of them however, promised that they would make time to respond but even after repeated reminders by the researcher they failed to respond. A few of them $(3: 7 \%)$ reported that they were new in their stations and could not adequately answer the questions. This seemingly low response rate was compensated by the fact that the deputy registrars who doubles up as administrators and magistrates were interviewed and a wealth of data gathered. However, according to Babbie and Mouton (2001) 52\% is still considered adequate for answering the research problem. 


\subsection{The Findings}

The findings of the study are organized into themes obtained from the research questions indicated in section 5.1. The themes are as follows: records management from creation to disposition; e-records readiness in the judiciary; records management policies, plans, and guidelines available; skills and competencies among records management staff; level of awareness about records and attitude of staff towards sound records management practices; and records management related strategies for openness in the judiciary.

The findings from interviews, questionnaire, observation and document review were collated and presented under respective themes as identified above.

\subsubsection{Records Management from Creation to Disposition}

One of the underpinning models for the study was the Records Continuum Model which as described in chapter 2 is a consistent and coherent regime of management processes from the time of records creation through to the preservation and use of records as archives. It follows therefore that records must be managed in the judiciary right from creation especially in view of the transformation and openness currently underway in Kenya. That has involved adopting a people-focused delivery of justice, improving public engagement and adopting ICT as an enabler of justice delivery among other deliverables. Research question one therefore sought to find out how records were managed in the judiciary from their creation through to disposition. Questions $1-7$ of the interview schedule for records staff (Appendix 1), questions 2 (i) - 2 (vi) of the interview schedule for registrars and executive officers (Appendix 2) and questions 2 (i) - 2 (xiii) of the questionnaire for judges and magistrates (Appendix 3) addressed this research question. Question 2-19 of the observation checklist (appendix 4) also helped address this research question. The following aspects - records creation; records access and use; records storage and maintenance; records appraisal and disposition; records preservation, erecords management and overall state of records management were covered under this research question and the data is presented in sections 5.3.1.1 to 5.3.1.7: 


\subsubsection{Records Creation}

In order to understand how records are created, the records officers and registry staff were asked to state their responsibilities (see question 2 (i) in appendix 1). The corresponding responses of a few respondents are sampled up and summarized in Table $5:$

Table 5: Responsibilities of Records Officers and Registry Staff

\begin{tabular}{|l|l|}
\hline Respondent & Response \\
\hline R13 & $\begin{array}{l}\text { Receiving files from court rooms, Filing the files, Retrieving them } \\
\text { when needed and ensuring the safety of the files. }\end{array}$ \\
\hline R14 & $\begin{array}{l}\text { "Opening of files, File retrieval, File repair, File tracking and } \\
\text { maintenance" } \\
\text { "Receiving requests from clients, Receiving files from different } \\
\text { functional areas and facilitating file retrieval" }\end{array}$ \\
\hline R15 & $\begin{array}{l}\text { "File Opening, Custodian of files, File retrieval, Assessment of } \\
\text { documents and file maintenance" }\end{array}$ \\
\hline R25 & $\begin{array}{l}\text { "Receiving files with dates, Filing the files, Retrieving the files when } \\
\text { "Opening of files, File storage, File retrieval, File tracking and } \\
\text { ensuring security of the files in my custody" }\end{array}$ \\
\hline R34
\end{tabular}

Source: Field Data (2014)

Those respondents that mentioned opening of files or records creation were further asked how the files were created. Their responses are summarized in the words of two respondents one from criminal registry (R34) and the other from civil registry (R14).

We receive a charge sheet from the police, which is then registered on a charge sheet register after which a folder is opened for it and is given a case number. The file is later dispatched to the court and if the accused pleads guilty, the matter is finalized and the file is filed away on finalized files and taken to the archives 
after one year. However, if the accused pleads not guilty, then the case is given a mention and hearing dates and the file is filed on unfinalized section awaiting the mention and/or hearing date.

According to the testimony of R14, the procedure in the civil registry is as follows:

Application is filed through a plaint which is then assessed for credibility and if it meets the requirements, then the plaintiff is asked to make the necessary court payments and on proof of payment it is given a case number after which it is registered and a folder is opened. The file is then filed away awaiting the next action date.

These officers were further asked if their actions were guided by the existence of documented instructions/procedures and in response they were unanimous that there was a lack of documented directions except for verbal instructions from the registry supervisors when the need arose. An interview with a senior records officer however showed that there was a High Court Registry Operations Manual which at the time of the study had just been launched but the staff had not been sensitized on its existence. Plans were however underway to raise the awareness of all registry staff about the existence of the manual and train them in its use. The researcher reviewed this document and perceived it to be very useful because it carries all the instructions on registry operation. When it is finally put to use, it is likely to streamline and improve registry operations in the judiciary.

On being asked what type and format of records were being created, all the respondents $(25: 100 \%)$ indicated paper formats of case files, court registers and diaries. Judges and magistrates were also asked (see question 2(i) in appendix 3) what type of records they found useful for their service delivery and gave slightly different responses. Their responses are indicated in Figure 3. 


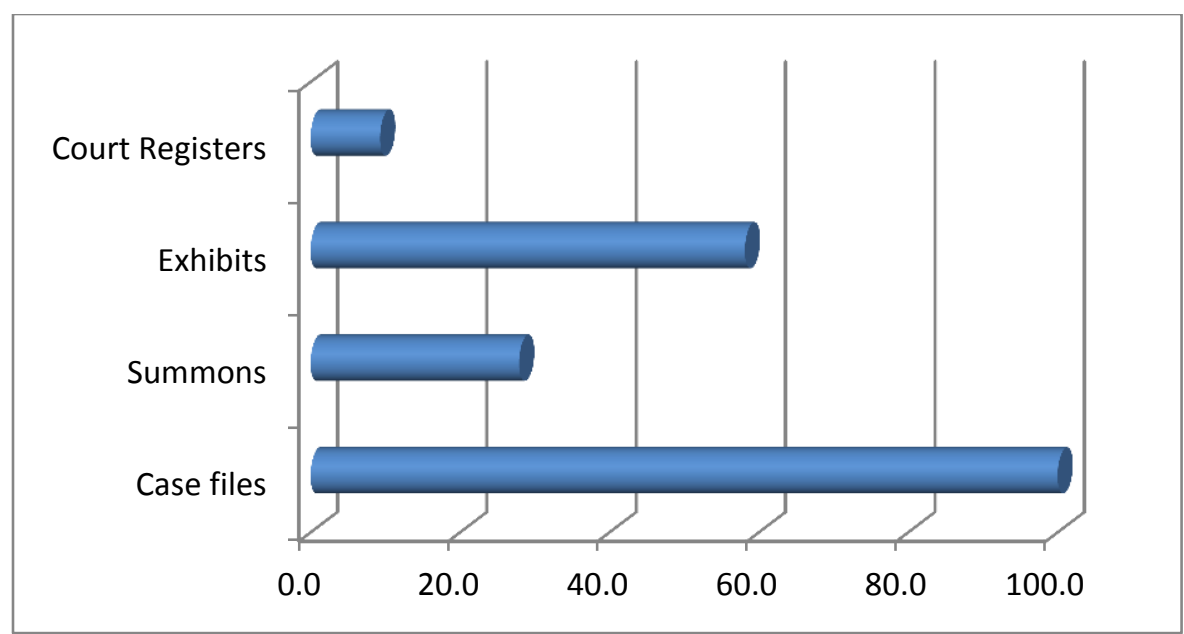

Figure 3: Types of Records Used by Judges and Magistrates Source: Field Data (2014)

Figure 3 shows that all the judges and magistrates [43 (100\%)] relied on case files to adjudicate their duty while slightly more than half [25 (58\%)] indicated that exhibits were also useful. On the other hand a few 12(27.9\%) indicated summons and 4(9.3\%) indicated court registers as other useful records in the administration of justice.

The judges and magistrates were then asked if they agreed that records are vital for the administration of justice (question 2 (ii) Appendix 3). Their response is presented in figure 4 .

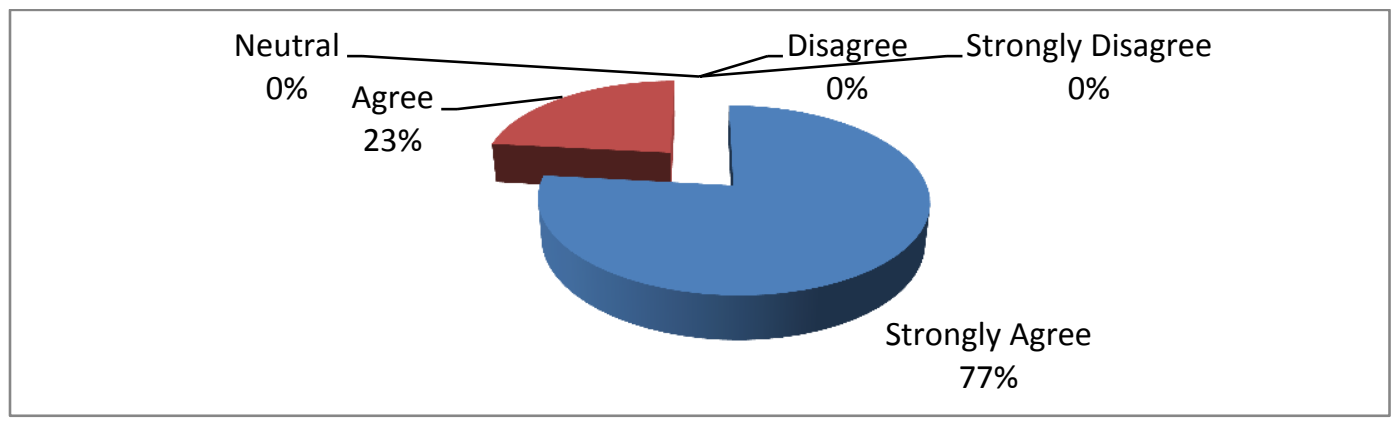

Figure 4: Records are Vital for the Administration of Justice

Source: Field Data (2014) 
Figure 4 shows that $33(77 \%)$ of the judges and magistrates strongly agreed that records are vital for the administration of justice. On the other hand, 10 (23\%) only agreed on the same while none $(0 \%)$ were neutral, disgreed or strongly disagreed.

From the data presented, the researcher deduced that records are vital for the administration of justice in the Kenyan judiciary. Being a crucial resource, records must therefore be managed in tandem with the ideals of the RC Model which requires that records be managed right from their creation to their disposal. However, from the findings presented, it would seem that although there was some sought of a procedure followed in records creation, the absence of documented instructions/procedures may suggest lack of standardization and in effect not so well managed records creation contravening the ideals of the RC Model.

\subsubsection{Records Access and Use}

The records officers and registry assistants were asked if they had tools to aid in records retrieval whenever the records are required. All (25:100\%) of the respondents indicated that they had a filing system that worked well for them. They explained that the records were arranged based on an alpha numeric classification scheme where records were numbered in the order in which they were created in a year and reflecting the court where the records were created. To further understand the filing system used, the researcher was taken through a section of the filing area and was able to ascertain the filing system in use. An example of reference number of a file as seen by the researcher is HCC 345/2014 denoting a record number 345 created in the year 2014 in the High Court Civil Division. The respondents were asked how useful the system was in the retrieval of files and they explained that it made retrieval easy since it points to the position where the record is likely to be found and combines well with shelf labelling presented below.

A majority of the respondents $20(80 \%)$ reported further that the shelves had labels that facilitated retrieval of the records. Out of these, six further indicated that they had a form of computerized retrieval which assists in establishing the current position of the file for 
ease of retrieval. A few of the respondents $5(20 \%)$ however reported that retrieving files in some sections of the registry was an uphill task. They explained that it was impossible to arrange the files according to the classification scheme or label the shelves since the shelves were heavily congested and often times the files were placed on the floor or on top of shelves as is explained in section 5.3.1.3 below.

The researcher then sought to establish whether there was an access policy regulating who has access to the records and how the access could be facilitated. All the records officers and registry staff interviewed (100\%) were in agreement that there was no policy on access of records in the Kenyan judiciary. They were however quick to note that from common practice it was clear to everyone working at the judiciary which individuals have a right to access court records. These included advocates and lawyers of the accused persons and the complainant, the accused and the complainants, judiciary staff and accredited media houses. Apart from the media houses the rest are required to pay a fee (perusal fee) if they wished to peruse the files. These persons were required to peruse the files in the presence of a registry clerk so as to ensure security of the files. The researcher was able to observe this being done at the time of data collection.

The records officers and registry assistants were also asked if they had a tracking system to facilitate the movement of the files / records from one point of use to the other. All the respondents $25(100 \%)$ indicated that they had file movement registers where files were recorded as they leave one point of use to the other. In three court stations (Makadara law court, Eldoret Chief Magistrate Court and Milimani High Court Civil Division) however, there was some form of computerized tracking system.

From this finding, although the Kenyan judiciary lacked a formal access policy at the time of data collection, there seemed to be common / sufficient knowledge based on practice over time as to who could gain access to the court records. The classification scheme and shelf labels assisted in retrieval of records ensuring timeliness in the access of the records. The tracking system was also efficient as every file could be accounted for 
as it moved from one point to the other. It can therefore be concluded that access and use of court records in the Kenyan judiciary was fairly well-managed.

\subsubsection{Records Storage and Maintenance}

Records storage and maintenance plays a key role in ensuring that records remain retrievable, accessible and usable for as long as they are required for business transactions and/or for research, evidential and historical purposes. Proper storage is therefore crucial for successful implementation of open government initiatives since such initiatives depend on the availability of quality information that can only be obtained from a sound records management regime.

In a bid to understand how records are stored in the judiciary, the deputy registrars, executive officers, the records officers and registry assistants were asked if there were designated areas for storage of current, semi-current and non-current records. Their responses of a few of the respondents are summarized in the Table 6.

\section{Table 6: Summary of Responses on Records Storage}

\begin{tabular}{|l|l|}
\hline Respondent & Response \\
\hline R9 & $\begin{array}{l}\text { "Space is a very critical challenge that the entire judiciary is facing, registries } \\
\text { are often congested and current records sometimes stored together with semi- } \\
\text { current records making timely retrieval difficult to achieve" }\end{array}$ \\
\hline R11 & $\begin{array}{l}\text { "Space is generally a problem in judiciary but compared to other court } \\
\text { stations, this station is fairly okay". }\end{array}$ \\
\hline R12 & $\begin{array}{l}\text { "Unlike other court stations we do not have a problem since USAID donated } \\
\text { to until some space is created in the archives to allow some older records to be } \\
\text { Roved in }\end{array}$ \\
\hline
\end{tabular}

Source: Field Data (2014) 
The above responses like others not presented on the table suggested varying state of records storage in the different court stations in Nairobi and Uasin Gishu counties. In some court stations the registries reportedly housed current records while the archives served as storage for both semi-current and non-current records. In other stations, the respondents indicated that there were no areas designated for current, semi-current and non-current records. This state of affairs made the registries appear very disorganized and congested.

Observations further showed an appalling state of records storage in majority of the registries. In one of the registries in Nairobi County for instance, new files at the time of data collection were being kept on the floor as shown in the picture in Figure 5 for lack of space.

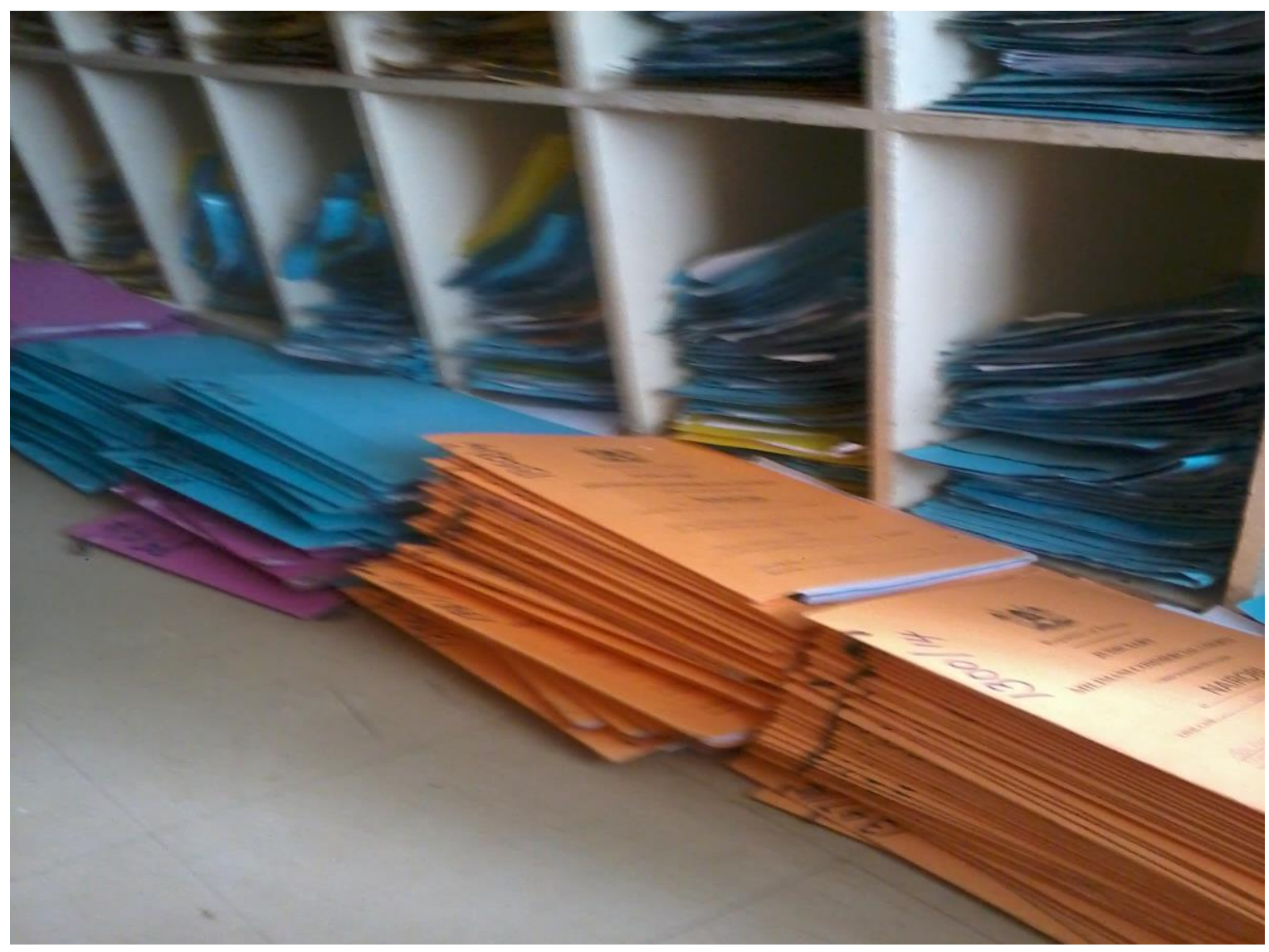

Figure 5: Files Kept on the Floor in One Registry in Nairobi County Source: Field Data (2014) 
The situation was even worse in Eldoret High Court station in Uasin Gishu County. Observation revealed current records that were heaped in some fabricated storage without any form of arrangement as shown in the two adjoined pictures in Figures 6(a) and 6(b).

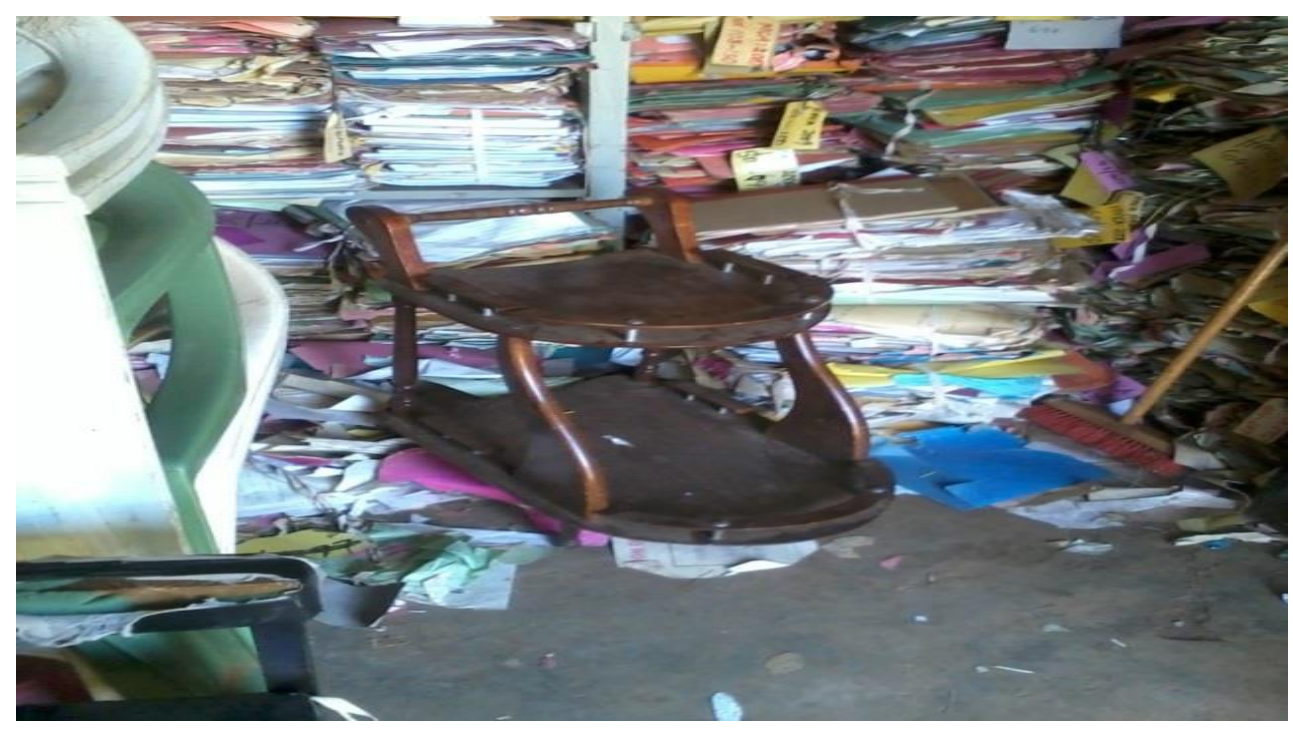

Figure 6(a): Records Competing for Space with Broken Chairs and Tables in a Fabricated Storage Area

Source: Field Data (2014)

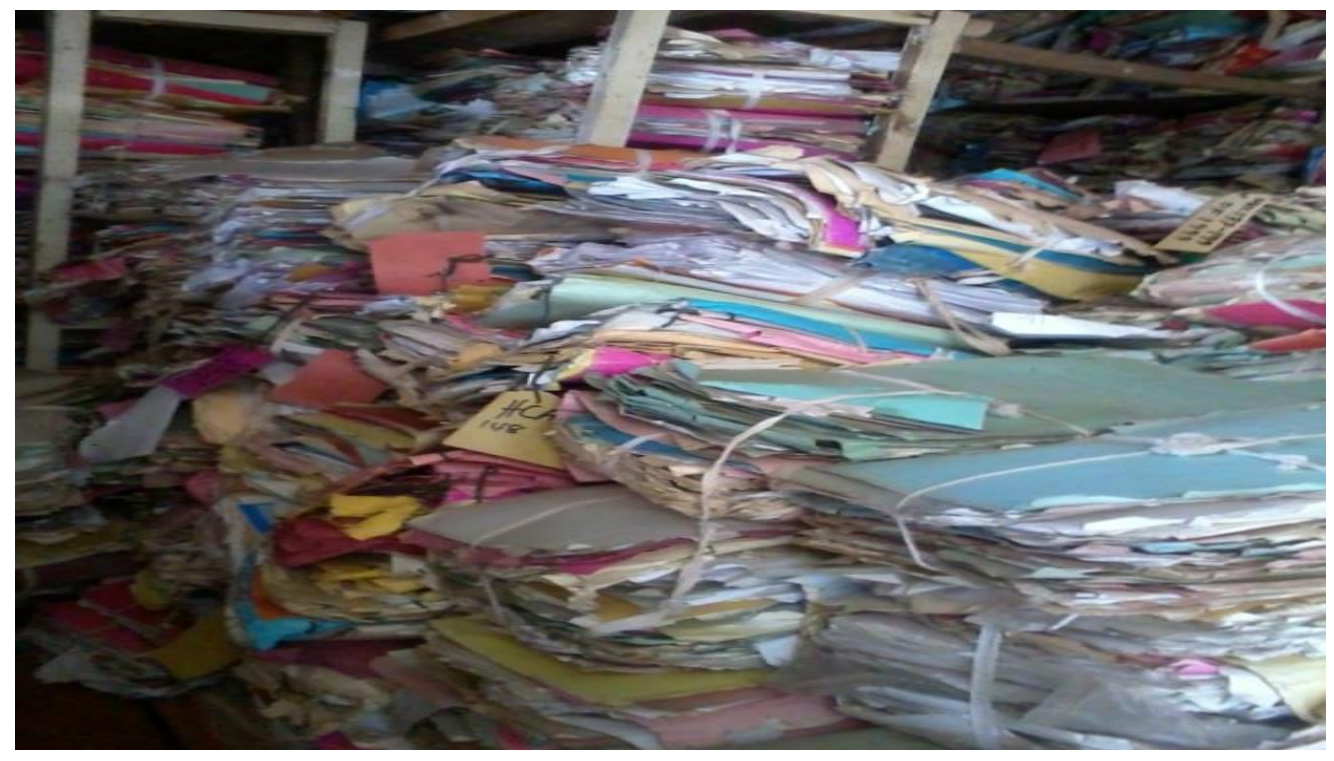

Figure 6(b): Deplorable State of Records Storage in One Registry in Uasin Gishu County

Source: Field Data (2014) 
These findings confirmed an article that appeared in the Standard Newspaper indicating very poor records storage in many court stations across Kenya (Ronoh, 2014). The article observed that in some courts the registries were doubling up as kitchens while in others the files were heaped in some worn out buildings with hardly any form of arrangement.

However, it was observed that storage in some court stations was exceptionally good. A case in point was the Chief Magistrates Court in Eldoret, Uasin Gishu County, which reportedly benefitted from a partnership with the United States Agency for International Development (USAID). The archivist in this station reported that through the donation, the station received two containers which at the time of the study served as the archives for the station. The researcher observed that with the two containers space was no longer a major problem at the station.

Another notable improvement on storage space was in Milimani High Court in Nairobi County. The researcher observed that in this court each division of the high court had storage areas within the registry which held all the current records. Semi-current and noncurrent records were however moved to an off-site storage facility but within the premises of the judiciary. This eased congestion within the registries.

\subsection{Storage Facilities and Equipment}

For further insights into the storage of records in the judiciary a question on the available storage facilities and equipment was asked. The responses given varied from one registry to another: 30 of the respondents (65\%) indicated that the available storage equipment was wooden shelves, 10 of the respondents $(21 \%)$ indicated bulk filers as the available storage equipment while $2(4 \%)$ of the respondents indicated fire proof shelves and 4 $(10 \%)$ of the respondents indicated both wooden shelves and still cabinets. Of those respondents that indicated both wooden shelves and still cabinets, they explained that the cabinets were used to store sensitive files. However, those respondents that indicated bulk filers explained that such equipment was not working well for the registries since files could not be accessed from more than one section thus causing delays as staff retrieving 
files needed to take turns while retrieving them. Without this hindrance this offered the best storage as it kept dust, light and pollutants away because once closed the files were sealed in completely. A picture of the bulk filer is shown in Figure 7

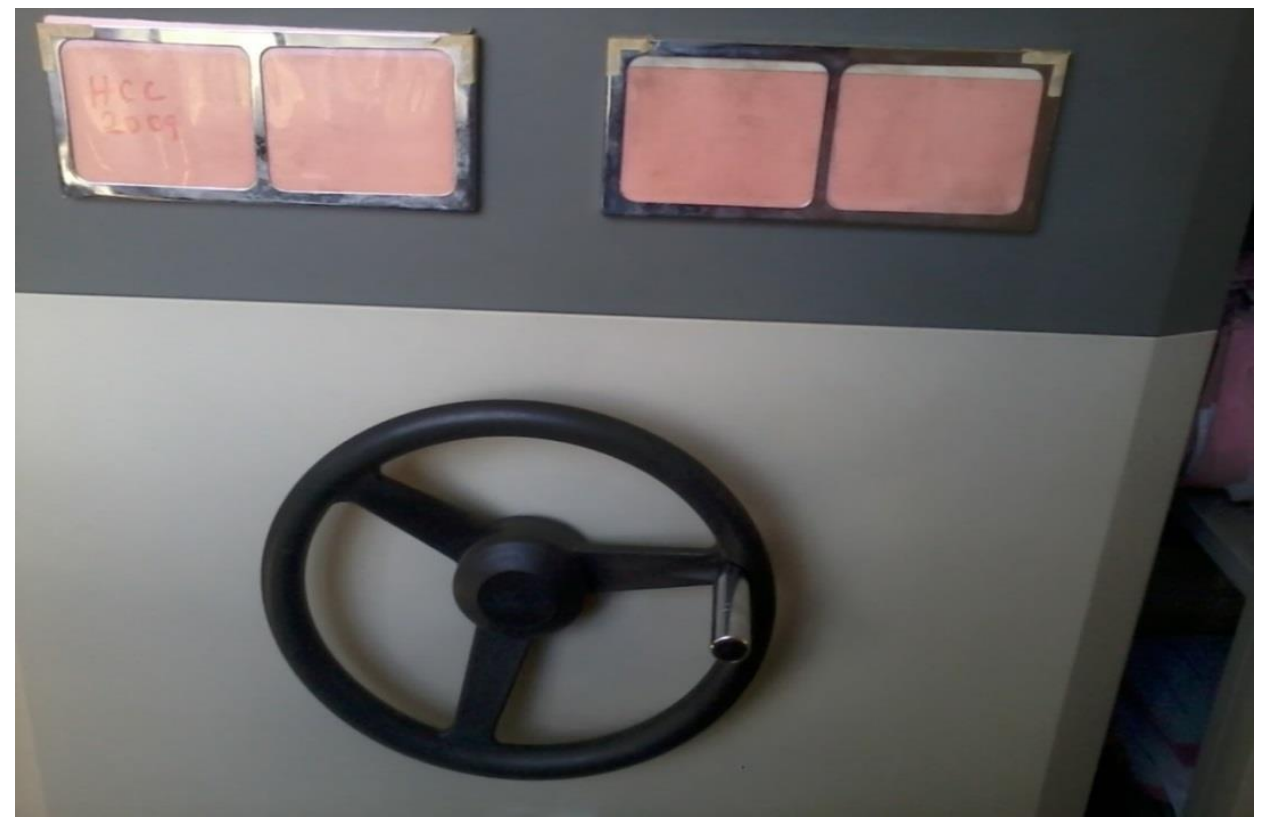

Figure 7: Bulk filers used in Milimani High Court Registries in Nairobi County Source: Field Data (2014)

The data shows that the judiciary seemed not to have the right storage equipment thus aggravating the challenges of lack of space seen earlier.

\subsection{Security of Records at Storage}

The researcher asked about security of the records at storage. The question elicited different reactions from the respondents. Some of the respondents [28 (60\%)] thought the records were secure. The reason they gave was that records created in a particular year especially those that had been moved to the "archives" were taken care of by a particular staff who ensured that the room remained locked to ensure security of the records. They also made an observation that sensitive files were kept under lock and key to facilitate 
their security. Furthermore, they indicated that since all the corridors and some rooms had closed circuit television (CCTV) fittings, this provided some measure of security to the files.

On the other hand those respondents with a contrary opinion [18 (39\%)] felt that since all the registries doubled up as storage and working spaces of the registry staff, it was difficult to ensure security of the records as accountability seemed impossible. One particular respondent (R11) had this to say:

...security of the records has not been very good, every staff can access the filing area and accountability is not possible since it is impossible to ensure that only one staff receives the files, shelves them away and retrieves them when the need arises.

The respondent went on to say that in some instances where the space problem was acute, clients are served right inside the filing areas. This was corroborated by the researcher who observed that in two stations, clients had to wade through filing areas to access services because service counters could not accommodate all work stations and some were found right inside the filing areas.

One other respondent, R13 pointed out that in her station, the shelves and cabinets were not adequate and some of the records were placed on top of the shelves while some sensitive records could not be accommodated in the cabinets thus exposing the security of such records. The respondent also indicated that at the time of the study, cabinets were faulty and could not be locked thus threatening the security of the sensitive records that should be kept under lock and key as required.

In relation to security of the records, another question was posed concerning the extent of missing files in the judiciary and the respondents had different points of view. A respondent in the high court in Eldoret, Uasin Gishu County (R10) noted that the challenge of missing files was fairly common due to lack of space and especially so with 
the records that were heaped in some temporary storage without any arrangement as reported in section 5.4.3. In some stations however incidences of missing files were reported to have gone down drastically since the launch of the Judiciary Transformation Framework and the promulgation of the Kenyan Constitution 2010. For example R7 indicated that in one month five files could be reported as missing and in most cases due to misfiling. On the other hand a deputy registrar in one of the divisions of the high court in Nairobi County reported that at the time of the study, one file was missing and the staff were doing all they could to find the file. Lastly, another deputy registrar in yet another division of the high court in Nairobi County noted that in the last six months only one file was reported as missing. She further explained that before the promulgation of the Constitution 2010 and the launch of the Judiciary Transformation, the Kenyan judiciary had been marred by corrupt dealings where often the files were hidden and cases of missing files was rampant. This confirmed the observation made by Mutunga (2011) as he took office that "we found an institution so frail in its structures, so thin in resources, so low in its confidence, so deficient in integrity, so weak in public support that to expect it to deliver justice was wildly optimistic”.

On being asked how the Constitution 2010 and the transformation framework may have helped reduce cases of missing files a respondent (R2) had this to say:

...with the new constitution and the judiciary transformation, a new culture of doing business had been adopted characterized by public oversight;; accountability and transparency is now the norm rather than the exception and justice delivery has been taken to a new level.

This confirms a report by the judiciary (Republic of Kenya, the Judiciary, 2013) indicating that the most important investment from which the institution has arguably had the greatest return has been on culture change. According to the report, the culture change strategy was based on two important thrusts: improvement of staff welfare and attitude as a self-confidence building strategy and transformation from below for ownership and sustainability. As a result there has been an institutional cultural revolution including the establishment of customer care desks in each and every court station, a growing and 
effective public complaints system, a more widespread internal ownership of the transformation program and most significantly an important realization among staff that the judiciary is and should always be a public rather than self-service institution. With all these came great improvement in service delivery within the Kenyan judiciary including but not limited to a reduction of missing files.

For further insights into the issue of missing files, the judges and magistrates were asked in the questionnaire if they experienced missing files and how often in their court stations (question 2 (viii) Appendix 3). Their responses are indicated in the Figure 8.

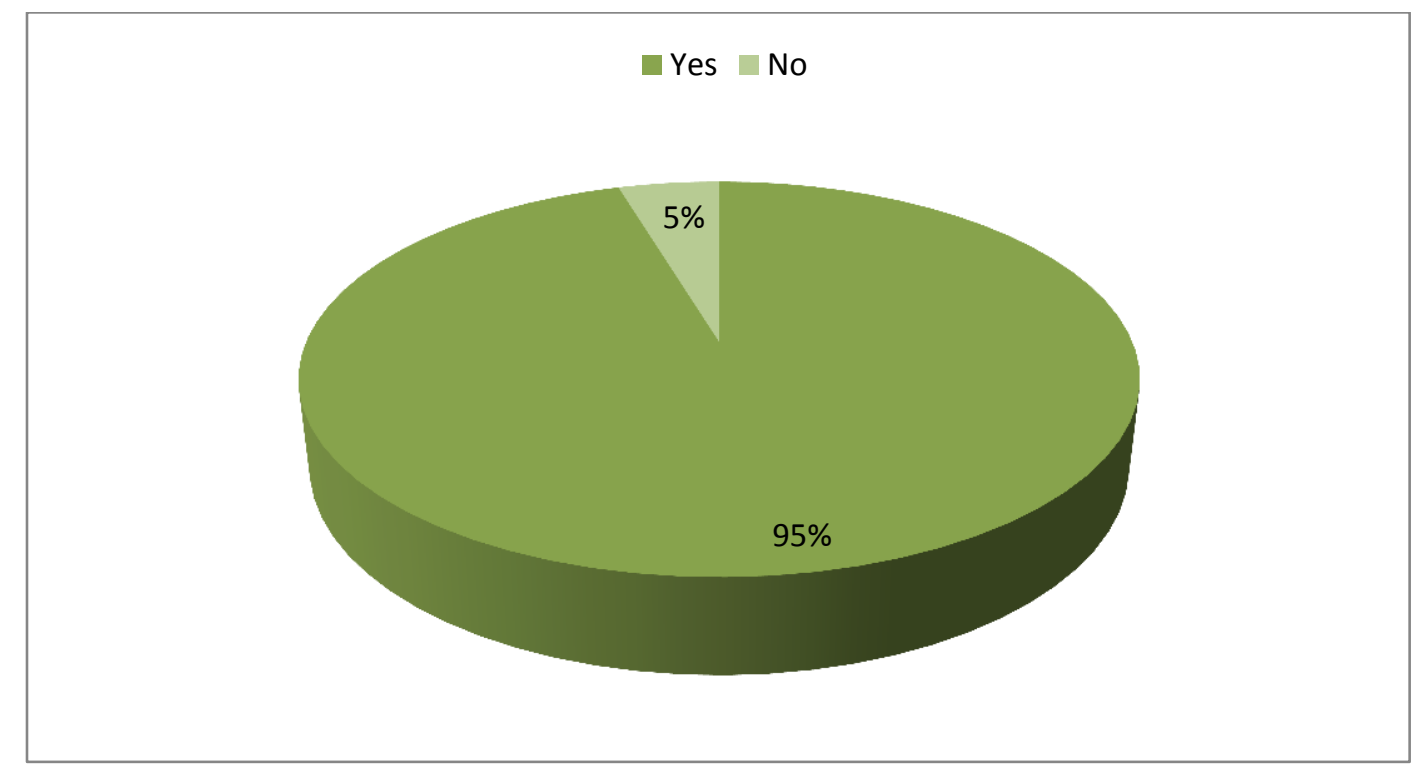

Figure 8: Missing files experiences $(\mathrm{N}=43)$

Source: Field Data (2014)

Figure 8 shows that 41 (95\%) of respondents experienced missing files in their court stations while only $2(5 \%)$ of respondents did not experience any instances of missing files.

Those respondents that indicated that they experienced missing files were asked to state the frequency of missing files and gave responses shown in Figure 9. 


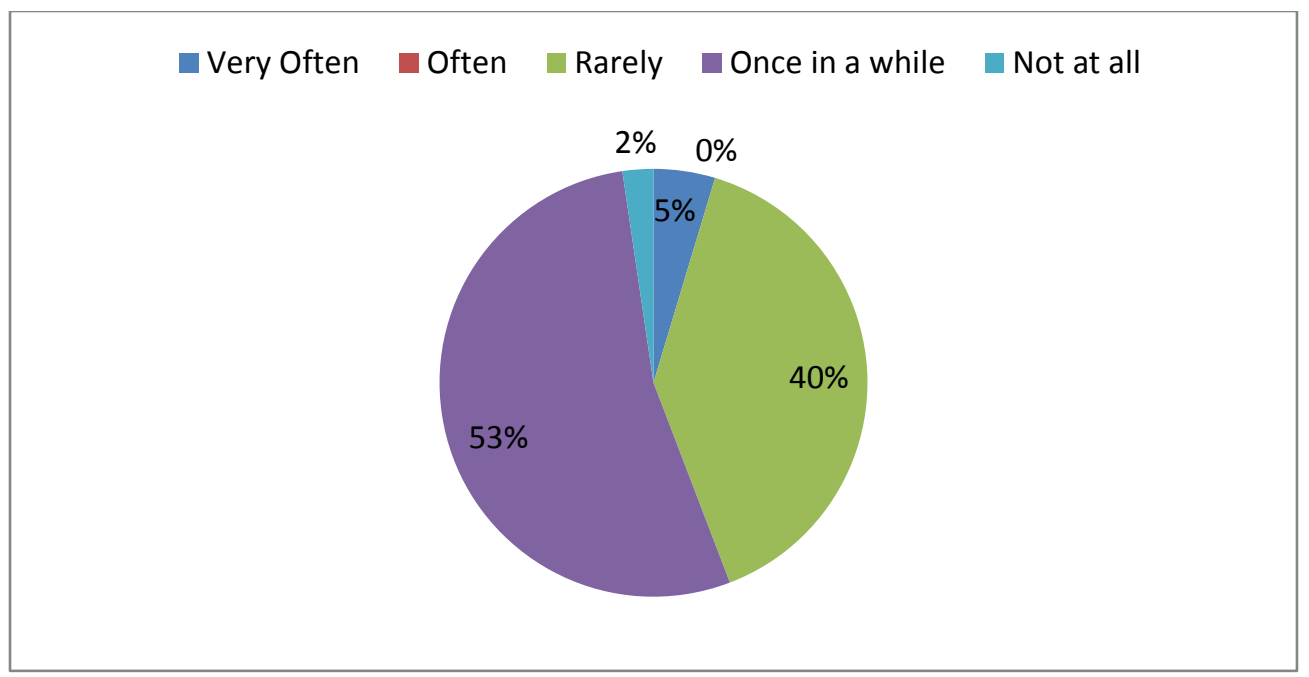

Figure 9: Frequency of Missing Files

Source: Field Data (2014)

Figure 9 shows that $23(53 \%)$ of respondents, indicated that they experienced missing files once in a while, $17(40 \%)$ of respondents experienced missing files rarely, 2 (5\%) experienced it very often, $1(2 \%)$ did not experienced it at all and no one indicated that they experienced missing files often.

Of those respondents that experienced missing files, they were further asked to indicate the factors they thought contributed to missing files. The results are reflected in Figure 10.

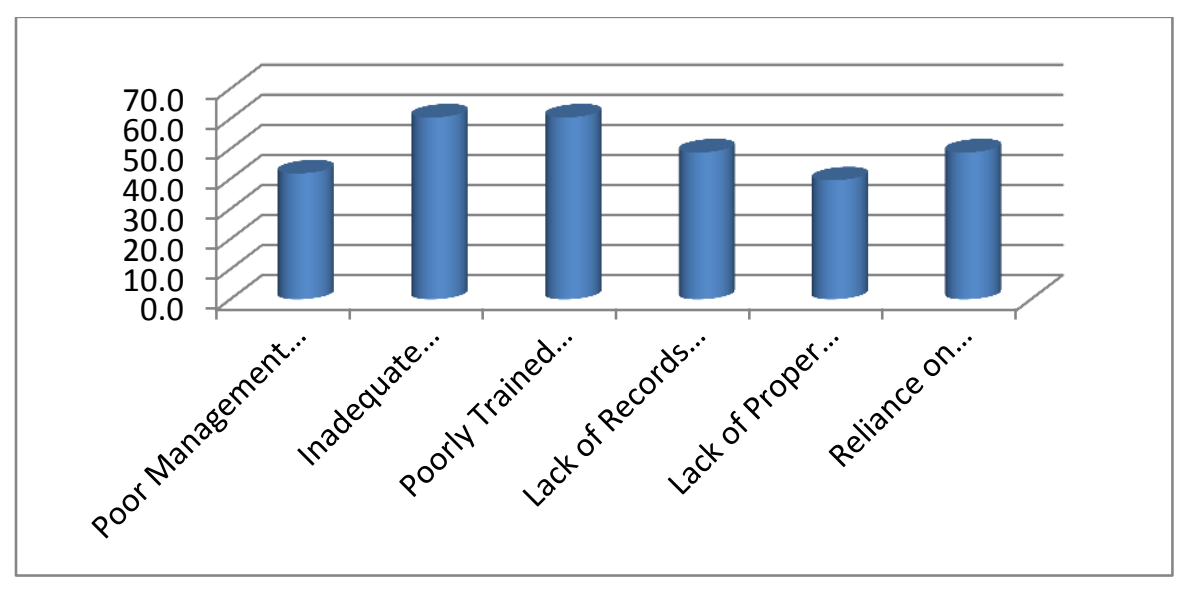

Figure 10: Factors Contributing to Missing Files 
Figure 10 shows $26(60.5 \%)$ respondents cited inadequate records management staff, another $26(60.5 \%)$ cited poorly trained records management staff, 21 (48.8\%) cited lack of policies and guidelines, another $21(48.8 \%)$ cited reliance on manual records management strategies, $18(41.9 \%)$ indicated poor management of records and 17 $(39.5 \%)$ suggested lack of proper storage equipment.

From the data presented, it seemed that records storage in the Kenyan judiciary experienced enormous challenges that if left unchecked would drastically affect service delivery and inhibit the on-going transformation and the move towards openness in the judiciary.

\subsubsection{Records Appraisal and Disposition}

Records and registry officers were asked if they had an appraisal programme. Most of the registry assistants seemed unaware of what appraisal is and when it is done. They reported that appraisal is in the docket of the archivist (records officers) and that they should respond to the question. The records officers on their part had varying responses on when records were appraised and whether an appraisal programme was in existence. The responses are shown in Table 7.

\section{Table 7: Programme for Records Appraisal}

\begin{tabular}{|l|l|}
\hline R12 & $\begin{array}{l}\text { "There is a programme for records appraisal and disposition where those files } \\
\text { that have been dismissed are destroyed as per the provision of Records } \\
\text { Disposal Act Cap } 14 \text { of the laws of Kenya while those found to have continuing } \\
\text { value are transferred to the Kenya National Archives (KNA). However, KNA is } \\
\text { currently experiencing space problems and these records are therefore boxed, } \\
\text { properly labeled and kept within the archives in the station" }\end{array}$ \\
\hline R13 & $\begin{array}{l}\text { "Appraisal and disposition is done once in a while especially when there is an } \\
\text { acute shortage of storage space. There is therefore no programme for records }\end{array}$ \\
\hline
\end{tabular}




\begin{tabular}{|l|l|}
\hline R14 & $\begin{array}{l}\text { "There is no programme for records appraisal and disposition, the last } \\
\text { appraisal exercise was done in } 2009 \text { and even then the records that were found } \\
\text { to have been dismissed were moved to some room away from the station and no } \\
\text { action was done on them and are still there to date". }\end{array}$ \\
\hline R15 & $\begin{array}{l}\text { "There is no programme for records appraisal and disposition and as far as I } \\
\text { can remember no appraisal and disposition has ever been done". } \\
\text { shortage of staff, there is a huge backlog of records that have not been } \\
\text { appraised; the station is currently appraising } 2006 \text { files. }\end{array}$ \\
\hline R25 & $\begin{array}{l}\text { "Appraisal is done though very rarely, provisions of Cap } 14 \text { are followed } \\
\text { though destroying civil records is an exception rather than the norm because of } \\
\text { the nature of these records". }\end{array}$ \\
\hline R38 & $\begin{array}{l}\text { Appraisal and disposition is rarely done. I am not aware of Cap } 14 \text { and its } \\
\text { provisions". }\end{array}$
\end{tabular}

Source: Field Data (2014)

Perhaps the state of records appraisal and disposition in the Kenyan judiciary can be summarized in the testimony of one senior records officer (R11) who had this to say:

Records appraisal and disposition is done at station level and it appears that irrespective of the importance of the exercise, it is done at the whims of the individual records officer in the station. There is therefore an enormous discrepancy of the state of records appraisal and disposition in the judiciary.

\subsection{Criteria for Records Disposal}

From the interviews with the concerned staff, the majority agreed that records disposal was based on provisions of the Disposal Act (Cap 14) of the Laws of Kenya as indicated in the above responses. For clarity, the researcher reviewed the Act and its provisions are summarized in Table 8 


\section{Table 8: Criteria for Records Disposal}

\begin{tabular}{|c|c|c|}
\hline No & Description of Records & $\begin{array}{l}\text { Period after which } \\
\text { the records may be } \\
\text { destroyed }\end{array}$ \\
\hline 1 & $\begin{array}{l}\text { All records rendered illegible or useless by climate, } \\
\text { insects, fire or water. }\end{array}$ & At once \\
\hline 2 & $\begin{array}{l}\text { Records in civil proceedings, other than those } \\
\text { relating to: } \\
\text { - title to immovable property } \\
\text { - Succession causes/inheritance/ right of heirship } \\
\text { - Constitutional and Human Rights issues } \\
\text { - Rights to water, air, way, light or other easement } \\
\text { - Custom of a tribe, community or locality. }\end{array}$ & $\begin{array}{l}12 \text { years from date of } \\
\text { judgment or final order. }\end{array}$ \\
\hline 3 & $\begin{array}{l}\text { Records in criminal proceedings where acquittal or } \\
\text { discharge has been ordered or fines only imposed, } \\
\text { orders for security made or sentences of } \\
\text { imprisonment not exceeding one (1) year passed } \\
\text { and where accused has been committed for trial } \\
\text { and complaints dismissed by a magistrate. }\end{array}$ & $\begin{array}{l}3 \text { Years from date of } \\
\text { judgment or final order. }\end{array}$ \\
\hline 4 & $\begin{array}{l}\text { - Police reports of death and Inquest records. } \\
\text { - Miscellaneous police reports. } \\
\text { - Reports of railway accidents }\end{array}$ & $\begin{array}{l}3 \text { Years from date of } \\
\text { preparation. }\end{array}$ \\
\hline 5 & Judicial returns from magistrates Courts & $\begin{array}{l}3 \text { Years from date of } \\
\text { preparation. }\end{array}$ \\
\hline 6 & $\begin{array}{l}\text { Books of accounts lodged in bankruptcy } \\
\text { proceedings where a discharge was granted }\end{array}$ & $\begin{array}{l}3 \text { Years from date of } \\
\text { discharge. }\end{array}$ \\
\hline 7 & $\begin{array}{l}\text { Miscellaneous correspondence regarding dates of } \\
\text { trial, service of summons, execution of warrants, } \\
\text { transfer of proceedings, attendance of witnesses } \\
\text { and related correspondence. }\end{array}$ & $\begin{array}{l}3 \text { Years from date of } \\
\text { correspondence. }\end{array}$ \\
\hline
\end{tabular}




\begin{tabular}{|l|l|l|}
\hline 8 & $\begin{array}{l}\text { Books of account and miscellaneous documents, } \\
\text { other than records relating to estates of deceased } \\
\text { persons which have been distributed and accounts } \\
\text { audited. }\end{array}$ & 3 Years from date of audit. \\
\hline 9 & $\begin{array}{l}\text { Books of account lodged in connection with } \\
\text { bankruptcy proceedings. }\end{array}$ & $\begin{array}{l}12 \text { Years from date of } \\
\text { adjudication. }\end{array}$ \\
\hline
\end{tabular}

(Source: Records Disposal Act, (Cap 14) Laws of Kenya)

During the interview it emerged that some of the provisions of the Act may require amendment since it requires the locking up of many files that should otherwise be disposed of through destruction. An example of such provision is the requirement that records in criminal proceedings can only be destroyed if imprisonment of the accused person does not exceed one year. One respondent (R11) explained it is a common practice to see petty offenders being imprisoned for three to five years and this means that their records cannot be destroyed as per the provision of the Act.

\subsection{Procedure for Disposal}

The researcher sought to establish the procedure followed in the disposal of records. The registry operations manual has a clear description of the procedure followed in records disposal as follows: Physical audit of case files is conducted after conclusion of the cases, to ascertain whether they qualify for disposal or permanent preservation as per the guidelines provided for by the Records Disposal Act; the audit is triggered by maintaining a bring- up register to be informed by the retention and disposal schedule maintained in the registry/archives; the case files identified for disposal are then listed. A draft gazette notice is then prepared for cases destined for disposal and submitted to the Chief Registrar or other designated officer to facilitate gazettement and publication; the archivist communicates to the responsible registry/court upon gazettement, the date of gazettement and gazette number of the intended destruction; on expiry of three months after gazettement, the court makes a request to the Hon. Chief Justice seeking authority to 
destroy the records, books or papers in respect of which the gazette notice was issued; and once authority is granted, the Archivist ensures that the disposal authority is communicated to the courts/ registries within twenty (24) hours.

Other procedures followed in records disposal are that:

- All records to be destroyed are burnt in the presence of a magistrate or deputy registrar or any other authorized officer. The said officer makes an entry in the court register in red the letter ' $\mathrm{D}$ " and the date of destruction against each case's particulars.

- In the interest of environmental conservation, authority to burn shall be sought from the National Environment Management Authority (NEMA).

- Upon destruction, the court or station submits a certificate of destruction.

- A register is maintained in the archives of all records destroyed as per the certificates of destruction submitted. The register shall contain particulars of the records disposed, the date of disposal authority granted by the Chief Justice, the date of destruction, and the date of the certificate of destruction.

To check whether this procedure was followed the records officers were asked to give their account of the procedure followed in disposing records and their account matched that outlined in the manual except for the fact that at the time of data collection, retention and disposal schedules were reportedly not in place contrary to point number two in the above procedure.

The data reveals a very clear procedure for records appraisal and disposition in the judiciary, however, the data also revealed that appraisal and disposition was not being properly done in all court stations. 


\subsubsection{Records Preservation}

The researcher asked how records were preserved in the judiciary. The respondents cited dusting and spraying that is done periodically in the storage areas as ways through which records were preserved. They were probed further as to whether there was any monitoring and control of environmental conditions done and they all responded negatively.

The observation checklist was useful in gathering data on the state of records preservation since much of this lent itself to observation. The researcher thus observed the following: because of congestion in storage areas, records in most court stations were dusty indicating that proper house-keeping was not being done; there was also no sign of temperature and relative humidity levels being monitored and / or controlled; in fact many of the archives were found in basements and air conditioning plants were conspicuously missing; light was also observed to pose possible threats to the records; because of storage challenges highlighted earlier, some of the files were kept on top of the shelves in close proximity to lighting equipment notably florescent tubes that are known to emit ultra violet rays harmful to records; the majority of the storage areas did not have curtains and/or blinders allowing direct sunlight in some areas to reach the files; and in one storage area, a water pipe was seen crossing the middle of the room adding to the list of preservation challenges.

However, in a magistrate's court in Eldoret, Uasin Gishu County, the observed scenario of preservation of records was different. In the containers serving as archives air conditioning plants were seen and working properly. This storage was free of dust showing that proper house-keeping was observed here. Additionally there were no files on shelf tops and florescent tubes had filters fitted. All windows in the archives and registries had curtains and blinders. 
Moreover, all the registries and storage areas in all court stations studied had fire extinguishers that were in good working condition at the time of the study. They were also reported to be serviced on regular basis.

\subsection{Preservation Policy}

The researcher sought to know if the judiciary had a preservation policy which would guide preservation practices in the judiciary ensuring implementation of standards and best practice in the preservation of court records. All respondents indicated that such a policy was not in existence. When asked what their opinion was if such a policy was to be formulated and implemented, both registry assistants and records officers had mixed feelings. Among those interviewed, 15 (60\%) felt that there was no need since they already knew what they are expected to do to preserve the records and even if the policy was to be provided it may not significantly change much the way preservation is currently done. However the remaining 10 (40\%) thought the policy would drastically change the practice of records preservation and was therefore a welcome idea.

From these responses, it would seem that the majority of the staff charged with the responsibility of preserving and ensuring security of records are not aware of the value a preservation policy.

\subsection{Disaster Planning and Preparedness}

As an aspect of preserving records, the respondents were asked if the judiciary had a disaster preparedness plan to provide a road map for disaster prevention, reaction and recovery. All the $25(100 \%)$ records officers and registry assistants indicated that the judiciary did not have a disaster preparedness plan. In connection with this, they were asked if they had a vital records management programme and they equally responded that they did not have such a programme. The absence of a disaster planning and preparedness together with the lack of a vital records management programme shows that 
in the event that a disaster strikes, the Kenyan judiciary is not prepared and may lose its records and resumption of its business operations may be impeded.

The data showed that, though there were elements of preservation of records in the judiciary, it would seem that much work still needs to be done. This would have an impact on continuous availability and accessibility of the records that are essentially paramount in judicial service delivery and by extension transformation and openness in the judiciary.

\subsubsection{E-records Management}

The literature reviewed revealed that the management of electronic records is rapidly taking center stage in most governments and government agencies since there is a wide spread adoption of ICTs in business transactions. To ascertain whether the judiciary managed electronic records, the respondents were asked if they had electronic records management systems. Some $40(87 \%)$ of the respondents indicated that they did not have any electronic records management system and in-fact the records created and managed are all in paper format.

However, 6 (13\%) indicated that they had an electronic records management system. Further probing showed that Eldoret Magistrate Court in Uasin Gishu benefited from an electronic legal case management system as part of the donation from USAID alluded to earlier. The registrars explained that this was introduced as a pilot to be rolled later to all court stations. The researcher asked to be shown on how the system worked and at the time of the study, the system was seen to be useful in managing basic information on the case files. The system could for example search for a file given its case number, name of the accused, date the case was filed, mention and / or hearing date of the case among other basic information. A clerical officer who had been trained (R36) on the use of the system explained that the capabilities of the system had not been fully utilized. The system had the potential of managing every aspect of a case including court proceedings which though created manually by a judge or magistrate presiding over a case could be 
scanned and uploaded onto the system. It would therefore seem that if the potential of the system was tapped, then it could be relied on to manage the records without having to refer to the manual files. A senior registrar (R2) intimated that plans were underway to upgrade the system and roll it out to all court networks in Kenya. Moreover it would seem that the infrastructure for managing e-records had been put in place since every registry visited had computers in readiness for the much waited computerization. The registrars interviewed explained that computerization had also been piloted at the Supreme Court which they said was a paperless court claims that could not be confirmed since the Supreme Court was out of the scope of this study. Another form of electronic system was encountered in another magistrate court in Nairobi County (Makadara Chief Magistrate Court). Here the registry staff developed an in-house system that was basically used as a catalog of all files created and maintained in the station. The system was able to give basic information as mentioned above and also used to track the movement of files from one user point to the other.

Moreover, literature reviewed showed that the high court in Nairobi County (Milimani High Court) had initiated a digitization project and a study by the International Records Management Trust based in London United Kingdom (IRMT, 2011) revealed that by October 2010, five million court records had been scanned. However it emerged from the interviews that the digitization exercise did not yield much fruit. The majority of the respondents did not know what happened with the scanned images while one of them candidly reported that the images of the scanned files were still with the Kenya ICT Board four years down the line.

To determine the attitude towards and the level of awareness of e-records management among the staff, the interviewees were asked if they thought managing e-records was essential in the judiciary. An overwhelming majority of the respondents opined that the need to manage e- records in the judiciary was long overdue. Their responses are encapsulated in the response of one of the registrars (R2) who had this to say: 
Managing e-records in the judiciary is long overdue. At the moment, almost all the court stations in this country are grappling with space problems and if the records were to be managed electronically then this challenge would be no more. Furthermore, although the issue of missing files has drastically reduced, electronic records management would offer a lasting solution. Moreover delays in justice delivery occasioned by among other things poor records management would greatly improve.

The judges and magistrates were also of the same opinion. One of the judges in suggesting the way forward indicated that there is need for urgent computerization of court records and ensuring that in each courtroom there is recording and transcribing equipment for live recording of proceedings. This he explained would improve delivery of justice and reduce corrupt and inept practices in the courtrooms.

From the data presented, other than pockets of electronic case files management, the judiciary seemed not to have embarked on a serious digitization of its records. However, the staff showed a positive attitude towards e-records management and also a commendable level of awareness of e-records management. However although the technological infrastructure seemed to have been developed to some extent, all the respondents $100 \%$ indicated that there was no policy yet on e-records management and the staff had not been trained to specifically manage e-records. This is most likely going to pose a challenge when the exercise is finally implemented.

\subsubsection{Overall State of Records Management in the Kenyan Judiciary}

The interviewees were asked to rate the overall state of records management in the judiciary. The majority of them felt that the records management function was fair with one of them, R2, explaining that compared to how the judiciary managed its records in the past, its current performance was indeed an improvement and a lot more improvement is underway. 
The judges and magistrates were also asked to rate the management of records and their responses are presented in Figure 11.

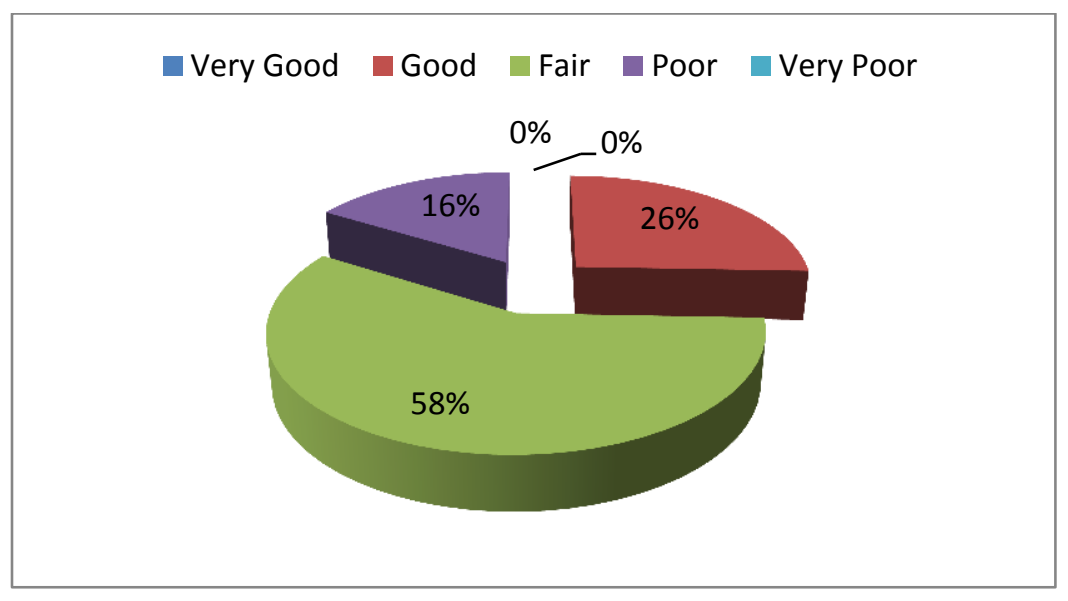

Figure 11: Records Management Rating by the Judges and Magistrates Source: Field Data (2014)

Figure 11 shows that $25(58 \%)$ of the respondents thought that records management in the judiciary was fair, $11(26 \%)$ thought it was good, 7(16\%) thought it was poor and no respondent indicated either very good or very poor.

They were also asked to indicate factors they thought contributed to the then state of records management and they gave multiple responses as shown in Figure 12.

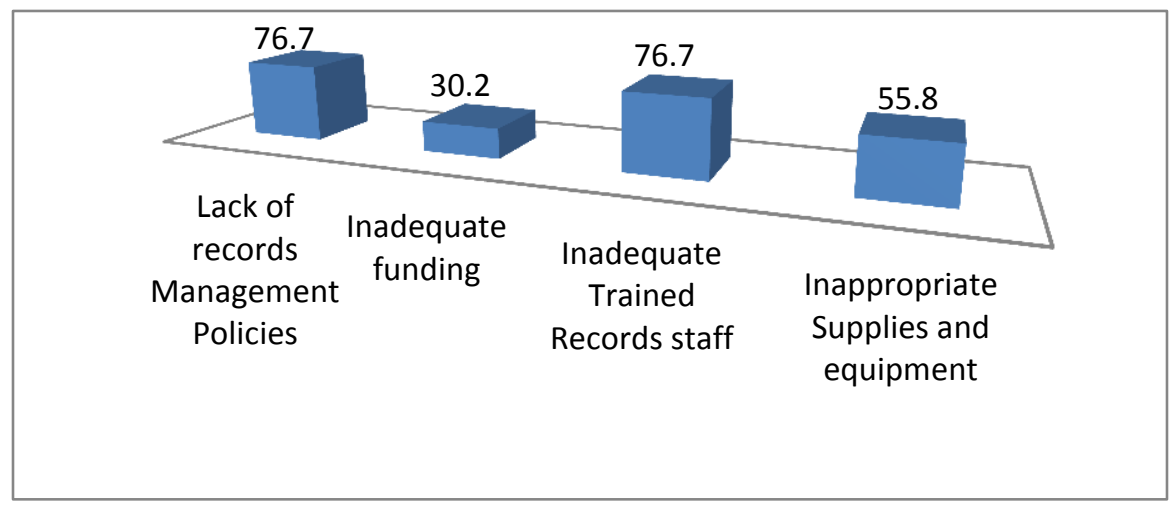

Figure 12: Reasons for the State of Records Management in the Kenyan Judiciary Source: Field Data (2014) 
Figure 12 above shows lack of records management policies and inadequately trained records staff as topping the list of explanations for the state of records management in the judiciary with $33(76.7 \%)$ respondents, followed closely by inappropriate supplies and equipment with $24(55.8 \%)$ respondent, and lastly inadequate funding with $13(30.2 \%)$ of respondents.

To establish the possible effect of the state of records management on delivery of justice in the Kenyan judiciary at the time of the study, the judges and magistrates were asked if they had case backlogs in their court stations and if so if they could indicate the possible reasons for the backlog. All the respondents [43 (100\%)] agreed that they had case backlogs and on being asked what reasons may have caused the backlogs, they gave multiple responses as shown in table 9.

\section{Table 9: Reasons for Case Backlogs in the Kenyan Judiciary}

\begin{tabular}{|l|r|r|}
\hline Reasons for backlogs & Frequency & Percentage \\
\hline Inadequate Judicial Staff & 41 & $95 \%$ \\
Inadequate Records Staff & 20 & $47 \%$ \\
Poor Records management & 16 & $37 \%$ \\
Corruption in the Judiciary & 1 & $2 \%$ \\
Inadequate Tools and Equipment & 9 & $21 \%$ \\
Inadequate Use of ICT & 23 & $54 \%$ \\
& & \\
\hline
\end{tabular}

Source: Field Data (2014)

Table 9 shows that an overwhelming 41 (95\%) of the respondents attributed the case backlogs to inadequate judicial staff. Some 23 (54\%) indicated inadequate use of ICT as the cause for the backlogs, while 20 (47\%) indicated inadequate records staff, a further 16 (37\%) indicated poor records management. A few respondents nine $(21 \%)$ and one $(2 \%)$ indicated inadequate use of ICT and corruption in the judiciary respectively. 
For further clarification, the registrars and deputy registrars were asked during the interviews if records management contributed in a way to case backlogs in the Kenyan judiciary. They all agreed that to some extent records management contributed to the case backlogs. One of the registrars R2 explained that:

...case backlog is a global issue; there are many reasons for these backlogs ranging from inadequate human resource to infrastructure development. However, records management also contributes to these backlogs since being a back office it should support the front office in order to ensure smooth service delivery. In instances where records management face a lot of challenges ranging from space, lack of policies to inadequate trained personnel its support to the front office suffers and such issues as backlog may arise.

The responses from the judges and the magistrates supported by the testimony of the registrars indicate that records management contributes to case backlogs in the Kenyan judiciary.

\subsubsection{E-records Readiness in the Judiciary}

The second theory underpinning the study was the IRMT E-readiness Tool that provides a mechanism for testing e-readiness in governments and government agencies especially in developing countries. The researcher believed that a measure of e-readiness would be a key indicator for open government readiness which is part of the subject of this study.

The variables normally used to test institutional e-readiness espoused by the IRMT Ereadiness tool include but are not limited to: the existence of policies; skills and competencies; and awareness and attitude of staff towards records management. Research questions two, three and four covered these aspects of the study and the results are presented below in sections 5.3.2.1 to 5.3.2.3. 


\subsubsection{Existing Records Management Policies, Plans and Guidelines}

A records management policy is a cornerstone for effective management of records in an institution as it provides statements of intention that underpin a records management programme. Research question 2 sought to establish the existence of records management policies, plans and guidelines in the Kenyan judiciary. Questions 8 (i) to 8 (vii) of the interview schedule for records staff and questions 3 (i) to 3 (vii) of the interview schedule for registrars and executive officers addressed this research question. Document review also provided useful insights that complimented the data from the interviews.

The two (100\%) registrars interviewed and all the eight (100\%) deputy registrars noted regretfully that there was no records management policy in place in the judiciary. However, of the 11 executive officers interviewed, two (18\%) reported that the judiciary had a records management policy while the remaining nine $(82 \%)$ thought that the judiciary did not have a records management policy. On the other hand, all the nine (100\%) records officers indicated that there was no policy in place while $10(63 \%)$ of the registry assistance also agreed that there was no policy and the remaining six (37\%) were of a contrary opinion.

Those respondents that indicated that the judiciary had a records management policy were probed further and asked to identify the type of policy in place. They all explained that since each staff handling court records at whatever point knew what is expected of him / her means that there was a policy in place albeit being verbal in nature. It became evident to the researcher that these staff may not have had knowledge on records management policies.

On being asked whether there were any plans and /or guidelines for records management in place, they gave mixed responses. The registrars, deputy registrars and a senior records officer indicated that a high court registry operations manual had just been launched and that they had been tasked with the responsibility of drafting the manual. The rest of the respondents had however not been sensitized on the availability of the manual as 
explained earlier. They therefore responded that there was nothing in the form of instructions, guidelines or regulations for records management in the Kenyan judiciary. Those that were involved in drafting the manual (registrars, deputy registrars and a senior records officer) explained that their next phase was to sensitize the staff on the availability and use of the manual. They were also to formulate a records management policy as a matter of urgency since they rightly felt that the manual should be anchored on a policy platform.

\subsection{Judiciary Strategic Management Plan}

For more insights into the policies, plans and guidelines, the two registrars and eight deputy registrars interviewed were asked as to whether records management function formed part of the judiciary strategic management plan. This was because they were perceived to be well informed on overall policy matters in the judiciary given their positions. The two registrars and six deputy registrars indicated that records management being a key functional area in the judiciary formed part of the strategic management plan. Two deputy registrars were however not sure whether records management featured in the strategic plan.

Of those respondents that responded positively they were asked to indicate plans for records management in the next five years. They all indicated that it is envisaged in the plan that records should be fully digitized by the end of five years beginning 2012. In addition, court rooms should also be digitized by installing stenographers and recorders so that records could be captured in soft copies straight from the court rooms.

With regard to strategic management planning, the researcher also asked whether records management was integrated in the Judiciary Transformation Framework being a blue print for transformation and this elicited varying opinions. Half of those interviewed thought that records management was integrated in the framework while the other half thought that it was not directly integrated into the framework. 
The respondents who felt that records management was integrated in the JTF explained that there was no way the judiciary could be transformed if records management function was ignored. To them records management played a pivotal role in the transformation process since successful delivery of justice depends entirely on the records. They identified two transformation pillars which to them had a lot to do with how records are managed: people focus delivery of justice; and ICT as an enabler of judicial services. However, the other half of the respondents explained that they did not find a direct mention of records management in the JTF. For clarification, the researcher reviewed the JTF document and although it became obvious to the researcher that there was actually no direct mention of records management, the two pillars identified by the respondents seemed to have had a lot to do with records management in the judiciary. Apart from the operation manual, it would seem that the judiciary did not have any policies regulating records management. It however had plans that are to be implemented in the next five years which would improve records management for enhanced transformation and openness of the judiciary in Kenya.

\subsubsection{Skills and Competencies}

Proper management of records would require staff that are trained in records management field either at a certificate, diploma or degree level. This group of people should be charged with the responsibility of managing active records in registries where the bulk of records creation, maintenance access and storage is done and also be responsible for managing semi-current and non-current records in the archives. Research question 3 sought to find out if the Kenyan judiciary had the right skills and competencies required for the management of court records. Questions 9 (i) - 9 (iv) of the interview schedule for records staff (Appendix 1) and questions 4 (i) - 4 (vii) of the interview schedule for registrars and executive officers (Appendix 2) addressed this research question.

The interviews revealed that in both Nairobi and Uasin Gishu counties, there were 13 officers trained in records management at different levels. At the time of the study three of these officers were pursuing degree courses in records management at Masters Level 
while four were at Bachelors level. Of these officers only one was stationed in Uasin Gishu County while the remaining 12 served the seven divisions of the high court and five stations of magistrate courts in Nairobi County. At the time of the study two of these officers were said to be due for retirement in two months' time without any replacement in sight.

The records officers were asked whether the judiciary organized their training and only one agreed that she was facilitated to do a certificate course in records management while the majority indicated that they took the training on their own initiative and were selfsponsored.

The deputy registrars and executive officers manning the stations were asked if records officers in their stations were adequate in number and all (100\%) expressed dissatisfaction with the adequacy of the staff.

Moreover, it emerged from the interviews that the trained staff were designated as archivists and posted to secondary storage areas while registries were left to be manned by untrained staff who were either executive assistants or clerical officers. Among this group of staff, those who had some training were trained in other fields such as human resource or public relations. These officers were therefore expected to train on the job. One of the respondents (R2) had this to say "...due diligence has not been shown in engaging skilled staff, and those who have taken their own initiative to train have not been deployed adequately". The effect of this was evident during the interviews when the "archivists" expressed a lot of dissatisfaction in their current posts since they felt they should be allowed to run the registries so that there is proper management of records right from their creation to disposition.

To shed more light the records officers and the registry assistants were asked if they would be supported in order to attend records management conferences and workshops by the judiciary as a way of developing their career. The responses from a few of them are summarized in Table 10. 


\section{Table 10: Responses on Facilitation to Attend Conferences and Workshops}

\begin{tabular}{|l|l|}
\hline R13 & $\begin{array}{l}\text { "I have never been facilitated to attend a conference or a workshop and I'm not } \\
\text { even sure if such facilitation exist" }\end{array}$ \\
\hline R15 & $\begin{array}{l}\text { "I was facilitated to attend a two week training and I believe if one asked for } \\
\text { facilitation to attend any conference he/she would be facilitated" }\end{array}$ \\
\hline R31 & $\begin{array}{l}\text { "No I have never been facilitated by the judiciary to attend any conference, I } \\
\text { with favouritism". }\end{array}$ \\
\hline R35 & $\begin{array}{l}\text { "I have not heard any one being facilitated to attend any conference or } \\
\text { workshop; I think such facilitation does not exist". }\end{array}$ \\
\hline
\end{tabular}

Source: Field Data (2014)

Further, the registrars were asked if the judiciary had a training policy and whether continuous training was in operation in the judiciary. All the respondents $(100 \%)$ indicated that the judiciary did not have a training policy as such, but its training needs were taken care of by the judiciary Training Institute. It emerged from the interviews that the institute had developed modules incorporating all aspects of the judiciary functions. It was reported that records management had recently been incorporated into the modules which were to be offered in the near future. The inclusivity of records management could not however be verified since the Institute was not part of the scope of the current study.

The data presented indicates that the judiciary had inadequate number of staff trained in records management. The few who had some training, it would seem took their own initiatives in getting trained. However these trained personnel were wrongly designated and placed in the periphery of records management. The findings further shows that the staff was seldom facilitated to attend conferences and workshops on records management though it emerged that the Judiciary Training Institute was soon taking over records management training needs for the staff. 


\subsubsection{Level of Awareness about Records and Attitude of Staff towards Sound Records Management}

The level of awareness and attitude of staff towards records management is another important measure of e-records readiness in an institution and by extension a measure of open government readiness. Research question 4 sought to find out the level of awareness of staff about records and their attitude towards sound records management. Questions 10 (i) - 10 (iv) of the interview schedule for records staff (Appendix 1), questions 5 (i) - 5 (iv) of the interview schedule for registrars and executive officers (Appendix 2) and question 3 of the questionnaire for judges and magistrates (Appendix 3) addressed this research question.

In order to establish the level of awareness of top management about records and their attitude towards sound records management, the records officers and registry assistants were asked how much support in terms of finances and infrastructure development they received from top management. More than half indicated that they received minimal support and they all justified the claim by showing the almost non-existent level of training support they received from the judiciary. Those that were of a contrary opinion thought that since the launch of JTF the management had started to show great support for records management. This they said was seen by their willingness to put together a task force to prepare a records management manual which will facilitate the reengineering of registry operations. They also indicated that records management had been made one of the modules in the induction workshops at Judiciary Training Institute thus further indicating support and appreciation of records management by top management in the judiciary.

To probe further on the top management support, the deputy registrars being the administrative officers at station level in the high court were asked if they were aware of any budgetary allocation for records management function in their stations. Their responses indicated that there was no allocation for records management as a function but activities were funded through the general station allocation. To further scrutinize the 
attitude towards records management, the researcher asked the two registrars interviewed and the eight deputy registrars where records management function was placed on the general judiciary organogram. This elicited mixed reactions with more than half of those interviewed responding that they were not sure where records management was placed. Those that gave some response had different opinions; one of the registrars (R1) had this to say:

...at the moment, the judiciary does not have a proper organogram and it is not clear what falls where. We are however working on a proper organogram and records management is going to definitely feature prominently.

Another registrar (R2) said this:

Currently, it is not clear who is in charge of records management as a function since unlike other functional areas it does not have a directorate. It is however assumed that it falls under the office of the Chief Registrar but this will be made clear when the organogram that we are working on is completed which will also assign records management a directorate.

The data indicated that although the top management appreciated the role of records and records management at the time of the study the records management function had not been accorded the importance it deserved and a lot more required to be done.

To shed more light on the awareness and attitude of staff towards records management, magistrates and judges were asked in the questionnaire what value they placed on sound records management as a key component of the administration of justice. Their responses are indicated in the figure 13 . 


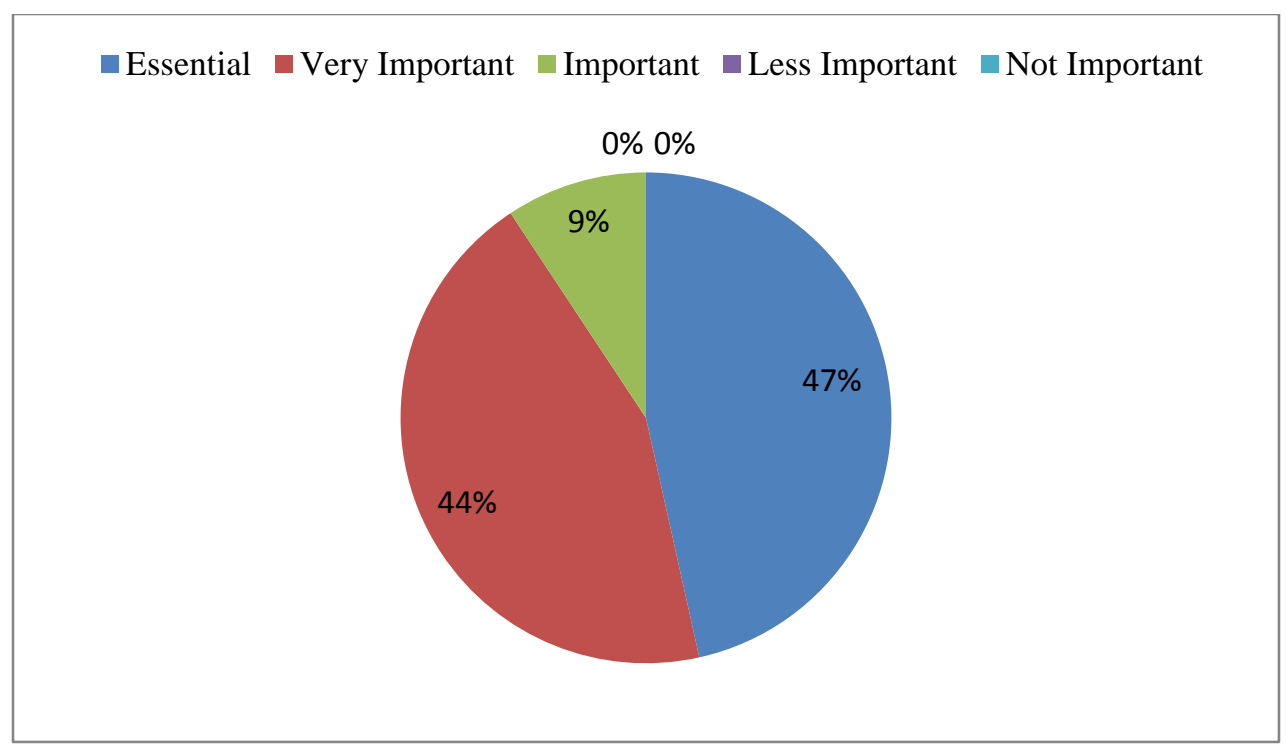

Figure 13: Value of Records Management in the Administration of Justice Source: Field Data (2014)

Figure 13 indicates that $20(47 \%)$ respondents opined that records management was essential in the administration of justice, 19 (44\%) indicated that it was very important while only four (9\%) indicated important. On the other hand none of the respondents indicated less important or not important. This indicates that the judges and magistrates valued records as a major component in justice administration.

The value of records management in the administration of justice could be summarized through the testimony of one registrar (R2).

Records management plays a critical role in delivery of justice since the driving force of justice delivery is anchored on proper records management. In-deed, sound records management is indispensable in the courts and its platform should be flagged as a first line of management in any justice system.

From the data presented, the staff especially the judicial officers in the Kenyan judiciary valued records as an important component of the administration of justice. However, 
records management function had not received 100\% support from the top management and this explains the status of records management at the time of the study.

\subsubsection{Status of E-Government in the Kenyan Judiciary}

E-government can be defined as the use of ICT by the public sector in order to improve information and service delivery, encourage citizen participation in decision making processes and make government more accountable, transparent and efficient (UNESCO, 2004). From the definition, the researcher observed that e-government espouses the ideals of an open government which are: transparency, participation and collaboration. It therefore became necessary for the study to establish the current state of e-government in the judiciary before looking at open government initiatives.

Consequently, the registrars were asked in the interviews to indicate whether they thought the judiciary was ready to operate an e-government (see Appendix 2 question 6 (i)). All the eight (100\%) registrars interviewed indicated that the judiciary had all it takes to operate an e-government. They explained that the infrastructure for e-government had been developed since almost every judicial officer and every office had a computer with internet connectivity though the registries were still ill equipped. In furtherance to this they said all other administrative functions are done electronically and gave examples of memos and pay-slips which were being delivered electronically. However, they indicated that the court records (case files) which unfortunately are key to the administration of justice were still being created and maintained manually bringing about great inefficiencies and ineffectiveness in service delivery. One of the registrars (R3) explained the scenario as follows:

The judiciary is more than ready to operate an e-government and all preparations have been done. The JTF for instance has very brilliant ideas on the way forward much of which is about digitizing every aspect of judiciary operations including the management of the records. In fact, the CJ is very passionate about going 
electronic but unfortunately two years down the line very little has been done towards implementing the plans.

Another registrar (R4) explained that it is true that the judiciary was ready to operate an e-government but was wary about the fact that many of the litigants were illiterate or semi-literate let alone having access to the internet. The respondent further noted that sometimes the nature of cases handled was very sensitive and so its security in an egovernment environment will need to be guaranteed before full implementation of egovernment. The respondent gave examples of cases related to family and children which under normal circumstance are classified as closed records. The respondent therefore did not see the possibility of the judiciary going completely electronic in the near future unless the obvious challenges are addressed.

For more insights into this, the judges and magistrates were also asked in the questionnaire whether they thought the judiciary was ready to operate an e-government. Their response was not any different from those of the registrars. The 43 (100\%) judges and magistrates all agreed that the judiciary was ready to operate an e-government. An open ended question was posed asking them to explain their answers and few of their responses are shown in Table 11: 
Table 11: Questionnaire Response on the Judiciary E-government Readiness

\begin{tabular}{|c|c|}
\hline Respondent & Response \\
\hline Q 37 & $\begin{array}{l}\text { JTF envisages the use of ICT platform in every aspect of the judiciary } \\
\text { and the infrastructure for it is being laid. }\end{array}$ \\
\hline Q7 & $\begin{array}{l}\text { Almost every judicial officer is now provided with a laptop hence if } \\
\text { adequate equipment can be provided to all the registries then we are } \\
\text { good to go. }\end{array}$ \\
\hline Q 11 & We are harnessing technology as an enabler for justice. \\
\hline Q 1 & $\begin{array}{l}\text { This is already happening, however, the practice is not widespread but } \\
\text { the infrastructure is in place. }\end{array}$ \\
\hline Q 6 & $\begin{array}{l}\text { The desire and need is openly appreciated but poor planning and } \\
\text { prioritization has failed its implementation }\end{array}$ \\
\hline
\end{tabular}

Source: Field Data (2014)

From both the responses of the registrars and the judges and magistrates, it became apparent that the judiciary was ready for e-government but its implementation was derailed by many factors which included: poor planning; poor prioritization; inadequate equipment in the registries; ICT office moving in a slow pace; insufficient trained staff in the registries; and insufficient funding.

\subsubsection{Records Related Strategies Used to Achieve Openness}

The third model underpinning the study was the Open Government Implementation Model (OGIM) which recommends a step by step implementation process for an open government initiative. The variables of the OGIM addressed by the study include: data transparency; public participation; collaboration and engagement. To ascertain the level of openness in the judiciary, research question 5 sought to find out the records related strategies used by the judiciary to achieve openness. Questions 11 (i) - 11 (viii) of the 
interview schedule for records staff (Appendix 1), questions 6 (i) - 6 (ix) of the interview schedule for the registrars and executive officers (Appendix 2) and questions 4 (i) - 4 (vi) of the questionnaire for judges and magistrates (appendix 3) covered the research question.

In order to understand how the judiciary was becoming more available to the public, and possibly the level at which the openness had been implemented, the researcher asked those interviewed to indicate the strategies that were being used to open up access. All the respondents pointed out that the judiciary website was a key tool used to increase access to the public. One of the respondents (R11) explained that the cause lists and summaries of cases of public interest are often posted on the website. Other strategies mentioned were e-mail service, judiciary open days, court users committees and short message service (SMS) where one respondent (R11) explained that members of the public could communicate with the judiciary through a number (20583) in one of the common mobile networks service provider (Safaricom).

This response is complemented by data from a document reviewed (The Republic of Kenya, the Judiciary, 2013) which identified several channels used to publish information to guide the public on how to access and use court services. These include: the use of website; production of television documentaries; publication of reports; notices and posters as well as leaflets and brochures. The report indicated that the judiciary's website had continued to be an important source of news as well as useful information for many people as it provided a search driven access to information, services, directories and mobile applications. According to the report, summaries of cases of public interest and cause lists from courts were published on the website. The website had also become a repository of policy, official speeches, and general regulations. Additionally, the report identified social media (particularly Facebook) as a platform where court users interact with officers and a medium to post adjournment notices. 
The judges and magistrates were also asked in the questionnaires to indicate the strategies they thought the judiciary was using to open up to the public and they gave multiple responses as shown in Figure 14.

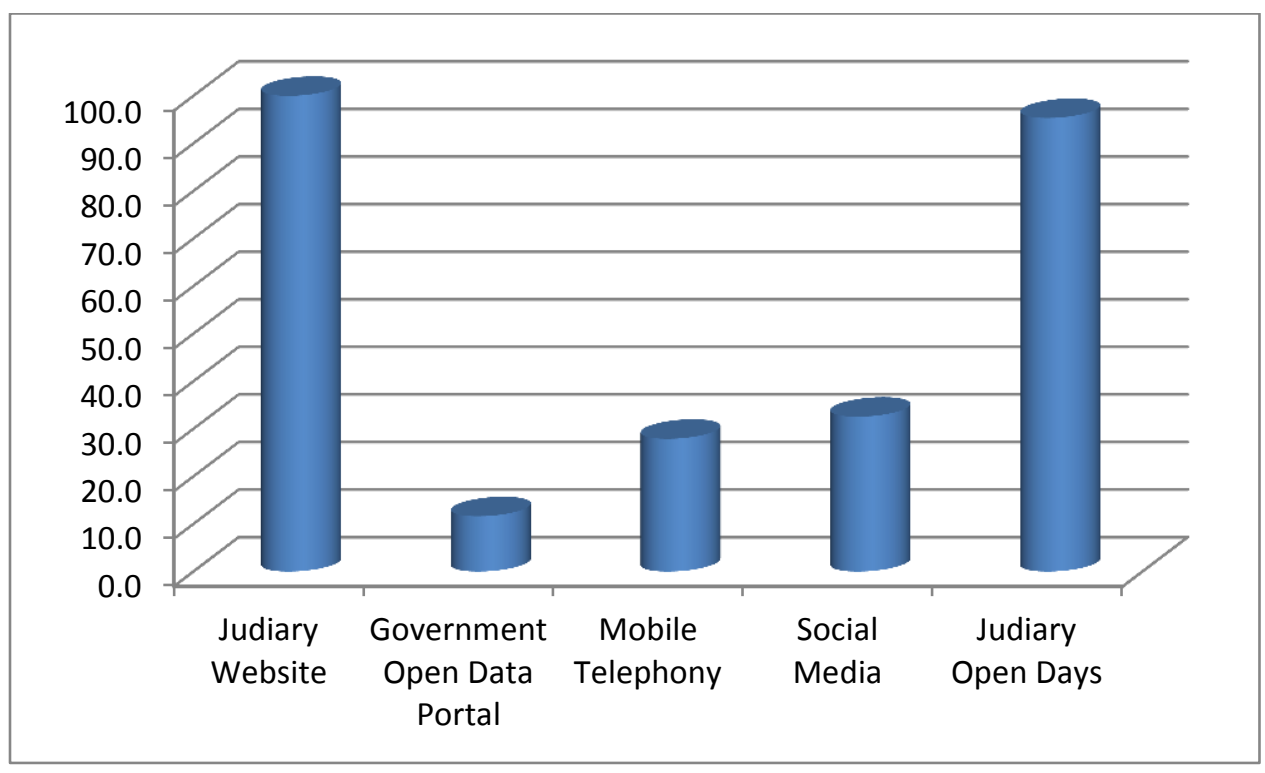

Figure 14: Strategies Used to Open up to the Public

Source: Field Data (2014)

Figure 14 shows that the most commonly used strategy for openness was the judiciary website and judiciary Open Days with 43 (100\%) and 41 (95.3\%) respondents respectively. Other measures given were social media with 14 (32.6\%) respondents, mobile telephony with $12(27.9 \%)$ and government open data portal with 5(11.6\%) respondents.

From the above it seemed that the judiciary engaged members of the public through its official web site and open days and in some cases would make use of social media, mobile telephony and government open data portal. 


\subsubsection{Level of Openness}

To establish the extent / level of openness in the judiciary, the registrars were asked to indicate how they thought the judiciary had benefited from implementing the open government initiative. This elicited several responses as shown in table 12.

\section{Table 12: Benefits of Opening Up}

\begin{tabular}{|l|l|}
\hline Respondent & \begin{tabular}{l} 
Response \\
\hline R4
\end{tabular} \\
$\begin{array}{l}\text { Opening up of the judiciary to the public is a result of JTF pillar on } \\
\text { public and stakeholder engagement which has brought about far } \\
\text { reaching benefits. There has been improved transparency and } \\
\text { accountability and generally the delivery of justice has drastically } \\
\text { improved }\end{array}$ \\
\hline R7 & $\begin{array}{l}\text { Openness has brought about public oversight which has changed the } \\
\text { institutional culture in the judiciary. The judiciary is now friendlier than } \\
\text { it was before and the judiciary now has a new face. There is more } \\
\text { transparency and accountability which has subsequently improved } \\
\text { justice delivery }\end{array}$ \\
\hline R8 & $\begin{array}{l}\text { There has been a change of attitude among the staff and judicial officers } \\
\text { which has contributed to a reduction of case backlogs and a reduction of } \\
\text { missing files. Since the media is allowed in court rooms in some cases, } \\
\text { transparency has gone up. Generally there has been an improvement in } \\
\text { service delivery. }\end{array}$ \\
\hline
\end{tabular}

Source: Field Data (2014)

The judges and magistrates were also asked to indicate the benefits of opening up the judiciary and their responses are summarized in figure 15 . 


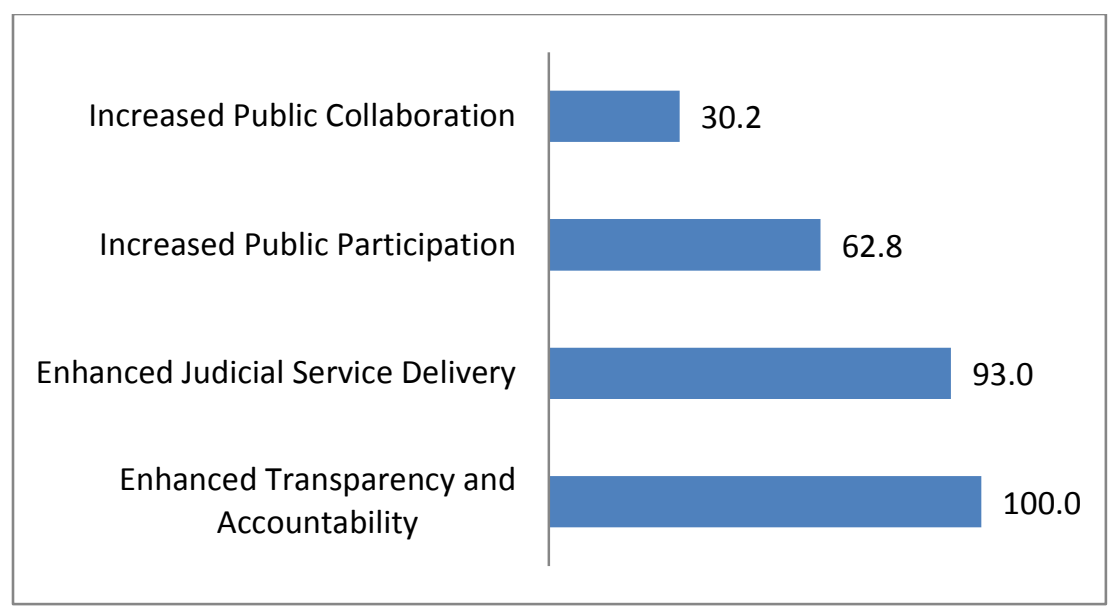

Figure 15: Benefits of Opening up the Judiciary

Source: Field Data (2014)

Figure 15 shows that all the 43 (100\%) judges and magistrates felt that openness in the judiciary has brought about enhanced transparency and accountability. A significant number (40 (93\%)) indicated enhanced judicial service delivery whereas slightly more than half (27 (62.8)) indicated increased public participation. Lastly a few (13(30.2\%)) felt that openness has also brought about increased public collaboration.

Perhaps, the benefits of increasing access to / openning up the judiciary can be summarized by the response of one registrar (R1) who said:

Openning up the judiciary has introduced a new culture of doing business, transparency and accountability has been raised and justice delivery has been taken to a new level. Judicial officers and staff have traditionally maintained distance in an attempt to communicate impartially. This posture had limited public access to information and created unnecessary mysticism which fed a negative public perception of the justice system in Kenya. With the move towards openness, the judiciary has adopted deliberate innovations that provide information to the public and receive feedback as well as position itself as an important partiticipant in the public arena by opening itself up to scrutiny through continous public, stakeholder and media engagement. 
The data presented in this section indicates that the Kenyan judiciary is in its initial stages in implementing its open government initiative. Much of the activities are geared towards increasing transparency which is a basic requirement for openness.

\subsubsection{Challenges Faced by the Judiciary as it Transforms Itself and Move towards Openness}

A question was asked regarding records management related challenges that the judiciary faced as it tried to transform itself and move towards openness. The majority of the respondents interviewed indicated lack of trained personnel especially among the paralegal staff where the records officers fell, lack of records management policies and guidelines, inadequate tools and equipment, inadequate storage space and equipment, and general lack of resources.

The judges and magistrates were also asked to indicate the challenges they faced as they discharged their duties and they gave the following as reflected in Figure 16.

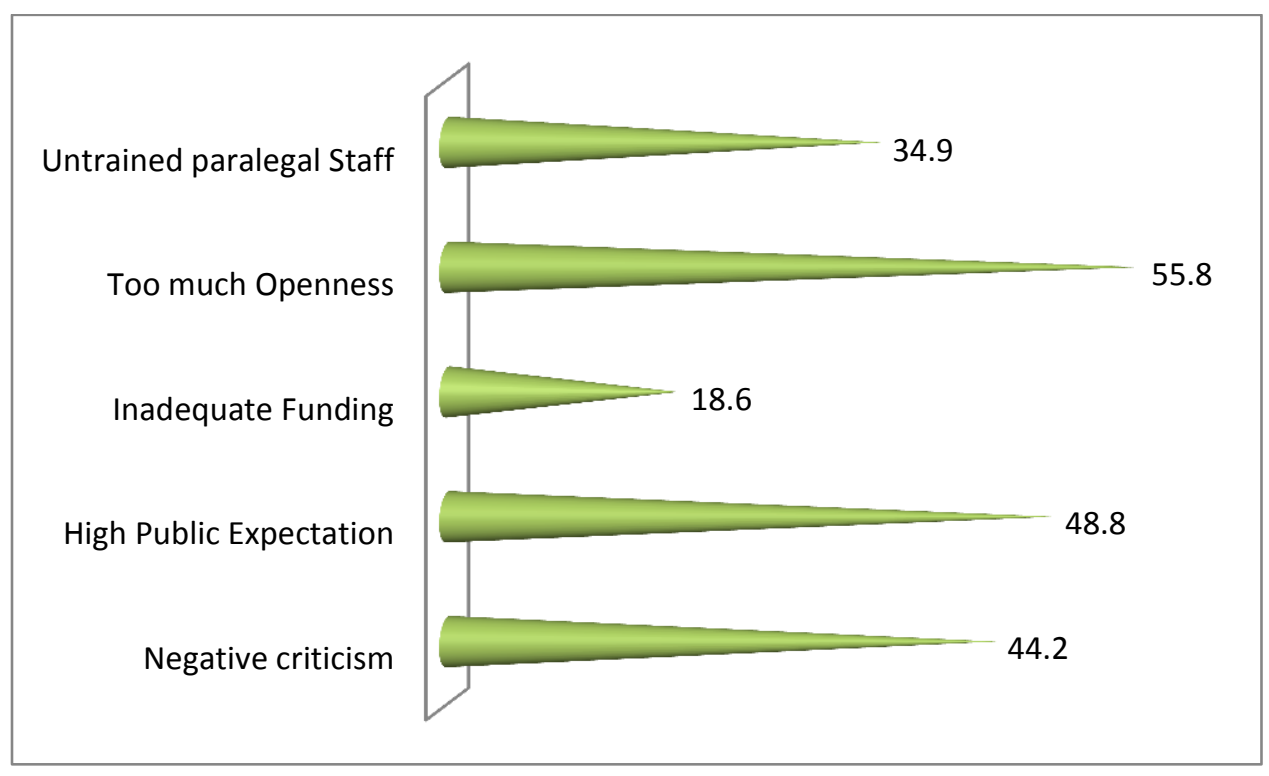

Figure 16: Challenges Facing the Judiciary

Source: Field Data (2014) 
Figure 16 indicates too much openness as a major challenge facing the judiciary which as explained by one judge in an open ended question, had drastically increased litigants contributing to backlogs in the courts. Other challenges cited by the judges and magistrates were high public expectations 21 (48.8\%), negative criticism 19 (44.2\%), untrained paralegal staff 15 (34.9\%) and inadequate funding eight (18.6\%). Of the challenges cited by the judges and magistrates, untrained paralegal staff is a records management related challenge since records staff fall in this category of staff.

\subsubsection{Possible Solutions to Records and Archives Management Related Challenges Facing the Kenyan Judiciary}

Following the cited challenges, the respondents were asked to suggest what they felt could be done to alleviate the situation. Those respondents interviewed proposed the following solutions: capacity building; infrastructure development; records management policy formulation; providing refresher courses to the staff handling records; hiring more trained records officers; computerizing the registries and the management of records in general; providing recording equipment in all court rooms; raising more awareness on the importance of records and records management in the justice chain; and hiring or constructing go downs in every region where the entire semi active and none active files in the region would be stored. The judges and magistrates also proposed several solutions as shown in figure 17.

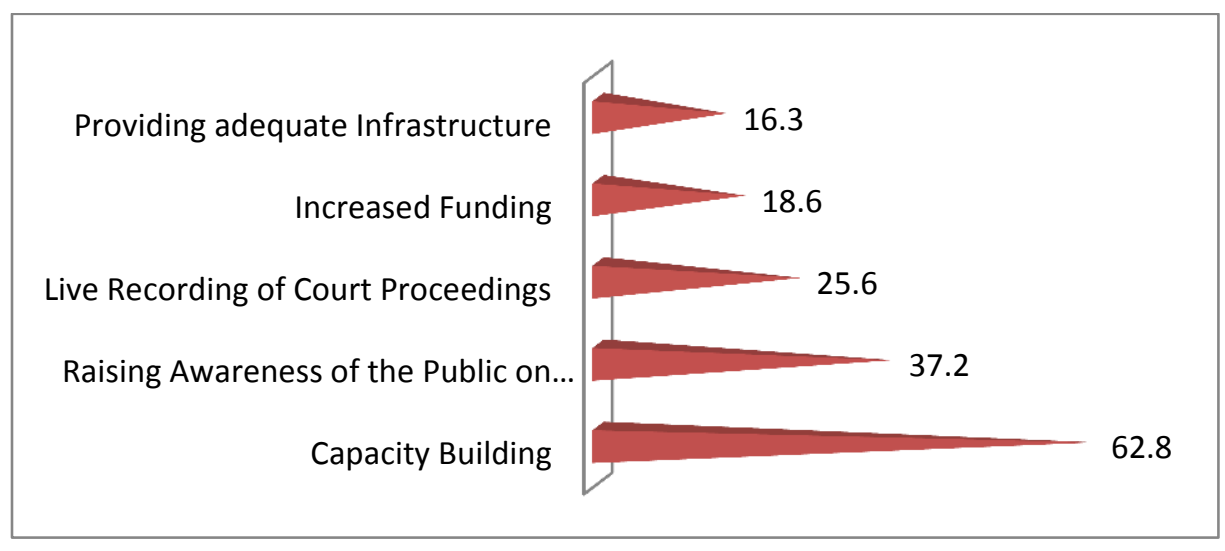

Figure 17: Possible Solutions to the Challenges

Source: Field Data (2014) 
Figure 17 shows that $27(62.8 \%)$ of the respondents indicated capacity building as a solution to the challenges, 16 (37.2\%) indicated raising awareness of the public on judicial mandate, $11(25.6 \%)$ indicated live recording of court proceedings, eight (18.6\%) indicated increased funding and seven $(16.3 \%)$ cited providing adequate infrastructure.

Of the proposed solutions, capacity building which was cited by a majority has a bearing on records and archives management since it touches on the training of records officers. Providing live recording of court proceedings also has an impact on records management as it is a step towards computerizing court records cited by those that were interviewed. Lastly increased funding and providing adequate infrastructure would also improve records and archives management.

\subsection{Summary}

The chapter dealt with data analysis and presentation of the findings. The presentation of findings was based on themes derived from the research questions and was as follows: records management from creation to disposition; existence of records management policies, plans and guidelines; skills and competencies available in the Kenyan judiciary; level of awareness about records and attitude towards sound records management; and records management related strategies used to achieve openness in the Judiciary.

The major findings revealed that records were considered vital for the administration of justice in the Kenyan judiciary. The findings showed marked improvement in the management of records following the promulgation of the Kenya Constitution 2010 and the launch of Judiciary Transformation Framework. However, findings further showed that the management of records from creation to disposition was still faced with many challenges which included: documented instructions / procedure for records creation was lacking; the judiciary did not have an access policy; storage space and storage equipment were inadequate; appraisal and disposition of records was not adequately done; the judiciary did not have a preservation policy; and the records were not well preserved. 
Further, the findings revealed that records management policies were missing. The Kenyan judiciary however had a High Court Operation Manual though its existence had not been sensitized to the staff at the time of data collection. Additionally, the Kenyan judiciary had records management plans to be implemented within a period of five years from 2012 as was indicated in the judiciary strategic management plan. The Judiciary Transformation Framework also revealed the activities that had been planned with regards to managing court records.

Further still, the findings revealed that judiciary had inadequate trained records management staff and that the few had been wrongly designated. The findings also showed that the staff were rarely supported to attend records management conferences and workshops.

Moreover, top management support of records management was minimal, there was no budgetary allocation for records management functions for example and records management had not been accorded the status of a directorate like other administrative functions in the judiciary such as human resources.

With regards to open government in the Kenyan judiciary, findings showed that the judiciary was in its initial stages of implementation. A majority of the open government activities were therefore geared towards increasing judiciary transparency. The findings showed that the judiciary website was a useful tool in opening up the judiciary. However, the findings revealed many challenges facing the judiciary in regards to opening up to the members of public and stakeholders. Nevertheless, solutions to these challenges were suggested which could alleviate their effect.

The data was subjected to discussions in chapter 6 (Discussion of Results) based on the research questions of the study. 


\section{CHAPTER SIX \\ INTERPRETATION AND DISCUSSION OF FINDINGS}

\subsection{Introduction}

This chapter interprets and discusses the findings of the study in the order in which they were presented in chapter five. "Interpretation chapter of a thesis is aimed at making sense of the findings and examining their implications" (Polit and Beck, 2004:52). Interpretation begins with an attempt to explain the research findings within the context of the theoretical framework and prior empirical knowledge. Blaxter, Hughes and Tight (2006) point out that when interpreting data, a researcher adds their own meaning to the collected data and compares the meaning with the view of others.

The study sought to investigate records management in the Kenyan judiciary with a view to promoting transformation and open government so that justice can be achieved effectively and efficiently. The following research questions were addressed: How are records created, accessed and used, stored and maintained, appraised and disposed of, and preserved?; What records management policies, plans, and guidelines are available?; What skills and competencies do the records management staff have?; What is the level of awareness about records and attitude of staff towards sound records management practices? ; and what records management strategies is the Kenyan judiciary using to achieve openness?

The framework used in organizing this chapter is the research questions and broader issues around the research problem that included: records management from creation to disposition; e-records readiness in the judiciary; records management policies, plans, and guidelines available; skills and competencies among records management staff; level of awareness about records and attitude of staff towards sound records management practices; state of e-government in the judiciary; and records management related strategies for openness in the judiciary. 


\subsection{Records Management from Creation to Disposition}

If records are to meet the requirements for accountability and good governance, their management must cover the whole extent of their existence i.e. from creation to disposition (Wamukoya, 2000). The Records Continuum Model being a consistent and coherent regime of management processes from the time of the creation of records through to the preservation and use of records as archives, recognizes the need to manage records holistically from creation to disposition(Standards Australia, 1996).

The discussion of findings on the theme of records management from creation to disposition is presented under the following headings: records creation; records access and use; records storage and maintenance; records appraisal and disposition; records preservation; e-records management; and overall state of records management.

\subsubsection{Records Creation}

The findings of the study revealed that the judicial officers (judges and magistrates) depended entirely on records to adjudicate their role and they recognized that records were vital for the administration of justice. This was supported by $77 \%$ of the judges and magistrates who strongly agreed that records were vital for the administration of justice and another $23 \%$ who agreed on the same as illustrated in Figure 4. This was in agreement with the assertion of Motsaathebe and Mnjama (2007) in their study on the management of high court records in Botswana who found that the daily operations of the court depends on the availability of accurate, authentic and reliable information presented in a timely manner, hence the need to maintain an effective and efficient records management system for the judicial system. They pointed out that if a case file relating to a trial cannot be located it becomes impossible for a judge or magistrate to pass a judgment, thus justice being delayed or denied to the plaintiff altogether.

In tandem with the provisions of the RC Model, records must be well managed right from the time they are created to their ultimate disposition to ensure their continuous 
availability. The findings of the current study however revealed that at the Kenyan judiciary, records were being created without any form of documented instructions. Staff charged with the statutory responsibility of creating the records demonstrated a thorough knowledge of the requirements for records creation. However, the availability of guidelines would enhance management of records and ensure standardization and continuity. Dimension one (1) of the RC Model requires that records are managed from creation so that only the important organizational business transactions are captured in a record keeping system to ensure essential evidence of the transactions are kept. Moreover, the RC Model emphasizes the importance of guidelines for the proper management of the records. In dimension 2 of the RC Model, Upward (2000) points out that, record keeping professionals are required to establish a master plan to manage each record until its disposal. This therefore means that instructions designating how a record is to be organized, identified, accessed and preserved for as long as it is required should be put in place. In case of electronic records, metadata plays an important role just like printed guidelines to achieve effective management of the records.

The absence of records management guidelines or metadata in the Kenyan judiciary suggested that records management in the judiciary was ineffective. This may undermine transformation and open government in the Kenyan judiciary which may inhibit effective and efficient justice delivery.

These findings corroborated those of Kemoni's (2007) in a study on records management practice and public service delivery in Kenya which decreed the absence of instructions in registries in Kenya. Kemoni concluded that this had implications for service delivery in the administration of justice. In yet another study by Uwaifo (2004) on management and use of records in Delta State University, Abraka, Nigeria, he found that there were no established procedures for controlling records creation. The author opined that as a result most records were disorganized affecting effective dissemination of information. The findings were however different from those of Sichalwe (2010) in a study on the significance of records management to fostering accountability in the public service reform programme of Tanzania. Sichalwe's results revealed the existence of a registry 
procedures manual and desk instructions for registry staff and records users. Such a manual according to Sichalwe provided guidelines and procedures for managing records from their creation to eventual disposition. In addition, it outlined the management responsibilities in the registries.

The importance of managing records creation cannot be overemphasized. Records are created for use in the conduct of current business, to enable decisions to be made and actions taken (Shepherd, 2006). Wamukoya (2000) pointed out that records represent a major source of information and are almost the only reliable and legally verifiable data source that can serve as evidence of decisions, actions and transactions in the public service. Records therefore play an even more important role in agencies with statutory responsibility for maintaining law and order like the Kenyan judiciary. Cox and Wallace (2002) also note that records are used in courts as evidence and by giving silent but effective testimony, records help determine matters of fact and matters of law in both civil and criminal proceedings.

\subsubsection{Records Access and Use}

The respondents were asked if they had retrieval tools in place. The general findings revealed that the Kenyan judiciary had a filing system that worked fairly well as was indicated by all (100\%) of the respondents. The study established that the Kenyan judiciary classified and arranged the records using an alpha-numeric classification scheme. The Civil Procedure Act, Cap 21 of the Laws of Kenya states that judiciary records should be numbered numerically according to the order in which they are created every year. The filing system ensures that there is consistency in classifying records which consequently makes retrieval easier (Chinyemba and Ngulube, 2005). The current study also established that three registries had computerized in-house catalogues which showed the current position of each file created and maintained thus facilitating retrieval of these files. 
In addition to the filing system and the computerized catalogues, the current study established that in a majority of the registries shelves were labelled as indicated by 20 $(80 \%)$ of the records officers and registry assistants interviewed. Labelling further facilitated the retrieval process as was similarly indicated by a study on the management of records at the University of KwaZulu-Natal. In this study by Chinyemba and Ngulube (2005) $77.8 \%$ of the respondents indicated that their drawers were labelled, $19.9 \%$ showed that they had indices and $22.2 \%$ had automated retrieval systems. According to the RC Model, the records created in dimension one and two of the model are important for immediate business and regulatory use within the organization. Access to these records should therefore be facilitated so that the records can be of use to the organization. This is supported by Motsaathebe and Mnjama (2009) who note that access to records contributes greatly to the attainment of accountability and good governance ethos and sustenance of judicial operation. The findings of the current study as explained above showed that access and use of records in the judiciary was fairly well managed thus agreeing with the ideals of the RC Model.

The respondents were further asked if the judiciary had a records tracking system. The findings revealed that all registries in the Kenyan judiciary had a good tracking system that ensured any record leaving the registry was documented in a file movement register and the recipient of files would sign against the file(s) he/she had received. Among the registries a few (three) had a computerized tracking system which made tracking of their files easier and more efficient. In such cases the computerized system complemented the manual registers. The results suggested that there was a good tracking mechanism for records in the Kenyan judiciary.

In contrast, at the University of KwaZulu-Natal a study by Chinyemba and Ngulube (2005) established that records were hardly tracked as evidenced by only $5.6 \%$ of the respondents who indicated that they tracked the movement of records. Similarly An and Jiao (2004) observed that tracking of records was not common in Chinese records management practices. They pointed out that when tracking of files and records was done it was limited to location tracking as there was no action tracking done. The findings on 
tracking of records in the Kenyan judiciary seems to conform to the recommendation by Chachage and Ngulube (2006) that all organizations need to put in place mechanisms for records tracking. According to Ngoepe (2008), tracking records means documenting the movement of records so that the organizations can account for records they create and maintain. The Judicial Council of California (2013) contends that the most frustrating and wasteful of staff time in courts is searching for lost or misfiled records. Accordingly implementing an effective record tracking system can save staff time and enable their deployment in more productive work. ISO (2001) asserts that tracking of records is important because it facilitates identifying outstanding action required; enabling retrieval of a record; preventing loss of records; and for purposes of maintaining an audit trail of records transactions.

Although the overall findings indicated that access and use of records in the Kenyan judiciary was fairly well managed, the judiciary did not have a records access policy as indicated by all (100\%) the respondents. Garaba (2010) observed that access to records should be facilitated by a relevant policy. Garaba's study which investigated the management of the records and archives of former liberation movements in east and southern Africa held by national and private archival institutions found that a majority of the institutions studied did not have any guidelines regulating access to the records.

Managing access and use of records is an important aspect of records management since organizational records can only be useful to the organization if the various users of the records can access them in a timely manner. Records systems should therefore provide timely and efficient access to, and retrieval of records in support of the organization's business transaction and in meeting accountability and regulatory requirements (ISO: 2001). The ISO 15489 standard underscores the importance of effective management of records access and use in upholding the integrity of the records and in maintaining an audit trail as proof that records were effectively protected from unauthorized use, alteration or destruction. The current study established that the users of court records in the Kenyan judiciary included the judicial officers (judges and magistrates), judiciary staff, lawyers and advocates of both the litigants and the accused, the individual litigants 
and accused persons and accredited media houses. An effective records retrieval system would enable these users to access the records whenever they need them.

\subsubsection{Records Storage and Maintenance}

The findings from this study revealed that in a majority of the court stations, there were no designated areas for storage of current, semi current and non-current records. Consequently there were instances where current and semi current records were put together making the registries appear congested and disorganized as was the case in Eldoret High Court registry. Wema (2003) opined that keeping current and non-current records together makes records storage difficult and may render the records irretrievable. The findings revealed a serious space problem in the majority of the registries in the Kenyan judiciary as was illustrated in Table 6, Figures 5 and 6a and 6b. Out of the seven court stations visited, only two seemed to have conducive storage conditions for the records. The remaining five were however grappling with the issue of space as records were sometimes filed on the floor impeding their ease of retrieval. One of the stations that had conducive storage conditions reportedly benefited from donations from a nongovernmental organization (NGO) and two containers had been provided to serve as an archive for the station. The records in this court station appeared well organized and all the shelves were clearly labelled. The registry assistants explained that retrieval of the files took very little time since the labels clearly indicated where records were filed and the fact that the registry was not congested made retrieval easier. This satisfactory status of records storage was in stark contrast with what was happening in registries that did not receive any financial aid or other resources.

The findings of the current study are similar to those of a recent study by Tsabedze, Mutula and Jacobs (2012) on records management in the government of Swaziland which revealed a rather poor state of records storage. The study showed that although registries were available for storage of current records, a majority of action officers (81.1\%) would rather keep records in their offices because they feared losing them if they kept them in the registries. In the Tsabedze et al. study $52.2 \%$ of respondents kept the records in the 
registries and another $24.4 \%$ kept records in a storeroom. The study established that the Action Officers moved the records to the store room when there was no more space in their offices. Regrettably the records in the store room competed for space with nonrecords materials such as chairs and old computers and such records were neither arranged nor documented. Retrieving such records when required was reportedly a big challenge. In another study by Nengomasha (2009) on managing public sector records in Namibia, the findings showed that there was lack of storage space for paper records in the selected ministries resulting in congestion and inappropriate storage for semi-current and non-current records consequently affecting service delivery in the ministries. Similarly, Kargo (2009) in a study on the connection between good governance and record keeping in Sierra Leone pointed out that records in all sectors of government were utterly neglected to the extent that it was rumored that in one of the Law Courts, a mermaid was dwelling in the records storage area. This observation is similar to an observation by Michira (2013) in one local daily newspaper in Kenya which stated that in some court registries the records were at times infested with termites and in one of the law courts snakes and hedgehogs were found crawling under the files.

The findings of this study when looked at from the perspectives of related studies especially in Africa show that a majority of the organizations in the public sector are struggling with issues related to records storage especially because of limited space. However, there are a few exceptions as indicated in a study by Ngoepe (2008) on records management trends in the South Africa public sector where findings revealed that the South African legal framework required government offices to have registries that are spacious enough to accommodate the growth in documentation.

With regard to storage equipment, the findings of the current study revealed wooden shelves as the most prevalent (indicated by $65 \%$ of the respondents) followed by bulk filers made of steel (indicated by $21 \%$ of the respondents) and fire proof shelves (indicated by $10 \%$ of the respondents). This equipment was not considered to be the most appropriate for storage in the judiciary for the following reasons. Firstly, the wooden shelves are not recommended by records management professionals especially in the 
event of disasters such as fire. A case in point was files destroyed by fire in Kerugoya, Nakuru, Nyahururu and Sotik court stations in Kenya (Motsaathebe and Mnjama 2009). This reportedly caused serious difficulty for litigants who may have wanted to appeal their judgments. Secondly, the bulk filers inhibited speedy retrieval of records since files could not be accessed from more than one section at a time as presented in section 5.3.1.3.1. ISO 15489 recommends that the storage equipment for records should be able to protect the records from eminent destruction by disasters. A study by Iwhiwhu (2005) on the management of records in Nigerian Universities established that more than half of the respondents (54\%) stated that their institutions did not have good and adequate storage facilities. As a result, records were at risk in the event of fire, floods or other disasters.

Storage is a vital aspect of every records management programme (Iwhiwhu, 2005). According to ISO (2001) records require suitable storage conditions and handling so as to protect the records from unauthorized access, loss or destruction and from theft and eminent disasters. This is especially with regard to records with continuing value which require a higher quality of storage and handling to preserve them as long as the value exists. The ISO 15489-1 standard therefore advises that an appropriate storage environment and media, physical protective materials, handling procedures and storage systems should be considered when designing the records system in order to ensure their long-term preservation. This position is echoed by the US Environmental Agency which recommends that records in all government entities should be stored no closer than six inches to ceilings or suspended lights, and no closer than eighteen inches to sprinkler heads. Records should also not be stored in contact with electrical or fire alarm systems or where they will obstruct any exit door, access panel, air conditioning duct or fire extinguisher (US Environmental Agency, 2012).

\subsubsection{Security of Records}

The security of the records was another issue of concern to the researcher. The respondents were asked how secure the records were in the Kenyan judiciary. The 
findings established that records were relatively secure as suggested by more than half $(60 \%)$ of the respondents. It emerged that good security measures including CCTV cameras were fitted in all corridors and in some rooms in all the courts under study. Most of the registries were also restricted to staff only except in a few cases where, because of paucity of storage space, clients were served in storage areas (see section 5.3.1.3.2).

Related to the issue of security was the prevalence of missing files in the judiciary. Millar (2003) cautions that where security of court records is not guaranteed, corruption is rife and cases of missing files and documents geared towards evidence destruction is common. The study in the current findings revealed that missing files were reported in all the courts as indicated by $95 \%$ of the judges and magistrates and the testimonies of all the deputy registrars and executive officers interviewed. This was largely attributed to inadequate records management staff, poorly trained records management staff, lack of records management policies and guidelines, and reliance on manual records management strategies (see Figure 10). The findings of a study by Motsaathebe and Mnjama (2009) on managing court records in selected countries in Africa found that missing files had been a perennial problem in the Kenyan judiciary. This was attributed to manual recording and filing systems of the courts or lack of due diligence on the part of the staff although deliberate effort to frustrate the course of justice could not be ruled out.

However, the findings in the current study revealed that the frequency of missing files had drastically diminished following the promulgation of the Constitution 2010 of Kenya and the launch of judiciary Transformation Framework (JTF) in 2012. It was explained that before the new Constitution and the JTF the Kenyan Judicial system was marred by corrupt practices and as such cases of missing or lost files were high. The Chief Justice of the Kenyan judiciary in his speech pointed out evils that had been associated with the Judicial system for a long time to include "lack of structures", "limited resources", "low public confidence" and "lack of integrity" to name but a few (Mutunga, 2011). Similarly the Human Rights Watch (2012) made an observation that the courts were understaffed and underfinanced and Kenyans awaiting trial faced long delays that violated right to due 
process. These observations are consistent with those of Motsaathebe and Mnjama (2009) who found that missing files had been a perennial problem in the Kenyan judiciary.

The New Constitution paved the way for Kenyans to institute the much needed reforms in the judiciary. Together with JTF, the Constitution changed the organizational culture of the judiciary so much so that the judicial system is widely acclaimed to have a new face. The Republic of Kenya, the Judiciary (2013) acknowledges that the judicial system which had long been seen as an institution out of touch with the public but now engages and interacts with the public as a result of the transformation framework. Moreover, there has been reduction in missing / lost files; and corruption in the judiciary. In addition the judiciary has nurtured a culture of public and stakeholder engagement and providing an enhanced service delivery.

\subsubsection{Records Appraisal and Disposition}

The overall results of the current study on appraisal and disposition revealed that the Kenyan judiciary did not have a well-coordinated programme for appraisal and disposition of its records. It would appear that the records were appraised very irregularly especially when there was an acute storage space in the registries as shown in Table 7. Often the appraisal and disposition were left to the discretion of the "archivist" at each court station. Given that a single archivist would serve a whole station comprising of many registries, one archivist in Eldoret Law Court, Uasin Gishu County, who also served in two other stations observed that his responsibilities were overwhelming and he did not have time for records appraisal. This contravened the ideals of the RC Model which recommends that organizations should have appraisal and disposition programmes to ensure consistency and systematic approaches to the appraisal and disposition exercise. This view is supported by ISO (2001) which recommends that appraisal and disposition of records should be done on a systematic and routine basis in the course of normal business activity. 
The findings of the current study are similar to those of a study by Ngulube and Tafor (2006) on the management of public records and archives in the member countries of ESARBICA which showed that appraisal and disposition was done as the need arose because a majority of the countries that were studied did not have an effective programme for records appraisal and disposition. In another study by Iwhiwhu (2005), it was observed that appraisal and disposition of records was left to the discretion of the officer in charge of the records. Chachage and Ngulube (2006) in their study also established that despite the benefits associated with records retention schedules most exporting business organizations in the Iringa region of Tanzania tended to overlook this aspect of records management. It was reported that only three (3) companies appraised records at the end of the records life-cycle whereas six (6) did it on an ad hoc basis and another six (6) did not appraise their records at all. Similarly, a study by Ngoepe (2008) in the Department of Provincial and Local Government in South Africa revealed that appraisal and disposition programme was not effective. The study showed that $3.8 \%$ of the respondents indicated that they disposed of the records regularly while $17.3 \%$ did it randomly and $59.6 \%$ did not dispose of the records at all.

The findings of this current study further revealed that the Kenyan judiciary predicated their records appraisal and disposal on the requirements of the Records Disposal Act Cap 14 of the Laws of Kenya. This Act makes provision on when records in different categories in the judiciary should be disposed of by way of destruction. One of the provisions of the Act is that destruction of records relating to criminal cases should be done three years after the judgment date or final order in cases where acquittal or discharge had been ordered or fines only imposed. Alternatively, destruction could also be done in cases where sentences of imprisonment not exceeding one (1) year has been served by the accused or where the accused has been committed for trial and complaints dismissed by a magistrate. The implication for this is that any record pertaining to an accused person charged with a jail term of more than one year should be kept permanently. Discussions with the respondents revealed that currently there were many petty offenders whose jail terms exceeded one year and therefore their files were to be kept permanently thus clogging up storage spaces unnecessarily. The researcher felt that 
this Act should be amended to increase the minimum period of jail sentence to say five years beyond which the records could be kept permanently.

The current study findings further established that there was an elaborate procedure for records disposal by destruction in the Kenyan judiciary as presented in section 5.3.1.4.2. The procedure begins with a physical audit of the records to identify those that qualify for destruction and culminates in the documentation of the records that have been destroyed and the issuance of a certificate of destruction. This documentation and the certification are two important aspects of records destruction since they provide proof and evidence that indeed the records were destroyed according to the laid down procedures. This action is in tandem with requirements of the ISO standard on records management that requires that once disposition has been done then a record should be maintained that clearly states the action taken (ISO, 2001). A contrast is drawn from this finding with that of Chinyemba and Ngulube (2005) which established that $61.1 \%$ of the respondents indicated that they had destroyed records but did not have any proof of evidence while $13.9 \%$ of the respondents indicated that they maintained a list of all records they had destroyed. According to the authors, this had serious implication especially if such records would be required later in litigation.

Records appraisal and disposition are fundamental to efficient and effective records management as they help the organization to: control the growth of records; demonstrate compliance to disposition laws and reduce financial loses that may arise from missing files (Iwhiwhu, 2005).

\subsubsection{Records Preservation}

The present study established that the Kenyan judiciary did not have a preservation policy. Moreover, the staff seemed not to be aware of the role that a preservation policy would play in an organization. This was supported by all (100\%) of the respondents indicating that the judiciary did not have a preservation policy and $60 \%$ who did not see the need for such a policy. Ngulube and Tafor (2006), identified preservation planning 
and policy formulation as one of the activities that ensured the maintenance of records and other materials in a useable state. IRMT (2009) noted that a clearly documented and realistic preservation policy is an essential foundation for any sustainable preservation programme. If the preservation policy were to be formulated it would serve the following purposes: provide a statement of intentions that underpin preserving of the records; serve as a mandate for the activities of a preservation manager; demonstrate to staff and stakeholders that preserving records is important to the organization; used to solicit funds from the parent organization or donors; and would serve as a training tool for both the staff and the user. Akussah (2012) posits that among other things policies on preservation of records should be formulated by government and government agencies and any other organization in order to strengthen the preservation of records and other information materials to ensure their continued access.

The findings of the present study further showed that preservation of records in the Kenyan judiciary was not taken seriously. The researcher observed that environmental conditions were neither monitored nor controlled in almost all the registries; light readings were not taken and curtains and/or blinders were conspicuously missing. This was compounded by the fact that most of the storage areas were found in basements where relative humidity was always high with poor aeration. The RC Model recognizes the need to protect records from the time they are created through to the time they are used as archives if such records should remain useful for the creating organization and society in general. Ngulube (2007) observes that the maintenance of proper temperatures and relative humidity is key in preserving records since inappropriate temperature and relative humidity contribute significantly to the deterioration of records of all formats.

Akussah (2002) shares this view and points out that controlling the environmental conditions should be done following the results of environmental monitoring. Meanwhile, Dean (2002) explains that high temperature levels accelerate the rate at which chemical reactions occurs causing damage to the records. He also observes that high relative humidity causes the growth of mould which causes decomposition of the records and also creates a hospitable environment for insects and other biological organisms to thrive 
causing harm to the records. Abankwah and Ngulube (2012) assert that an increase in temperature by $10^{\circ} \mathrm{C}$ accelerates a chemical process by a factor of two while a drop in temperature by $10^{\circ} \mathrm{C}$ retards a reaction to half its speed. Dean (2002) therefore recommends temperature levels of between $20^{\circ} \mathrm{C}-21^{\circ} \mathrm{C}$ and a relative humidity between 35-40\%. However, IRMT (1999) contends that different information materials require different temperature and relative humidity levels. The optimum temperature and relative humidity levels for paper records and cartographic materials for instance are between $18^{0} \mathrm{C}-20^{\circ} \mathrm{C}$ and $35-45 \%$ respectively.

Light is another aspect of the environment that needs to be controlled. Garaba (2010) noted that light has been seen as a silent destroyer of records and other information materials since its damage is mostly invisible to the eye. Williams (2006) adds that the damage is cumulative and irreversible and so direct light from the sun should be prevented from reaching the records by use of curtains and blinders and fitting filters in the case of florescent tubes. Ngulube (2005c) explained that the light provides the energy required for chemical reaction and acts as a catalyst to the oxidation process which weakens the records and other information materials. Sichalwe (2010) observed that records can become very vulnerable especially when exposed to light for a long time during displays or when they are stored under constant light for example in front of a window. IRMT (1999) recommends light levels of about 50 lux.

The current study found out that the major sources of light were the natural light and artificial light where florescent tubes were used. Both sources of light are known to emit ultra violet rays. The researcher observed that light was posing a problem to records in the judiciary because in all except one registry, windows were positioned in directions that let the light into the storage areas and many of the windows did not have curtains or blinders. Moreover, some records were placed on the top of shelves which put them in close proximity to the florescent tubes which did not have any filtering material. Moreover, light readings were not recorded at all and therefore there was no way of establishing the amount of light that was allowed in the storage areas. These findings were similar to those from a study by Ngulube (2003) which revealed that archival 
institutions in South Africa did not control light in records storage areas because they did not take light level readings at all. Sichalwe's (2010) study also established that light levels were never taken in the Tanzania public service facilities however, the registry personnel tried to control the light by fitting ultra violet filters on the florescent tubes.

\subsubsection{Disaster Planning and Preparedness}

Disaster planning and preparedness is another aspect that is vital for records preservation and continued accessibility especially when faced with disasters. Sichalwe (2010) observed that any item lost in the event of a disaster may never be recovered and this calls for mitigation measures to be put in place. Przybyla and Huth (2004), defined disasters as sudden unexpected occurrences that significantly destroy records or prevent access to the information they contain. Okello-Obura and Sseketto (2011) cautioned that a disaster does not need to be catastrophic or vast in nature and could be an insect infestation or human action such as a bomb blast. The authors observed that the key attribute to disasters is that they pose a threat to the physical safety and integrity of records. To minimize the impact of the disasters, an organization needs to be prepared by putting in place a disaster preparedness plan which helps in avoiding or minimizing the effect of a disaster (Przybyla and Huth, 2004). The plan should therefore be part of the larger records management activities.

The current study established that the Kenyan judiciary did not have a disaster preparedness plan despite the fact that disasters caused by fire in some stations have been reported. The absence of a disaster plan therefore spells doom for records in the Kenyan judiciary should a disaster occurs. The lack of disaster management and security control in records repositories poses a risk of losing valuable records in public organizations (Sichalwe, 2010).

The findings of the study concur with a study by Okello-Obura and Sseketto (2011) on records and information disaster preparedness in selected organizations in Uganda. They found that although the organizations studied were committed to disaster management, 
they handled the disasters in a rather haphazard manner posing even a greater risk. The findings of the current study were also similar to those of Ngoepe and Van der Walt (2009) which established that South African public sector departments were ill prepared to handle disasters with $77.8 \%$ of the respondents indicating that they did not have disaster recovery plans. In yet another study, Ngulube (2005a) established that many archives institutions in the ESARBICA region had neither a disaster preparedness policy nor security plans. Ngulube noted that disaster preparedness and security of records and archives did not form a significant part of the preservation activities of archival institutions in many organizations.

Another aspect of records preservation which is closely related to disaster planning and preparedness is vital records management. The findings of the current study revealed that the Kenyan judiciary did not have a vital records management programme. Vital records are those records that are required by an organization for business resumption in the event of a disaster. The US Department of Energy (2011) pointed out that vital records are required to support an organization's roles and responsibilities during and following an event that significantly disrupts normal operations, such as a national security emergency or natural disaster. An effective vital records program is therefore essential to successful records management. It is also an integral part of an organization's information resources management program. Moreover, it is one of the emergency preparedness responsibilities any organization should put in place (US Environmental Protection Agency, 2012) (EPA). According to the EPA, identifying and protecting vital records can save valuable time and resources after an emergency. Besides this will allow recovery personnel to concentrate on restoring operations rather than finding the information or spending money and time on restoring unnecessary information. A vital records management programme would have the following objectives: identify records containing information that programs need to conduct business under emergency operating conditions; identify those records that support and are needed for the performance of the organization's most critical functions; develop policies, procedures, and a plan of action that will allow the assessment of damage to the recovery of any records that may be affected by a disaster; and develop and implement cost effective methods, including off-site storage and the 
application of technology, to protect and safeguard those records identified as vital from loss, misuse, and unauthorized information access or modification.

From the foregoing discussion, the Kenyan judiciary should develop a vital records management programme alongside the recommended disaster preparedness plan. A review of a study by Ambira and Kemoni (2011) on records management and risk management at the Kenya Commercial Bank shows that private sector (especially financial institutions) organizations may be doing well in the management of vital records. They noted that the bank had given priority to vital records management. The findings showed that every branch of the bank had a security safe which was fire proof to protect the vital records. This sharply contrasted with the findings of the current study which depicts the Kenyan judiciary as ill prepared with regard to protecting its records in the event of disasters.

\subsubsection{E-records Management}

A study by IRMT (2012) revealed that east African countries (Kenya, Uganda, Tanzania and Rwanda) had made substantial investment in ICT procurement and deployment. According to the study, ICT plans had received significant senior level support and the countries were moving forward progressively in implementing ICT plans which included the management of e-records. It therefore became mandatory for the researcher to establish the level of e-records management in the judiciary.

In order to establish whether the Kenyan judiciary managed electronic records, the respondents were asked if they had an electronic records management system. The findings showed that the majority of the registries did not have an electronic records management system as indicated by $87 \%$ of the respondents. A few of the registries represented by $13 \%$ of the respondents seemingly had some form of electronic records management systems. Interviews revealed that in one of the court stations a system had been donated along with other donations from USAID alluded to earlier and the judiciary was using this as a pilot study. The system was however used alongside the manual 
records management system. Other two court stations (Millimani High Court Civil Division and Makadara Chief Magistrate Court both in Nairobi County) had some inhouse electronic records management systems that handled basic management of the records like retrieval and tracking of the records. The interviews with the registrars also revealed that another pilot study had been done in the Supreme Court which had transformed to a paperless court but this could not be verified since the Supreme Court was outside the scope of the current study.

The overall findings of the current study on e-records management in the Kenyan judiciary therefore indicate that the managing of electronic records was just beginning. Apart from the two pilot studies, the infrastructure for electronic records management had been laid and at least every work station in the registries had a computer and all the computers had been networked with good internet connectivity. At the time of this study, it was reported that plans were underway to upgrade the e-records system used in the pilot before rolling it out to other court stations. Moreover, the staff responsible for managing records seemed to have been aware of the importance of managing e-records and also appreciated the impact this would have on the overall service delivery.

However, the findings of the current study showed that the Kenyan judiciary had not formulated an e-records management policy and the staff had not been trained specifically on the management of e-records. The majority of the records clerks had basic computer literacy skills obtained from taking short courses in computer packages while a few of the staff that had degrees in records management or related fields reported that they studied e-records management in the course of their studies which was largely theory based with limited hands-on experience. This training was seen as being insufficient for effective management of e-records in the judiciary. The absence of an erecords management policy together with inadequately trained staff present a challenge to the Kenyan judiciary even as it plans to rollout e-records management. This is in keeping with findings of a study by Akotia (2000) on the management of financial records in the ministry of finance in Uganda. The study noted that the ministry had no capacity for managing the basic elements of an electronic records management programme. The 
Ministry lacked staff with the right skills and competencies; legal and administrative requirements for managing e-records; and accurately documented policies, and standard operating procedures.

Similarly, Wato (2006) in a study of e-records readiness in the ESARBICA region noted that national archives in the ESARBICA region had no capacity to preserve e-records. This was attributed to inadequate skills and lack of policies among other issues. Sichalwe (2010) opined that lack of policies presented a danger of losing access to e-records, a view supported by Moloi (2009) who adds that in the absence of an enabling policy erecords may not be captured in a systematic manner. Keakopa (2007) observed further that the absence of policies and procedures may compromise the long term preservation and availability of electronic records as archives.

The Kenyan judiciary should therefore address the above issues on policy and staff competence as prerequisites to successful management of e-records which in the long ran will enhance judicial service delivery. Maguire (2005) identifies the following reasons for managing electronic records: enable sharing of documents across several sites; easy and timely retrieval of information; reduced duplication of records; and helps in version control of the records. Chachage and Ngulube (2006) however caution that although managing e-records is beneficial to organizations, it comes with challenges for record keepers. The challenges according to the authors include: fragility and transient nature of the storage media; technological obsolescence; difficulty in maintaining integrity of the records; and technical skills requirement. The challenges notwithstanding, the Kenyan judiciary should move with speed to implement the planned computerization of the registries. The respondents felt that computerization would immensely improve the speedy delivery of justice as envisaged in the JTF pillar on ICT.

IRMT (2004:1) defines e-records as "recorded information that is capable of giving evidence of policies, transactions and activities carried out in e-government and ecommerce environments". The management of electronic records gained impetus the world over from the mid-1990s (Kalcul, 2009). This was occasioned by the increased use 
of ICT and more so the Internet in government operations which led to an increase in generation of e-records. Wamukoya and Mutula (2005) observed that e-records support the day-to-day operations of government services in the same way as paper records. Concurrent with this view, is IRMT (2004) which asserts that in developed regions of the world, e-records are becoming the basis for confirming pension and other entitlements; registering births and deaths; verifying citizenship; certifying voting rights; enabling collection of taxes; supporting financial management; and supporting litigation.

\subsubsection{Overall State of Records Management in the Kenyan Judiciary}

The respondents were asked to rate the current state of records management with regards to the overall performance in the Kenyan judiciary and their responses depicted an average or fair management of records. The majority of those that were interviewed opined that compared to how records were managed in the past, there was an improvement especially after the promulgation of the Constitution 2010 of Kenya and the launch of JTF although they explained that records management still needed to be improved further. The perceived improvement was more on reduction of missing and/or lost files and a reduction in inept practices in the general management of the registries. Their opinion was corroborated by the judges and magistrates who also gave a positive response where $58 \%$ indicated that records management was fair while $26 \%$ indicated that it was good and only $16 \%$ indicated that it was poor.

The study further established that the average state of records management was generally as a result of the absence of a records management policy as indicated by $76.7 \%$ of the judges and magistrates and inadequately trained records staff as indicated by $76.7 \%$ of the judges and magistrates (see Figure 11). Other reasons given were inappropriate supplies and equipment supported by $55.8 \%$ and inadequate funding supported by only $30.2 \%$. The implication for this was that if these issues were addressed then records management would be rated as being good in the Kenyan judiciary. 
In order for the researcher to understand the effect of the current state of records management on the delivery of justice the judges and magistrates were asked if they had case backlogs in the courts and whether they thought the current state of records management contributed to the backlog. The findings indicated that there were case backlogs in all court stations in the judiciary as indicated by all (100\%) of the respondents. Although inadequate judicial staff was cited as the major cause of the backlogs as supported by $95 \%$ of the respondents, other records management related issues were identified. These included: inadequate use of ICT as supported by $23 \%$ of the respondents, inadequate records staff indicated by $20 \%$ of the respondents; poor records management supported by $16 \%$; inadequate tools and equipment supported by $9 \%$; and corruption in the judiciary indicated by only $1 \%$ of the respondents.

From the fore going although records management in the judiciary was said to have improved, but a continuous process of improvement is necessary. Thurston (2005) noted that the growing emphasis on transparency and the need to reduce large backlogs of court cases calls for effective records management. She opined that well-managed court records are essential to efficient and effective legal systems, capable of supporting accountability by making the judiciary more transparent. Saman and Haider (2012) noted that a reliable and accurate case file management system is fundamental to the effectiveness of day-to day court operations and fairness of judicial decisions. On the other hand, dysfunctional records management undermines legal and judicial reforms and leaves scope for corruption or collusion between court official and lawyers (Thurston, 2005). An effective records management system is therefore imperative if the transformation in the Kenyan judiciary is going to be achieved and sustained.

\subsection{E-records Readiness in the Kenyan Judiciary}

E-records readiness in the Kenyan judiciary was studied using the IRMT E-records Readiness Tool as the analytical lens. E-records readiness is a catalyst for the implementation of open government hence the inclusion in the study. The discussion on this aspect is provided in sections 6.3 .1 to 6.3 .3 covering: existing records management 
policies, plans and guidelines; skills and competencies; and awareness about records and attitude of staff towards sound records management.

\subsubsection{Existing Records Management Policies, Plans and Guidelines}

The findings of the study showed that, the Kenyan judiciary did not have a records management policy. This was indicated by all the registrars $(100 \%)$ and records staff (100\%) interviewed and $82 \%$ of the executive officers. The observed scenario was contrary to the provisions of IRMT E-readiness Tool. Component seven (7) of the IRMT tool provides that each organization that implements e-records management and egovernment services should establish internal policies and responsibilities for records and information management in a form appropriate to its internal organizational structure, culture and resources. Accordingly if an organization does not have a records management policy its readiness is ranked low, in that out of a maximum of twenty points it gets a lower score of five points. Consequently, the absence of a records management policy in the Kenyan judiciary may be an indication that the judiciary did not have the required readiness to manage e-records and operate an e-government and enhance openness in the administration of justice.

The absence of the policy could impact negatively on the ongoing transformation and move towards openness in the judiciary. This is because as explained earlier, records play a key role in the delivery of justice and openness is predicated on sound records management. According to Mnjama and Wamukoya (2007), the level of organizational commitment to managing records can be gauged by the existence or non-existence of records management policies, plans and guidelines. This view is supported by ISO 15489-1 which recommends that organizations seeking to manage their records effectively should first and foremost establish, document, maintain and promulgate policies, procedures and practices for records management (ISO, 2001). As Roper and Millar would have it policy and legislative framework are necessary to create a conducive environment for effective management of records (Roper and Millar 1999). Meanwhile, ISO (2001) indicates the objectives of records management policy as the creation and 
management of authentic, reliable and useable records capable of supporting business functions and activities for as long as they are required.

Related studies revealed the absence of records management policies in many public sector organizations especially in developing countries. A study by Kemoni (2007) for instance showed that there was lack of records management policies in government ministries in Kenya. This he said impacted negatively on public service delivery in areas such as access to education and training opportunities. Similarly, a study by Komen (2012) on the management of personnel records in support of good governance at the Ministry of Local Government also in Kenya, established that there were no policies governing the management of records.

The lack of policies is not peculiar to Kenyan organizations. An and Jiao (2004) established that in China as a rule, many organizations have archival policies for semicurrent and non-current records management but few policies and procedures for managing current records exist. Iwhiwhu (2005) in a study on the management of records in Nigerian universities revealed that policies in records management were not available. Another study by Kargo (2010) on the connection between good governance and record keeping in Sierra Leone established that the lack of a records management policy was one of the major impediments to good governance in the country. Yet another study by Chinyemba and Ngulube (2005) showed that policies for the management of records in the university were inadequate resulting to neglect of records.

Lastly, a more recent study by Keorapete and Keakopa (2012) on records management as a means to fight corruption in Botswana revealed that there was a lack of proper records management policies, procedures and other guidelines. The authors explained that the Botswana National Archives and Records Service (BNARS) which is mandated by law to provide guidelines to government bodies with regard to records management had not been able to come up with a national records management policy from which government bodies could derive their own specific policies. Keorapata and Keakopa note that the lack of such a policy has hampered development in total records management programmes in 
the public sector which would otherwise ensure security and protection of public records in government offices. They argued that this poor state of records management may contribute towards breeding corruption in the country.

The gravity of the absence of records management policies in Africa may be summarized in the words of Mnjama and Wamukoya (2007) who pointed out that one of the major challenges to the management of records in the ESARBICA region was the absence of organizational records management policies and procedures to guide records management. They noted that the management of records in all formats must be supported by clear policies, procedures and guidelines if they are to retain their evidentiary value for accountable and transparent governance.

However, there seems to be a different experience in the private sector in as far as records policies were concerned. A study by Chachage and Ngulube (2006) on the management of business records in Tanzania revealed that majority of the companies had records management policies. In the same vein a study by Ambira and Kemoni (2011) on records management and risk management at the Kenya Commercial Bank also revealed that there were records management policies in place. Both of these studies were done in private sector organizations and it may imply that these organizations are ahead of their counterpart in the public sector regarding records management policies. This may be due to the fact that they are driven by profit making.

\subsubsection{Judiciary Strategic Management Plan}

Although the Kenyan judiciary seemed not to have a records management policy in place, it had five (5) year records management plans the year 2012 to 2016 . A key project in the plan was computerization of the registries and courtrooms. It was hoped that in a period of the five years all registries would be fully computerized and all court rooms modernized so that all court proceedings would be timeously captured in a soft copy. 
Besides the strategic management plan, the JTF provides blue prints for all the activities in the judiciary. The JTF is anchored on four pillars and ten overlapping key result areas (KRAs) all of which have one overriding objective: to achieve access to and expeditious delivery of justice to all (Judiciary Transformation Framework, 2012). The four pillars of the framework are: people-focused delivery of justice whose key focus is access to and expeditious delivery of justice, people centeredness and public engagement, and stakeholder engagement; transformative leadership, organizational culture and professional and motivated staff with KRAs being philosophy and culture, leadership and management, organizational culture, and growth of jurisprudence and judicial practice; adequate financial resources and physical infrastructure whose KRAs are physical infrastructure and resourcing, and value for money; and harnessing technology as an enabler for justice which has only one KRA on Information and Communication Technology (ICT).

Under pillar one (1) on access to and expeditious delivery of justice, the judiciary planned to among other things: develop and deploy an electronic case management system; an integrated document management system; embrace ICT and apply appropriate technology to enhance court efficiency and effectiveness - including audio-visual recording and transcription of court proceedings and ensure appropriate staffing levels to deal with caseloads. Pillars two (2) and three (3) are not however discussed in this section since they have very little to do with records management. However, under pillar four, (4) the judiciary planned to create an e-judiciary framework that will make ICT an enabler of its transformation program. Under the framework, the judiciary sought to implement the following activities: digitize court records; establish an SMS inquiry system to inform members of the public about the status of their cases; install teleconferencing facilities; establish an integrated personnel and payroll system; and ensure the recording of proceedings and transcription. Further the judiciary sought to establish a paperless Supreme Court as an emblem or symbol of an efficient judiciary.

From the foregoing, although the JTF does not mention records management vividly, some of the plans identified above resonate with records management practices. The 
electronic case management system and digitization of court records suggest that the judiciary envisages a situation where court records will be managed electronically. It is however regrettable that the framework does not identify mechanisms to improve records management prior to computerization. Borrowing from Thurston (2005) computerization does not always provide a panacea for poor records management since it introduces a new range of records management challenges. Furthermore Nengomasha (2009) cautioned that any deficiencies in the management of paper records may be transferred to the management of electronic records if proper planning is not undertaken. The implication for this is that before computerization, the management of paper records should be efficient and effective.

\subsubsection{Skills and Competencies}

According to the IRMT E-Records Readiness Tool, qualified records management staff are required for effective implementation of records management policies in any given organization (IRMT, 2004). Skills and competencies in records management are necessary for organizations to demonstrate accountability, transparency and a commitment to root out corruption and malpractice (Wamukoya and Mutula, 2005). The

findings of this current study found that the Kenyan judiciary had adopted a new culture of doing business which was characterized by public oversight; accountability and transparency. This was made possible by the Judiciary Transformation Framework and the Kenya Constitution 2010. For these ideals to be sustained, sound records management was recognized as an imperative.

The findings of the current study revealed that the judiciary did not have adequately trained records management staff with both Nairobi and Uasin Gishu counties having only 13 trained records officers. Out of these, only one was posted to Uasin Gishu County who had to oversee records management in the entire region comprising Eldoret high court station, Eldoret chief magistrate court and a sister magistrate court in the neighboring county of Nandi. The remaining 12 records managers were posted in Nairobi to serve the seven divisions of Milimani high court, Supreme Court, Court of Appeal and 
five stations of magistrates' courts spread across the county. It is therefore evident that the records management staff in post were not adequate and could not fully discharge their duties competently.

Moreover, the trained records managers were designated as "archivists" and were charged with the responsibility of managing semi-active or non-active records. The management of active records was left to staff that were not necessarily trained in records management such as executive assistants or registry clerks. The majority of them did not have any training at all while a few were trained in other fields like human resource management or public relations. This state of affairs affected the quality of records management as the majority of the staff did not seem to have knowledge of technical aspects of records management such as appraisal and disposition (see section 6.1.4.). From these findings, the judiciary must ensure enabling records management policies are put in place and records management staff adequately trained as required by component ten (10) of the IRMT E-Records Readiness Tool which deals with resources and training of records management personnel.

These findings of the current study seem to confirm those of a study done by IRMT (2011) on managing records as reliable evidence for ICT / e-government in the Kenyan judiciary which decried the inadequacy of records management staff. The study showed that out of an establishment of 66 staff in the whole country's judicial system only 40 had been employed and posted. This cohort of staff was stationed in different courts in the country. The study further revealed that the staff that were trained had various qualifications such as degrees, diplomas or certificates in archives and records management or related fields. The staff had made own initiatives to facilitate their own training

Other related studies also seemed to indicate similar results. For example, a study by Ngulube and Tafor (2006) on the management of public records and archives in the member countries of ESARBICA indicated that national archival institutions were experiencing shortages of qualified staff since only $40-50 \%$ of the staff had 
qualifications directly related to either library and information science or records and archives management. They pointed out that the shortage of records management personnel caused tremendous pressure on the few staff that were in post.

In another related study by Nasieuku, Kemoni and Otike (2011) on management of erecords at Moi University Kenya, they established that only $10.6 \%$ of the respondents had knowledge and skills in records management. They pointed out that effective management of records was dependent on staff receiving adequate records management training to effectively deal with specialized areas such as e-records, appraisal and disposition of records. In yet another study, Okello-Obura and Ssekitto (2011) established that a number of organizations in Uganda did not have qualified personnel in records and archives management although they were tasked with managing records in their organizations. This state of affairs was attributed partly to the fact that for a long time institutions of higher learning had not been offering courses on records management, until 1999 when Makerere University introduced a diploma in records and archives management and later in 2009 a Bachelor's degree. The authors noted that the quality of human resources was critical in planning and developing strategies for good records management.

Similarly a study by Iwhiwhu (2005) on management of records in Nigerian universities revealed that records staff were employed without paying much attention to their records management expertise. The staff hired had mainly with clerical / administrative skills and did not understand the importance of sound creation and management of records. Consequently, they lacked the culture of record keeping. Lastly the study by Tsabedze, Mutula and Jacobs (2012) on records management in the government of Swaziland pointed that staff appointed to the position of records / registry officer were not fully trained in records management and could therefore not be entrusted with managing government records during their entire lifecycle. The study revealed that most of the staff held Ordinary level certificates with none of them having undergone formal training to at least a Diploma level in records management. In comparison with the Kenyan situation, one would say the judiciary was in a relatively better position since as reported earlier, 
three (3) records staff were pursuing records management training at Masters Level and others at Bachelors and Diplomas levels.

Continuous training through workshops, conferences and refresher courses should be encouraged by the Kenyan judiciary. The findings of the current study showed that records management staff in the Kenyan judiciary did not receive support to attend conferences and workshops. This is supported by the findings of a study by Nasieku, Kemoni and Otike (2011) which established that 50\% of the line management Moi University did not regard workshops and seminars as possible sources of skills and knowledge in records management. The study found out that all the respondents $(100 \%)$ indicated that they thought knowledge and skills in records management was obtained by going to colleges and universities, $75 \%$ indicated that they obtained training on the job and only 50\% indicated workshops and seminars. Plans were however underway to offer continuous education and training in records management through Judiciary Training Institute that had just been established.

Related studies have shown an absence of trained personnel or inadequate or completely missing continuous training in records management (Iwhiwhu, 2005; Chinyemba and Ngulube, 2005; Sichalwe, 2010 and Uwaifo, 2004). Sichalwe (2010) in particular observed that though the government ministries in Tanzania had records management courses to offer, only $45.8 \%$ of the respondents had attended the courses while $54.2 \%$ had not attended any of such courses. Sichalwe pointed out that the lack of training to update knowledge and skills of registry personnel had negative implications for fostering accountability in the public service. She maintained that registry personnel needed to receive continuous training in order to develop the right attitude and knowledge in methods and procedures for managing records. The study further indicated that among the registry staff themselves they recognized the need to be given additional training and the most cited area was on managing electronic records and the general application of ICT on records management. 
Nevertheless, a study by Ngoepe and Van der Walt (2009) indicated somewhat different findings. The study showed that in the South African public sector, records management training was offered. Some $15.4 \%$ of the respondents indicated that training was offered during induction of new employees, $7.7 \%$ indicated that it was offered as refresher courses while $23.1 \%$ showed that they had scheduled training and another $26.9 \%$ indicated that the training was offered whenever the need arose such as when a request is made or when money is available in the budget for such training. This painted a different picture from similar institutions in other countries in Africa. This may be explained by the fact that South Africa has records management policies that give effect to principles of records management.

The foregoing discussion demonstrates that the views of Wamukoya and Mutula (2005) on capacity building requirements for records management and e-records management in east and southern Africa need to be taken more seriously. The authors asserted that an effective capacity building strategy for records management needed to be developed, firstly, by having a regional conference involving institutions with core responsibility for managing records, scholars in the area of archives and records management, policy makers and donor agencies to discuss training needs for the region. Second, the authors suggested that the following actions needed to be taken, amongst others: sensitization and awareness creation workshop for key stakeholders; continuing professional development for records and archives professionals; development of a database of experts of institutions, resources and experts; and establishment of a secretariat to coordinate training and hiring of a champion to be responsible for implementing the regional capacity building plans and projects.

\subsubsection{Level of Awareness about Records and Attitude of Staff towards Sound Records Management}

The study sought to determine the awareness and attitude of the staff towards sound records management by looking at the value placed on records and records management in the administration of justice by top management and the staff; budgetary allocation for 
records management; and the value attached to records management in the organizational structure of the judiciary. The findings of the study showed that records management was highly valued and seen as an important component in the administration of justice in the Kenyan judiciary. This was supported by all judges and magistrates who took part in the study, where $47 \%$ of them indicated that records management was essential, $44 \%$ indicated that it was very important and $9 \%$ indicated that it was important. All the registrars $(100 \%)$ in the interviews also indicated the value of records and one of them explained that records management plays a critical role in the delivery of justice and was indispensable in the administration of justice.

However, the study revealed that top management did not accord records management full support in terms of financial and infrastructure development. This view was expressed by more than half of the records officers and registry assistants who cited issues like the almost non-existent training support and the general deficiency in resources and infrastructure. It would however seem that the level of support had improved notably after the launch of the transformation framework.

Further, the deputy registrars were asked if they were aware of any budgetary allocation for records management functions. Their responses indicated that there was no budgetary allocation for records management at all. Activities related to records management were funded from the general station allocation but such budget was hardly ever made available. Moreover, the records management portfolio did not have a directorate like other administrative functions such as human resource management. It was therefore not clear where records management was placed in the structure of the judiciary and no one was responsible to champion records management interests especially at high level meetings where policies were made. However, it was pointed out that plans were underway to appoint a directorate for records management. The respondents believed that this would drastically improve the status of records management and improve service delivery in the judiciary. 
The overall finding therefore, on the level of awareness about records and attitude of respondents towards records management seemed low at the time of the study. Component eleven (11) of the IRMT E-Readiness Tool recommends that managers and staff need to be aware of the importance of trustworthy and well managed records for delivering effective government services and protecting the institutional accountability and integrity. This together with records management policies, procedures, tools and resources would give effect to sound records management. Consequently any organization that recognizes the vital role of records and records management like the judiciary but does not give it full support would get a score of ten points out of a maximum twenty.

Previous related studies indicated that records management in sub-Saharan Africa has perennially suffered lack of top management support and absence of budgetary allocation. Mutula and Wamukoya (2009) pointed out that one of the critical challenges facing the ESARBICA region was inadequate support by governments especially in as far as funding was concerned. It emerged from their study that governments did not provide adequate funding to ministries and government agencies. Similarly, among the challenges identified by Mnjama and Wamukoya (2004) as facing ESARBICA countries, was the absence of budgets dedicated to records management. In such a situation the records management agenda became difficult to implement. Mnjama and Wamukoya (2007) explained awareness and attitude towards records management as having to do with the extent to which senior management is aware of, understand and demonstrate commitment to a clear vision and set of objectives for the management of records.

\subsection{State of E-government in the Judiciary}

E-government is broadly defined as the use of ICTs in the public sector to improve operations and delivery of services (Kumar and Best, 2006). Other definitions however abounds in literature, the World Bank website (2004:1), for instance defines it as "the use of ICTs to transform relations with citizens, businesses and other arms of government for better service delivery and increased transparency and accountability". The researcher 
regards e-government as akin to open government since it aims at increasing accountability and transparency which are core values of an open government.

The overall results of the study established that the Kenyan judiciary was in its infancy as regards e-government implementation. This is because, at the time of the study, the ground was just starting to be prepared for the implementation of e-government services by way of putting in place the necessary infrastructure and operating administrative functions of the judiciary electronically. As discussed under the section 6.1.6 on managing e-records in the judiciary, computers had been bought for each registry and each judge or magistrate was connected through a local area network (LAN) and the internet. Moreover some court rooms in Milimani high court in Nairobi County had fitted recorders but were not yet operational. Transcription equipment had not yet been installed though they were needed for live recording of the court proceedings.

Previous related studies showed that generally African countries are lacking behind in as far as e-government is concerned. Bannister (2007) for example, observed that countries in the sub-Saharan region were still in their initial stages of development with regards to e-government. Schuppan (2009) attributed this to limited internet access and only a few select government services being offered electronically. On the other hand, Akther, Onishi and Kidokoro (2007) observed that African countries were still lagging behind with the implementation of e-government since required data such as land registers, residential or geographic data was often non-existent or outdated.

The findings of the current study also showed that the judiciary was faced with challenges that included: lower literacy levels among court users; digital divide; security of classified information; inadequate equipment; lack of trained personnel; insufficient funding; and poor planning and prioritization. Ebrahim and Irani (2005) pointed out the necessity for government support to ensure that there are sufficient resources, adequate infrastructure, management support, capable IT staff and effective IT training and support before the implementation of the e-government programme. 
Ebrahim and Irani (2005) posited that there are a number of barriers experienced in public sector organizations that prevent successful adoption of e-government projects: inadequate IT infrastructure including required hardware and software, intranet and extranet; inadequate security and privacy especially with regard to personal data; shortage of IT skills; organizational culture, management strategy and individual attitudes within the organization; central government funding that is often hard to control and make it difficult to plan sustainable IT initiatives such as e-government. Choudrie, Weerakkody and Jones (2005) pointed out that lack of internet and broadband connectivity were restricting citizens from accessing e-government services in a rural setting in the UK. The authors also identified digital divide and lack of trust and security of personal data as the major impediment of e-government in this setting. Additionally Ndou (2004) pointed to another challenge on policy issues. He asserted that in an egovernment environment, new rules, policies, laws and legislative changes are required to address electronic activities such as electronic signatures, electronic archiving, freedom of information, data protection, computer crime and many others. Fortunately for the Kenyan judiciary, Laws of Kenya Cap 80 for instance has been revised to allow electronic records to be used as evidence in the courts.

Based on the findings of the current study and evidence given in the extant literature, the Kenyan judiciary had challenges that needed to be addressed if the e-government initiative was to be successfully implemented. However, not all is lost for the judiciary, literature shows that there is great potential among countries in sub-Saharan Africa, Kenya included, for successful implementation of e-government. Mutula (2013:18) for instance pointed out that "with mobile penetration growing significantly in sub-Saharan Africa, e-government projects should leverage these new technologies, including social media applications to provide citizens the opportunity to obtain services or information timeously". Further, the Collaboration on International ICT Policy for East and Southern Africa (CIPESA) (2011) noted an increasing number of people in Africa accessing modern communication technologies such as the internet and mobile phones allowing many of the conversations at Citizen to Citizen e-government interaction (C2C) level. CIPESA (2011) showed for instance that Kenya had 24.9 million mobile subscribers and 
was ranked highly on the use of social media and particularly Facebook. Furthermore, Mutula (2013) pointed out that the completion of the under-sea fibre connectivity on the east coast of Africa has provided Africa with high speed internet links to the rest of the world and is therefore likely to improve internet connectivity on African continent thus improving the rate of success on e-government projects.

\subsection{Records Related Strategies Used to Achieve Openness}

The Kenyan judiciary could implement its open government initiative using the open government Implementation Model (OGIM) as a benchmark. OGIM provides a logical, sequential and systematic step by step approach to the implementation of open government. It requires that governments or agencies implementing open government initiatives should do so incrementally on a step by step basis. The model identifies increasing data transparency as the first step in the implementation of open government. The findings of the current study revealed that the Kenyan judiciary was at its very initial stages (data transparency) of implementing openness which entails providing information to the citizens. The study established that several channels were used to publish information so that the public would be guided on access and use of court services. These channels included the judiciary website which reportedly was used to post case lists, summaries of cases of public interest, official speeches, policies and other regulations to name but a few; e-mail services; judicial road shows; judiciary open days; , court users committees and the social media such as Facebook.

The judicial road shows for instance were held in a week that the judges would traditionally hold their annual colloquium and the judges, magistrates and kadhis across the country marched in a symbolic gesture to take justice to the people (Republic of Kenya, the Judiciary, 2013). In the process, the officers held meetings in public places to explain how the court works, and how one could access and use them. Additionally, there was an increasing move towards localizing strategies aimed at increasing transparency and opening up to the public. The high court and magistrate courts in Eldoret for instance were reported to be receiving at least four primary school delegations every month to 
create awareness about the judiciary operations and functions. In the High Court in Nairobi, the Civil Division had introduced a feedback form in every case filed while the Family Division reportedly communicated with parties on the status of cases by way of telephone. On the other hand, rulings and judgments were emailed to parties in the Judicial Review as well as Constitution and Human Rights Divisions.

Consequently, the judiciary, through the eyes of the majority of the respondents was more transparent and accountable since more information on the judiciary was available to the citizens. This view is shared by Armstrong (2010) in a study on an examination of transparency on local government websites which noted that one way that transparency in government / citizen relationship is gauged is through the availability of public records. The author argues that as more information appears on government websites, trust and confidence in government leaders increases. Armstrong's study showed that the local government website had the following information: official contact information, procedure manuals, meeting schedules, meeting agendas, job openings, local demographics, budgets and contract summaries to name but a few. From the findings therefore, it would seem that the judiciary was moving in the right direction towards open government implementation as provided for in the Open Government Implementation Model. Lee and Kwak (2011) identified two issues as being important at the data transparency stage: identifying high value data for the public; and improving and assuring data quality in terms of accuracy, consistency and timeliness. Following this, the judiciary should work on the data that is made available to the citizens to ensure that it is of high quality. Since records are a major source of information and the only reliable and legally verifiable data source (Wamukoya, 2000), the judiciary should manage its records management in a regime that ensures accuracy, integrity, timeliness and reliability of data.

The Kenyan judiciary was found not to have records management policies, procedure manuals adequate trained personnel and a sufficient top management support. This is likely going to have a negative impact on the judiciary's move towards openness. Wamukoya (2013) observed that in most sub-Saharan African countries (Kenya 
included), official records are not managed to meet international best practices. The implication for this according to IRMT (2012) is the likelihood that openness is impeded since the evidence base required in formulating policy, managing state functions, building reliable systems and monitoring official transaction is undermined. Thurston (2012) cautioned that in situations where official records are poorly managed, there is a high risk that open government initiatives will not meet international expectations since inaccurate data is most likely going to be used for development planning or holding governments accountable.

Moreover, from the findings of the current study, it was also deduced that the Kenyan judiciary was keen on deploying ICT infrastructure irrespective of the state of records management with the hope that this was going to facilitate transformation in the judiciary to enhance openness. The judiciary for instance had a directorate of ICT that spearheaded ICT deployment. This is unlike the records management function which as presented elsewhere did not have a directorate and lacked strong support at senior level meetings where policies were formulated. The ICT directorate therefore had formed a Judicial Information Communication Technology Committee (JICT) which oversees all ICT matters in the judiciary. The membership of the committee is drawn from the Court of Appeal, High Court, finance office, ICT office, National Council for Law Reporting, eGovernment and the Kenya ICT Board. The JICT Committee had initiated several ICT projects such as: digitization of court records which as explained earlier was not wholly successful; creation of a case management system; development of ICT policy and strategic plan; establishment of communication infrastructure; acquisition of hardware and software; and tele-presence court sessions.

Similarly, according to the fourth pillar of the Judiciary Transformation Framework, properly harnessed and deployed ICT can facilitate speedier trials and enhance the efficiency and effectiveness of administrative processes through data management, data processing and secure archiving of information while guaranteeing more transparency and fairness in the adjudication of cases facilitating internal and external communication (Judiciary Transformation Framework, 2012). As stated elsewhere, under this framework 
the judiciary planned to implement the following: establish an electronic case management system; establish an SMS inquiry system to inform members of the public about the status of the cases; digitize court records; install teleconferencing facilities; and to ensure the digital recording of proceedings and transcription among other activities (JTF, 2012).

Although all these plans would seem to be excellent ideas which will turn around the judiciary, there is a danger of concentrating on improving ICT deployment while ignoring the fundamental principles and practices of sound records management which as explained elsewhere is a critical tool in the administration of justice. Drawing from Thurston (2012), to be trusted government data needs to be drawn from reliable sources which in most cases are records managed within the auspices of a sound records management programme. Thurston cautions that with poorly managed records, the open data is not likely going to meet international expectations. Adding his voice to the debate, Wamukoya (2013) opined that the veracity of government data as a tool for open, transparent and accountable government, lies in the ability of government to demonstrate that information and data made available to citizens is accurate, complete, reliable, authentic and trustworthy.

As if to confirm the findings of the current study, an empirical study by IRMT (2012) observed that governments across the east Africa region (where Kenya belongs) were aggressively pursuing ICT and e-government projects without regulatory frameworks for records management in such areas as policy, legislation, human capacity and infrastructure as a means towards more openness. The study noted that such projects were bound to fail because of the gaps left by the absence of the regulatory framework mentioned.

Furthermore, the literature reviewed showed that studies on open government elsewhere (Alonso, Boyera, Bratt, Grewal and Iglesias, 2011; Nam, 2011; NASCIO, 2009; Davies 2010; Centre for Technology Policy Research, 2010; Stott, 2012; and Africa Centre for Open Government, 2011) tended to concentrate on datasets (data files or a group of 
related files usually found in websites) and related ICT with very little regard if any to government records or records management processes. Wamukoya (2012) rightly points out that open government cannot be complete without records since much of the information generated and maintained by any government is in the form of records. Wamukoya maintains that it is no longer a secret that records management processes in both public and private sectors, essentially determine the quality and integrity of the data generated and maintained in a manual as well as automated systems. Stott (2012) points out that the greatest pitfall in open government is the way it is perceived as just an ICT issue. Similarly, Wamukoya (2013) is of the view that too much reliance on technology has blurred the boundaries between open government data and the power of information, particularly in terms of records as evidence.

The success of open government therefore depends on the availability of accurate, reliable and trustworthy information in government records. Thurston (2012) observed that by aligning records management with open government initiatives, the information provided to citizens and other stakeholders can be trusted as a means of demonstrating transparency and a tool for the citizens to participate more fully in government decision making. Similarly, Wamukoya (2013) identifies the following as critical success factors for successful open government implementation: an infrastructure of laws, policies, standards, procedures and qualified staff that ensure the creation and maintenance of trustworthy records to document and support government decision making; the appropriate positioning of the records authority to support open government programmes; and the establishment of organization-wide records management programmes and policies.

The findings of the current study further showed that the Kenyan judiciary was not following the step by step procedure for open government implementation suggested by the OGIM. It would seem for instance that improving transparency was being pursued concurrently with seeking ubiquitous engagement. Under the transformation pillar on people-focused delivery of justice (pillar 1), one of its key result areas (KRA) was on public and stakeholder engagement. Under this pillar, the judiciary sought to engage the 
public in the administration of justice at various levels. The following activities had been undertaken or plans were underway: judicial open days, judicial road shows, public and student visitation had been institutionalized to close gap with public engagement; delivery of an annual status address by the Chief Justice; open court proceedings had been normalized as opposed to chamber hearing; the office of the ombudsperson had been established and expanded to receive internet or SMS based complaints; and lastly a public feedback mechanism was underway to harness public opinion and views on the judiciary's performance.

The findings suggest that too many open government activities were being pursued simultaneously which could possibly overburden the judicial officers and staff, overstretch the budgets and overwhelm the public (Lee and Kwak, 2011). As explained earlier the OGIM suggests a logical, sequential and systematic approach to the implementation of open government which seeks to minimize risks while maximizing benefits. It is the view of the researcher that for the judiciary to benefit more from its openness it should implement the ideals of the OGIM described above.

Further still, the findings of the current study revealed that the judiciary had already benefited from its move towards openness. The findings indicated a positive change as observed by the judicial officers and staff that took part in the study. Among the benefits of openness that stood out were: change of organizational culture; enhanced transparency and accountability; enhanced judicial service delivery; increased public participation; positive image of the judiciary; and improved public confidence in the judiciary. These benefits underline the importance of building open government initiatives (Wamukoya, 2013 quoting Fernando, 2012). Moreover, open government brings about: greater transparency and accountability of governments; efficiency and efficacy of public service delivery; and innovation in the creation and improvement of public services to name but a few.

These benefits however do not come without challenges, the findings showed that the judiciary was still grappling with challenges such as: too much openness which ordinarily 
would be viewed as a benefit but as explained by the judicial staff has resulted in a drastic increase in litigation which may contribute to case backlogs in the courts; negative criticism which as explained is sometimes misplaced as was illustrated with a situation where the Chief Justice (CJ) advised on the use of alternative dispute resolution mechanism and this was blown out of proportion by the media to indicate that the CJ was rooting for witch craft; untrained paralegal staff who ordinarily include records staff which as explained elsewhere were not adequately trained and could not offer the much needed support to the delivery of justice; inadequate funding which resulted in inadequate storage space and equipment and a general resource inadequacy all of which negatively affected service delivery especially records management in respect to inadequate storage space; and absence of records management policies and guidelines.

From the foregoing, it would seem that the judiciary was facing more challenges than the benefits they were obtaining from the transformation and openness. However the participants of the study proposed some solutions that they felt would help deal with the challenges if implemented. They proposed: capacity building; infrastructure development; putting in place records management policies; re-training of the staff or offering refresher courses; computerizing the registries and courtrooms and raising awareness on the importance of records and records management in the justice chain.

It is the opinion of the researcher that if these proposed solutions were implemented the majority of the challenges would be addressed and the benefits of openness maximized.

\subsection{Summary of Discussion of Findings}

This chapter offered an interpretation of the findings of the study in the light of the research questions underpinned by the Records Continuum Model, IRMT E-Readiness Tool and open government Implementation Model. The chapter therefore, discussed and interpreted the findings presented in chapter five, gave them meaning and provided implications for the study. 
The study sought to address the following research questions: How are records created, accessed and used, stored and maintained, appraised and disposed of; and preserved?; what records management policies, plans, and guidelines are available?; what skills and competencies do the records management staff have?; what is the level of awareness and attitude of staff towards sound records management practices?; and what records management strategies is the Kenyan judiciary using to achieve openness?

The study established that the judiciary did not manage its records well from creation to disposition as provided for by the RC Model. This was indicated by the following: absence of instructions or guidelines at the time of records creation; absence of a policy on access and use of records; inadequate storage space and equipment leading to poor storage of records; absence of an appraisal and disposition programme; inadequate preservation of records; lack of a disaster preparedness plan; and lack of a vital records management programme. The study also revealed that e-records management in the judiciary was in its infancy stage of development. The RC Model requires that records must be properly managed from creation and even before in the design of records management systems. Absence of proper records management ethos therefore contravenes the ideals of the model.

The Kenyan judiciary did not have records management policies, plans and guidelines. The IRMT E-Records Readiness Tool recognizes the importance of records management policies especially in organizations implementing e-government (IRMT, 2004). The absence of these policies therefore portrayed the judiciary as being far from successfully implementing an e-government and open government culture. However, an operation manual had just been launched and it emerged that records management had been captured in the judiciary strategic management plan. Further although records management was not vividly integrated in the Judiciary Transformation Framework, its elements were discernible.

Moreover, the study established that the judiciary had inadequate trained records management staff and the few that were trained were not properly deployed. 
Furthermore, these staff were not given the necessary support for attending records management conferences and workshops for purposes of career development and advancement. The IRMT E-Records Readiness Tool identifies qualified records management staff as being important for successful records management and implementation of e-government (IRMT, 2004). IRMT notes that although organizations may have established records management policies, they will be ineffective unless they are supported by qualified records management staff. The absence of these staff in the Kenyan judiciary suggests that the judiciary has a long way to go in order to successfully implement e-government and openness for the effective and efficient administration of justice. Further still, though records and records management was regarded as pivotal for the administration of justice, top management support was still regarded as minimal. Until top management support is guaranteed, effective records management may not be achieved. The IRMT E-Readiness Tool recommends that managers and staff need to be aware of the importance of trustworthy and well managed records for delivering effective government services and protecting the institutional accountability and integrity.

Lastly the judiciary was at its initial stage of implementing openness and its level of transparency had improved a great deal. However since openness is predicated on sound records management, the state of records management noted at the time of the study is likely to impede successful implementation of the judiciary transformation and openness thereof. Moreover, the findings indicated that the judiciary had planned for many activities aimed at opening up information to the public and stakeholders. The Open government Implementation Model however suggests a logical sequential and systematic step-by step approach to the implementation of open government (Lee and Kwak, 2011). The authors opined that this would minimize risks while maximizing benefits. Unfortunately the judiciary was not following this approach.

In summary, the Kenyan judiciary did not have a sound records management programme at the time of data collection. This state of affairs is likely to undermine the Kenyan judiciary's move towards openness which would facilitate an effective and efficient administration of justice. 
Table 13 presents a summary of findings mapped to the theoretical models underpinning the study, attributes of the models and the research questions.

Table 13: Summary of Findings Mapped to the Theoretical Models and the Research Questions

\begin{tabular}{|c|c|c|c|}
\hline $\begin{array}{l}\text { Theoretical } \\
\operatorname{Model}(\mathrm{s})\end{array}$ & $\begin{array}{ll}\text { Key } & \text { Variables } \\
\text { Addressed } & \end{array}$ & $\begin{array}{l}\text { Research } \\
\text { Questions }\end{array}$ & Summary of Findings \\
\hline RC Model & $\begin{array}{l}\text { (1) Records } \\
\text { Creation } \\
\text { (2) Records Access } \\
\text { and Use } \\
\text { (3) Records Storage } \\
\text { and Maintenance } \\
\text { (4) Records } \\
\text { Appraisal and } \\
\text { Disposition } \\
\text { (5) Records } \\
\text { Preservation }\end{array}$ & $\begin{array}{l}\text { (1) How are } \\
\text { records created, } \\
\text { accessed and used, } \\
\text { stored and } \\
\text { maintained, } \\
\text { appraised and } \\
\text { disposed of and } \\
\text { preserved? }\end{array}$ & $\begin{array}{l}\text { (1) Ineffective } \\
\text { records management at } \\
\text { creation } \\
(2) \quad \text { Fairly well } \\
\text { managed access and } \\
\text { use } \\
(3) \quad \text { Poor storage } \\
\text { and maintenance of } \\
\text { records } \\
\text { (4) Absence of an } \\
\text { appraisal and disposal } \\
\text { programme } \\
(5) \quad \text { Ineffective } \\
\text { preservation of records } \\
(6) \quad \text { E-records } \\
\text { management was just } \\
\text { starting } \\
\text { (7) The overall } \\
\text { records management } \\
\text { was fair/average }\end{array}$ \\
\hline $\begin{array}{l}\text { IRMT E- } \\
\text { Records } \\
\text { Readiness Tool }\end{array}$ & $\begin{array}{l}\text { (1) Records } \\
\text { Management Policies } \\
\text { and Responsibilities } \\
\text { (2) Records } \\
\text { Management Skills, } \\
\text { Competencies and } \\
\text { Training } \\
\text { (3) Records } \\
\text { Management } \\
\text { Awareness and Attitude }\end{array}$ & $\begin{array}{l}\text { (2) What } \\
\text { records } \\
\text { management } \\
\text { policies, plans and } \\
\text { guidelines are } \\
\text { available? } \\
\text { (3) What skills } \\
\text { and competencies } \\
\text { are available } \\
\text { among the records } \\
\text { management staff? } \\
\text { (4) What is the } \\
\text { level of awareness } \\
\text { about records and } \\
\text { attitude of staff } \\
\text { towards sound } \\
\text { records }\end{array}$ & $\begin{array}{l}\text { (8) Records } \\
\text { management policies } \\
\text { were not available } \\
(9) \quad \text { A registry } \\
\text { Operations manual had } \\
\text { been launched but had } \\
\text { not been implemented } \\
(10) \text { judiciary } \\
\text { strategic management } \\
\text { plan had taken records } \\
\text { management into } \\
\text { consideration } \\
(11) \quad \text { JTF had also } \\
\text { integrated records } \\
\text { management } \\
\text { (12) Inadequate } \\
\text { trained records staff }\end{array}$ \\
\hline
\end{tabular}




\begin{tabular}{|c|c|c|c|}
\hline & & management? & $\begin{array}{l}\text { (13) Records } \\
\text { management was } \\
\text { recognized as vital in } \\
\text { the administration of } \\
\text { justice. } \\
\text { (14) Records } \\
\text { management received } \\
\text { minimal support } \\
\text { (15) E-government } \\
\text { readiness was low }\end{array}$ \\
\hline $\begin{array}{l}\text { Open } \\
\text { Government } \\
\text { Implementation } \\
\text { Model }\end{array}$ & $\begin{array}{l}\text { (1) Data } \\
\text { Transparency } \\
(2) \quad \text { Open } \\
\text { Participation } \\
(3) \quad \text { Open } \\
\text { Collaboration } \\
\text { (4) Ubiquitous } \\
\text { Engagement }\end{array}$ & $\begin{array}{l}\text { (5) What strategies } \\
\text { is the Kenyan } \\
\text { judiciary using to } \\
\text { achieve openness? }\end{array}$ & $\begin{array}{l}\text { (16) judiciary was more } \\
\text { transparent } \\
\text { (17)Openness was } \\
\text { looked at from ICT } \\
\text { point of view } \\
\text { (18) State of records } \\
\text { management likely to } \\
\text { impede successful open } \\
\text { government } \\
\text { implementation. } \\
\text { (19) Too many } \\
\text { activities planned for } \\
\text { opening up the } \\
\text { judiciary which } \\
\text { overstretch the } \\
\text { judiciary staff and the } \\
\text { citizens } \\
\text { (20) Many challenges } \\
\text { facing the judiciary } \\
\text { required to be } \\
\text { addressed. } \\
\text { (21) Possible solutions } \\
\text { were suggested that } \\
\text { would avert these } \\
\text { challenges }\end{array}$ \\
\hline
\end{tabular}

\section{Source: Field Data 2014}

The next chapter (Chapter seven) provides a more detailed summary of the findings, conclusions and recommendations. 


\section{CHAPTER SEVEN \\ SUMMARY OF FINDINGS, CONCLUSIONS AND RECOMMENDATIONS}

\subsection{Introduction}

The summary and concluding chapter of a thesis is aimed at drawing together the threads of the research to arrive at some general conclusion and to suggest some way forward in addressing the research problem (Denscombe, 2007). The purpose of this study was to investigate records management in the Kenyan judiciary with a view to promoting transformation and open government for effective and efficient administration of justice. This study was motivated by the fact that the Kenyan judiciary was undergoing a transformation after many years of poor service delivery in part due to poor records management, lack of accountability and transparency in the administration of justice. The study addressed the following research questions:

1. How are records created, accessed and used, stored and maintained, appraised and disposed of, and preserved?

2. What records management policies, plans, and guidelines are available?

3. What skills and competencies do the records management staff have?

4. What is the level of awareness about records and attitude of staff towards sound records management practices?

5. What records management strategies is the Kenyan judiciary using to achieve openness?

The study was underpinned by the Records Continuum, IRMT E-records Readiness and Open Government Implementation models. A pragmatic research paradigm was used to guide the study using mixed methods where the qualitative and quantitative approaches were the dominant and less dominant respectively. The study adopted a case study design where data were collected using interviews, questionnaires, observations and document 
review. Qualitative data was analyzed thematically and presented in a narrative description while quantitative data were analyzed using SPSS and presented using descriptive and inferential statistics.

The rest of this chapter is organized around the research questions and broader issues around research problem covering: summary of findings, conclusions; recommendation; contribution of the study and further areas of research.

\subsection{Summary of the Findings}

The summary of findings covers records management from creation to disposition; erecords management; state of records management in the Kenyan judiciary; e-records readiness in the judiciary; records management policies, plans, and guidelines; skills and competencies among records management staff, level of awareness about records; attitude of staff towards sound records management practices; status of e-government in the judiciary; and records management related strategies for openness in the judiciary.

\subsubsection{Records Management from Creation to Disposition}

This section summarizes findings on the first research question which sought to establish how records were created, accessed, used, stored, maintained, appraised, disposed of, and preserved. The research question was addressed by the empirical part of the study with data collected from records officers, registry assistants, executive officers and deputy registrars. The findings presented under sections 7.2.1.1 to 7.2.1.7 respectively cover: records creation; records access and use; records storage and maintenance; security of records; records appraisal and disposition; records preservation; disaster preparedness; vital records management; e-records management and overall state of records management. 


\subsubsection{Records Creation}

The findings of the study showed that the judiciary depended entirely upon records in the delivery of justice. However, at the point of records creation there were no documented instructions to guide the staff on how the records needed to be created (Chapter 5 section 5.3.1.1). This meant that the staff were left to rely on experiential knowledge which often led to inconsistency in standardization in records creation and discontinuity especially whenever there were staff retirements, transfers or new recruitment. The results in general suggested ineffective management of records in the Kenyan judiciary especially at creation stage. This contravened the ideals of the RC Model which envisages management of records to conform to a continuum of care throughout the records lifecycle.

\subsubsection{Records Access and Use}

The findings of the study revealed that access and use of records in the judiciary was fairly well managed (see Chapter 5 section 5.3.1.2). All registries which were studied had filing systems that enabled the records to be arranged in an orderly manner using an alpha-numeric classification scheme thus facilitating easy retrieval of the records. Additionally, a few of the registries had computerized catalogues that facilitated easy retrieval of the records. Except in isolated cases, all the shelves where records were stored were labelled to facilitate retrieval. The judiciary also had in place a good records tracking system where any record leaving the storage areas was recorded and the recipient of the file(s) signed proof that they had received them. The tracking of files was facilitated by file movement registers. In some cases electronic tracking systems complemented the manual registers. However, the judiciary did not have a policy to regulate access to the records and how the access was to be facilitated. The lack of records access policy presented challenges such as determining who has the right to access the records especially to new staff and this could compromise standardization of records access procedures in the judiciary. 


\subsubsection{Records Storage and Maintenance}

The findings showed that the majority of the registries did not have designated areas for storing current, semi-current and non-current records. Consequently, these records were all stored together creating a congested and disorganized appearance of the affected registries (see chapter 5 section 5.3.1.3). Overall, the Kenyan judiciary had a serious problem of shortage of storage space such that at the time of the study some of the records were dumped on the floor without any logical arrangement. This problem affected easy retrieval of records as misfiling was common. However, in a few registries storage space was not a problem as such, especially in courts that had received donations in the form of containers among other things as explained elsewhere.

The findings revealed that generally the Kenyan judiciary did not have appropriate storage equipment. The most common storage equipment was wooden shelves which would aggravate disaster in the event of fire. The situation was exacerbated by the majority of the registries using bulk filers which were considered inappropriate since records could not be retrieved from more than one section at a time.

\subsubsection{Security of Records}

The overall results showed that the records in the Kenyan judiciary were relatively secure given that CCTV cameras had been installed in corridors and some rooms in all the court stations that were visited. Additionally, except in few isolated cases, most of the registries were restricted to staff only. Moreover, specific clerical officers were charged with the responsibility of overseeing files created in a particular year and this instilled in them a sense of responsibility to ensure the files were properly stored for ease of retrieval.

The respondents were asked if there were instances of missing files and if so the level of prevalence. The study findings revealed that in almost all the court stations missing files

were reported mostly as a result of misfiling (see results presented in Figure 8). The misfiling was attributed to such factors as: inadequate records staff, poorly trained 
records staff, lack of records management policies and guidelines, and reliance on manual records management strategies (see results in Figure 10). However the findings also indicated that the prevalence of missing files had been greatly reduced (see results in Figure 9) following the promulgation of Constitution 2010 of Kenya and the implementation of the Judiciary Transformation Framework (JTF) which helped change the organizational culture of the judiciary consequently reducing corrupt practices and instances of missing / lost files. These two initiatives also nurtured a culture of public and stakeholder engagement for enhanced service delivery.

\subsubsection{Records Appraisal and Disposition}

The overall findings on records appraisal and disposition in the Kenyan judiciary showed that the judiciary did not have a well-coordinated programme for appraisal and disposition of its records (see Chapter 5 section 5.3.1.4). It would appear that this exercise was left to the discretion of the "archivist" who was often overwhelmed with so much responsibility that he/she hardly undertook regular appraisal and disposal of records.

The findings further revealed that the Kenyan judiciary appraised and disposed records based on the Records Disposal Act Cap 14 of the Laws of Kenya (see Table 8) which provides guidelines of how all court records should be disposed by destruction and when. The study established that some provisions of the Act required amendment to reflect the current practices of the courts. One of the provisions for instance is that records relating to criminal cases should not be destroyed if the sentence of imprisonment of the accused exceeds one year. It was established however that currently many criminal cases including petty offenders were being given sentences of imprisonment of more than one year. The implication of this is that almost all records created ended up being kept permanently contributing to the shortage of storage space for records.

The findings further revealed that although the Kenyan judiciary did not have an appraisal and disposition programme, it had an elaborate procedure for appraising and 
disposing of records. This procedure begins with an audit of the records and culminates in destruction and issuance of a destruction certificate. Thereafter documentation of the action in a destruction register is done as proof of records that have been destroyed and how and why they were destroyed.

\subsubsection{Records Preservation}

The overall findings on records preservation in the Kenyan judiciary showed that records were not well preserved (Chapter 5 section 5.3.1.5). Specifically, environmental conditions were neither monitored nor controlled in almost all the registries. Ironically most of the storage areas were in basements of buildings requiring thorough monitoring and control since such basements normally were associated with high relative humidity and poor aeration. The records were therefore vulnerable to relative humidity and temperature.

Secondly, light readings were not recorded and windows were positioned in such a way that they allowed light into the storage areas. Moreover, the windows did not have curtains and/or blinders to filter the light. Further, all registries had artificial lighting (fluorescent tubes) systems to complement the natural light. In most cases light from florescent tubes was not filtered. In addition, because of the space problem it was common for files to be placed on top of the shelves in close proximity to the florescent tubes thus exposing the records to imminent danger of damage.

Additionally, the research findings showed that the Kenyan judiciary did not have a preservation policy which would guide preservation of its records. Equally, the staff seemed oblivious of the role that such a policy would play if it were in place in helping in preserving the records. 


\subsection{Disaster Planning and Preparedness}

The findings showed that the Kenyan judiciary did not have a disaster preparedness plan thus, exposing records to imminent loss or damage in the event of disasters. Similarly, the findings showed that the Kenyan judiciary did not have a vital records management programme. This meant that if a disaster struck, the judiciary was not likely to resume its normal operations easily as records would easily be destroyed.

\subsubsection{E-records Management}

The research findings revealed that the Kenyan judiciary was just starting to put in place infrastructure for managing electronic records such as computer hardware, internet connection and audio recording systems in courtrooms. The infrastructure was being developed and pilot studies had been done in two different court stations and plans were underway to roll this out to all other court stations in Kenya. At the time of the study there was little to show with regard to systems for the management of e-records as almost

all the records were created and managed manually. The staff however, seemed to be aware of the need and importance of managing e-records in the same way as the paper records.

\subsubsection{Overall State of Records Management in the Kenyan Judiciary}

The records management in the Kenyan judiciary was not at its optimum. The respondents expressed the need for shortcomings such as absence of a records management policy; inadequately trained records staff; inappropriate equipment and supplies; and inadequate funding to be addressed.

The findings further suggest that all courts studied had case backlogs, attributed to inadequate judicial staff and poor registry procedures. 


\subsubsection{E-records Readiness in the Kenyan Judiciary}

This section summarizes findings addressing research question 2, 3, and 4. The questions were partly addressed by the literature review and partly by the empirical study on data collected from registrars, records officers, registry assistants and judges and magistrates. The summaries are provided in sections 7.2.2.1 to 7.2.2.3 respectively covering: existing records management policies, plans and guidelines; skills and competencies; the level of awareness about records; and attitude of staff towards sound records management.

\subsubsection{Existing Records Management Policies, Plans and Guidelines}

The findings of the study revealed that the Kenyan judiciary did not have a records management policy (see Chapter 5 section 5.3.2.1). However, the judiciary had a recently launched registry operations manual had not been operationalized. The absence of the policy hampered effective management of records.

With regards to future plans, the Kenyan judiciary had a five year plan that envisaged computerization of registries and courtrooms. As per the plan, the Kenyan judiciary would implement an electronic system meaning records would be created and maintained electronically by the year 2017. The JTF which is anchored on four pillars and ten key result areas aims at achieving access to and expeditious delivery of justice to all. Of the four pillars, two of them seem to standout as having the greatest effect on records management in the judiciary. These two pillars are: pillar one on access to and expeditious delivery of justice which identifies development and deployment of an electronic case management system and embracing ICT and appropriate technology to enhance court efficiency and effectiveness; and pillar 4 on harnessing technology as an enabler for justice which identifies digitizing of court records and ensuring automatic recording of proceedings among other plans.

Unfortunately, JTF does not mention efforts that are envisaged to improve records management prior to computerization. 


\subsubsection{Skills and Competencies}

The findings of the study showed that the judiciary did not have adequately trained records management personnel (see chapter 5 section 5.3.2.2). Of those that were trained they were designated as archivists and charged with the responsibility of managing semicurrent and none current records. The implication was that the registries were manned by registry clerks and executive assistants who did not have any records management training. This seemed to affect the quality of records management in the registries especially with regard to appraisal and disposition since this cadre of staff did not have the knowledge on technical aspects of records management.

The study further found that the few staff who were trained in records management took their own initiatives to train themselves without the involvement of the judiciary. It also emerged that the judiciary was not providing opportunities to staff for capacity building through attending workshops and conferences in records management. This impeded staff career developments and it also meant knowledge on new and emerging issues in records management was not being learned by the staff.

\subsubsection{Level of Awareness about Records and Attitude of Staff towards Sound Records Management}

The findings of the study established that records management was highly valued and seen by staff as an important component in the administration of justice in the Kenyan judiciary. However, the study revealed that top management did not accord full support to records management in as far as resources, capacity building and infrastructure development were concerned. For example, there was no budgetary allocation for records management functions. Activities related to records management were therefore funded from the general budget despite the fact that such funding was rarely available. In addition the study revealed that the records management portfolio did not have the status of a directorate like other administrative functions such as human resource management. The implication was that records management lacked a senior person responsible for 
championing records management interests with regard to policy, infrastructure, budgets, and more.

\subsubsection{Status of E-government in the Kenyan Judiciary}

The findings of the study showed that the Kenyan judiciary was in the infancy stages in e-government implementation as the necessary infrastructure was not in place (see section 5.3.3). However, the judiciary had started: purchasing computers for each registry and purchasing lap tops for each judicial officer; networking the computers both through a LAN and linking them to the internet; and fitting voice recorders in court rooms.

The findings of the study showed that though e-government was being planned, the judiciary was faced with challenges such as: low literacy levels among the court users; digital divide; data security; inadequate equipment; and lack of trained personnel among other challenges.

\subsubsection{Records Related Strategies Used to Achieve Openness}

The study findings established that the judiciary was at the initial stages (data transparency) of implementing openness as envisaged in the Kenya Constitution 2010 and JTF (Chapter 5 section 5.3.4). The judiciary was in the meantime using many channels to publish information to educate the public on how they would access and use court services. These channels included: judiciary website; e-mail services; judicial roadshows; judiciary open days; court users committees and social media. Through these channels, the judiciary was reportedly seen as being more transparent, open and accountable by the public.

Successful open government implementation requires a records management regime that ensures accuracy, integrity, authenticity and reliability of data. This is because records are a major source of information and the only reliable and legally verifiable data source. The study found that the records management in the Kenyan judiciary was not 
conforming to best practices. For example, records were not managed well from creation to disposition; there were no records management policies; trained personnel were inadequate; and top management support was minimal. As a result, the open government initiative was likely to be compromised because accurate data needed for holding the judiciary accountable would be difficult to achieve in such an environment.

Furthermore, the findings of the study showed that the Kenyan judiciary was keen on deploying ICT as an enabler for its transformation and openness agenda. However, improving records management was not top on their agenda. Literature reviewed showed that open government cannot be successful without effective records management being addressed since much of the information generated and maintained by any government is in the form of records. Open government initiatives should therefore be aligned with records management if the initiative is to succeed.

The findings further showed that the Kenyan judiciary had planned many open government activities that were being pursued simultaneously. This in the opinion of the researcher could possibly overburden the judicial officers and staff, overstretch the budgets and overwhelm the public because the judicial officers were now expected to perform additional activities such as the judicial shows. Furthermore this has financial implications since all the activities would need funding.

Moreover, the study found several benefits that the judiciary had reaped from opening itself up to the citizens. Such benefits included enhanced transparency and accountability; enhanced judicial service delivery; and increased public confidence in the judiciary. These benefits however were not without challenges which included: too much openness that brought about a drastic increase in litigations; negative criticism from the public; untrained paralegal staff; inadequate funding; and ineffective records management. To address these challenges and pave the way for effective administration of justice the following proposals were made by respondents: enhancing capacity building: infrastructure development; improving records management by formulating records 
policies and training the staff; computerizing registries and court rooms; and raising awareness on the importance of records and records management in the justice chain.

\subsection{Conclusions}

This section provided conclusions based on the major findings of the study. The conclusions were drawn in the order in which the research questions were stated in chapter one.

\subsubsection{Conclusion on Records Management from Creation to Disposition}

The overall findings revealed that records management in the Kenyan judiciary was weak because of lack of instructions to guide the staff; lack of access policy; lack of designated storage areas for current, semi-current and non-current records; inappropriate storage equipment, missing files; lack of a well-coordinated programme for appraisal and disposition of the records; records were not well preserved; lack of a disaster preparedness plan and a vital records management programme; and lack of e-records management systems.

The conclusion drawn from this finding is that though the Kenyan judiciary has made significant improvement following the promulgation of Constitution of 2010 and the JTF in the management of court records much more is needed with regard to managing records from creation all the way to their ultimate disposition.

\subsubsection{Conclusions on Policies, Plans, and Guidelines Available in the Kenyan Judiciary}

The study findings revealed that the Kenyan judiciary did not have a records management policy in place. Roper and Millar (1999) noted that policy and legislative framework are necessary to create a conducive environment for effective management of records. Mnjama and Wamukoya (2007) noted that the management of records in all formats must be supported by clear policies, procedures and guidelines if they are to retain their 
evidentiary value for accountable and transparent governance. Without requisite records management plans and policies, the judiciary's quest to create and manage authentic, reliable and useable records capable of enhancing speedy delivery of justice (ISO, 2001) is being undermined and consequently slow successful implementation of the ongoing transformation and open government initiatives.

\subsubsection{Conclusions on Skills and Competencies among Records Management Staff in the Kenyan Judiciary}

The overall findings of the study on skills and competencies among records management staff established that the judiciary did not have adequately trained records management staff. It also emerged that the few who were trained were wrongly designated and were charged with the responsibility of overseeing records at semi-current and non-current stage leaving the active records under the care of untrained personnel. The implication for this is that records were not well managed from creation to disposition following the ideals of the RC Model. Moreover, effective management of records in the Kenyan judiciary would unlikely be attained if staff were not trained in records management

practices. Wamukoya and Mutula (2005) noted that skills and competencies in records management are necessary for organizations to demonstrate accountability, transparency and a commitment to root out corruption and malpractice.

\subsubsection{Conclusions on the Level of Awareness about Records and Attitude of Staff towards Sound Records Management in the Kenyan Judiciary}

The study findings revealed that records management was not accorded full support by management in terms of financial and infrastructure development. At the time of the study for instance there was no budgetary allocation for records management function and low status accorded to the records management portfolio in the organization.

It would seem top management did not understand value of sound records management. For effective justice delivery and protection of institutional accountability and integrity, the staff and top management need to be aware of the importance of trustworthy and well 
managed records. The low level of awareness is likely to impact negatively on the attitude towards records management and in effect hamper effective management of records and implementation of the transformation and open government agenda.

\subsubsection{Conclusions on Records Management Strategies Used to Achieve Openness in the Kenyan Judiciary}

The study findings revealed that the Kenyan judiciary was implementing an open government initiative to enhance transparency and accountability in its operations. Besides, the JTF would enable the citizens and stakeholders to freely engage with the judiciary. The judiciary had also lined up several activities to further open up the judiciary. The study concluded therefore that although a number of initiatives are planned and others being implemented to enhance service delivery, this is likely to be compromised without a sound records management foundation Thurston (2012) pointed out that to be trusted, government data needs to be drawn from reliable sources which in most cases are records managed based on a sound records management programme. Similarly, Wamukoya (2013) opined that the veracity of government data as a tool for open, transparent and accountable government, lies in the ability of government to demonstrate that information and data made available to citizens is accurate, complete, reliable, authentic and trustworthy.

\subsubsection{Overall Conclusion on the Research Problem}

The purpose of this study was to investigate records management in the Kenyan judiciary with a view to promoting transformation and open government for effective and efficient administration of justice. The study established that although the Kenyan judiciary had registered remarkable improvement in the way records were managed following the promulgation of the Kenyan Constitution 2010 and the subsequent launch of the Judiciary Transformation Framework, the current records management regime needed improvement. The study identified several weaknesses in the way records were managed which included: absence of instructions on how records should be created; absence of an 
access policy to regulate who has access to the records and how this should be facilitated; poor storage of records characterized by a serious lack of space and inappropriate storage equipment; absence of an appraisal and disposition programme; ineffective preservation of the records; absence of a disaster preparedness plan and a vital records management programme; absence of a general records management policy; inadequate trained records management staff; and inadequate top management support. In this kind of environment, it is not possible to guarantee the creation and management of records that are accurate, authentic, timely, reliable, and records whose integrity can be ascertained. Furthermore, the study established that the transformation and move towards openness in the Kenyan judiciary was pursued without a strong foundation of records management. In these circumstances there is a likelihood that the transformation and openness envisaged in the judiciary may be impeded since the evidence base required in formulating policy, managing judicial functions, building reliable systems and monitoring official transactions is undermined.

In view of this, the study made specific recommendations as presented below on how records management could be improved so that it can facilitate transformation and openness in the judiciary in order to improve service delivery and overall administration of justice.

\subsection{Recommendations}

Based on the findings of the study, the interpretation thereof and conclusion adduced above, the recommendations are proffered in section 7.5.1 - 7.5.5 covering: recommendations on records management from creation to disposition; recommendation on records management policy formulation; recommendation on skills and competencies requirement; recommendation on top management support; and recommendation on open government implementation. 


\subsubsection{Recommendation: Records Management from Creation to Disposition}

The study established that the effective management of records from creation to disposition in the Kenyan judiciary faced many challenges. These challenges were most likely going to impede proper management of records.

Recommendation 1: Records Storage - The Kenyan judiciary should consider providing appropriate storage environment and media for the records. In addition, the judiciary's top management needs to provide alternate storage space for semi current and noncurrent records to free space in the registries for the active records. Wema (2003) asserts that keeping current and non-current records together makes records storage difficult and may render the records irretrievable. The judiciary needs to either hire or build regional go downs where all the semi current and non-current records in a given region are stored. This would offer cheaper high density storage while relieving the primary storage space in the registries for current records hence easing congestion in the registries and facilitating easy and fast retrieval of records.

Recommendation 2: Preservation - It is also important to develop a preservation programme which would be preceded by an environmental impact assessment to determine possible environmental risks to the records. Such a survey would highlight the records that could be vulnerable to environmental related degradation so that appropriate interventions for their management are implemented. In addition, simple control measures such as installing air conditioning plants, having curtains and /or blinds on all windows and fitting light filters on all fluorescent tubes are recommended. Borrowing from IRMT (1999), all storage areas in the Kenyan judiciary should be kept within temperature and relative humidity levels of between $18 \mathrm{C}-20 \mathrm{C}$, and $35-45 \%$ respectively and light levels of about 50 lux maintained.

Recommendation 3: Storage Equipment -Regarding the storage equipment, the study recommends that the bulk filers should be moved to secondary storage areas (station archives) since they seemed inappropriate for registries. At the same time the judiciary's 
top management needs to provide an annual financial allocation for the purchase of fire proof shelves and cabinets.

Recommendation 4: Appraisal and Disposition - It is recommended that the records management staff need to consider developing an appraisal and disposition programme to ensure that appraisal and disposition is done on a routine basis to avoid having to appraise and dispose of the records just for purposes of creating space in the registry. The study also recommends the amendment of some sections of the Records Disposal Act Cap 14 of the Laws of Kenya upon which appraisal and disposition in the Kenyan judiciary is based. The proposed amendment is particularly with respect to the clause that requires records of persons charged in criminal cases whose jail sentence exceeds one year to be retained permanently. The study therefore proposes that the judiciary's top management through the Kenya Association of Lawyers (KAL) could propose to the relevant committee in the Legislative Assembly of Kenya to extend this period to five years. This is informed by the observation that in the current practice most criminal cases including petty crimes attracts jail terms of between three to five years forcing the records staff to retain almost all the files under criminal cases.

\subsubsection{Recommendation: Records Management Policy Formulation}

The study revealed that the Kenyan judiciary did not have a records management policy in place.

Recommendation 5: Policy - The study therefore strongly recommends that the judiciary considers putting in place a general records management policy which should include the management of records in electronic media. The policy would give guidance and effect to records management and address issues such as records access, records security and records preservation. Alternatively, the judiciary would consider developing individual policies on these areas which together with the overall records management policy would stream line records management in the judiciary. 
The policy would also provide a solid foundation upon which the recommendations of this study on managing records from creation to disposition are implemented to ensure effective management of records. ISO (2001) notes that with a records management policy, institutions such as the judiciary will be able to create and manage authentic, reliable and usable records capable of facilitating speedy delivery of justice. By formulating the policy therefore, the judiciary will demonstrate its commitment to records management (Mnjama and Wamukoya, 2007). Tsabedze, Mutula and Jacobs (2012) recommended the enactment of records management policies which would facilitate development of capacity building plans and putting in place records management programmes.

Recommendation 6: Records Management Procedure Manual - It is recommended that staff should be made aware of and educated about the records procedure manual and all the registry staff should be trained on how the manual should be implemented. Chinyemba and Ngulube (2005) recommended the need for a records management manual in all institutions with statutory responsibility for records. They noted that manuals provide a reference point for practices and procedures while helping to standardize records management activities. Iwhiwhu (2005) also recommended that a records manual and policy guiding the management of records should be formulated.

\subsubsection{Recommendation: Skills and Competencies Requirement}

The study findings revealed that the judiciary did not have adequate trained records management staff. The few who were trained were wrongly designated and charged with the responsibility of managing semi current and non-current records while the active records were managed by staff that had no training in records management. Moreover, these staff did not receive any support to attend continuous training through seminars, workshops and conferences.

Recommendation 7: Capacity Building - It is therefore recommended that more trained personnel be hired from graduates from institutions of higher learning such as Moi 
University that offer records management and related courses. Alternatively, the executive assistants and clerical officers currently running the registries could be trained at diploma or degree levels in records management. This would ensure that records are managed by staff with required skills and competencies in order for them to contribute to effective records management for the realization of transformation and openness in the Kenyan judiciary. Ngulube (2001) emphasized the need for records staff with records management skills and knowledge as a prerequisite to effective records management. Similarly, in their study, Kemoni and Ngulube (2007) recommended that in order to raise the profile of records management in the public service in Kenya, staff in the registries should be recruited and deployed on the basis of their records management qualifications and experience. Ngulube and Tafor (2006) recommended that archival institutions in the ESARBICA region should collaborate with universities that offer archival training in the region so that they can get assistance regarding their critical skills needs. In addition, staff should be encouraged to attend records management conferences, workshops and seminars. Such continuous training is necessary to ensure career development among the staff and for them to be kept abreast with emerging issues in records management. In her study, Sichalwe (2010) recommended the provision of a higher level of training in records management among the registry staff and the need for providing more training through short courses, workshops and seminars in records management for them to update their knowledge and skills in records management.

Recommendation 8: Posts of Archivist and Records Officers - The study recommends the creation of a post of "Records officers" alongside that of "Archivists" in the Kenyan judiciary. The post should be occupied by staff with records management training either at Certificate, Diploma or Degree Level. Their responsibilities should be well defined in the proposed policy to include managing judiciary registries. The staff occupying the cadre of records managers should then work in hand with the archivists to ensure a continuum of care for the records from creation to disposition. This would ensure that records receive the necessary attention right from the time they are created through to their disposal thus meeting the requirements of the RC Model. 


\subsubsection{Recommendation: Top Management Support}

The study findings revealed that although records management was seen as an important component in the delivery of justice, it had not been supported fully by top management. There was no budgetary allocation for records management. In addition there was no provision for records management directorate to elevate its records management status in the organization.

Recommendation 9: Status of Records Management in the organization Structure - The study recommends that the judiciary should consider elevating the status of records management by appointing a records management director. The directorate would champion all the interests of the judiciary and ensure it receives its due recognition especially on matters relating to hiring of qualified staff, drafting records management policies and for budget planning. The study also recommends the allocation of an independent budget for records management to cater for capacity building, equipment, supplies and more.

\subsubsection{Recommendation: Open Government Implementation in the Kenyan Judiciary}

The study findings revealed that the judiciary had started implementing its transformation agenda and moving towards being more transparent and open to the citizens and the stakeholders. Consequently, the judiciary was more transparent and open to citizens and stakeholders than ever before. However, this openness was hinged on an ineffective records management regime. The study established that the poor state of records management is more likely to inhibit the success of the open government strategy in the judiciary.

Recommendation 10: Records Management and Open government -The study therefore recommends that the alignment of open government to records management using Lee and Kwak's (2011) model on open government implementation be used as a benchmark. 
This will allow the judiciary to employ a logical and systematic approach in the way the open government implementation is approached to minimize risks and achieve better results. Thurston (2012) observed that by aligning records management with open government initiatives, the information provided to citizens and other stakeholders can be trusted as a means of demonstrating transparency and a tool for the citizens to participate more fully in judiciary decision making. This is also important because records are a major source of information and probably the only reliable and legally verifiable data source (Wamukoya, 2000). Additionally, ICT deployment need not be seen as the only tool that can facilitate the transformation and openness in the judiciary. Stott (2012) decried the perception of open government as an ICT issue and emphasized the importance of a sound records management regime.

\subsection{Originality of the Study}

The concept of open government anticipates that all public data should be openly published and made available not only for scrutiny and review but for potential reuse. As a result open government Data (a pillar of open government) is widely used in literature to refer to a situation where government ministries and agencies put their raw data on the web in readable formats. Consequently, extant literature on open government has tended to concentrate on datasets and related ICTs with very little regard if any to government records or records management processes. In reality, Open Government Data cannot be effectively implemented and managed without sound records management since much of the information generated and maintained by any government is in the form of records (Wamukoya, 2013). The current study therefore attempted to look at open government in the Kenyan judiciary from a records management perspective. The study recommended the alignment of open government policies with records management policies in order to create meaningful openness and speedy delivery of justice in the Kenyan judiciary. This was premised on the fact that records management provides the means through which to guarantee the creation, capture, availability and usability of accurate, reliable and trustworthy records that can be trusted as evidence in open government. 
Furthermore, the literature reviewed revealed that open government was a relatively new field of study (Yu and Robinson, 2012) and most open government models have been generated in the developed countries notably the United States of America and United Kingdom. Studies such as the current one contribute to developing models peculiar to developing countries by providing empirical evidence of specific challenges that such countries contend with and that require to be factored in the models. Moreover, few empirical studies on open government have been done in Africa and particularly in Kenya. The current study is therefore significant in contributing to the scholarly research and literature on open government in developing countries such as Kenya.

\subsection{Suggestions for Further Study}

There are four suggestions for further study. The current study investigated records management practices in the Kenyan judiciary with a view to promoting transformation and open government for effective and efficient justice delivery. The study was limited to two courts that were thought to carry the most burden in the delivery of justice (the high court and the magistrate courts) in Kenya. However, there are other players in the justice chain who equally contribute to or undermine the delivery of justice in Kenya. These include: the police, the prison department, Judicial Service Commission, and lobby groups like the Kenya Association of Lawyers. The current study recommends firstly, a further study to be undertaken with these other players to determine how they manage their records and the impact this has on the overall delivery of justice in Kenya.

The current study revealed that most open government models that exist in literature originated in developed countries such as United Kingdom and the United States of America. The current study however used such a model as a bench mark for implementing open government in the Kenyan judiciary. The study did not attempt to propose a model, it therefore recommends a second further study specifically geared towards developing a model for open government implementation rooted in the developing world context. 
Thirdly, although the study touched on policy issues with regards to the management of records and the implementation of open government in the judiciary, it was not covered in detail. The study therefore recommends a further study on policy, legislative and regulatory framework for records management in the public sector in Kenya.

Lastly, a further study is recommended on the other types of courts (Supreme Court, Court of Appeal and Kadhis Court) to investigate the role of records management in transforming the judiciary and implementing open government initiatives. This would offer a holistic view of how records are managed in the entire judiciary and how it can facilitate or undermine transformation and open government initiatives. Moreover since the findings of the current study indicated that the judiciary had started implementing its open government initiative, a further study on the evaluation of the open governance is recommended. This would collect data from external users such as lawyers, advocates, members of the public and other stakeholders to be used in determining the level of openness in the Kenyan judiciary. 


\section{REFERENCES}

Abankwah, R. and Ngulube, P. (2012). Environmental Conditions and the Storage of Audiovisual Materials in Archival Institutions in the ESARBICA Region. ESARBICA Journal 31: 74-82.

Affisco, J. F. and Soliman, K. S. (2006). E-government: a Strategic Operations Management Framework for Service Delivery. Business Process Management Journal 12(1): 13-21.

Africa Centre for Open Governance, (2011). Kenya Governance report. Available at http://africog.org/sites/default/files/AGR\%20Report.pdf [Accessed 26 February 2013].

Aina, L. O. and Ajiferuke, I. S. (2002). Research Methodologies in Information Science. In L. O. Aina (ed.), Research in Information Science: an African Perspective (pp3262).Ibadan, Nigeria: Stirling-Horden.

Akotia, P. (2002). Management of Public Sector Financial Records In Ghana: Implications For Good Government. African Journal of Library, Archives and Information Science 10(2):153-165.

Akther, M., Onishi, T. \& Kidoro, T. (2007). E-Government in a Developing Country: Citizencentric Approach for Success. International Journal of Electronic Governance 1(1): 38-51.

Akussah, H. (2002). Records Management and Preservation in Government Ministries and Departments in Ghana. African Journal of Library, Archives and Information Science 12(2):155-165.

Akussah, H. (2011). Managing and Preserving Records and Archives that Guard Against Collective Amnesia. ESARBICA Journal 30: 5-14.

Alonso, J. M., Boyera, S., Bratt, S., Grewal, A., and Iglesias, C. (2011). Open government data: Feasibility Study in Ghana. Available at https://public.webfoundation.org/2011/05/OGD_Ghana.pdf [Accessed 23 February 2013].

Ambira, C. M. (2010). Records management and risk management at Kenya Commercial Bank Limited, Nairobi. MSc Thesis. Kenya: Moi University. 
Ambira, C. M. \& Kemoni, H. (2011). Records management and risk management at Kenya Commercial Bank Limited, Nairobi. SA Journal of Information Management 13(1): 1-11.

American Records Management Association. (2005). The Records as Documentary Evidence. Available at https://sites.google.com/site/getbetterconnected2/clubsassociations-3/professional/arma---american-records-management-association [ 27 November 2010].

An, X. (2001). A Chinese View of Records Continuum Methodology and Implications for Managing Electronic Records. Paper presented at an International Symposium on the Management of Archival Electronic Records: Theory and Practice. Held in Hangzhou, China, 11-13 November, 2001.

An, X. and Jiao, H. (2004). Assessing Records Management in China against ISO 15489 and the Implications. Records Management Journal 14 (1): 33-39.

Armstrong, C. L. (2010) Providing a Clearer View: an Examination of Transparency on Local Government Websites. Government Information Quarterly 28: 11-16.

Atherton, J. (1985). From Life Cycle to Continuum: Some Thoughts on Records Management - Archives Relationship. Archivaria 21(Winter 1985-1986):43-51.

Babbie, E. (2004). The Practice of Social Research. (10th ed.) Belmont, CA: Wadsworth.

Babbie, E. and Mouton, J. (2001). The Practice of Social Research. Cape Town: Oxford.

Bannister, F. (2007). The Curse of the Benchmark: an Assessment of the Validity and Value of E-Government Comparisons. International Review of Administrative Sciences 73(2): 171-188.

Bantin, P. (2002). Electronic Records: A review of a decade and a reflection of future directions. In Kent, A. and Hall, C. (eds). Encyclopedia of Library and Information Sciences Vol. 74 pp. 47-81. New York: Marcell Dekker.

Barry, R. E. (1994). Electronic Document and Records Management Systems: Towards a methodology for requirements definition. Information Management \& Technology 27 (6): 251-56.

Basu, S. (2004). E-Government and Developing Countries: an Overview. International Review of Law, Computers \& Technology 18(1): 109-132. 
Bazeley, P. (2008). Mixed Methods in Management Research. In R. Thorpe, and R. Holt (eds), The Sage Dictionary of Qualitative Management Research pp. 133-136.

London: Sage.

Blaxter, L., Hughes, C. and Tight, M. (2006). How to research. (3rd ed.) Berkshire: Open University Press.

Bonabeau, E. (2009). Decisions 2.0: The Power of Collective Intelligence. MIT Sloan Management Review 50(2): 45-52.

Case, D. O. (2007). Looking For Information: A Survey of Research on Information Seeking Needs and Behavior. ( $2^{\text {nd }}$ ed.) London: Academic Press.

Caughey, M. (2004). Keeping Attorneys from Trashing Identities: Malpractice as Backstop Protection for Clients under the United States Judicial Conference's Policy on Electronic Court Records. Washington Law Review 79:407.

Centre for Technology Policy Research. (2010). Open government: Some Next Steps for the UK. Available at http://ctpr.org/wp-content/uploads/2010/05/CTPR-Report-OpenGovernment.pdf

[Accessed 23 February 2013].

Chachage, B. L. and Ngulube, P. (2006). Management of business records in Tanzania: an exploratory case study of selected companies. South African Journal of Informatio Management 8 (3).

Chadwick, A. May, C. (2003). Interaction Between States and Citizens in the age of the Internet: "E-Government" in the United States, Britain, and the European Union. International Journal of Policy Administration 16(2): 271-300.

Chen, Y., Chen, H., Huang, W. \& Ching, R. (2006). E-Government Strategies in Developed and Developing Countries: an Implementation Framework and Case Study. Journal of Global Information Management 14(1): 23-46.

Chinyemba, A. and Ngulube, P. (2005). Managing Records at Higher Education Institutions: A Case Study of the University of Kwazulu-Natal, Pietermaritzburg Campus. South African Journal of Information Management 7(1).

Choudrie, J., Weerakkody, V., \& Jones, S. (2005). Realising E-Government in the UK: Rural and Urban Challenges. The Journal of Enterprise Information Management 18(5): 568-585.

Cohen, L., Manion, L. and Morrison, K. (2007). Research Methods in Education. (6th ed.) London: Routledge Falmer. 
Collaboration on International ICT policy for East and Southern Africa (CIPESA), 2011. Open Government: Which Way Africa? Available at http://zunia.org/post/open-government-which-way-africa [Accessed 23 February 2013].

Collaboration on International ICT policy for East and Southern Africa (CIPESA). (2012). Uganda open government Data Readiness Study. Available at http://www.apc.org/en/system/files/Open\%20Government\%20Data\%20Readiness\%20 Study\%20for\%20Uganda-final.pdf [Accessed 20 February 2013].

Constitution of Kenya Review Commission, (2012). Report of the Advisory Panel of Eminent Commonwealth Judicial Experts, May 17. Available at http://www.commonlii.org/ke/other/KECKRC/2002/8.html [Accessed 23 November 2012].

Cowell, F. (2010). The Road to Kenya's New Constitution. Available at http://www.consultancyafrica.com/index.php?option=com_content\&view=article\&i $\mathrm{d}=567$ :the-road-to-kenyas-new-constitution\&catid=91:rightsinfocus\&Itemid=296titution - [accessed 2 December 2012].

Cox, R. J. (2000). Closing an Era: Historical Perspectives on Modern Archives and Records Management. London: Greenwood Press.

Cox, R. J. and Wallace, D. A. (2002). Introduction. In: Cox, J. and Wallace, D. A. (eds). Archives and the public good: accountability and records in modern society. Westport, Connecticut: Quorum Books. pp. 1-18.

Creswell, J. W. 2003. Research Design: Qualitative, Quantitative and Mixed Methods Approaches. $\left(2^{\text {nd }}\right.$. Ed.), Sage Publication.

Curtin, D. and Meijers, H. (n.d.). The Principles of Open Government in Schengen and European Union: Democratic Retrogression? Available at https://atmire.com/dspacelabs3/bitstream/handle/123456789/6910/file14227.pdf?sequence=1 [Accessed 5 February 2015].

Curtin University of Technology, 2005. Understanding Society through its Records: Australian Contribution to Record keeping. Available at http://www.john.curtin.edu.au/society/australia/ [Accessed 10 January 2012].

Dada, D. (2006). The Failure of E-Government in Developing Countries: A literature Review. The Electronic Journal on Information systems in Developing Countries 26(7): 1-10. 
Davies, T. (2010). Open Data, Democracy and Public Sector Reform: A Look at Open government Data Readiness Study. Available at http://www.academia.edu/988533/Open_Data_Democracy_and_Public_Sector_Refo rm [Accessed 23 February 2013].

De Vos, A. H., Strydom, C. F. and Delport R. (2005). Research at Grass Roots: For the Social Science and Human Service Professions. $\left(3^{\text {rd }}\right.$ ed.) Hatfield, Pretoria: Van Schaik Publishers.

Dean, J. F. (2002). Environment and passive climate control chiefly in tropical climates. Paper presented at the 68th IFLA Council and General Conference, Glasgow, August 18-24, 2002. Available at http://ifla.queenslibrary.org/IV/ifla68/papers/120158e.pdf [Accessed 16 September 2012].

Denscombe, M. (2007). The Good Research Guide for Small-Scale Social Research Projects ( $3^{\text {rd }}$ ed). Maidenhead: Open University Press.

Denzin, N. K. and Lincoln, Y. S. (2005). Handbook of Qualitative Research. (2nd ed.). London: Sage Publication.

Ebrahim, Z. and Irani, Z. (2005). E-Government Adoption: Architecture and Barriers. BusinessProcess Management Journal 11 (5): 589-611.

Edmonds, W A. and Kennedy, T. D. (2013). An Applied Reference Guide to Research Designs: Quantitative, Qualitative and Mixed Methods. Sage Publications.

Excell, C. and Sendugwa, G. (2012). Open government Partnership: Africa Nations Commit to New Levels of Transparency. Available at http://insights.wri.org/news/2012/08/open-government-partnership-african-nationscommit-new-levels-transparency [Accessed 20 February 2013].

Fink, A. (2006). How to Conduct Surveys: A Step by Step Guide. (3rd ed). Thousand Oaks, CA: Sage Publications.

Flynn, S. J. A. (2001). The Records Continuum Model in Context and its Implications for Good Government. African Journal of Library, Archives and Information Science 10(2):153-165.

Garaba, F. (2010). An Investigation into the Management of the Records and Archives of Former Liberation Movements in East and Southern Africa Held by National and Private Archival Institutions. Ph.D Thesis. South Africa: University of KwaZuluNatal. 
Gaveline, K., Burall, S. and Wilson R. (2009). Open government: Beyond Static Measures. Available at http://www.oecd.org/gov/46560184.pdf [Accessed 2 March 2013].

Gorman, G. E. and Clayton, P. (2005). Qualitative Research for the Information Professional: a Practical Handbook. London: Facet Publication.

Griffin, A. (2003). Managing Records in the Electronic Age, unpublished, IRMT, London.

Harrison, T. M., Guerrero, S., Burke, G. B., Cook, M., Cresswell, A., Helbig, N., Hrdinova, J. and Pardo, T. (2012). Open Government and E-government: Democratic Challenges from a Public Value Perspective. Information Policy 17: 83-97.

Heusser, F. n.d. Understanding Open Government and Addressing its Impact (draft document).

Henning, E. (2004). Finding Your Way in Qualitative Research. Pretoria: van Schalk Publishers.

Human Rights Watch, (2012). World Report: Kenya. Available at http://www.hrw.org/world-report-2012/world-report-2012-kenya [Accessed 15 January 2013].

Infocomm Development Authority. (2013). Singapore Makes Strides in Open Data. Available at http://www.ida.gov.sg/blog/insg/special-reports/singapore-makes-strides-in-opendata/ [Accessed 5 February 2015].

International Standards Organization (ISO), (2001). ISO 15489-1:2001 Information and documentation: Records Management Standard . Part 1: General. Geneva: International Organization for Standardization.

International Records Management Trust. (1999). Managing Legal Records. London: International Records Management Trust.

International Records Management Trust. (2000). Managing Records as the Basis for Effective Service Delivery and Public Accountability in Development. London: International Records Management Trust. 
International Records Management Trust. (2002). South African Courts Records Management System. Available at http://www.irmt.org/documents/research_reports/case_studies/legal_judicial_rec_case studies/south_africa/IRMT_Legal_CS_Africa.pdf [Accessed 3 March 2013].

International Records Management Trust (IRMT). (2003). E-records Readiness: Establishing E-records as a component of Electronic Government. A proposal, IRMT, London.

International Records Management Trust. (2004). E-Records Readiness Tool._Available at http://www.nationalarchives.gov.uk/rmcas/documentation/eRecordsReadinessTool_v2 Dec2004.pdf [Accessed 25 February 2013].

International Records Management Trust. (2009). Understanding the context of electronic Records management. London: International Records Management Trust.

International Records Management Trust. (2011). Aligning Records Management with ICT/ E-Government and Freedom of Information in East Africa. Available at http://www.ica2012.com/files/data/Full\%20papers\%20upload/ica12final00116.pdf [Accessed 10 February 2013].

International Records Management Trust. (2011). Managing Records as Evidence for ICT/ E-Government and Freedom of Information: Kenya Court Case Study. IRMT, London.

International Records Management Trust. (2012). Public Records: Evidence for Openness (draft document). London. IRMT.

Iwhiwhu, E. B. (2005). Management of Records in Nigerian Universities: Problems and Prospects. The Electronic Library 23(3): 345-355.

Janssen, M., Charalabidis, Y. and Zuiderwijk, A. (20120. Benefits, Adoption Barriers and Myths of Open Data and Open Government. Information Systems Management 29 (4): $258-268$.

Jenkinson, H. (1937). A manual of Archival Administration. London: Percy Lund, Humphries and Co. Ltd.

Johnson, B. and Christensen, L. (2008). Educational Research: Quantitative, Qualitative and Mixed Approaches. (3rd ed). Thousand Oaks, CA: Sage Publications. 
Judicial Council of California. (2013). Trial Court records Management Manual Available at http://www.courts.ca.gov/documents/trial-court-records-manual.pdf [Accessed 12 September 2013].

Judiciary Transformation Framework. (2012). Laying the Foundations for the Transformation of the Kenyan Judiciary. Available at http://www.judiciary.go.ke/portal/assets/downloads/reports/Judiciary's\%20Tranform ation\%20Framework-fv.pd [Accessed 23 November 2012].

Kalcul, A. T. (2009). Evolution of E-Records Management Practices in E-Government: a Turkish Perspective. The Electronic Library 27(6): 999-1009.

Kargbo, J. A. (2009). The Connection between Good Governance and Recordkeeping: the Sierra Leone Experience. Journal of the Society of Archivists 30(2):249-260.

Keakopa, S. M. (2007). Policies and Procedures for the Management of Electronic Records in Botswana, Namibia and South Africa. ESARBICA Journal 26:70-82.

Kelly, A. (2014). Singapore government focuses on Big Data, Open Data, Cloud \& Security. Available at http://www.futuregov.asia/articles/singapore-governmentfocuses-on-big-data-open-data-cloud-security [Accessed 12 February 2013].

Kemoni, H. (2007). Records Management Practices and Public Service Delivery in Kenya. PhD Thesis. Pietermaritzburg: University of KwaZulu-Natal.

Kemoni, H. N. (2008). Theoretical Framework and Literature Review in Graduate Records Management Research. African Journal of Library, Archives and Information Science 18(2): 103-117.

Kemoni, H. N. and Ngulube P. (2007). National and the Effective Management of Public Sector Records in Kenya. Mousaion 25 (2): 120 -140.

Kemoni, H., Maseh, E. and Mzerah N. (2011). Student Assessment of the Master of Philosophy in Information Sciences (Records and Archives Management) Degree Programme at Moi University, Kenya. ESARBICA Journal. 30: 35-56.

Kenya ICT Board. (2012). Kenya Open Data. Available at http://www.ict.go.ke/index.php/hot-topic/416-kenya-open-data [Accessed 16 February 2013].

Kenya Law Reports Website. (2013). Office of the Chief Justice: Reorganization of the High Court and Court of Appeal. Available at http://www.kenyalaw.org/klr/index.php?id=25 [Accessed 4 March 2013]. 
Kenya Law Reporting. (2003). Records Disposal Act Cap 14 Laws of Kenya Available at www.kenyalaw.org:8181/.../Legislation/.../Acts\%20and\%20Regulations/... [Accessed 27 December 2012].

Keorapetse, D. L. and Keakopa, S. M. (2012). Records Management as a Means to Fight Corruption and Enhancing Accountability in Botswana. ESARBICA Journal 31: 2335 .

Kioko, W. (2000). The State of Constitutional Development in Kenya. Available at http://www.kituochakatiba.org/index2.php?option=com_docman\&task=doc_view\&g

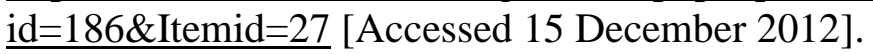

Komen, B. C. (2012). Management of Personnel Records in Support of Good Governance at the Ministry of Local Government Headquarters Nairobi. Master's Thesis, Kenya: Moi University.

Kothari, C. R. (2004). Research Methodology: Methods and Techniques. (2nd ed.) New Delhi: New Age International.

Krishnaswami, O. R. and Ranganathan M. (2010). Methodology of Research in Social Sciences. Mumbai: Himalaya Publishing House.

Kumar, R. and Best, M. L. (2006). Impact and Sustainability of E-Government Services in Developing Countries: Lessons Learned from Tamil Nadu, India. The Information Society: An International Journal 22(1): 1-12.

Lapan, S. D. \& Armfield, S. W. J. (2009). Case Study Research. In S. D. Lapan \& M. T. Quartaroli (eds) Research Essentials: An introduction to Designs and Practices. San Francisco: Jossey-Bass.

Lapan, S. D., Quartaroli, M. T. and Riemer, F. J. (2012). Qualitative Research: an Introduction to Methods and Designs. San Francisco: Jossey-Bass.

Lauden, L. (1995). Beyond positivism and Relativism: Theory, Method and Evidence. Boulder: West View Press.

Lee, G. and Kwak, Y. (2011). An Open government Implementation Model: Moving to Increased Public Engagement. Available at http://www.businessofgovernment.org/sites/default/files/An\%200pen\%20Government \%20Implementation\%20Model.pdf [Accessed 20 February 2013].

Lee, S. M., Tan, X., \& Trimi, S. (2005). Current Practices of Leading E-Government Countries. Communications of the ACM 48(10): 99-104. 
Leech, N. L. and Onwuegbuzie, A. J. (2009). A Typology of Mixed Methods Research Designs. Quality and Quantity 43(2):265-275.

Lincoln, Y. S. \& Guba, E. G. (1985). Naturalistic Inquiry. Beverly Hills, CA: Sage.

Lubale, G. (2012). Courts System in Kenya. Available at http://gabriellubale.com/courtssystem-in-kenyal [Accessed 24 April 2013].

Lyons, K. (2005). How to conduct a Literature Review. Available at: http://www library.ucsc.edu/ref/how to/literaturereview.html. [Accessed 16 July 2012].

Lipchak, A. (2002). Information Management to Support Evidence-based Government in an Electronic Age: A Public Policy Discussion Paper. Available at http:// www.ppforum.ca/ow/ow/p112002es.pdf [Accessed 20 December 2011].

Maguire, R. (2005). Lessons Learnt from Implemeenting an Electronic Records Management System. Records Management Journal 15 (3): 150-157.

Maingi, G. (2010). The Kenyan Constitutional Reform Process: A Case Study on the work of FIDA Kenya in Securing Women's Rights. Feminist Africa 15: 63-82.

Majeed, R. (2012). Disseminating the Power of Information: Kenya Open Data Initiative, 2011 - 2012. Available at https://www.princeton.edu/successfulsocieties/content/data/policy_note/PN_id206/Pol icyNote_ID206.pdf [Accessed 12 February 2013].

Majinge, M. M. (2014). Library Services' Provision for People with Visual Impairments and in Wheelchairs in Academic Libraries in Tanzania. Ph. D Thesis, South Africa: University of KwaZulu Natal.

McDonald, J. (2000). Information Management in the Government of Canada: a Situation Analysis. Available at http:// www.tbs-sct.gc.ca/ip-pi/im-gi/imreport/imreportrapportgi_e.pdf [Accessed 12 August 2010].

McDonald, J. (2002). Financial Capability Model and the Records Management Function: an Assessment. Ottawa: Public Policy.

McKemmish, S. (2001). Placing Records Continuum Theory and Practice. Archival Science 1:333-359.

Michira, M. (2013, October 14). Kenya's Reformed Judiciary Facing Acid Test in Latest Turn of Events. The Standard Newspaper: 1-3. 
Mikkelsen, B. (2005). Methods for Development Work and Research: A New Guide for practitioners ( $2^{\text {nd }}$ ed.). London: Sage Publication.

Millar, L. (1997). Principles of Records and Archives Management. London: ICA/IRMT.

Millar, L. (2003) The Right to Information - the Right to Records: the Relationship between Recordkeeping, Access to Information and Government Accountability. Commonwealth human Rights initiative (CHRI) Contribution. Available at http://www.humanrightsinitiative.org/programs/ai/rti/articles/record_keeping_ai.pdf [Accessed 23 November 2012].

Millar. L. (2003). The Right to Information-the Right to Records: the Relationship Between Mixed Approaches. (3rd ed.) Thousand Oaks, CA: Sage Publications.

Mnjama, N. (2003). Archives and Records Management in Kenya: Problems and Prospects. Records Management Journal 13(2): 91 - 10.

Mnjama, N. and Wamukoya, J. (2004). E-governance: the Need for an E-Records Readiness

Assessment Tool. Report on Proceedings of the SADC Regional Consultation on National e-Government Readiness, Gaborone, Botswana. 14-16 April 2004. 〈http://www.comnet-it.org/news/CESPAM-Botswana.pdf> [Accessed 12 March 2012].

Mnjama, N. and Wamukoya, J. (2007). E-government and Records Management: an Assessment Tool for E-records Readiness in Government. The Electronic Library 25(3): 274-284.

Moloi, J. (2009). E-records Readiness in the Public Sector in Botswana. ESARBICA Journal

28:105-127.

Moloi, J. and Mutula, S. (2007). E-records Management in an E-government Setting in Botswana. Information Development 23(4): 290-360.

Moore, T. S., Lapan, S. D. \& Quartaroli, M. T. (2012). Case Study Research. In S. D. Lapan, M. T. Quartaroli \& F. J. Riemer (eds) Qualitative Research: An Introduction to Methods and Designs (pp243-270). San Francisco: Jossey-Bass.

Motsaatheba, L. and Mnjama, N. (2007). The Management of High Court Records in Botswana. Records Management Journal 19(3) :173-189. 
Motsaathebe, L. and Mnjama, N. (2009). Managing Court Records: A Survey of Record Keeping Practices in Selected Countries. Mousaion 28 (2): 132-153.

Mue, N. (2007). Institutional Reform in the New Constitution of Kenya. Available at http://www.ictj.org/sites/default/files/ICTJ-Kenya-Institutional-Reform-2010English.pdf [Accessed 12 February 2013].

Mutula, S. and Wamukoya, J. (2009). Public Sector Information Management in East and Southern Africa: Implications for FOI, Democracy and Integrity in Government. International Journal of Information Management 29:333-341.

Mutula, S. M. (2013). E-Government Implementation Strategies and Best Practices: Implications for Sub-Saharan Africa. Mousaion 30 (2): 5-23.

Mutunga, W. (2011). Progress Report on the Transformation of the Judiciary. Available at http://www.kenyalaw.org/kenyaLawBlog/?p=518 [Accessed 19 December 2012].

Mutunga, W. (2012). Address by the Chief Justice at the Launch of the Judiciary Transformation Framework on May 31, 2012 at KICC Grounds._Available at http://www.jidiciary.go.ke [Accessed 19 December 2012].

Nam, T. (2011). Citizens Attitudes towards Open government and Government 2.0. International Review of Administrative Sciences 78 (2): 346-368.

National Archives of Australia (2000). Recordkeeping Metadata Standard for Commonwealth Agencies. Available at http://www.infotech.monash.edu.au/research/groups/rcrg/projects/spirt/deliverables/rk msgen-tech-intro.pdf [Accessed 27 November 2010].

National Archives of Australia, (2001). DIRKS: A Strategic Approach to Managing Business Information. Available at http://www.naa.gov.au/recordsmanagement/publications/DIRKS-manual.aspx [Accessed 27 November 2010].

National Archives of Australia (2006). Managing Records of Commonwealth Persons. Available at http://www.naa.gov.au/records-management/commonwealthpersons/index.aspx [Accessed 15 February 2012].

NASCIO. (2009). A Call to Action for State Government Guidance for Opening the Doors to State Data. Available at http://www.nascio.org/publications/documents/NASCIO-DataTransparency.pdf [Accessed 2 March 2013].

Nasieku, A. P., Kemoni, H. and Otike, J. (2011). Management of Electronic Records at MoiUniversity Eldoret, Kenya. ESARBICA Journal 30: 177-210. 
National Council for Law Reporting. (2003). Reports Disposal Act Cap 14. Available at www.kenyalaw.org:8181/.../Legislation/.../Acts\%20and\%20Regulations [Accessed 10 February 2013].

National Council for Law Reporting. (2010). The Constitution of Kenya. Available at http://www.rightnow.com/pdf/press/2010-open-government-report.pdf [Accessed 20 February 2013].

National Council for Law Reporting. (2010). The Constitution of Kenya: Article 163 (1). Available at http://www.kenyalaw.org/klr/index.php?id=741 [Accessed 15 April 2013].

National Council for Law Reporting. (2010). The Constitution of Kenya: Article 163 (3a, $3 \mathrm{~b}$ and 6). Available at http://www.kenyalaw.org/klr/index.php?id=741 [Accessed 15 April 2013].

National Council for Law Reporting. (2010). The Constitution of Kenya: Article 164. Available at http://www.kenyalaw.org/klr/index.php?id=741 [Accessed 15 April 2013].

National Council for Law Reporting. (2010). The Constitution of Kenya: Article 165 (3). Available at http://www.kenyalaw.org/klr/index.php?id=741 [Accessed 15 April 2013].

National Council for Law Reporting. (2010). The Constitution of Kenya: Article 169. Available at http://www.kenyalaw.org/klr/index.php?id=741 [Accessed 15 April 2013].

Ndou, V. D. (2004). E-Government for Developing Countries: Opportunities and Challenges. The Electronic Journal on Information Systems in Developing Countries 18(1): 1-24.

Ndungu, I. (2012). Cautious Optimism over Judicial Reform in Kenya. Available at http://www.issafrica.org/iss_today.php?ID=1433\%2621 [Accessed 12 February 2013].

Nengomasha, C. (2009). Managing Public Sector Records in Namibia: a Proposed Model. Information Development 25(2):112-126.

Neuman, W.L. (2000). Social Research Methods: Qualitative and Quantitative Approaches. Boston: Allyn and Bacon. 
Neuman, W.L. (2003). Social Research Methods: Qualitative and Quantitative Approaches. $\left(5^{\text {th }}\right.$ ed). Boston: Pearson Education, Inc.

Neuman, W. L. (2006). Social Research Methods: Qualitative and Quantitative Approaches. (6th ed). Boston: Pearson Education, Inc.

Ngoepe, M. (2008). An Exploration of Records Management Trends in the South African Public Sector: a Case Study of the Department of Provincial and Local Government. MIS, Thesis. South Africa: University of South Africa.

Ngoepe, M. and Van der Walt, T. (2009). An Exploration of Records Management Trends in the South African Public Sector. Mousaion 27(1):116-136.

Ngulube, P. (2001). Guidelines and Standards for Records Management Education and Training: a model for Anglophone Africa. Records Management Journal 11(3):155-173.

Ngulube, P. (2003). Preservation and Access to Public Records and Archives in South Africa.Ph.D Thesis. Pietermaritzburg: University of Natal.

Ngulube, P. (2005a). Research Procedures Used By Master of Information Studies Students at the University of Natal in the Period 1982- 2002 with Special Reference to their Sampling Techniques and Survey Response Rates: a Methodological Discourse. The International Information and Library Review 37: 127-143.

Ngulube, P. (2005b). Improving the Quality of Research Outputs in Higher Education through Knowledge Sharing and Collaboration: a Case Study Mousaion 23 (1): 3961.

Ngulube, P. (2005c). Disaster and Security Management in Public Archival Institutions in ESARBICA Region. African Journal of Library, Archives, and Information Science 15(1):15- 23.

Ngulube, P. (2007). Preserving South Africa's Paper Trial and Making Public Records Available for Present and Future Generations. ESARBICA Journal 26:45-69.

Ngulube, P. and Tafor, V. F. (2006). The Management of Public Records and Archives in the Member Countries of ESARBICA. Journal of Society of Archivists 1:57-83.

Ngulube, P., K. Mokwatlo and S. Ndwandwe. (2009). Utilization and Prevalence of Mixed Methods Research in Library and Information Research in South Africa 20022008. South Africa Journal of Libraries and Information Science 75(2): 105-116. 
Ngulupe, P. and Tafor, V. F. (2006). The Management of Public Records and Archives in the Member Countries of ESARBICA. Journal of the Society of Archivists 27(1): 5783.

Nyagowa, H. (2012). Evaluation of NEPAD's Pilot E-Schools in Keya. Ph. D Thesis, South Africa: University of Zululand.

Obama, B. (2009). Transparency and Open government. Available at http://www.whitehouse.gov/the_press_office/TransparencyandOpenGovernment [Accessed 24 February 2013].

OECD. (2005). Public Sector Modernization: Open government. Available at http://www.oecd.org/gov/34455306.pdf. [Accessed 2 March 2013].

Ojielo, O. (2010). Judicial Integrity and the Vetting Process in Kenya. Amani papers 1 (6): 1 .

Okello-Obura, C. and Ssekitto, F. (2011). Records and Information Disaster Preparedness in Selected Organizations in Uganda. ESARBICA Journal 30: 135-161.

Open Government Partnership. (2013). Brazil Progress Report 2011 - 2013. Available at http://www.opengovpartnership.org/country/brazil. [Accessed 5 February 2015].

Penn, I., Pennix, G. and Coulson, J. (1994). Records Management Handbook. (2nd ed.), Aldershot: Gower.

Pickard, A. J. (2007). Research Methods in Information. London: Facet Publishing.

Piggot, S. (2002). Evidence Based Governance in the Electronic Age. Paper presented at the $32^{\text {nd }}$ Annual Conference of the Association of Caribbean University Research and Institutional Libraries, Jamaica, 22 May- 1 June.

Polit, D, F. and Beck, C. T. (2004). Nursing Research: Principles and Methods. (7th ed.) Philadelphia: Lippincott.

Polit, D, F. and Beck, C. T. (2008). Nursing research: Generating and Assessing Evidence for Nursing Practice. Philadelphia: Lippincott.

Powell, R. R. and Connaway, L. S. (2004). Basic Research Methods for Librarians.( 4th ed.) Westport: Libraries Unlimited. 
Presidential Circular no.1 / (2008). Republic of Kenya: the Judiciary. Available at http://judiciary.insynque.com/index.php?option=com_content\&view=article\&id=57 \&Itemid=123[Accessed 27 February 2013].

Przybyla, A. M., and Huth, G. (2004). Preparing for the Worst: Managing Records Disasters. New York: the University of the State of New York.

Reddick, C. G. (2004). A Two-Stage Model of E-government Growth: Theories and Empirical Evidence for US Cities .Government Information Quarterly 21(1):51-64.

Republic of Kenya, the Judiciary. (2013). State of the Judiciary and the Administration of Justice: Annual Report. Nairobi: Government Printer.

RightNow. (2010). Open government Research Report. Available at http://www.rightnow.com/pdf/press/2010-open-government-report.pdf [Accessed 20 February 2013].

Ronoh, F. (2014, July 26). Courts of Shame: Shocking decay in the Corridors of Justice. The Standard Newspaper: pp. 3.

Roper, M. \& Millar, L. (eds.). (1999). Managing Public Sector Record, pp. 5-20, London: IRMT.

Saman, W. S. and Haider, A. (2012). Electronic Court Records Management: A Case Study. Journal of E-Government Studies and Best Practices. Available at http://www.ibimapublishing.com/journals/JEGSBP/jegsbp.html [Accessed 20 Sept. 2013].

Saunders, M., Lewis, P. and Thornhill, A. (2009). Research Methods for Business Students $\left(5^{\text {th }}\right.$ ed.) London: Prentice Hall.

Saunders, M., Lewis, P. and Thornhill, A. (2012). Research Methods for Business Students (6th ed.) London: Prentice Hall.

Schuppan, T. (2009). E-Government in Developing Countries: Experiences from SubSaharan Africa. Government Information Quarterly 26: 118-127.

Scriven, M. S. (1991). Evaluation Thesaurus ( $4^{\text {th }}$ ed.). Thousand Oaks, CA: Sage.

Security Sector Reforms in Kenya (2000). Available at http://www.ssrnetwork.net/document_library/detail/4391/security-sector-reform-inkenya

[Accessed 12. February 2013]. 
Sejane, L. (2004). An Investigation into the Management of Electronic Records in the Public Sector in Lesotho. MIS Thesis. South Africa: University of KwaZulu-Natal.

Sekaran, U. (2003). Research Methods for Business: a Skill Building Approach. (4th ed.) New York: John Wiley and Sons, Inc.

Shensul, J. J. (2012). Methodology, Methods and Tools in Qualitative Research in Lapan, Quartaroli and Riemer (eds). QualitativeResearch. San Francisco: Jossey-Bass pp 69103.

Shepherd, E. (2006). Why are Records in the Public Sector Organizational Assets? Records Management Journal 16(1):6-12.

Shepherd, E. and Ennion, E. (2007). How has the Implementation of the UK Freedom of Information Act. 2000 Affected Archives and Records Management Services? Records Management Journal 17(1):32-51.

Shepherd, E. and Yeo, G. (2003). Managing Records: a Handbook of Principles and Practice. London: Facet Publication.

Sichalwe, E. N. (2010). The significance of Records Management to Fostering Accountability in the Public Service Reform programme of Tanzania. Ph.D Thesis. South Africa: University of Kwazulu-Natal.

Sprehe, J. T. (2000). Integrating Records Management into Information Resources Management in U.S. Government Agencies. Government Information Quarterly 17(1): $13-26$.

Standards Australia. AS4390. (1996). Australian Standard: Records Management. Available at www.territoryrecords.act.gov.au/ .../Records_Advice_No_23 _Austra. [Accessed 20 November 2012.

State Records of New South Wales. (2005). Strategy for Documenting Government Business: Do DIRKS Project. Records Access and Security. Available at http://www.records.nsw.gov.publicsector/DIRKS/final/accesssecurity.html [Accessed 20 November 2012.

Stott, A. (2012). Refining a Working Open government Model in UK. Available at http://www.futuregov.asia/articles/2012/dec/28/refining-working-open-governmentmodel-uk/ [Accessed 20 February 2013]. 
Swan, K., Cunningham, A. and Robertson, A. (2002). Establishing a High Standard for Electronic Records management with the Australian Public Sector. Records Management Journal 12(3): 79-86.

Tashakkori, A. and Creswell, J. W. (2007). The New Era of Mixed Methods. Journal of Mixed Methods Research 1(1): 3-7.

The Guardian. (2010). Corruption Index 2010 from Transparency International: Find out how each Country Compares. Available at http://www.guardian.co.uk/news/datablog/2010/oct/26/corruption-index-2010transparency-international [Accessed 23 February 2013].

Thurston, A. (2005). Fostering Trust and Transparency through Information Systems: Reliable Official Recordkeeping systems Provide Evidence that is Crucial to Accountable, Transparent, Democracies. How can Countries Improve such Systems? The World Bank_Premnotes 2005, 97. Available at http://www1.worldbank.org/prem/PREMNotes/premnote97.pdf [Accessed 23rd Nov. 2012].

Thurston, A. (2012). Trustworthy Records and Open Data. The Journal of Community Informatics, Available at: 〈http://ci-journal.net/index.php/ciej/article/view/951/952〉. [Accessed 11 November 2014].

Thurston, A. (2013). The Open government Partnership. Association of Commonwealth Archivists and Records Managers Issue 48: 18-19.

Tsabedze, V., Mutula, S.M. and Jacobs, D. (2012). Records Management in the Government of Swaziland. ESARBICA Journal 31: 47-61.

UN E-Government Survey. (2012). E-Government for the People. Available at http://unpan1.un.org/intradoc/groups/public/documents/un/unpan04065.pdf [Accessed 23 November 2012].

UNESCO, (2012). Communication and Information: Freedom of Information Legislation in Africa. Available at http://www.unesco.org/new/en/communication-andinformation/freedom-of-expression/freedom-of-information/foi-in-africa/\# [Accessed 4 March 2013].

Upward, F. (2000). Modelling the Continuum as a Paradigm Shift in Recordkeeping and Archiving Process and Beyond: a Personal Reflection. Records Management Journal 10 (3):115-139. 
US Department of Energy. (2011). Identifying and Protecting Your Vital Records. Available at http://energy.gov/sites/prod/files/IDENTIFY\%20AND\%20PROTECT\%20YOUR\% 20VITAL\%20RECORDS\%20(2).pdf-[Accessed $16^{\text {th }}$ Sept 2014].

US Environment Protection Agency. (2014). Vital Records Protection. Available at http://www.epa.gov/records/tools/toolkits/vital/01.htm [Accessed 16th Sept 2014].

Uwaifo, S. O. (2004). Management Use of Records in Delta State University, Abraka, Nigeria. Records Management Journal 14(2): 85-89.

Wamukoya, J. (2000). Records and Archives as a Basis for Good Government: Implications and Challenges for Records Managers and Archivists in Africa. Records Management Journal 10(1):23-33.

Wamukoya, J. and Mutula, S. M. (2005). E-Records Management and Governance in East and Southern Africa. Malaysian Jounal of Library and Information Sciences 10(2): 67-83.

Wamukoya, J. and Mutula, S. M. (2005). Capacity-building Requirements for E-records Management: The case in East and Southern Africa. Records Management Journal 15(2): 71-79.

Wamukoya, J. M. (1996). Records Management and Administrative Programme in Kenya. Ph.D Thesis. London: University College London.

Wamukoya, J. M. (2012). The Role of Record Keeping and Open government Data Initiatives in Fostering a Critical Development of Open government Policies and Public services in Sub-Saharan Africa. A Paper Presented at an Archival Conference on Archiving and Digital Continuity in the Context of E-Government in Sub-Saharan Africa, University of South Africa, Pretoria, Senate Hall, 12-13 July 2012.

Wamukoya, J. M. (2013). The Role of Records Keeping and Open government Data Initiatives in Fostering a Critical Development of Open government Policies and Public Services in Sub-Saharan Africa. Mousaion 30(2): 117-127.

Wato, R. (2006). E-records readiness in the ESARBICA: Challenges and the Way Forward. ESARBICA Journal 26: 125-134.

Wema, E. (2003). Problems of Managing Semi-Active Records in Institutions of Higher Learning: the Case of University of Dares Salaam. University of Dares Salaam Library Journal 5(11): 46-56. 
Wescott, C. G. (2001). E-Government in the Asia-pacific region. Asian Journal of Political Sciences, 9(2): 1-24.

Williams, C. (2006). Managing Archives: Foundations, Principles and Practice. Hartcourt: Chandos Publishing (Oxford) Limited.

World Bank, (2000). Managing Records as the Basis for Effective Service Delivery and Public Accountability in Development: An Introduction to Core Principles for Staff of the World Bank and its Partners. Available at http://siteresources.worldbank.org/EXTARCHIVES/Resources/Core\%20Principles .pdf [Accessed 21February 2013].

World Bank. (2004). A Definition of E-government, Available at: www1.worldbank.org/ publicsector/egov/definition.htm[Accessed 23 November 2012].

World Wide Web Foundation. (2011). Open government Data: Feasibility Study in Ghana. Available at https://public.webfoundation.org/2011/05/OGD_Ghana.pdf [Accessed 20 February 2013].

Yin, R. K. (2009). Case Study Research: Design and methods. London: Sage.

Yu, H. and Robinson, G. (2012).The New Ambiguity of "Open government". Available at http://papers.ssrn.com/sol3/papers.cfm?abstract_id=2012489 [Accessed 28 November 2012].

Yusof, Z. M. and Chell, R. W. (1998). Records Management Education and Training World-Wide: a General Overview of the Current Situation. Records Management Journal 8(1):25-54.

Yusof, Z. M. and Chell, R. W. (2000). The Life Cycle: an Inadequate Concept for Technology-Generated Records. Information Development 16(3):135-141. 


\begin{abstract}
APPENDICES
Appendix 1: Interview Schedule for Records Officers and Registry Assistants

Dear respondent,

I am a PhD student at the University of KwaZulu - Natal, in the Information Studies Programme. I am carrying out a research as part of the requirements for the award of a doctorate degree (Information Studies). The title of my research topic is "Records Management Readiness for Open government in the Kenyan Judiciary".

The purpose of the study is to investigate records management in the Kenyan Judiciary with a view to providing a records management framework that would facilitate openness in the Judiciary for enhanced service delivery. The study will gather data on records management practices, records management policies, plans and guidelines, skills and competencies among the records staff, level of awareness and attitude of staff towards a sound records management and the strategies used for open government.

I wish to kindly request you to set aside some time for an interview which will enable me obtain data that will address the research questions. The information you will provide will be kept in confidence and used only for the current study.

Should you have questions about the research please contact me on 213538371@ukzn.ac.za or my supervisor on Mutulas@ukzn.ac.za.

Thanking you in advance for your time and cooperation.

Yours Faithfully
\end{abstract}

Elsebah Maseh 


\section{Background information}

(i) What is your highest academic qualification?

(i) Please indicate your current designation

(ii) What is your work experience?

\section{Records creation}

(i) What are the functions of your department?

(ii) What records are created at the Judiciary?

(iii) How are these records created?

(iv) In what format are the records created?

(v) How are the records in the different formats classified?

(vi) Is the classification based on a controlled vocabulary? If yes, please explain--

\section{Records access and use}

(i) Is there a records access policy in the Judiciary? If yes, what are its key elements?

(ii) Does the policy impose security classifications or any other restrictions on some of the records? If yes please explain

(iii)Does this promote or undermine openness in the Judiciary?

(iv) Who uses the records created in the Judiciary?

(v) What tools do you use in searching and retrieval of the records?

(vi)Do you have a tracking system for those records which have been issued out? How do you do this? 


\section{Records maintenance and storage}

(i) How are the records filed and/or arranged?

(ii) How do you maintain the records in your custody?

(iii) Which storage facilities do you use in the registry/records office?

(iv) What designated areas are available for the storage of active, semi active and non-active records?

(v) How is the security of stored records ensured?

\section{Records Appraisal and disposal}

(i) At what point are records appraised in the Judiciary?

(ii) What criteria do you use to appraise the records?

(iii) Does the Judiciary base the disposal of the records on any legal framework such as CAP 14 of the laws of Kenya? Please explain-

(iv) Is there a disposal policy at the Judiciary? Please explain

(v) Does the Judiciary have a structured disposal programme? If yes, what does it entail?

Is the disposal programme informed by a retention and disposal schedule?

Please explain

(vi) In your opinion, how is the retention and disposal schedule a useful tool in the management of records?

(vii) How do you deal with records which have been appraised and earmarked for destruction?

(viii) How do you ensure security at disposal of records?

(ix) Do you issue a records disposition certificate on records that have been disposed of? If yes

(x), what role does it play for the destroyed records?

\section{Records preservation}

(i) How are records preserved in the judiciary? 
(ii) Are the environmental conditions monitored and controlled in the records storage areas? If yes, how is this done?

(iii) What preservation challenges are experienced in relation to the following?

Pests

Dust-

Environmental conditions

Handling

Any other

(iv) What measures have been put in place to deal with the above?

(v) Do you have a disaster management programme? If yes, please explain-

(vi) Do you have a vital records management programme? Please explain

\section{Management of Electronic records}

(i) How are electronic records created?

(ii) How are they classified?

(iii) How do you ensure that e-records are accessed only by authorized persons?

(iv) How are the e-records stored?

(v) What standard procedure if any do you have for labeling storage devices such as compact disks?

(vi) How do you ensure security of electronic records?

(vii) What strategies have been put in place for the preservation of these records?

(viii) How are e-records appraised and disposed of?

(ix) What was your role in the planning and design of the automated document management system?-

(x) In your view how does this system meet all the records management functionalities?-

\section{Policies, Plans and Guidelines for records management}

(i) What policies regulates records management in the Judiciary?

(ii) If records management policies exist how often are they reviewed? 
(iii) How do the policies available apply to the different types and formats of records created?

(iv) What has been your role if any in the formulation of the records management policies?

(v) What responsibilities do the policies assign for managing records to specific managers and staff?

(vi) Does records management form part of strategic management plan in the judiciary? If yes, what records management plans have been identified for the next five years?

(vii) Please explain if there are any guidelines governing records management?

\section{Skills and competencies of records management staff}

(i) Have you been involved in any records management training since you joined judiciary?

(ii) How often do you attend records management workshops, conferences and seminars?

(iii) Is the management of electronic records part of your job description?

(iv) If yes has any training on e-records management been consciously organized for you?

\section{Level of awareness and attitude of staff towards sound records management practices}

(i) In your view, how do the other staff in the judiciary appreciate the role of records in their areas of operations?

(ii) What is the level of top management support for records management?

(iii) Where is records management placed relative to other units in the organizational structure? 
(iv) How are the budgetary requirements of the records management department met? Is the budget adequate?

\section{Strategies used in Judiciary to achieve openness}

(i) What is your level of awareness about the open government initiatives currently being implemented in Kenya's public sector organizations?

(ii) In your assessment, is the Judiciary ready to embrace e-governance as a means of attaining open governance? Please explain-

(iii) What kind of data is posted on to the Judiciary website?

(iv) Where is this data generated from?

(v) How relevant and up to date is the data posted on the web-site?

(vi) Apart from the website, outline the other means that the Judiciary uses to reach out to the citizens?

(vii) Does the Judiciary receive complaints about records management issues? Please explain

(viii) Do you think records management has a role to play in transforming the Judiciary and opening up to the public? Please explain

\section{Challenges faced and recommendation}

(i) What challenges does the judiciary face as it transforms itself and as it opens up to the public?

(ii) How does this impact on records management?

(iii)What is being done to address these challenges?

Thank you for your time 


\section{Appendix 2: Interview Schedule for Court Registrars and Chief Executive Officers}

Dear Sir / Madam

I am a PhD student at the University of KwaZulu - Natal, in the Information Studies Programme. I am carrying out a research as part of the requirements for the award of a $\mathrm{PhD}$ degree. The topic of my research is entitled "Records Management Readiness for Open government in the Kenyan Judiciary", supervised by Professor Stephen Mutula.

The purpose of the research is to investigate records management in the Kenyan Judiciary with a view to providing a records management framework that would facilitate openness in the Judiciary for enhanced dispensation of justice. The research will gather data on records management practices, records management policies, plans and guidelines, skills and competencies among the records staff, level of awareness and attitude of staff towards a sound records management programme and the strategies used for achieving open governance.

The purpose of this communication is to kindly request you to afford me audience to interview you to collect data that would address the research problem being studied. The information you provide will be kept in confidence and used only for academic purposes.

Should you have questions about the research please contact me on jmaseh@gmail.com or my supervisor on Mutulas@ukzn.ac.za.

Thanking you in advance for your time and cooperation.

Yours Faithfully

Elsebah Maseh 


\section{Background Information}

i. Designation-

ii. Number of years in that position

iii. Court served-

iv. Highest academic qualification-

\section{Records management}

i. When the Chief Justice Dr. Willy Mutunga took office in 2011, he observed that the Judiciary had accumulated impossible case backlogs. How do you explain the genesis of these backlogs?

ii. How is this being addressed?

iii. What records management issues could have contributed to the backlogs?

iv. Missing files have been a major complaint about the Judiciary in the public arena, what factors can be attributed to this situation?

v. What is being done to alleviate the problem of missing files?

vi. What is your assessment on the quality of records management in the Judiciary?

\section{Records management policies}

i. What policies regulates the management of records in the Judiciary

ii. Who is responsible for records management policy formulation in the judiciary?

iii. Does records management form part of strategic management plan in the judiciary? Please explain

iv. If yes what records management plans have been identified for the next five years? 
v. How is records management integrated in the Judiciary Transformation Framework?

vi. What guidelines are available for governing records management in the judiciary?

vii. What working relationship do you have with professional bodies and institutions like the Kenya National archives and Documentation Service?

\section{Skills and competencies among the records management staff}

i. What skills do you look for when recruiting records management staff?----

ii. What is the level of academic and professional qualification required for records management staff in the judiciary?

iii. What is the current status of records officers in reference to their qualification and adequacy?

iv. What is the optimum required number of records management staff that the Judiciary should have?

v. In your assessment, to what extent are the records officers motivated in their work?

vi. What kind of training policy for records staff does the Judiciary have?-----

vii. To what extent are records staff facilitated to in -service training and participation in records management conferences and workshops?

\section{Level of awareness and attitude of staff towards sound records management practices}

i. What value does the Judiciary place on sound records management as a key component of the administration of justice? 
ii. Where in the structure of the judiciary is records management positioned?

iii. How comparable is the scheme of service (in terms of relativity of salaries) of records officers comparable to related paralegal positions?

iv. Does the Judiciary have a budget for records management functions and activities? If yes how adequate is the budget?

\section{Strategies used in order to achieve openness}

i. In your assessment, is the Judiciary ready to operate an e-government as a means towards achieving an open government? Please explain

ii. Kenya is among the few African Countries that are implementing Open government Initiatives. What is your take on the relevance and applicability of openness in the judiciary?

iii. What kinds of data sets (computer generated data) are generated in support of open governance in the judiciary?

iv. How does the Judiciary engage with stakeholders and the public?

Use of the Judiciary website

Mobile telephony

Social media (facebook, twitter etc)

Judiciary Open days

Any other-

v. Can the citizens make their contribution on matters pertaining to the running of the Judiciary for instance offering some suggestions on what they think needs to be improved?

vi. How are such suggestions handled?

vii. Does the Judiciary have an Open government policy? Yes / No 
viii. If yes, what are the elements of the policy?

ix. Are there practical ways that the Judiciary has benefited from bringing citizens on board on matters pertaining to the functioning of the judiciary?

$\mathrm{x}$. Have there been any changes in the Judiciary since the promulgation of the new constitution in 2010 and the subsequent launch of the transformation framework in 2011?

xi. What challenges are faced or likely to be faced by the Judiciary as it moves towards openness?

xii. Do you think there is a point of convergence between records management and open government? Please explain

What is your parting shot on issues of records management and openness in the judiciary?

Thank you for your time 


\section{Appendix 3: Survey Questionnaire for Judges and Magistrates}

Dear Sir/Madam

I am a PhD student at the University of KwaZulu - Natal, South Africa in the Information Studies Programme. I am carrying out a research as part of the requirements for the award of a $\mathrm{PhD}$ degree. The topic of my research is entitled "Records Management Readiness for Open government in the Kenyan Judiciary.

It is expected that the outcome of the study will provide a records management framework that would facilitate openness in the Judiciary for enhanced judicial service delivery. The research will gather data on records management practices, records management policies, plans and guidelines, skills and competencies among the records staff, level of awareness and attitude of staff towards a sound records management programme and the strategies used for open government. The study is focused on how judicial records are managed from creation to disposition and excludes other records maintained by the Judiciary such as the administrative records.

The purpose of this communication is to kindly request you to set aside some time to complete the attached questionnaire which will enable me obtain data that will address the research problems of this study. The information you provide will be kept in confidence and used only for the academic purposes of the study and will not be divulged to third parties.

Should you have questions about the research please contact me on jmaseh@gmail.com or my supervisor Prof S. Mutula at Mutulas@ukzn.ac.za.

Thanking you in advance for your time and cooperation.

Yours Faithfully

Elsebah Maseh 


\section{Background information}

i. Court served-

ii. County where court is located

iii. Designation

iv. Years served in that position

v. Date the questionnaire is filled-

2. Records Management ( please tick the most appropriate option)

i. In discharging your duties and responsibilities what records do you require?
[ ] Case files
[ ] Sermons
[ ] Exhibits
[ ] Court registers
[ ] Others

Please rate the statements according to the scales provided:

ii. Records are vital for the administration of justice.

[ ] Strongly agree

[ ] Agree

[ ] Neutral

[ ] Disagree

[ ] Strongly disagree

iii. Without properly managed records there can be no rule of law.
[ ] Strongly agree
[ ] Agree
[ ] Neutral
[ ] Disagree
[ ] Strongly disagree

iv. Does records management contribute to the attainment of the Judiciary's mission, vision and core values?

\begin{tabular}{|l|l|l|}
\hline & Yes & No \\
\hline Mission & & \\
\hline Vision & & \\
\hline Core values & & \\
\hline
\end{tabular}

v. In what specific ways does records management contribute to the attainment of the Judiciary's mission, vision and core values (choose as many as they apply)

[ ] Enhances planning process 
[ ] Enhances service delivery

[ ] Facilitates the rule of law

[ ] Provides the necessary evidence

[ ] Demonstrates transparency

[ ] Demonstrates accountability

[ ] Others (please specify)

vi. The Judiciary is said to experience case backlogs. Is this true for your current station?

[ ] Yes

[ ] No

vii. Which of the following factors do you think are responsible for the case backlogs?

[ ] Inadequate judicial staff

[ ] Inadequate records staff

[ ] Poor records management

[ ] Corruption in the Judiciary

[ ] Inadequate tools and equipment

[ ] Inadequate use of ICT facilities

[ ] Others (please specify)

viii. Do you experience missing files as you deliver your judicial services?

[ ] Yes

[ ] No

If yes how often do you experience this?

[ ] Very Often

[ ] Often

[ ] Rarely

[ ] Once in a while

ix. Does the issue of missing files affect your delivery of services?

[ ] Yes

[ ] No 
x. What would you attribute the problem of missing files to?

[ ] Poor management of records

[ ] Inadequate records management staff

[ ] Poorly trained records management staff

[ ] Lack of records management policies and guidelines

[ ] Lack of proper storage equipment

[ ] Reliance on manual records management strategies

xi. How can you rate the management of records in the Judiciary?

[ ] Very good

[ ] Good

[ ] Fair

[ ] Poor

[ ] Very poor

xii. Which of the following factors contribute to the current state of records management in the Judiciary?

[ ] Lack of records management policy

[ ] Inadequate funding

[ ] Inadequate trained records staff

[ ] Inappropriate supplies and equipment

[ ] Others, please specify

xiii. How do the current records management practices affect judicial service delivery in the judiciary?

\section{Level of awareness and attitude of staff towards sound records management} practices

i. Do you think a sound records management strategy is required in the Judiciary?

[ ] Yes

[ ] No

Please explain 
ii. What value would you place on sound records management as a key component of the administration of justice?

[ ] Essential

[ ] Very important

[ ] Important

[ ] Less important

[ ] Not important

\section{Strategies used in order to achieve Open government}

i. In your assessment, is the Judiciary ready to operate an e-government as a means towards achieving an open government?

[ ] Yes

[ ] No

Please explain

ii. Kenya is among the few African Countries that are implementing Open government Initiatives. Do you think this is relevant and applicable in the Kenyan Judiciary?

[ ] Yes

[ ] No

Please explain

iii. Has the Judiciary Transformation Framework improved judicial service delivery in Kenya?

[ ] Yes

[ ] No

Please explain

iv. As part of the Judicial Transformation Initiatives, what strategies is the Judiciary using to open up to the Kenyan citizenry?

[ ] Posting data on to the Judiciary website

[ ] Posting judicial data on to the Government Open Data Portal

[ ] Through mobile telephony

[ ] Through social networking (Facebook, twitter etc.)

[ ] Through such forums as Judiciary open days

Others 
v. Please indicate the benefits of opening up the Judiciary. (select as many as may apply)

[ ] Enhanced transparency and accountability in the Judiciary

[ ] Enhance judicial service delivery

[ ] Leads to increased public participation in judicial affairs

[ ] Leads to collaboration with members of public on Judiciary development

[ ] Others-

vi. In your view, is there relationship between records management and open government?

[ ] Yes

[ ] No

Please explain-

vii. What challenges is the Judiciary likely to face as it opens up to the public?

viii. What suggestions can you make that can enhance Open government in the Kenyan Judiciary for improved judicial service delivery?

Thank you for your time 


\section{Appendix 4: Observation Checklist for the Management of Judiciary Records}

1. Background Information

Name of Court

County where court is located

Contact officer-

Data of observation

2. Types of records created

3. House-keeping practices

4. Storage facilities and equipment

5. Quality and adequacy of the storage facilities

6. Tools available for records control

7. Search and retrieval tools used-

8. Type of buildings housing the records

9. General layout of the records centre/registry

10. Temperature and humidity control equipment 
11. Type of lighting system used-

12. Availability of curtains and/or blinders in the room-

13. General security of records

14. Availability of computers and any other ICT infrastructure for managing records--

15. Computerized or automated systems in place

16. Records plans and schedules

17. Working space for records staff-

18. Classification/filing schemes

19. Physical condition of records- 


\section{Appendix 5: Research Permit}

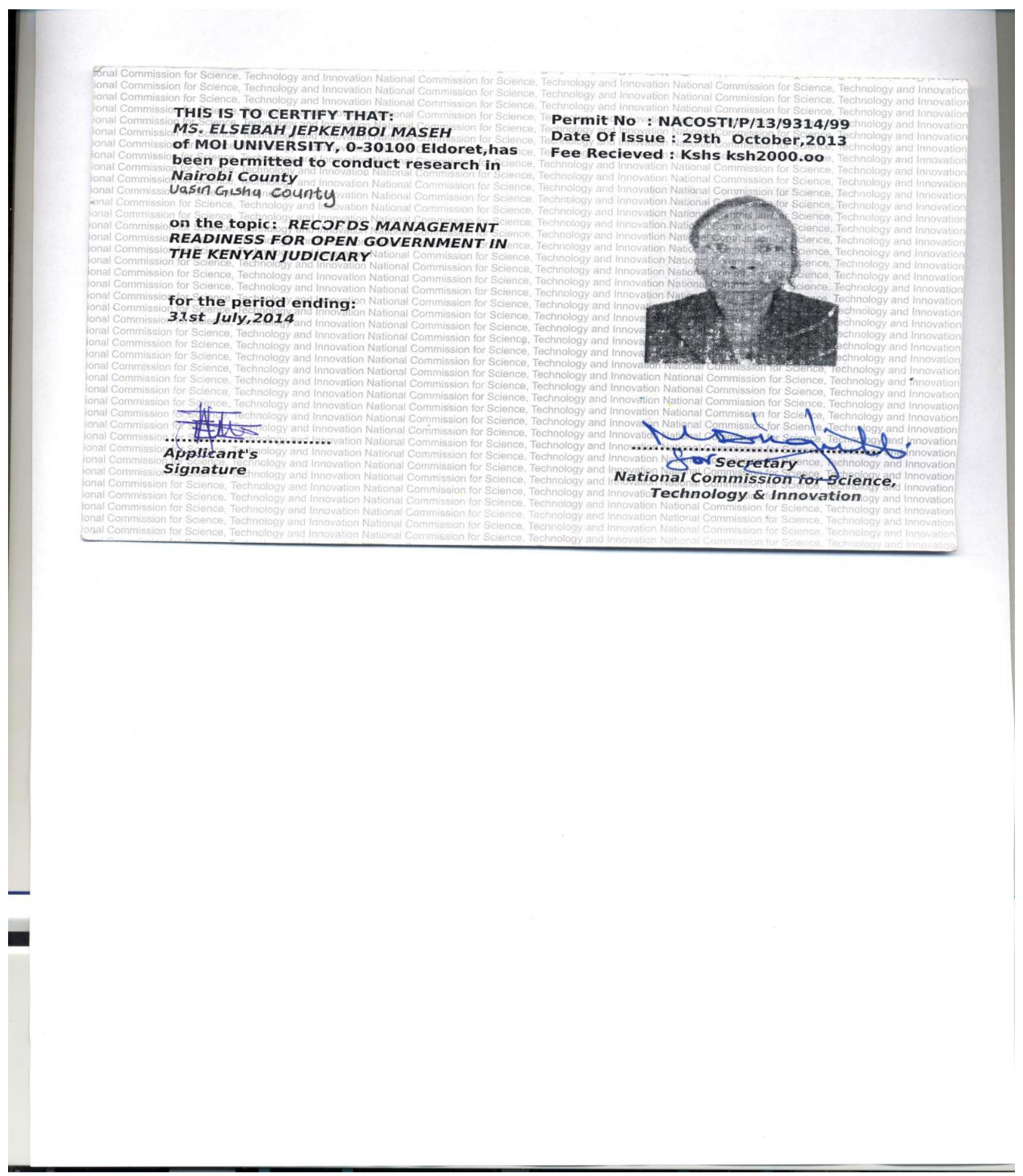




\section{Appendix 6: Clearance Letter from NACOSTI}

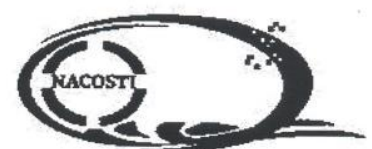

NATIONAL COMMISSION FOR SCIENCE, TECHNOLOGY AND INNOVATION

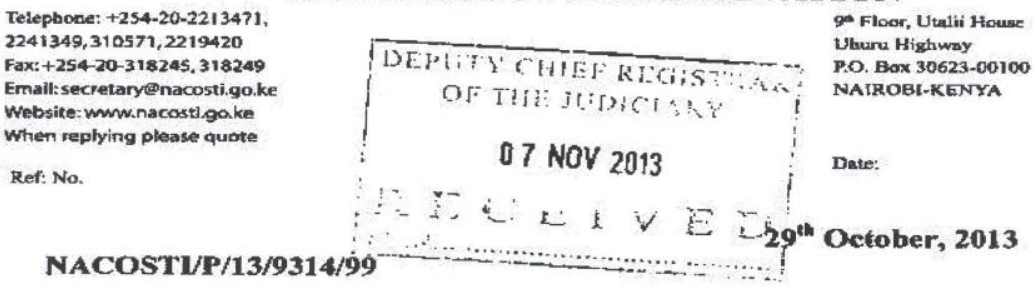

Elsebah Jepkemboi Maseh

Moi University

P.O.Box 3900-30100

ELDORET.

\section{RE: RESEARCH AUTHORIZATION}

Following your application for authority to carry out research on "Records management readiness for open government in the Kenpan Judiciary," I am pleased to inform you that you have been authorized to undertake research in Nairobi and Uasin Gishu Counties for a period ending $31^{\text {st }} \mathrm{July}, 2014$.

You are advised to report to the Court Registrars of selected Courts before embarking on the research project.

On completion of the research, you are expected to submit two hard copies and one soft copy in pdf of the research report/thesis to our office.

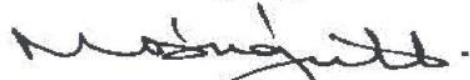

DR. M. K. RUGU T, PhD HSC.

DEPUTY COMMISSION SECRETARY

NATIONAL COMMISSION FOR SCIENCE, TECHNOLOGY \& INNOVATION

Copy to:

The Court Registrars

Selected Courts.

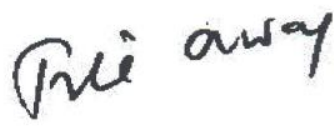




\title{
Appendix 7: Authorization Letter from the Judiciary
}

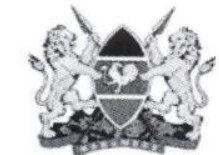

Republic of Kenya The Judiciary
Muthaiga North, off Kiambu Road P.O. Box 28872-00200, Nairobi :: Tel: 0202662254 jti@judiciary.go.ke :: www.judiciary.go.ke

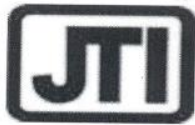

Judiciary Training Institute

Our Ref: JTI/Research/2013

Your Ref:

Elsebah Maseh

University of KwaZulu-Natal

School of Social Sciences

Private Bag XO1

Scottsville, Pietermaritzburg 326

Republic of South Africa

\section{Ref: Permission to Undertake Research in the Kenyan Judiciary}

I received your letter dated $6^{\text {th }}$ November, 2013 requesting permission to undertake your research on records management readiness for open government in the Kenyan Judiciary as part of your PhD studies at the University of KwaZuluNatal.

This is to confirm that you have been granted the permission to interview records officers and administer questionnaires to Magistrates and Judges between February and May 2014. We urge you to include our Registrars and Deputy Registrars as well as our Directorate of Performance Management in your research.

Kindly send us, for our records, a copy of the research instrument and interview list/schedule ahead of time. We request that you arrange for your interviewing sessions with your chosen interviewees well in advance to avoid disruption of court business. We also request a copy of your research findings upon completion.

We wish you the very best in your studies.

Yours faithfully,

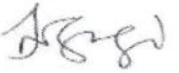

Joel Ngugi

Director

\author{
CC. 1. Hon. Chief Justice \\ 2. Principal Judge \\ Transforming the Judiciary through Training, Research and Constructive Engagement
}




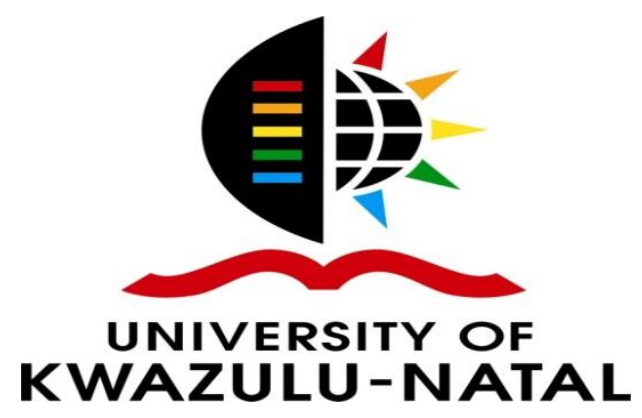

Dear Respondent
University of KwaZulu-Natal School of Social Sciences and Information Studies Programme

Private Bag X01Scottcville 3209, PMB

Telephone: +254721981695/ $+27743779236$

Email: jmaseh@gmail.com 13th December 2013

Informed Consent Letter

Researcher: Ms Elsebah Maseh

Institution; University of KwaZulu-Natal

Telephone number: +254721981695

Email address: jmaseh@gmail.com

Supervisor: Prof. Stephen Mutula

Institution: University of KwaZulu-Natal

Telephone number: 033-260 5093

Email address: Mutulas@ukzn.ac.za

I, Elsebah Maseh of University of KwaZulu-Natal, kindly invite you to participate in the research project entitled Records Management Readiness for Open government in the Kenyan Judiciary. The study is aimed at making a contribution towards promoting transformation and facilitation of open government in the Judiciary. It is undertaken as part of the requirements of the award of $\mathrm{PhD}$ degree (Information Studies), at the University of KwaZulu-Natal.

Your participation in this research project is voluntary. You may decline to participate or withdraw from the research project at any stage and for any reason without any form of disadvantage. There will be no monetary gain from participating in this research project. Confidentiality and anonymity will be maintained by the researcher and the Information Studies Programme, at the University of KwaZulu-Natal. The data collected will be securely kept at the school premises and eventually disposed of by incineration after a period of five years. Meanwhile the results will be availed to the participants after analysing the data as a way of improving the trustworthiness of the study. Eventually a copy of the theses will be deposited at the Judiciary Training Institute. 
If you have any questions or concerns about participating in this study, please feel free to contact myself or my supervisor at the contacts provided above. It should take you about 15 minutes to complete the questionnaire or 20 minutes for an interview session.

Thank you for agreeing to participate in this research project.

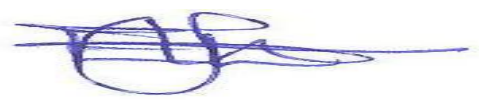

\section{DECLARATION BY THE PARTICIPANT}

I ..................................................(full names of participant) hereby confirm that I understand the contents of this document and the nature of the research project, and I consent to participating in the research project.

I understand that I am at liberty to withdraw from the project at any time, should I so desire.

I consent / do not consent to this interview being recorded.

SIGNATURE OF PARTICIPANT: DATE

\section{Supervisor's details}

Prof. Stephen Mutula

Institution: University of KwaZulu-Natal

Telephone number: 033-260 5571

Email address: Mutulas@ukzn.ac.za

\section{Student's details}

Ms. Elsebah Maseh

Institution; University of KwaZulu-Natal

Telephone number: +254721981695

Email address: jmaseh@gmail.com

\section{HSSREC Research Office}

Ms P. Ximba

Telephone number: 0312603587

Email address: ximbap@ukzn.ac.za 


\section{Appendix 9: Introduction Letter by the Supervisor}

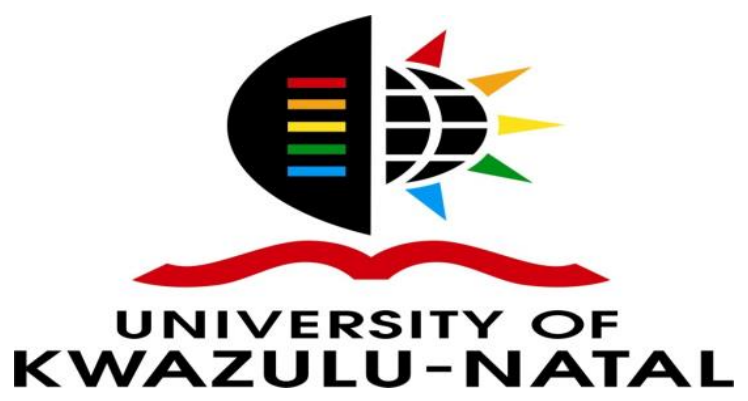

University of KwaZulu-Natal Information Studies Programme Private Bag X01Scottsville, 3209

Pietermaritzburg $6^{\text {th }}$ Nov. 2013

\section{TO WHOM IT MAY CONCERN}

\section{$\underline{\text { RE: Introducing Ms Elsebah Maseh - PhD Student at University of KwaZulu Natal }}$}

This letter serves to introduce and confirm that Ms Elsebah Maseh is a duly registered $\mathrm{PhD}$ (Information Studies) candidate at the University of KwaZulu Natal. The title of her $\mathrm{PhD}$ research is 'Records Management Readiness for Open government in the Kenyan Judiciary'. The outcome from the study is expected to improve practice, inform policy and extent theory in this field of study. As part of the requirements for the award of a $\mathrm{PhD}$ degree she is expected to undertake original research in an environment and place of her choice. The UKZN ethical compliance regulations require her to provide proof that the relevant authority where the research is to be undertaken has given approval. Her data collection is expected to commence from February 2014 and end May 2014.

We appreciate your support and understanding to grant Ms Elsebah Maseh permission to carry out her research in your organisation(s). Should you need any further clarification, do not hesitate to contact me.

Thank you in advance for your understanding

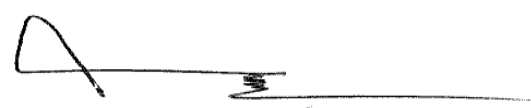

Prof Stephen Mutula (Information Studies Programme)

Supervisor and Academic Leader, Development Cluster

University of KwaZulu Natal

Private Bag X01 Scottsville 3209

Pietermaritzburg

Email: mutulas@ukzn.ac.za

Tel: +2733260 5571; +27712750109 


\section{Appendix 10: Introduction Letter by Moi University}

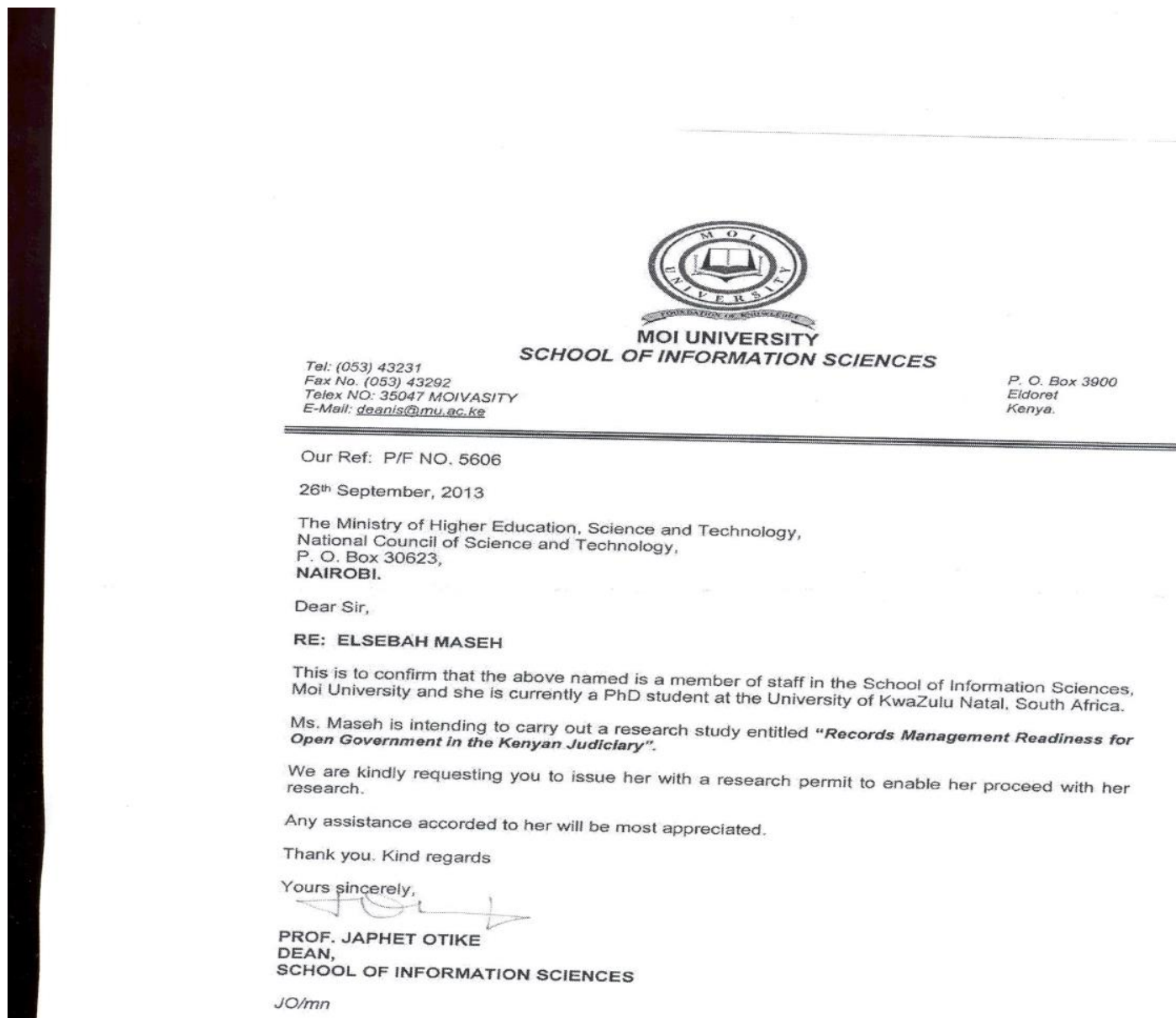




\section{Appendix 11: Request for Permission to Undertake Research}

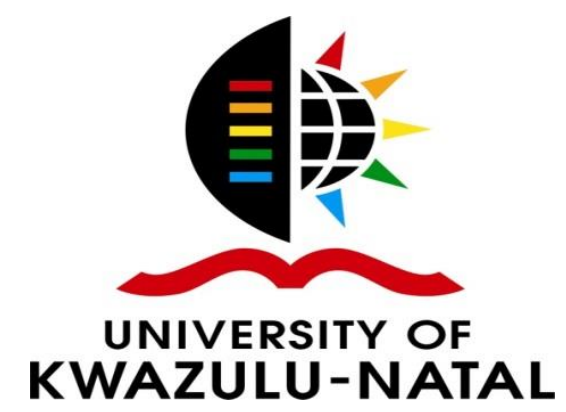
The University of KwaZulu-Natal, School of Social Sciences Private Bag X01, Scottsville, Pietermaritzburg 3209 Republic of South Africa. $6^{\text {th }}$ November 2013

The Director,

Judiciary Training Institute,

Dear Sir/Madam

\section{RE: REQUEST FOR PERMISSION TO UNDERTAKE RESEARCH}

I am a Kenyan doctoral student at the University of KwaZulu-Natal, School of Social Sciences in information studies programme, Republic of South Africa.

As part of the requirements for the award of a $\mathrm{PhD}$ (information Studies), I am required to undertake a research on Records Management Readiness for Open government in the Kenyan Judiciary. I am required to collect data from records officers and court registrars in the Judiciary through interviews and administering of questionnaires to judges and magistrates. The outcome of the study would provide relevant information that would be useful in aligning records management policies with Open government policies for enhanced judicial service delivery.

The purpose of this letter is to request for your permission to carry out the research at the Judiciary from February 2014 to May 2014.

I shall be very grateful for your assistance and I appreciate your cooperation in advance.

Yours Faithfully

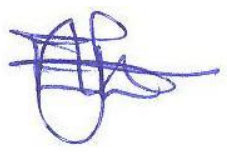

Elsebah Maseh

Telephone: +254 721981695

Email: jmaseh@gmail.com 